INSTITUTO DE PESQUISAS ENERGÉTICAS E NUCLEARES

Autarquia Associada à Universidade de São Paulo

\begin{abstract}
AVALIAÇÃO DA CONCENTRAÇÃO DE MICRO E MACROCONSTITUINTES DO SEDIMENTO DO RESERVATÓRIO ITUPARARANGA/SOROCABA-SP
\end{abstract}

SHARLLENY ALVES SILVA

Dissertação apresentada como parte dos requisitos para obtenção do grau de Mestre em Ciências na área de Tecnologia Nuclear - Aplicações

Orientadora:

Profa. Dra. Déborah Inês Teixeira Fávaro

São Paulo 
Aos que me fizeram o que sou hoje meus pais, Gilda e Luiz, irmão João Paulo e aqueles que hoje me moldam: Fábio, família e amigos 


\section{AGRADECIMENTOS}

Eis que chega o momento de expressar meus agradecimentos a muitos familiares e amigos que me levaram a chegar aqui. Devo contar que esta não foi uma caminhada breve, mas uma travessia que parecia sem fim, principalmente pelas intercorrências pessoais de toda ordem, que me atropelaram. Esses percalços, longe de obscurecerem o trajeto, aumentaram o brilho. E ao invés de me deterem, me impulsionaram com mais força, principalmente pelas generosidades espontâneas que fizeram a transformação de momentos de angústias e sofrimento em uma estrada larga, com flores e frutos, uma estrada mais fácil de caminhar. Desta forma, dedico algumas palavras àqueles que fizeram parte desta jornada de forma direta, indireta ou que pelo simples fato de existirem, contribuíram.

A Deus, pela saúde e força espiritual.

A Dra. Deborah Inês Teixeira Fávaro, por te aceitado e me guiado por este desafio, com especial paciência, companheirismo e colaboração.

A Dr. José Eduardo Bevilacqua pelo apoio, incentivo, ideia, sugestões e disponibilidade.

Ao Msc Francisco Jorge Ferreira por todo apoio e incentivo.

As Dras Maria Inês Zanoli Sato e Maria Yumiko Tominaga, por incentivarem e acreditarem neste estudo.

Aos Msc Robson Leocádio Franklin e Eleine Bostelmann por todo apoio espiritual e acadêmico, pela paciência, incentivos incondicionais e por me mostrarem que seria possível chegar ao fim.

Aos colegas de Laboratório de Química Inorgânica da CETESB, em especial para Patricia Akemi Koga, Adalberto Aparecido Diniz e aos demais colegas pela ampla ajuda dada: Claudia Lúcia Aguiar Araújo, Claudio Amaro, Concenttina Lanza, Daniel Quarentei Rossini, Eliana Maria de Cerqueira, Ewerton Ferrão, Fernanda de Mendonça, Juliana Freitas, Leonina Machado de Sant'ana, Paula Ludmila Marche, Sergio Rodrigues Mendes, Tibério Cezar Oliveira Brandi, Uyara Cayenne da Silva, Valéria Silveira, Valter Roberto Diniz. 
A todos os funcionários do Setor de Química Orgânica e do Laboratório da CETESB de Limeira, pelas Análisesde COT e granulometria.

Aos funcionários do Setor de Coleta e Amostragem da CETESB, especialmente para Oswaldo Atanaglido da Silva, o grande "gordela", Gasparino Gomes da Silva, Paulo Sergio Gonçalves da Rocha, Rogério Visquetti e Carlos Jesus Brandão.

À Comissão Nacional de Energia Nuclear (CNEN) e ao Instituto de Pesquisas Energéticas e Nucleares (IPEN), pela oportunidade de realização do presente trabalho.

A meus pais, Gilda Helena Alves Silva e Luiz Fernandes Domingos Silva, meus avós Elza, Joaquim e Carmem e Luiz Carlos, pelo amor, apoio, paciência, exemplo e por acreditarem no sucesso desta jornada.

A meu irmão João Paulo Alves Silva e minha cunhada Lívia Melo Carneiro por todo incentivo, motivação, ajuda, exemplo e empurrões.

A Fábio Domingos da Silva, por todo amor, paciência, apoio e compreensão pelas ausências, e por ter acreditado em mim e no meu sucesso.

A todos que contribuíram direta ou indiretamente todo o tempo do Mestrado com compreensão, amizade, carinho, torcida mesmo que a distância, que me propiciaram bons momentos, boas risadas e fizeram desta jornada mais leve, suave e feliz. Este trabalho jamais teria sido realizado sem cooperação de tantas pessoas, cada qual com a sua ajuda, sempre com a mesma importância. A todos que de alguma forma me ajudaram...

Todos vocês são coautores deste trabalho. 
"Quando tudo nos parece dar errado Acontecem coisas boas Que não teriam acontecido Se tudo tivesse dado certo".

Renato Russo

"Não está na natureza das coisas que o homem realize um descobrimento súbito e inesperado; a ciência avança passo a passo e cada homem depende do trabalho de seus predecessores.' 


\title{
AVALIAÇÃO DA CONCENTRAÇÃO DE MICRO E MACROCONSTITUINTES DO SEDIMENTO DO RESERVATÓRIO ITUPARARANGA/SOROCABA-SP
}

\author{
Sharlleny Alves Silva
}

\begin{abstract}
RESUMO
O reservatório de Itupararanga foi construído pela LIGHT para gerar energia elétrica, iniciando suas operações em 1912. É formado pela barragem das águas do rio Sorocaba, o qual possui como afluentes os rios Sorocamirim, Sorocabuçu e Una. O reservatório localiza-se em uma área de fortes pressões ambientais devido à poluição difusa da produção agrícola, à carga orgânica e uso e ocupação do solo com atividades antrópicas. Desde 2003 vem recebendo alertas da CETESB, devido à presença de grande quantidade de cianobactérias que têm se mantido até os dias atuais. Em decorrência dos problemas observados nesse reservatório, o presente estudo teve por objetivo, avaliar a concentração, dos micro e macroconstituintes em amostras de perfil sedimentar de quatro pontos distintos do reservatório. Para estas análises foram utilizadas as seguintes técnicas analíticas e os respectivos elementos analisados: Análise por Ativação com Nêutrons Instrumental (INAA): As, Ba, Br, Ca, Ce, Co, Cr, Cs, Eu, Fe, Hf, K, La, Lu, Na, Nd, Rb, $\mathrm{Sb}, \mathrm{Sc}, \mathrm{Sm}, \mathrm{Ta}, \mathrm{Tb}, \mathrm{Th}, \mathrm{U}, \mathrm{Yb}$ e Zn; Espectrometria de Emissão Ótica com Plasma Indutivamente Acoplado (ICP OES): Ag, Al, Ba, Be, Co, Cr, Cu, Fe, Li, Mg, Mn, Mo, Ni, P, Sn, Sr, Ti, V e Zn; Espectrometria de Absorção Atômica com Forno de Grafite (FG AAS) As, $\mathrm{Cd} \mathrm{e} \mathrm{Pb}$ e Analisador Direto de Mercúrio: Hg total. A validação das metodologias utilizadas foi realizada por meio das análises de materiais de referencia certificados. Os resultados obtidos foram comparados aos valores de referência NASC (North American Shale Comosite) e UCC (Upper Continental Crust). Foram calculados o fator de enriquecimento (FE) e o índice de geoacumulação (Igeo), ferramentas usadas para avaliação da presença de fontes de poluição antrópicas. As concentrações dos metais obtidos por ICP OES e FG AAS foram comparadas aos valores orientadores TEL e PEL do Conselho Canadense de Ministros do Meio Ambiente (CCME) e adotado pela CETESB. A partir desse estudo, foi possível realizar um diagnóstico da qualidade e a carga de fósforo contida nos sedimentos do reservatório, direcionando para ações corretivas que antecipem um dano maior a qualidade do reservatório.
\end{abstract}




\title{
MICRO AND MACRO SEDIMENT CONSTITUINT CONCENTRATION ASSESSMENT OF THE ITUPARARANGA RESERVOIR/SOROCABA-SP
}

\author{
Sharlleny Alves Silva
}

\begin{abstract}
The Itupararanga reservoir was constructed by LIGHT for generating electrical energy, starting its operations 1912. It is formed by the barrage of the waters of the Sorocaba river, formed by the rivers Sorocamirim, Sorocabuçu and Una. The reservoir finds itself in an area of strong environmental pressures due to the diffuse pollution from the agricultural production and the organic load and the use and the occupation of the soil with anthropic activities. Since 2003 it keeps receiving alerts from CETESB due to the presence of cyanobacteria that continues today. In its waters there is the presence of a toxicity which did not correlate with the results of chemical analyzes performed. Due to the problems observed in this reservoir, the present study aimed to evaluate the concentration of micro and macro constituents in samples of sedimentary profile of four different reservoir points. For these analyzes the following analytical techniques were used, with the respective elements analyzed: Analysis by Instrumental Neutron Activation (INAA): As, Ba, Br, Ca, Ce, Co, Cr, Cs, Eu, Fe, Hf, K, La, Lu, Na, Nd, Rb, Sb, Sc, Sm, $\mathrm{Ta}, \mathrm{Tb}, \mathrm{Th}, \mathrm{U}, \mathrm{Yb}$ and $\mathrm{Zn}$; Optical Emission Spectrometry with Inductively Coupled Plasma (ICP OES): Ag, Al, Ba, Be, Co, Cr, Cu, Fe, Li, Mg, Mn, Mo, Ni, P, Sn, Sr, Ti, V and $\mathrm{Zn}$; Atomic Absorption Spectrometry with Graphite Furnace (FG AAS) As, Cd and $\mathrm{Pb}$ and Direct Mercury Analyzer: total $\mathrm{Hg}$. The validation of used methodologies was performed by the analysis of certified reference materials. The results obtained were compared to reference values NASC (North American Shale Comosite), UCC (Upper Continental Crust). The enrichment factors (EF) and the geoaccumulation index (Igeo), were calculated; they are tools used to evaluate the presence of anthropic pollution sources. The metal concentrations obtained by ICP OES and FG AAS were compared to the guiding values TEL and PEL from the Canadian Council of Ministers of the Environment (CCME) and adopted by CETESB. From this study, it was possible to make a diagnosis of the quality and load of phosphorus in the reservoir sediments, directing to corrective actions that prevent greater harm to the quality of the reservoir.
\end{abstract}




\section{LISTA DE TABELAS}

TABELA 1.1 - VARIÁVEIS DE QUALIDADE DE ÁGUA UTILIZADAS PARA CÁLCULO DOS RESPECTIVOS ÍNDICES.

TABELA 1.2 - ClasSifiCAÇÃO DA QUALIDAdE DE ELEMENTOS EM SEDIMENTOS A PARTIR DE TEL E PEL (CETESB, 2011).....

TABELA 3.1 - DESCRIÇÃO, LOCALIZAÇÃO E PROFUNDIDADES DOS PONTOS AMOSTRADOS

TABELA 3.2-CONDIÇÃO DE OPERAÇÃO DO ICP OES: ELEMENTOS E AS RESPECTIVAS LINHAS DE EMISSÃO E OS VALORES DE LIMITE DE DETECÇÃO (LD) DA TÉCNICA

TABELA 3.3 - SOLUÇÕES UTILIZADAS NA CONSTRUÇÃO DA CURVA DE CALIBRAÇÃO PARA AS DETERMINAÇÕES POR MEIO DA TÉCNICA GF AAS

TABELA 3.4 - PARÂMetros de DETERminAÇão DE As, CD E PB AJUSTAdos PARA ANÁLISE POR GF AAS

TABELA 3.5 - RADIOISÓTOPOS IDENTIFICADOS NOS ESPECTROS DE EMISSÃO GAMA UTILIZADOS PARA DETERMINAÇÃO DOS ELEMENTOS DE INTERESSE PELA TÉCNICA DE INAA, SUAS RESPECTIVAS ENERGIAS E MEIAS-VIDAS $\left(\mathrm{T}_{1 / 2}\right)$

TABELA 3.6 - ClASSIFICAÇÃO DO NÍVEL DE POLUIÇÃO A PARTIR DOS VALORES DE IGEO CALCULADOS

TABELA 4.1- RESUlTAdOS DAS ANÁLISES GRANULOMÉTRICAS, UMIDADE, CARBONO ORGÂNiCO TOTAL (COT), NitROGÊNIO (NKT) E RELAÇÃo COT/NKT .. 99

TABELA 4.2 - RESUltados DAS ANÁLISES DO MATERIAL DE REFERÊNCIA WQB-3 POR ICP OES.

TABELA 4.3 - RESULTADOS DAS ANÁLISES DO MATERIAL DE REFERÊNCIA SRM 1646 POR ICP OES. 
TABELA 4.4 - RESULTADOS DAS ANÁLISES DO MATERIAL DE REFERÊNCIA SRM 2710A POR ICP OES

TABELA 4.5 - RESULTADOS DAS ANÁLISES DOS MATERIAIS DE REFERÊNCIA PARA A DETERMINAÇÃO DE FÓSFORO, POR ICP OES

TABELA 4.6 - RESULTADOS DAS ANÁLISES DOS MATERIAIS DE REFERÊNCIA PARA A DETERMINAÇÃO DE AS, CD E PB, POR FG AAS

TABELA 4.7 - RESUltados DE Hg TOTAL NOS MATERIAIS DE REFERÊNCIA PELA METODOLOGIA DE ANÁLISE DiRETA DE MERCúRIO.

TABELA 4.8 - VALORES DE LQ E LD (MG L ${ }^{-1}$ ), DETERMINADOS PELAS TÉCNICAS ICP OES, GF AAS E ANÁLISE DiRETA DE MERCÚRIO

TABEla 4.9 - RESUltados (MG KG ${ }^{-1}$ ) DAS ANÁLiSE DAS AMOSTRAS DE SEDIMENTOS POR ICP OES

TABELA 4.10 - RESULTADOS DAS DETERMINAÇÕES DE FÓSFORO POR ICP OES, NAS AMOSTRAS DE SEDIMENTO.

TABELA 4.11 - RESULTADOS (MG KG ${ }^{-1}$ ) DAS ANÁLISES DE SEDIMENTOS POR GF AAS .. 115

TABELA 4.12 - RESUltAdOS (MG KG ${ }^{-1}$ ) DE MERCÚRIO TOTAL OBTIDOS POR ANÁLISE DiRETA DE MERCÚRIO, NAS AMOSTRAS DE SEDIMENTOS

TABELA 4.13 - COMPARAÇÃo DOS RESUltADOS DE ICP OES, FG AAS E ANÁLISE DIRETA DE MERCÚRIO COM OS VALORES DE TEL E PEL

TABELA 4.14 - VALORES DE FE, TENDO SC COMO ELEMENTO NORMALIZADOR E VALORES DE CONCENTRAÇÃO DO UCC COMO VALORES DE REFERÊNCIA.

TABELA 4.15 - VALORES DE FE, TENDO SC COMO ELEMENTO NORMALIZADOR E VALORES DE CONCENTRAÇÃO DO NASC COMO VALORES DE REFERÊNCIA. 
TABELA 4.16 - VALORES DE FE TENDO SC COMO ELEMENTO NORMALIZADOR E VALORES DE CONCENTRAÇÃO DA BASE DO PERFIL COMO VALORES DE REFERENCIA

TABELA 4.17 - VALORES DE IGEO OBTIDOS A PARTIR DOS VALORES DE CONCENTRAÇÃO DO UCC.

TABELA 4.18 - VALORES DE IGEO OBTIDOS A PARTIR DOS VALORES DE CONCENTRAÇÃO DO NASC

TABELA 4.19 - VALORES DE IGEO OBTIDOS A PARTIR DOS VALORES DE CONCENTRAÇÃO DA BASE DO PERFIL SEDIMENTAR

TABELA 4.20 - RESULTADO DA ANÁLISE FATORIAL UTILIZANDO ROTAÇÃO VARIMAX COM VALORES /0,6/ SELECIONADOS

TABElA 4.21 - Resultado DA AnÁlise Fatorial COM EXTRAÇÃo DE COMPONENTES PRINCIPAIS.

TABELA 4.22 - VALORES DE LD E LQ $\left(\mathrm{MG} \mathrm{KG}^{-1}\right)$ PARA OS MATERIAIS DE REFERENCIA ANALISADOS POR INAA

TABELA 4.23 - RESUltAdOS (MG KG ${ }^{-1}$ ) DAS ANÁLISES DAS AMOSTRAS DE SEDIMENTOS POR INAA

TABELA 4.24 - VALORES DE FE, TENDO SC COMO ELEMENTO NORMALIZADOR E VALORES DE CONCENTRAÇÃO DO UCC COMO VALORES DE REFERÊNCIA.

TABElA 4.25 - VALORES DE FE, TENDO SC COMO ELEMENTO NORMALIZADOR E VALORES DE CONCENTRAÇÃO DO NASC COMO VALORES DE REFERÊNCIA.

TABEla 4.26 - VALORES DE FE, TENDO SC COMO ELEMENTO NORMALIZADOR E VALORES DE CONCENTRAÇÃO DA BASE DO PERFIL (PT 03) COMO VALORES DE REFERÊNCIA

TABELA 4.27 - VALORES DE IGEO OBTIDOS A PARTIR DOS VALORES DE CONCENTRAÇÃO DO UCC. 
TABELA 4-28 VALORES DE IGEO OBTIDOS A PARTIR DOS VAlORES DE CONCENTRAÇÃO DO NASC

TABELA 4.29 - VALORES DE IGEO OBTIDOS A PARTIR DOS VALORES DE CONCENTRAÇÃO DA BASE DO PERFIL................................................. 161

TABELA 4.30 - RESUlTAdO DA ANÁLISE FATORIAL UTILIZANDO ROTAÇÃO VARIMAX COM VALORES /0,6/ SELECIONADOS

TABELA 4.31 - RESUltado DA ANÁlise FATORIAL COM EXTRAÇÃO DE COMPONENTES PRINCIPAIS. 


\section{LISTA DE FIGURAS}

FIGURA 1.1 - ClassiFiCAÇÃO DAS UNIDAdES DE GERENCIAMENTO DE RECURSOS HÍdRICOS DO ESTADO DE SÃo PAULO

FIGURA 1.2 EVOLUÇÃO DO PROCESSO DE EUTROFIZAÇÃO EM UM LAGO OU RESERVATÓRIO. ASSOCIAÇÃO ENTRE OCUPAÇÃO DO USO E OCUPAÇÃO DO SOLO E A EUTROFIZAÇÃO (ESTEVES, 1998).

FIGURA 1.3 - ESTRUTURAS GEOLÓGICAS NA REGIÃO DO RESERVATÓRIO DE ITUPARARANGA.

FIGURA 1.4 - MAPA ESQUEMÁTICO CONTENDO OS PRINCIPAIS CORPOS D'ÁGUA, MUNICÍPIOS E A LOCALIZAÇÃO DOS PONTOS DE AMOSTRAGEM DA URGHI 10, TENDO EM DESTAQUE O RESERVATÓRIO DE ITUPARARANGA

FIGURA 1.5 - RESERVATÓRIO ITUPARARANGA COM SEUS PONTOS DE MONITORAMENTO REALIZADOS ANUALMENTE PELA CETESB.

FIGURA 1.6 - VALORES MÉDIOS ANUAIS DO ÍNDICE DE QUALIDADE DA ÁGUA NO RESERVATÓRIO DE ITUPARARANGA, EXTRAÍDOS DOS RELATÓRIOS DE QUALIDADE DAS ÁGUAS INTERIORES DO ESTADO DE SÃO PAULO.

FIGURA 1.7 - VALORES MÉDIOS ANUAIS DO ÍNDICE DE QUALIDADE DAS ÁGUAS PARA FINS DE ABASTECIMENTO PÚBLICO NO RESERVATÓRIO DE ITUPARARANGA, EXTRAÍDOS DOS RELATÓRIOS DE QUALIDADE DAS ÁGUAS INTERIORES DO ESTADO DE SÃO PAULO

FIGURA 1.8 - VALORES MÉDIOS ANUAIS DO ÍNDICE DE QUALIDADE DA ÁGUA PARA PROTEÇÃO DA VIDA AQUÁTICA NO RESERVATÓRIO DE ITUPARARANGA, EXTRAÍDOS DOS RELATÓRIOS DE QUALIDADE DAS ÁGUAS INTERIORES DO ESTADO DE SÃO PAULO.

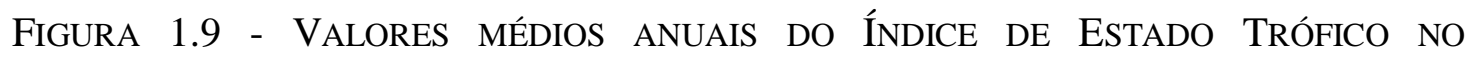
RESERVATÓRIO DE ITUPARARANGA, EXTRAÍDOS DOS RELATÓRIOS DE QUALIDADE DAS ÁGUAS INTERIORES DO ESTADO DE SÃo PAULO. 
Figura 1.10 -EvOluÇÃo dO NÚMERO DE CIANOBACTÉRIAS E IET ENTRE 2006 E 2011, NOS PONTOS DE MONITORAMENTO DA CETESB

FIGURA 2.1 - REPRESENTAÇÃO ESQUEMÁTICA DA INTERAÇÃO DO NÊUTRON COM UM NÚCLEO ALVO.

FIGURA 2.2 - ESQUEMA DE ANÁLISE DE UM ICP OES 67

Figura 2.3 - ESQUEMA DE ANÁLISE DA TÉCNICA DE ANÁLISE DIRETA DE MERCÚRIO 71

FIGURA 3.1- LOCALIZAÇÃO DOS PONTOS DE AMOSTRAGEM NO RESERVATÓRIO DE ITUPARARANGA 73

FIGURA 3.2 - AMOSTRADOR CORE SAMPLE 74

FIGURA 4.1 Porcentagem de Argila, Silte E Areia Em CAda FraÇão das AMOSTRAS DE SEDIMENTO, POR PONTO AMOSTRADO. 98

FIGURA 4.2 DiSTRIBUIÇÃO DOS ELEMENTOS ANALISADOS POR ICP OES (MG KG ${ }^{-1}$ ), EM CADA FRAÇÃO DE SEDIMENTO, PARA CADA PONTO AMOSTRADO 108

FIGURA 4.3 - BoX PLOT DOS ELEMENTOS Be, HG E SN 117

FIGURA 4.4 - Box Plot dos elementos Al, As, Co, Cu, Fe E Ni 118

FIGURA 4.5 - BOX PLOT DOS ELEMENTOS CR, LI, PB, ZN E V 119

FIGURA 4.6 - Box Plot dos Elementos BA, CA, MG, Mn, P E Ti. 120

FIGURA 4.7 - FOTO DO PERFIL SEDIMENTAR DO PONTO 03.

FIGURA 4.8 - DENDROGRAMA RESUltante DA ANÁlise DE Agrupamento, VARIÁVEIS: PONTOS DE AMOSTRAGEM

FIGURA 4.9 - Dendrograma Resultante da AnÁlise DE Agrupamento, VARIÁVEIS: PARÂMETROS ANALISADOS 
FIGURA 4.10 - Z-SCORE OBTIDO PARA OS RESULTADOS DO MATERIAL DE REFERÊNCIA SL-01, POR INAA .

FIGURA 4.11 - Z-SCORE OBTIDO PARA OS RESULTADOS DO MATERIAL DE REFERÊNCIA BEN-BASALT, POR INAA

FigURA 4.12 DisTRIBUIÇÃO DOS ELEMENTOS ANALISADOS POR INAA (MG KG ${ }^{-1}$ ), EM CADA FRAÇÃO DE SEDIMENTO, PARA CADA PONTO AMOSTRADO

FIGURA 4.13 - Box Plot dos elementos As, CA, Co, Cs, Fe, Sb, Sc, TA, Th e U........ 147

FIGURA 4.15 - BOX PLOT DOS ELEMENTOS BA, NA E NKT. 149

FIGURA 4.16 - BoX PLOT DOS ELEMENTOS EU, Lu, SM, TB E YB. 149

FIGURA 4.17 - BOX PLOT DOS ELEMENTOS CE, LA E ND 150

FIGURA 4.18 - BOX PLOT PARA OS DADOS DE AREIA, SILTE, ARGILA E COT 150

FIGURA 4.19 - Dendrograma RESUltante dA ANÁlise DE Agrupamento, VARIÁVEIS: PONTOS DE AMOSTRAGEM

FIGURA 4.20 - Dendrograma RESUltante DA ANÁlise DE AgRUPAMENTO, VARIÁVEIS: ELEMENTOS E PARÂMETROS ANALISADOS.

FIGURA 4.21 COMPARAÇÃO DAS CONCENTRAÇÕES OBTIDAS PELAS TÉCNICAS DE INAA E ICP OES (BA, CR, CO, FE E ZN) E GF AAS (As), NAS AMOSTRAS DE SEDIMENTO 


\section{SUMÁRIO}

1 INTRODUÇÃO--

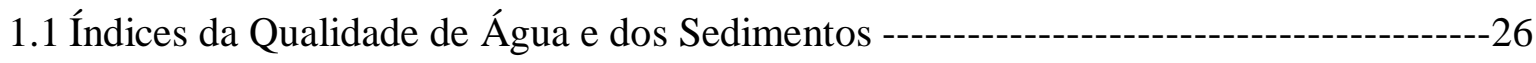

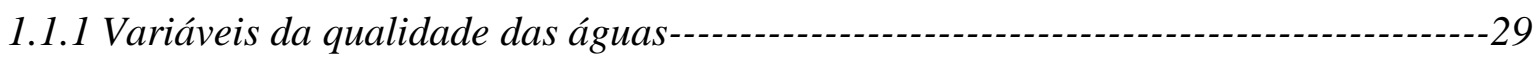

1.1.2 Variáveis da qualidade dos sedimentos ---

1.2 Eutrofização -----------------------------------------------------------------------32

1.3 Sedimento como testemunho do histórico de contaminação antrópica------------------35

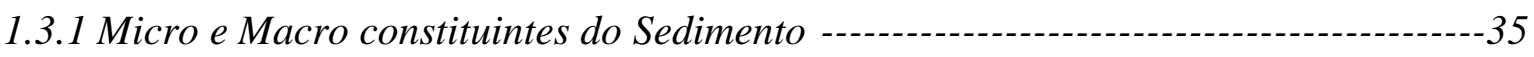

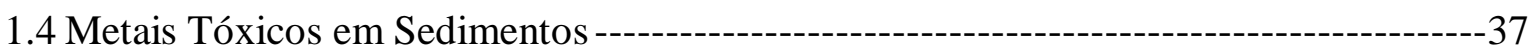

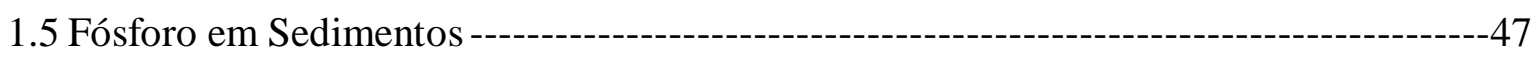

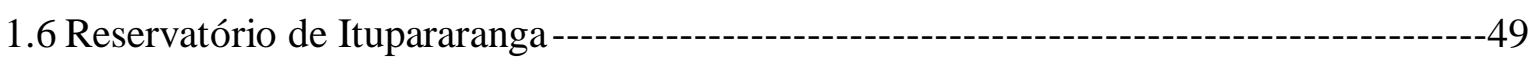

1.7 Histórico do monitoramento no reservatório de Iupararanga ----------------------------51

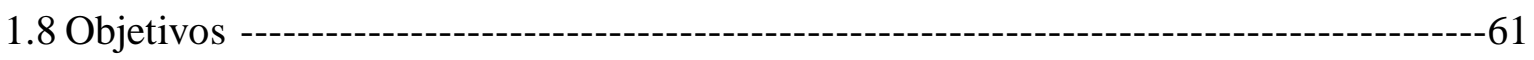

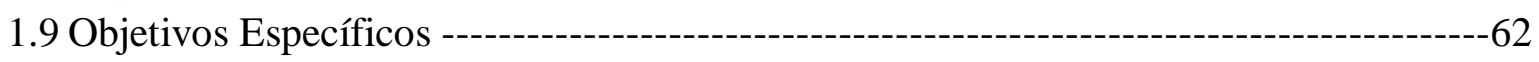

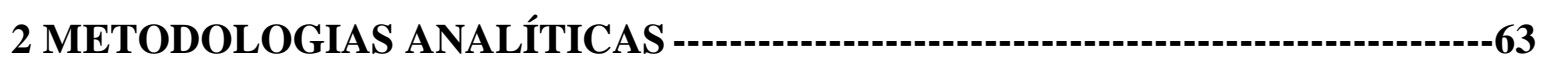

2.1 Técnicas analíticas para determinação de metais em sedimentos ---------------------------63

2.1.1 Análise por Ativação com Nêutrons (INAA) -----------03

2.1.2 Espectrometria de Emissão com Plasma Indutivamente Acoplado (ICP OES) -------66

2.1.3 Espectrometria de Absorção com Atomização em forno de grafite (GF AAS)-------68

2.1.4. Espectrometria de Absorção Atômica por Decomposição Térmica e Amalgamação 70

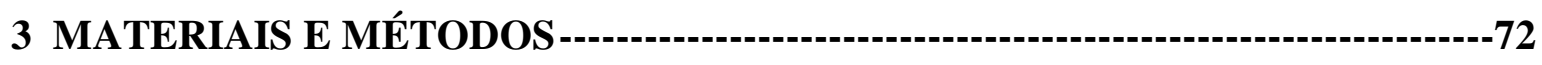

3.1.Amostragem--------------------------------------------------------------------------------------72

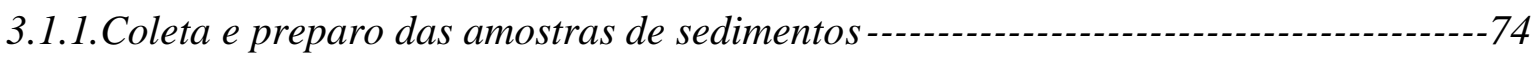

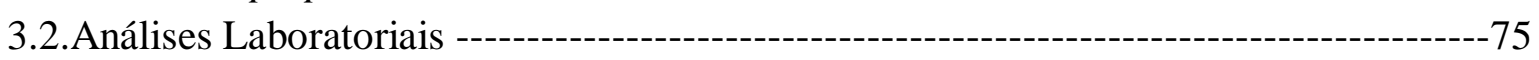

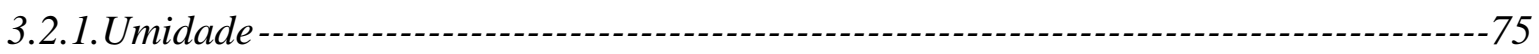

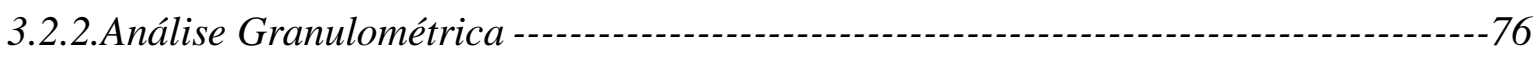

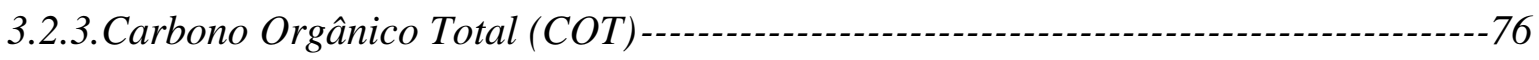

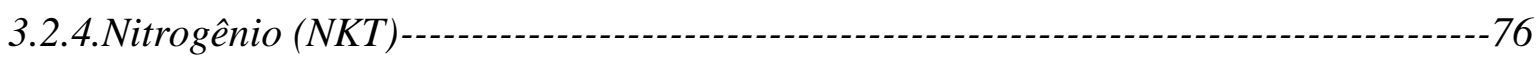

3.2.5.Metais e fósforo - ICP OES e FG AAS --

3.2.6.Digestão das amostras de sedimentos (ICP OES, GF AAS)--------78

3.3.Determinação por ICP OES (fósforo e metais) -----------------------------------------78

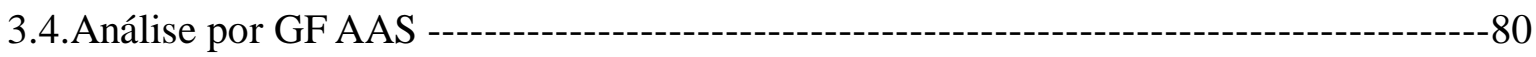

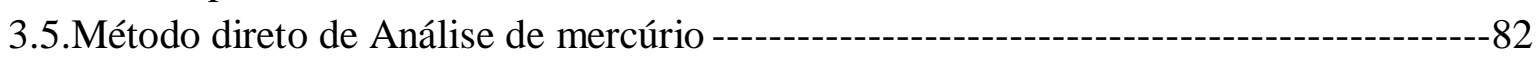

3.6.Aceitação dos resultados (ICP OES, FG AAS, método direto de Análise de mercúrio)-- 
3.7.Limites de Detecção (LD) e Quantificação (LQ) dos métodos ICP OES, GF AAS e

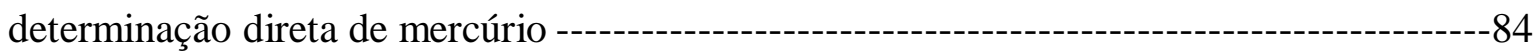

3.8.Análise por Ativação com Nêutrons Instrumental (INAA) --------------------------------85

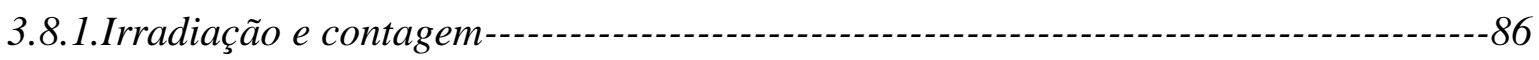

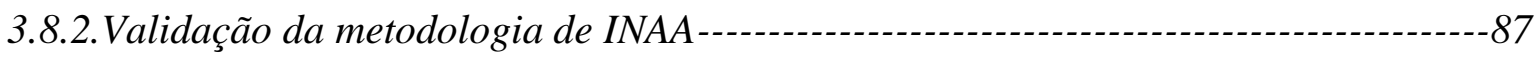

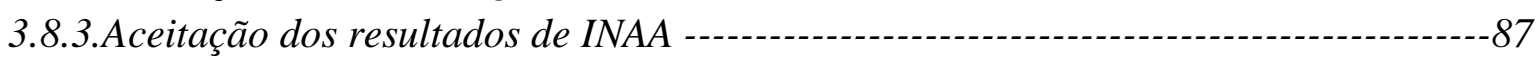

3.8.4.Limites de Detecção (LD) e Quantificação (LQ) -

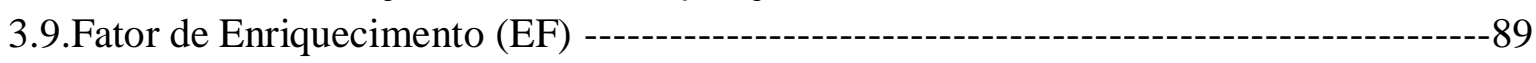

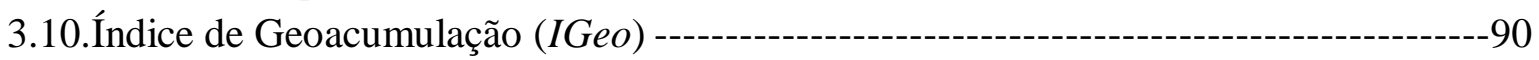

3.11.Tratamento estatístico dos dados - Análise estatística multivariada--------------------91

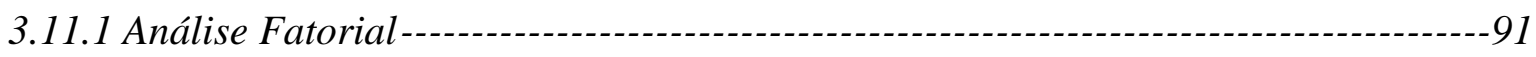

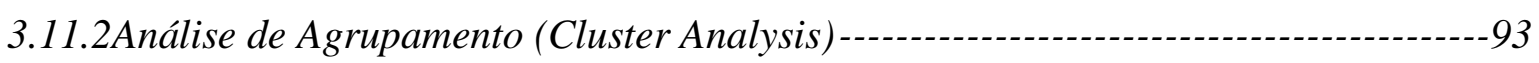

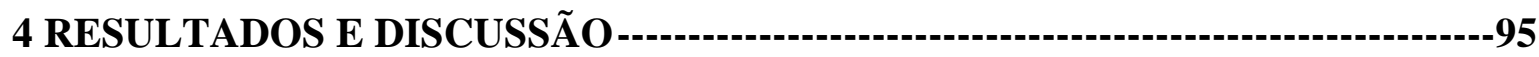

4.1.Análise Granulométrica, Conteúdo de Matéria Orgânica (MO) e Nitrogênio Kjeldahl Total 95

4.2.Análises dos Sedimentos pelas Técnicas ICP OES, FG AAS e Análise Direta de

Mercúrio. ---------------------------------------------------------------------------------------------99

4.2.1. Validação da metodologia de ICP OES, FG AAS e Análise Direta de Mercúrio--- 100

4.2.2. Limites de Detecção (LD) e Limite de Quantificação (LQ) --------------- 103

4.2.3.Resultados obtidos para as amostras de sedimento pela técnica de ICP OES------ 104

4.2.4.Resultados obtidos para as amostras de sedimento pela técnica de GF AAS ------ 114

4.2.5.Resultados de Hg total obtidos por análise direta de mercúrio ------------------- 115

4.2.6. Variação de concentração dos elementos analisados por ICP OES e AAS nas

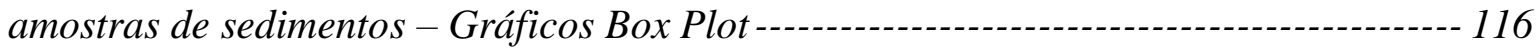

4.2.7. Comparação dos resultados de concentração para alguns metais, com os valores de

TEL e PEL (CCME, 2001__ 120

4.2.8. Fator de Enriquecimento (FE)-- 121

4.2.9.Índice de Geoacumulação (Igeo) -

4.2.10.Tratamento estatístico dos dados de ICP OES e AAS ----------- 128

4.3Análise por Ativação Neutrônica Instrumental (INAA) ------------------------------- 133

4.3.1 Validação da metodologia de INAA-------- 133

4.3.2 Limites de Deteç̧ão (LD) e Limites de Quantificação (LQ) --- 135

4.3.3 Resultados obtidos nas análises das amostras de sedimentos por INAA ---------- 136

4.3.4 Variação de concentração dos elementos determinados por INAA nas amostras de sedimentos - Gráficos "Box Plot”-

4.3.5 Fator de Enriquecimento (FE)-- 151

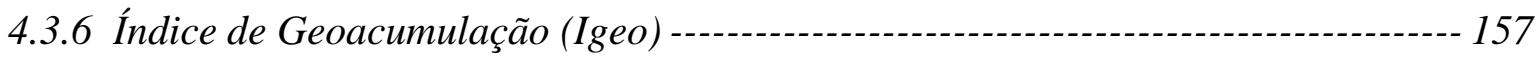

4.3.7 Tratamento Estatístico dos Dados -- 162 
4.4 Comparação dos resultados das Análises obtidos pelas técnicas ICP OES, FG AAS e INAA 167

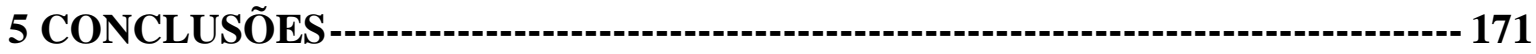

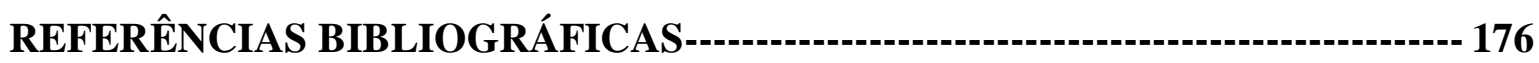




\section{CAPÍTULO 1}

\section{INTRODUÇÃO}

O aumento de atividades impactantes em todo o mundo tornou crescente a preocupação com relação à qualidade da água. Os lançamentos de substâncias tóxicas, através de efluentes industriais ou resultantes da aplicação de pesticidas, podem afetar a qualidade do ambiente para os organismos aquáticos, ou mesmo a saúde humana, por meio do consumo de águas contaminadas (Esteves, 1988).

A água é um elemento essencial à manutenção da vida humana em nosso planeta que possui um valor inestimável. É também um recurso indispensável nos ciclos geológicos, biológicos e químicos e possui ainda uma fundamental importância para o desenvolvimento econômico mundial.

As águas são indispensáveis a múltiplos usos em um largo espectro das atividades humanas, onde se destacam, entre outros, o abastecimento público e industrial, a irrigação, a produção de energia elétrica e as atividades de lazer e recreação, bem como a preservação da vida aquática (CETESB, 2006).

O problema da disponibilidade de água é atualmente um tema discutido no mundo todo. Esta discussão passa pela avaliação quantitativa de disponibilidade hídrica bem como pela qualidade da água disponível para os diferentes usos possíveis, como recreação, pesca, irrigação, geração de energia e abastecimento público (Lamparelli, 2004). 
A conservação da quantidade e qualidade da água depende de condições naturais e antrópicas das bacias hidrográficas. Isto porque, ao mesmo tempo em que os rios, riachos e córregos fornecem água para o reservatório, eles também podem trazer substâncias poluidoras que tenham sido despejadas neles ou no solo por onde passaram.

O lançamento de nutrientes em excesso pode mudar as características de corpos d'água e afetar o uso ao qual este manancial se destina. Este fenômeno é conhecido como eutrofização (Esteves, 1988).

Nos últimos anos, o processo de eutrofização tem se acelerado nos reservatórios brasileiros devido ao aumento do uso de fertilizantes nas bacias hidrográficas, aumento da população, elevado grau de urbanização sem tratamento de esgoto doméstico e intensificação de algumas atividades industriais que levam excessiva carga de fósforo, nitrogênio e matéria orgânica para estes reservatórios (Fonseca, 2010).

Os estudos em sistemas aquáticos naturais ou artificiais são de grande importância, afinal é a partir destes que é possível o conhecimento do real estado de contaminação ou eutrofização no qual, o sistema se encontra, sendo assim possível, tomar decisões a partir das quais estes processos de degradação possam ser contidos ou retardados. Neste trabalho pretendeu-se avaliar sedimentos do Reservatório Itupararanga, um reservatório considerado como de boa qualidade que, entretanto, começa a apresentar alguns indícios de que esta qualidade esteja se perdendo. Para confirmar seu real estado, busca-se uma análise de seus sedimentos, para que se possa conhecer o estágio de poluição por meio da quantificação de macro e micronutrientes.

\section{1 Índices da Qualidade de Água e dos Sedimentos}

Na medida em que se torna mais intenso e diversificado o uso dos mananciais e de suas bacias hidrográficas, maior é a necessidade de se definir formas de manejo sustentado e de gerenciamento desses corpos hídricos. Para isso, torna-se necessário um monitoramento sistemático, que resulta em séries temporais de dados que permitam avaliar a evolução da qualidade do corpo aquático e conhecer as tendências de sua variação. 
No Estado de São Paulo a CETESB, Companhia de Tecnologia de Saneamento Ambiental, é a responsável pela fiscalização e monitoramento da qualidade das águas do Estado, que iniciou a partir de 1974, a operação da Rede de Monitoramento da Qualidade das Águas Interiores (rios e reservatórios). Esse monitoramento tem possibilitado o conhecimento adequado das condições reinantes nos principais cursos d'água situados nas 22 Unidades de Gerenciamento de Recursos Hídricos (UGRHIs), em que se divide o Estado de São Paulo, de acordo com a Lei Estadual n ${ }^{\circ} 9.034$ de 27 de dezembro de 1994. A UGRHI está estruturada no conceito de bacia hidrográfica, onde os recursos hídricos convergem para um corpo d'água principal. A FIG 1.1 traz um mapa do Estado de São Paulo com a atual divisão das UGRHIs.

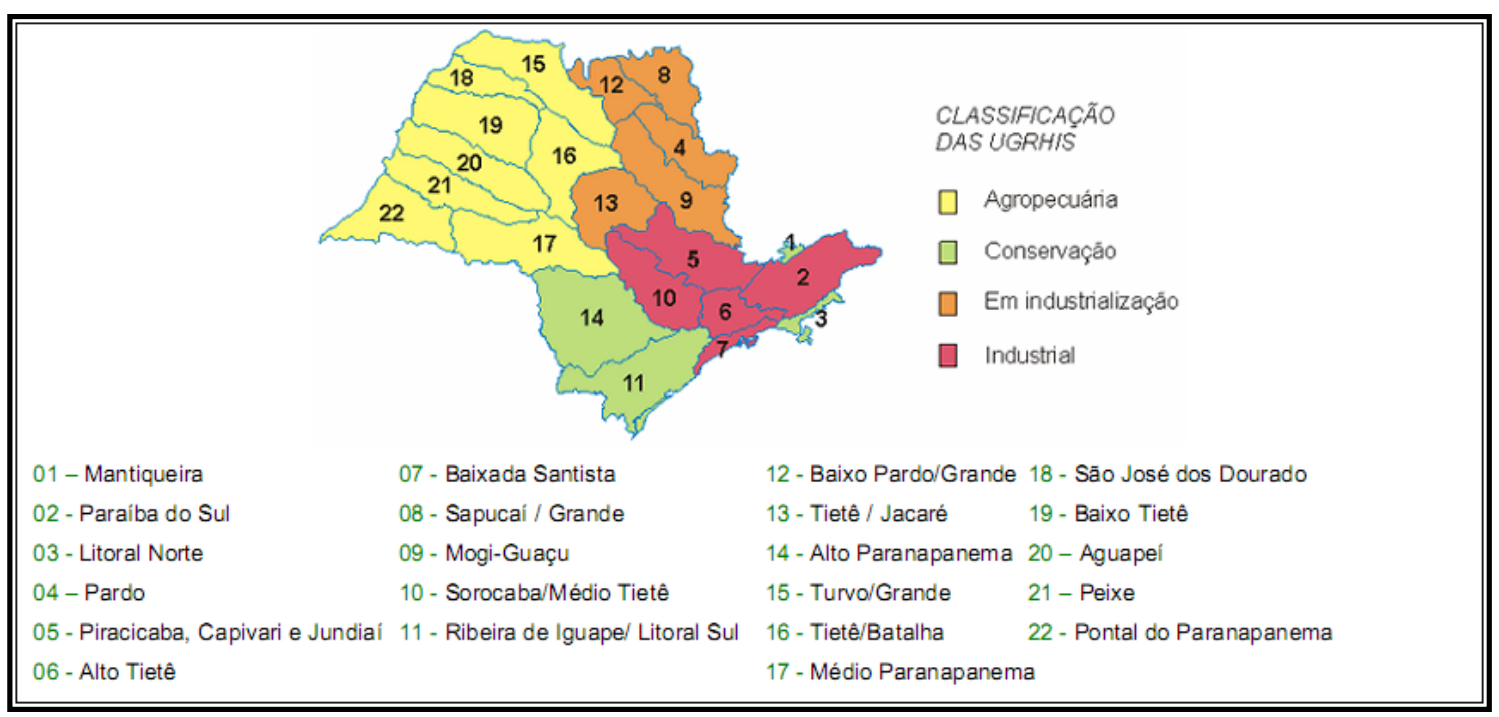

FIGURA 1.1 - Classificação das Unidades de Gerenciamento de Recursos Hídricos do Estado de São Paulo

Em 13 de agosto de 1998, a Resolução da Secretária do Meio Ambiente, SMA65, criou o Índice de Qualidade de águas brutas para fins de Abastecimento Público (IAP) e o Índice de Preservação da Vida Aquática (IVA). Em função dessa Resolução, criou-se um Grupo de Trabalho multi-institucional, que contou com a participação de técnicos da CETESB, da SMA, da Companhia de Saneamento Básico do Estado de São Paulo (SABESP) e da Universidade de São Paulo (USP), para a revisão dos índices de qualidade da água (CETESB, 2004). 
A CETESB com o intuito de fornecer uma visão geral da qualidade das águas e dos sedimentos, integram dos resultados de diversas variáveis através de um único indicador, os índices de qualidade, os quais refletem a qualidade das águas para os seguintes usos (CETESB, 2009):

- $\quad$ IQA -Índice de Qualidade das Águas.

- $\quad$ IAP - Índice de Qualidade das Águas para fins de abastecimento público.

- $\quad$ IET - Índice do Estado Trófico.

- $\quad$ IVA - Índice de qualidade das águas para proteção da vida aquática. Esse índice é completado pelos índices de Comunidades Aquáticas.

- $\quad$ IB - Índice de Balneabilidade.

- CQS - Critério de Avaliação da Qualidade dos Sedimentos.

Sendo um dos últimos a ser adotados, o CQS foi criado por ser o sedimento cada vez mais utilizado em estudos de avaliação da qualidade de ecossistemas aquáticos, por retratar condições históricas da influência de atividades antrópicas sobre esses ambientes, nem sempre detectáveis pelo uso de variáveis da água (CETESB, 2006). A TAB 1.1 apresenta os parâmetros utilizados para os cálculos dos respectivos índices da qualidade. 
TABELA 1.1 - Variáveis de qualidade de água utilizadas para cálculo dos respectivos índices

\begin{tabular}{|c|c|}
\hline $\begin{array}{l}\text { Índice de } \\
\text { qualidade }\end{array}$ & Variáveis de qualidade \\
\hline IQA & $\begin{array}{l}\text { Temperatura, } \mathrm{pH}, \text { oxigênio dissolvido, demanda } \\
\text { bioquímica de oxigênio, coliformes termotolerantes, nitrogênio } \\
\text { total, fósforo total, resíduos totais e turbidez. }\end{array}$ \\
\hline IAP & $\begin{array}{l}\text { Temperatura, } \mathrm{pH}, \text { oxigênio dissolvido, demanda } \\
\text { bioquímica de oxigênio, coliformes termotolerantes, nitrogênio } \\
\text { total, fósforo total, resíduos totais e turbidez, ferro dissolvido, } \\
\text { manganês, alumínio dissolvido, cobre dissolvido, zinco, } \\
\text { potencial de formação de trihalometanos, número de células de } \\
\text { cianobactérias, cádmio, chumbo, cromo total, mercúrio e níquel. }\end{array}$ \\
\hline IET & Clorofila a e fósforo total. \\
\hline IVA & $\begin{array}{l}\text { Oxigênio dissolvido, } \mathrm{pH} \text {, toxicidade, cobre, zinco, } \\
\text { chumbo, cromo, mercúrio, níquel, cádmio, surfactantes, fenóis, } \\
\text { clorofila a e fósforo total. }\end{array}$ \\
\hline IB & Coliforme termo tolerante ou E. coli. \\
\hline CQS & $\begin{array}{l}\text { Leva em consideração a classificação dos sedimentos em } \\
\text { diferentes linhas de evidência: concentração de substâncias } \\
\text { químicas, ecotoxidade, mutagenicidade e comunidade bentônica. }\end{array}$ \\
\hline
\end{tabular}

Em 2008, a CETESB adotou um novo critério para a avaliação da qualidade de sedimento, alterando a classificação em relação à concentração presente no sedimento, passando de três para cinco classes. O CQS - Critério de Avaliação da Qualidade dos Sedimentos leva em consideração a classificação dos sedimentos em diferentes linhas e evidencia: concentração de substâncias químicas, ecotoxicidade, mutagenicidade e comunidade bentônica.

\subsubsection{Variáveis da qualidade das águas}

A poluição das águas tem como origem diversas fontes, dentre as quais se destacam as cargas pontuais e difusas. Estas diferentes formas de aporte tornam, na prática, 
inexequível a análise sistemática de todos os poluentes que possam estar presentes nas águas superficiais. Por isso, a CETESB atualmente faz uso de 50 variáveis de qualidade de água, considerando-se aquelas mais representativas, que são (CETESB, 2009):

* Variáveis Físicas: Absorvância no ultravioleta, coloração, série de resíduos (dissolvidos, total e volátil), temperatura da água e do ar, turbidez e transparência.

* Variáveis Químicas: Alumínio, Bário, Cádmio, Carbono Orgânico Dissolvido, Chumbo, Cloreto, Cobre, Condutividade, Cromo, Demanda Bioquímica de Oxigênio (DBO), Demanda Química de Oxigênio (DQO), Fenóis, Ferro, Fluoreto, Fósforo Total, Manganês, Mercúrio, Níquel, Óleos e Graxas, Ortofosfato Solúvel, Oxigênio Dissolvido, pH, Potássio, Série de Nitrogênio (Kjeldahl, Amoniacal, Nitrato e Nitrito), Sódio, Surfactantes e Zinco.

* Variáveis Microbiológicas: Coliformes termotolerantes e E.coli.

* Variáveis Hidrobiológicos: Clorofila-a e comunidades fitoplantônica, zooplantônica e bentônica.

* Variáveis Toxicológicas: Microcistinas, ensaio de toxidade aguda com a bactéria luminescente - V fischeri (Sistema Microtox); ensaio de toxicidade aguda com o microcrustáceo Ceriodaphnia Dúbia e ensaio de mutação reversa (teste de Ames).

\subsubsection{Variáveis da qualidade dos sedimentos}

Os sedimentos têm sido cada vez mais utilizados em estudos de avaliação da qualidade de ecossistemas aquáticos, por retratar condições históricas da influência de atividades antropogênicas sobre esses ambientes, nem sempre detectáveis pelo uso de variáveis da água.

Para as análises dos sedimentos a CETESB faz uso de 34 variáveis de qualidade (físicas, químicas, hidrobiológicas e toxicológicas), considerando-se aquelas mais representativas, a saber:

* Variáveis Físicas: granulometria (areia, silte e argila), série de resíduos (fixos, total e volátil) e umidade.

* Variáveis Químicas: 
○ Inorgânicas: alumínio, cádmio, chumbo, cobre, cromo, fósforo, ferro, manganês, mercúrio, níquel e zinco.

○ Orgânicas: HAP (acenafteno, antraceno, benzo(a)antraceno, benzo(a)pireno, benzo(b)fluoranteno, benzo(g,h,i)perileno, benzo(K)fluoranteno, criseno, dibenzo(A,H)antraceno, fenantreno, fluoranteno, fluoreno, indeno(1,2,3cd) pireno, naftaleno e pireno); Compostos organoclorados (aldrin, BHC, clordano, DDD, DDE, DDT, dieldrin, endosulfan, endosulfansulfato, endrin, heptaclor, heptacloroepóxido, hexaclorobenzeno, lindano, metoxiclor, mirex, PCBs, TDE e toxafeno).

* Variáveis Hidrobiológicas: comunidade bentônica.

* Variáveis Toxicológicas: deformidade em bento de Chironomus sp., ensaio de toxicidade aguda/subletal com o anfípodo Hyalellaazteca e ensaio de mutação reversa (teste de Ames)

Infelizmente no Brasil, ainda hoje, não há critérios pré-definidos para a classificação da qualidade de sedimentos em relação a teores de metais. Em vista disto, a CETESB, utiliza-se do critério estabelecido pelo Ministério do Meio Ambiente do Canadá (Environment Canada) para a avaliação e classificação dos sedimentos por ela analisados e os valores estabelecidos pela resolução do CONAMA, Conselho Nacional do Meio Ambiente (CONAMA), número 344 (CONAMA, 2004). Essa resolução estabelece valores orientadores para disposição do material dragado em águas brasileiras, especificando valores limites de contaminantes químicos para dragagem e disposição final, que institui os mesmos valores estabelecidos pela combinação do CCME e NOAA.

Estes valores atualmente foram divididos e classificados em cinco classes de qualidade, visto que há uma grande distância entre os valores de concentração para os elementos abrangidos pela classificação de TEL (Threshold Effect Level) e PEL (Probable Effect Level) e assim dimensionar melhor as concentrações observadas. A qualidade ÓTIMA, para cada contaminante, corresponde à concentração inferior a TEL. A qualidade BOA, a faixa entre TEL, inclusive, e a concentração correspondente a $50 \%$ da distancia entre TEL e PEL, somado a TEL. A qualidade REGULAR, a faixa superior a $50 \%$ da distância entre TEL e PEL, somado a TEL e inferior a PEL. A qualidade RUIM, a faixa entre PEL, inclusive, e a concentração correspondente a 1,5 x de seu próprio valor. E a qualidade PÉSSIMA acima de 1,5 x PEL. Assim, considerou-se a pior situação dentro da 
série de contaminantes avaliados, quando as concentrações encontradas superam significativamente o valor de PEL (em mais de 50\%). A TAB 1.2 exemplifica melhor a classificação adotada atualmente pela CETESB na avaliação dos sedimentos do Estado de São Paulo (CETESB, 2011).

Segundo o CONAMA, as substâncias não listadas na Tabela 1.4, quando necessária a sua investigação, terão seus valores orientadores previamente estabelecidos pelo órgão ambiental competente. Existindo dados sobre valores basais (valores naturais reconhecidos pelo órgão ambiental competente) de uma determinada região, estes deverão prevalecer sobre os valores da $\mathrm{TAB} 1.2$, sempre que se apresentem mais elevados (CONAMA, 2004).

TABELA 1.2 - Classificação da qualidade de elementos em sedimentos a partir de TEL A PEL (CETESB, 2011)

\begin{tabular}{lccccc}
\hline & ÓTIMA & BOA & REGULAR & RUIM & PÉSSIMA \\
\hline $\mathrm{As}\left(\mathrm{mg} \mathrm{kg}^{-1}\right)$ & $<5,9$ & $\geq 5,9-11,5$ & $>11,5-<17,0$ & $17,0-25,5$ & $>25,5$ \\
\hline $\mathrm{Cd}\left(\mathrm{mg} \mathrm{kg}^{-1}\right)$ & $<0,6$ & $\geq 0,6-2,1$ & $>2,1-<3,5$ & $3,5-5,3$ & $>5,3$ \\
\hline $\mathrm{Pb}\left(\mathrm{mg} \mathrm{kg}^{-1}\right)$ & $<35,0$ & $\geq 35,0-63,2$ & $>63,2-<91,3$ & $91,3-137,0$ & $>137,0$ \\
\hline $\mathrm{Cu}\left(\mathrm{mg} \mathrm{kg}^{-1}\right)$ & $<35,7$ & $\geq 35,7-116,4$ & $>116,4-<197,0$ & $197,0-295,5$ & $>295,5$ \\
\hline $\mathrm{Cr}\left(\mathrm{mg} \mathrm{kg}^{-1}\right)$ & $<37,3$ & $\geq 37,3-63,7$ & $>63,7-<90,0$ & $90,0-135,0$ & $>135,0$ \\
\hline $\mathrm{Hg}\left(\mathrm{mg} \mathrm{kg}^{-1}\right)$ & $<0,170$ & $\geq 0,170-0,328$ & $>0,328-<0,486$ & $0,486-0,729$ & $>0,729$ \\
\hline $\mathrm{Ni}\left(\mathrm{mg} \mathrm{kg}^{-1}\right)$ & $<18$ & $\geq 18-27$ & $>27-<36$ & $36-54$ & $>54$ \\
\hline $\mathrm{Zn}\left(\mathrm{mg} \mathrm{kg}^{-1}\right)$ & $<123$ & $\geq 123-219$ & $>219-<315$ & $315-473$ & $>473$ \\
\hline
\end{tabular}

\subsection{Eutrofização}

A eutrofização é o aumento da disponibilidade de nutrientes, especialmente fósforo e nitrogênio, nos ecossistemas aquáticos e tem, como consequência, o aumento de sua produtividade. Como decorrência deste processo, o ecossistema aquático altera sua condição de oligotrófico a mesotrófico para eutrófico e até mesmo hipereutrófico.

Pode-se dizer que a eutrofização é o crescimento excessivo das vegetais aquáticas, tanto planctônicas quanto aderidas, a níveis tais que sejam considerados como causadores de interferências com os usos desejáveis do corpo d'água, sendo o principal fator de estímulo um nível excessivo de nutrientes no corpo d’água, principalmente 
nitrogênio e fósforo. A FIG 1.2 ilustra a possível sequência do processo em um corpo d'água, como um lago ou reservatório.

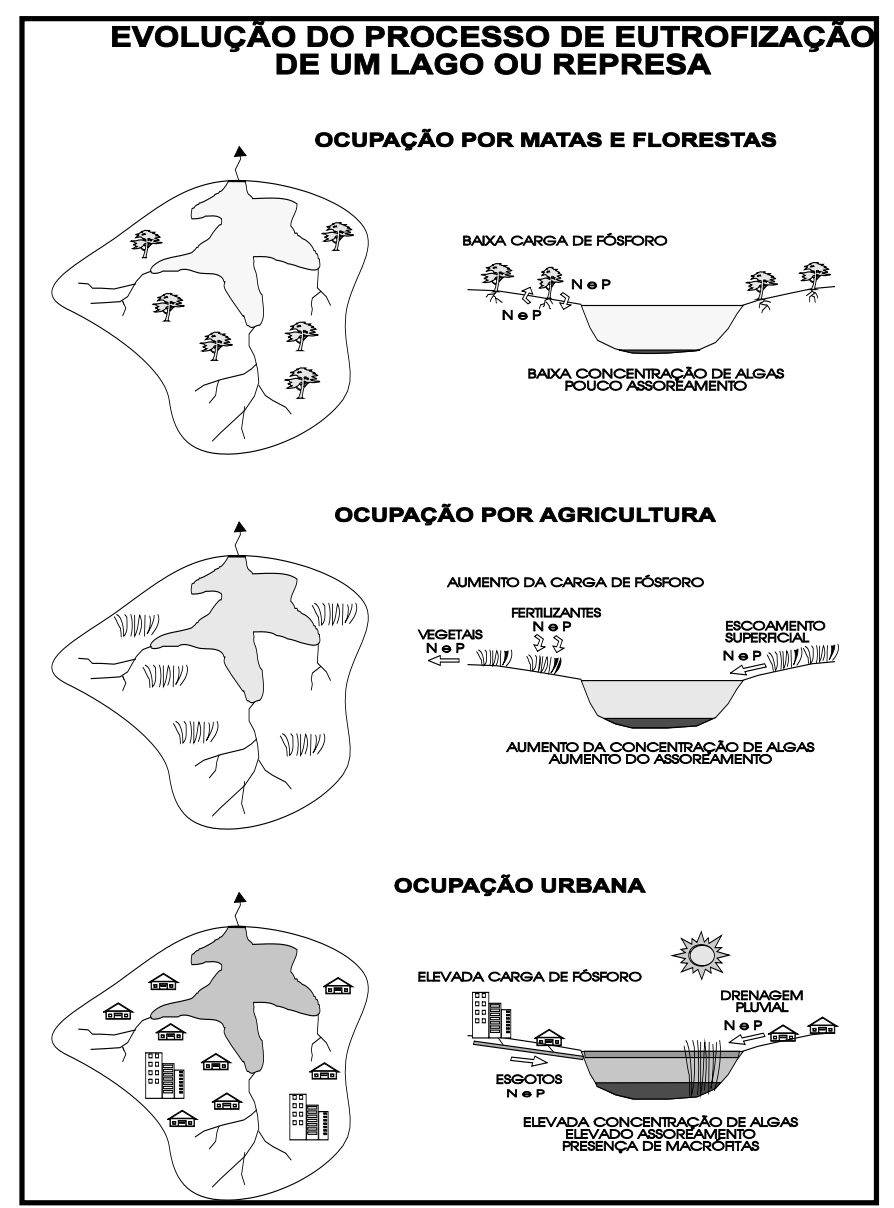

FIGURA 1.2 Evolução do processo de eutrofização em um lago ou reservatório. Associação entre ocupação do uso e ocupação do solo e a eutrofização (Esteves, 1998)

Conforme já mencionado o fenômeno da eutrofização ocorre quando no ambiente aquático passa a haver mais produção de matéria orgânica do que o sistema pode decompor. O crescimento e a posterior morte de algas que se sedimentam, provoca um aumento na contribuição de matéria orgânica à região mais profunda dos lagos e represas. A decomposição desta matéria orgânica implica em uma substancial redução da massa de oxigênio dissolvido disponível no corpo d'água. Como nesta região não há normalmente produção fotossintética, em função da ausência de luminosidade, pode ocorrer um consumo completo de todo o oxigênio disponível, atingindo-se uma condição de anaerobiose. 
O aumento da concentração de nutrientes no corpo aquático influi não só no acréscimo da densidade de algas, mas também pode causar alterações qualitativas, como o surgimento de novas espécies e o desaparecimento de outras.

Ao atingir o estágio eutrófico, a água se torna imprópria para o abastecimento, mesmo com o tratamento convencional, em função da alta quantidade de substâncias tóxicas e odor desagradável excretado pelas algas. É um processo de degradação que pode tornar o corpo d'água inaproveitável para o abastecimento e este processo poder ser natural ou artificial.

A eutrofização natural é um processo lento e contínuo que resulta do aporte de nutrientes trazidos pelas chuvas e pelas águas superficiais que erodem e lavam a superfície terrestre. A eutrofização natural corresponde ao que poderia ser chamado de "envelhecimento natural", de lagos ou corpos hídricos. A eutrofização ocorre artificialmente, ou seja, quando é induzida pelo homem e é também denominada antrópica. Neste caso, os nutrientes podem ter diferentes origens, como efluentes domésticos, efluentes industriais e/ou atividades agrícolas entre outras. Este tipo de eutrofização é responsável pelo "envelhecimento precoce" do reservatório. Esta se inicia com a entrada de nutrientes, especialmente $\mathrm{P}$ e $\mathrm{N}$, trazidos por efluentes domésticos, industriais e carga difusa. A recuperação de lagos e represas atingidas demandam projetos adequados e gerenciamento dos mananciais associados (Esteves, 1988).

Para que se possam tomar medidas preventivas e/ou corretivas deve-se saber o estado real do processo de eutrofização no lago e/ou reservatório e isto usualmente é realizado através de uma caracterização do estágio de eutrofização em que um corpo d'água encontra-se, adotando-se um sistema classificatório. Usualmente, podemos adotar a seguinte classificação dos níveis de trófia:

Oligotrófico - Baixas concentrações de nutrientes, lagos claros e com baixa produtividade;

$>\quad$ Mesotrófico - Lagos com produtividade intermediaria;

$>\quad$ Eutrófico - Altas concentrações de nutrientes, lagos com elevada produtividade comparada ao nível natural. 


\subsection{Sedimento como testemunho do histórico de contaminação antrópica}

O sedimento pode ser encarado como o resultado da interação de todos os processos que ocorrem em um ecossistema aquático, por isto pode ser considerado um dos compartimentos mais importantes, pois nele ocorrem processos biológicos, físicos e/ou químicos, que influenciam o metabolismo de todos os sistemas. Os sedimentos podem ser divididos em duas camadas: a recente e a permanente. A camada recente compreende a parte superior e suas características mais importantes são o alto teor de matéria orgânica e maior densidade de organismos bentônicos. A camada permanente localiza-se abaixo da camada recente e é caracterizada pelo baixo teor de matéria orgânica e pelo fato de apresentar-se, geralmente, em anaerobiose (Esteves, 1988).

Tanto a camada recente como a camada permanente, são compostas por duas frações distintas: a fração formada pela matéria particulada e a fração que compreende a água intersticial. A fração particulada, em ambientes com alta produtividade é composta principalmente por matéria orgânica; a fração formada pela água intersticial (água do sedimento) é de fundamental importância para a produtividade do ecossistema aquático. Isto se deve ao fato de que a coluna d'água sofre um processo constante de enriquecimento de nutrientes, que se difundem a partir da água intersticial, onde se encontram em concentrações mais elevadas. A água intersticial apresenta concentrações de nutrientes muitas vezes superiores àquela apresentada pela coluna d'água (Esteves, 1988).

\subsubsection{Micro e Macro constituintes do Sedimento}

Processos naturais responsáveis pela formação dos sedimentos podem ser alterados por atividades antrópicas e a análise de sedimentos fornece informações significativas sobre o meio ambiente. Sua caracterização química é necessária para o entendimento dos processos naturais e também da influência antrópica nesses processos (IAEA, 2003).

Além disso, a concentração de metais tóxicos em sedimentos, sempre excede a sua concentração em água e em alguns casos, em até 1000 vezes. Isto implica em uma maior biodisponibilidade, visto que uma pequena fração de sedimentos pode apresentar altas concentrações de metais e assumir uma importância considerável. Esta 
biodisponibilidade torna-se mais evidente se considerarmos organismos marinhos que filtram a água (Bryan \& Langston, 1992).

A avaliação de sedimentos e sua correlação com o meio ambiente tornaram-se importantes e necessárias nos últimos anos.

O sedimento constitui um compartimento de suma importância na avaliação da intensidade, das formas e impactos que os ecossistemas aquáticos estão ou estiveram submetidos, pois realizam constantes trocas de nutrientes e outras substâncias poluentes ou não com a coluna d'água (Protazio et al., 2004)

A coluna sedimentar de ambientes aquáticos, principalmente a sua fração orgânica, realiza trocas de nutrientes com a coluna da água sobrejacente. Em geral, os sedimentos não são apenas um depósito de produtos que estão, ou que chegam à coluna da água, mas representam um compartimento que recicla compostos, envolvendo alguns processos, os quais podem ser tanto biológicos (bioturbação, ação de bactérias oxidantes e redutoras), físico-químicos (adsorção, dessorção), químicos (precipitação, oxidação, redução e complexação) e ainda processo de transporte por difusão (Baumgarten et al., 2001)

Nos sedimentos, principalmente a partir da sub-superfície, as condições redutoras são mais frequentes e intensas do que na coluna da água. Como em ambientes sedimentares redutores são favorecidos a redissolução de muitos íons, que então passam a fazer parte da água intersticial, os sedimentos, nesse caso, funcionam como reservatório de espécies dissolvidas para a coluna de água, basicamente através da difusão molecular via água intersticial, que ocorre no sentido do mais concentrado para o menos concentrado. Assim, os processos biogeoquímicos que ocorrem nos sedimentos podem alterar a qualidade da água sobrejacente, principalmente quando fatores como a turbulência e a hidrodinâmica aumentam os intercâmbios químicos entre a água e o sedimento, principalmente em ambientes aquáticos de pouca profundidade (Baumgarten et al., 2001)

Portanto, a avaliação do potencial dos sedimentos no comprometimento, ou na melhoria, da qualidade da coluna da água deve enfocar a composição química da coluna da água intersticial, que é o valor do transporte sedimento/água. Também deve ser enfocada a especiação de elementos químicos na coluna sedimentar, delineando-se perfis verticais de concentrações e definindo-se quali-quantitativamente o intercâmbio químico com a coluna 
da água, principalmente de compostos que podem comprometer o equilíbrio ecológico do ambiente aquático (Baumgarten et al., 2001).

Em condições aeróbias, o sedimento apresenta uma camada de oxidação, geralmente de alguns milímetros (aproximadamente 2-5 $\mathrm{mm}$ em lagos tróficos), sobre uma camada reduzida (sem oxigênio).

Com o emprego da análise de sedimentos provenientes destes sistemas aquáticos, podemos avaliar a contaminação dos mesmos por metais tóxicos (Presley et al., 1980), compreender os fenômenos de transporte que ocorrem nestes complexos sistemas e traçar um histórico da poluição (Al-Jundi et al., 1997).

A preparação da amostra inclui a separação da fração inferior a $2 \mathrm{~mm}$, homogeneização e secagem, e esta é a primeira etapa crucial na análise de sedimentos. Técnicas analíticas nucleares e relacionadas são usadas para análise de sedimentos. A espectrometria de raios gama é usada para a determinação de radionuclídeos naturais e/ou artificiais, enquanto a análise por ativação neutrônica (NAA) e fluorescência de raios $\mathrm{X}$ (XRF), são usadas para a caracterização multielementar. Outras técnicas não destrutivas utilizadas na análise de sedimentos são: Análise por feixe de íons (IBA) que inclui a técnica PIXE (Emissão de Partículas induzidas por raios X) e "Rutherford Backscattering Spectrometry" (RBS) (IAEA, 2003).

A maioria das determinações de elementos maiores, menores e traço em sedimentos usando técnicas analíticas destrutivas, envolve a espectrometria de emissão ótica com plasma indutivamente acoplado (ICP OES) ou espectrometria de massa (ICPMS) e técnicas monoelementares como espectrometria de absorção atômica. Alguns métodos eletroquímicos, espectrometria de massa por diluição isotópica, métodos fluorimétricos e espectrofotométricos são usados, mas as técnicas de preparação da amostra não são diferentes (IAEA, 2003).

\subsection{Metais Tóxicos em Sedimentos}

Os metais podem ser encontrados em todos os lugares, nunca se esgotam e diferem das demais substâncias tóxicas por sua perenidade. Podem produzir efeitos na 
saúde em consequência de sua presença no ar, na água, no solo e nos alimentos (Pascalicchio, 2002).

Existe uma conexão típica da acumulação de metais nos sedimentos, para fontes como as de descargas de fundições $(\mathrm{Cu}, \mathrm{Pb}, \mathrm{Ni})$, metais industriais, entre outras. Os sedimentos são importantes compartimentos para a liberação de metais na coluna d'água, além disto, devido à sua capacidade para sequestrar metais em águas de superfície, logo os sedimentos podem refletir a qualidade da água e registrar os efeitos das emissões antrópicas (Baudo et al., 1990).

Sedimento contaminado com nutrientes, metais, metalóides e compostos orgânicos podem ser encontrados em águas doces, estuarinas e marinhas. Embora algumas destas contaminações estejam presentes em elevadas concentrações como resultado de processos naturais, na maioria dos casos são de origem antrópica. Contaminantes podem ser introduzidos por muitas vias ao sistema aquático (Burton Júnior, 1992)

As principais fontes antrópicas de metais no ambiente são os fertilizantes, os pesticidas, a água de irrigação contaminada e queima de biomassa na zona rural, combustão de carvão e óleo, emissões veiculares, incineração de resíduos urbanos e industriais e, principalmente, mineração, fundição, refinamento e efluentes industriais. (Carvalho, 1992)

Um problema comum do sedimento é conter níveis tóxicos de contaminantes persistentes, muitos dos quais podem ser imediatamente letal ou ter em longo prazo, efeitos deletérios. Em termos geológicos, fala-se que o sedimento encontra-se no caminho para materiais naturais e antrópicos, que são as raízes do problema de contaminação do sedimento. (Burton Júnior, 1992)

As partículas de sedimentos são oriundas da mistura da entrada de diferentes materiais, incluindo a erosão de rochas e solos, partículas de resíduos oriundas da atmosfera e material inorgânico produzido biologicamente. A determinação da qualidade da água pode ser refletida na qualidade dos sedimentos. (Burton Júnior, 1992)

Sedimentos são camadas de partículas minerais e orgânicas, frequentemente de granulometria fina, que são encontrados no fundo de corpos de águas naturais como lagos, rios e oceanos. A proporção entre minerais e matéria orgânica varia substancialmente, 
dependendo da localização. Os sedimentos são de muita importância ambiental porque eles são o depósito de muitas substâncias químicas, especialmente metais pesados e compostos orgânicos, a partir dos quais eles podem ser transferidos para os organismos que habitam essa região (Baird \& Cann, 2011). A mobilidade dos elementos no ambiente terrestre ou aquático é reflexo da dissolução e frações sólidas. Segundo Baudo et al. (1992) existem pelo menos três fatores principais que afetam a distribuição de metais traço entre solução e partícula: (1) forma química dos metais dissolvidos que podem ser originários tanto de fontes naturais quanto antrópicas; (2) o tipo de processo de interação (sorção/desorção) ou mecanismos de controle de precipitação e (3) concentração e composição da partícula mãe.

Portanto, a proteção da qualidade dos sedimentos é um dos componentes do gerenciamento de águas (Baird \& Cann, 2011).

Os sedimentos são bons indicadores da poluição por metais, porque mesmo os metais que funcionam como micronutrientes essenciais podem-se tornar-se tóxicos para os organismos aquáticos e para os seres humanos, desde que o nível de exposição seja suficientemente elevado.

Alguns destes elementos mesmo sendo essenciais para nossas funções fisiológicas e bioquímicas ( $\mathrm{Co}, \mathrm{Fe}, \mathrm{Mn}, \mathrm{Ni}, \mathrm{Se}, \mathrm{V}, \mathrm{Cu}, \mathrm{Cr}$ e $\mathrm{Zn}$ ) em altas concentrações, passam a ser tóxicos. Entretanto outros metais são comprovadamente tóxicos para o homem a níveis de exposição que podem ocorrer naturalmente no ambiente tais como $\mathrm{Hg}$, Ag, As, Cd e Pb (Malm, 1986 Apud Loureiro, 2006).

A seguir, descrevem-se as principais características de cada um dos metais tóxicos seja por sua natureza ou por sua quantidade.

Alumínio (Al): é o terceiro elemento mais abundante na crosta terrestre. É utilizado nas linhas de transmissão, em forma de ligas na construção de navios, foguetes e aviões, também é amplamente utilizado em utensílios de cozinha, construção civil, embalagens longa vida, siderurgia e outros produtos do nosso cotidiano (Vaitsman et al, 2001 Apud Quináglia, 2006)

A maior parte da liberação antrópica de alumínio se dá de maneira indireta, por exemplo, através da emissão de substâncias acidificadas como o dióxido sulfúrico e os óxidos de nitrogênio presentes na atmosfera. Desta forma, a chuva ácida e a composição do 
solo contribuem para dissolução do alumínio no solo. Os íons de alumínio retiram o cálcio permanente dos sítios de troca (Azavedo \& Chain, 2003).

O alumínio é reconhecidamente um agente neuro-tóxico, podendo causar vários danos à saúde humana, os quais se relacionam com as alterações neurológicas, e que podem ser irreversíveis. A exposição ocupacional ao alumínio é responsável, principalmente, pelo desenvolvimento de efeitos do trato respiratório (fibrose pulmonar e asma, causadas principalmente pela exposição a pós-finos contendo alumínio) e sistema nervoso (alterações na função cognitiva, disfunção motora e neuropatia periférica) (Azavedo \& Chain, 2003).

Arsênio (As): é um metalóide de ocorrência natural, utilizado como agente de fusão para metais pesados, em processos de soldagens e na produção de cristais de silício e germânio. Na forma de arsenito é usado como herbicida e como arseniato, é usado como inseticida. No homem, produz efeitos nos sistemas respiratórios, cardiovascular, nervoso e hematopoiético (Revisa Elerônica, 2011). Águas de rios, lagos E mananciais, geralmente

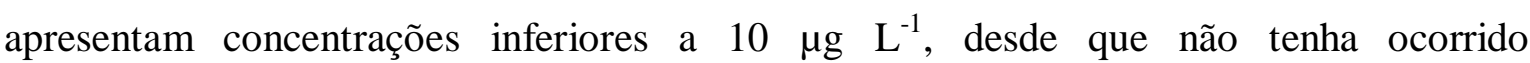
contaminação antrópica (Quináglia, 2006).

É usualmente encontrado em minérios de ouro, prata, cobalto, níquel, cobre e antimônio. Na natureza, existe mais de 200 espécies minerais cujo componente principal é o arsênio. Comercialmente, o arsênio é obtido como subproduto do tratamento dos minérios de cobre, chumbo, cobalto, manganês e ouro. Em algumas partes do mundo, onde há ocorrência natural de arsênio na água, predominam os compostos inorgânicos que são mais solúveis. Esta presença natural está associada ao ambiente geoquímico, ao depósito vulcânico e aos rejeitos de mineração (Azevedo \& Chain, 2003).

O efeito tóxico das espécies de arsênio depende, principalmente, de sua forma química, em águas naturais pode ocorrer como As (III) (arsenito) - sendo esta forma a pior para os seres humanos em função de seu redox, As(V) (arseniato), íon monometilarsênico (MMA) e íon dimetilarsínico (DMA). Águas subterrâneas contêm arsênio como arsenito e arseniato. Em águas marinhas, lagoas, lagos, e onde houver possibilidade de biometilação, arsenito e arseniato ocorrem junto com MMA e DMA (Azevedo \& Chain, 2003). 
Os efeitos não carcinogênicos do arsênio estão relacionados a alguns poucos mecanismos de ação conhecidos, como inibição da respiração celular, alterações na síntese da heme e metabolismo das porfirinas e alterações nas expressões genéticas de proteínas de estresse. Já o potencial carcinogênico do arsênio foi observado pela primeira vez há mais de 100 anos. A exposição a partir da ingestão de água potável contaminada aumenta o risco de câncer de pele.

Bário (Ba): é um metal alcalino terroso. As principais fontes antrópicas são as da fabricação de papel que usam o bário como pigmento branco, lâmpadas fluorescentes, tintas, borrachas, cerâmicas, entre outras.

Muitos são os efeitos do bário no ser humano, como retardo metal em crianças, perda de memória, tendência de amigdalites repetidas, formação de gânglios, envelhecimento precoce, degeneração das artérias, predisposição a aneurismas e derrames. A ingestão de aproximadamente $0,5 \mathrm{~g}$ de compostos de bário é fatal na maioria dos casos. As fontes antrópicas de bário são as indústrias de fabricação de papel, lâmpadas, tintas, borrachas, cerâmicas, entre outras (Quináglia, 2006).

Berílio (Be): metal alcalino terroso. As fontes antrópicas são indústrias nucleares, fabricação de ligas de $\mathrm{Cu}-\mathrm{Be}$ para uso de contatos elétricos, interruptores, material usado na indústria aeroespacial. A concentração em solos em geral é na faixa de 0,1 - $40 \mathrm{mg} \mathrm{kg}^{-1}$ (Quináglia, 2006).

Os compostos de berílio têm sido associados com lesões nos pulmões e ossos e são considerados cancerígenos aos animais de laboratório expostos a altos níveis durante longos períodos da vida.

Cádmio (Cd): é um metal considerado não essencial e muito toxico sendo extensamente distribuído pela crosta terrestre, apresentando concentração média de $0,1 \mathrm{mg}$ $\mathrm{kg}^{-1}$. Altas concentrações podem ser encontradas em rochas sedimentares e fosfatos marinhos que, frequentemente, contem em torno de $15 \mathrm{mg} \mathrm{kg}^{-1}$. É encontrado como subproduto do processamento de zinco, cobre e chumbo. Em sistemas aquáticos, a presença de Cd deve-se a vários fatores como: intemperismo, erosão do solo e da camada de rocha viva, descargas atmosféricas diretas devido a operações industriais, vazamentos 
em aterros e locais contaminados pelo uso de lodos e fertilizantes na agricultura (Quináglia, 2006).

A toxicidade do cádmio se expressa em vários órgãos e tecidos, entretanto os órgãos-alvo são os rins e o fígado. Órgãos como testículos, pâncreas, tireoide, glândulas adrenais, ossos, sistema nervoso central e pulmões foram estudados quanto aos efeitos tóxicos do cádmio (Azavedo \& Chain, 2003).

Crômio (Cr): é o sétimo metal mais abundante, entretanto quase todo cromo presente no ambiente provém de atividades humanas. O cromo é encontrado naturalmente em rochas, animais, plantas, solo, poeira e névoas vulcânicas. A concentração em rochas varia de 2 a $90 \mathrm{mg} \mathrm{kg}^{-1}$ em rochas graníticas, 1.000 a $3.400 \mathrm{mg} \mathrm{kg}^{-1}$ em rochas ultramáficas e de 30 a $590 \mathrm{mg} \mathrm{kg}^{-1}$, em xisto e argila (Azevedo \& Chain, 2003).

O cromo é usado em ligas de aço inox, cromeações, curtumes, pigmentos, preservativos de madeira, sínteses orgânicas e alguns tipos de fertilizantes. Efluentes contendo cromo levam este para rios, lagos, etc e uma vez disponibilizado na água, o cromo deposita-se nos sedimentos. Entretanto, sedimentos que contêm matéria orgânica demonstram que a redução de $\mathrm{Cr}^{+6}$ para $\mathrm{Cr}^{+3}$ é lenta e vai depender de outras condições, tais como o tipo e a quantidade de matéria orgânica presente e das condições de oxiredução da água (Quináglia, 2006).

A toxicidade do cromo depende do seu estado de oxidação, sendo o Cr (VI) de maior toxicidade que o $\mathrm{Cr}$ (III). Acredita-se que um dos fatores que contribui para esta elevada toxicidade seja a grande habilidade do Cr (VI) em penetrar nas células. Uma vez dentro das células, o $\mathrm{Cr}$ (VI) sofre redução a $\mathrm{Cr}$ (III), tendo como intermediários o $\mathrm{Cr}$ (V) e o Cr (IV). Estes radicais livres parecem ser os responsáveis pelo efeito carcinogênico, isto por que a interação destes produtos com o DNA pode resultar em dano estrutural e funcional do mesmo e em efeitos celulares.

Cobre (Cu): metal marrom avermelhado e nobre como o ouro e a prata. Possui elevada condutividade térmica e elétrica, baixa corrosividade, habilidade de amalgamar, daí seu amplo uso pelo homem na indústria elétrica, linhas de transmissão, em rolamento de motores, como veneno agrícola, algicida, entre outras. Sua biodisponibilidade em sistemas aquáticos é influenciada por muitos processos como a complexação a ligantes 
orgânicos e inorgânicos, adsorção a óxidos metálicos, argila e material particulado em suspensão e principalmente na troca entre sedimento e água (Quináglia, 2006).

Segundo Azevedo \& Chain (2003), a biodisponibilidade é geralmente pequena para as concentrações totais de metais na água; em sedimento, o cobre liga-se, principalmente, à matéria orgânica, a menos que o sedimento seja pobre neste tipo de material. A toxicidade deste metal não é observada quando este se liga aos sedimentos e quando a concentração de Sulfetos Ácidos Voláteis (SVA) é maior que a soma da concentração molar dos metais ali presentes.

A necessidade de cobre nos vários órgãos ou nos sistemas do organismo é regulada por mecanismos de controle homeostático. A toxicidade do cobre ocorre quando tais mecanismos de controle dentro de um determinado compartimento são sobrecarregados e/ou quando os mecanismos de reparo celular estão deteriorados. O cobre é um metal essencial utilizado como cofator de diversas enzimas celulares. A deficiência pode causar disfunção cardíaca.

Chumbo (Pb): os sais de chumbo são considerados venenosos e acumulativos, e a doença associada chama-se saturnismo. Os principais usos do chumbo estão relacionados às indústrias extrativa, petrolífera, de baterias, tintas e corantes, cerâmica, cabos, tubulações e munições. O chumbo é liberado na água de lagos, rios, etc., proveniente de emissões atmosféricas, lixiviação do solo, algumas fontes naturais ou como na maioria das vezes, oriundo de fontes antrópicas (Quináglia, 2006). Qualquer excesso entra no tecido leve, incluindo os órgãos. Na realidade, a absorção de chumbo aumenta em pessoas com uma deficiência de cálcio ou ferro. Em altos níveis, o chumbo inorgânico é um veneno metabólico. Sua toxicidade é proporcional à quantidade presente nos tecidos leves, ao contrário, portanto, do sangue ou dos ossos. O chumbo permanece em ossos humanos por décadas, portanto ele pode acumular-se no corpo. O chumbo pode causar efeitos sistêmicos (cardiovasculares, gastrointestinais, hematológicos, renais, endócrinos, neurológicos, imunológicos, reprodutivos) (Azevedo \& Chain, 2003).

Cobalto (Co): fontes antrópicas de cobalto são: fabricação de imã, instrumentos e ferramentas de alta velocidade e de serviços pesados, em ligas de corte, no aço inoxidável e na eletrodeposição de metais. Nos sedimentos e nos solos, o cobalto está 
associado às partículas sólidas de solos e sedimentos por adsorção ou ainda nas águas intersticiais. A mobilidade do cobalto só irá ocorrer em meio ácido (Quináglia, 2006).

A intoxicação por cobalto pode causar dores abdominais, vômitos, náuseas, alterações na tireoide e no pâncreas, lesões cardíacas e distúrbios circulatórios. Há fortes indícios de que o cobalto seja carcinogênico. Por outro lado, a falta de cobalto pode causar anemia, falta de apetite, parada do crescimento, irritabilidades e falta de concentração (Quináglia, 2006).

Estanho (Sn): elemento extremamente tóxico, sendo suas fontes antrópicas provenientes da fabricação de vidros foscos, papéis laminados, peças de decoração, fungicidas e inseticidas (Quináglia, 2006).

A toxicologia dos compostos de estanho tem sido revisada por muitos pesquisadores. Sabe-se que a ingestão de excessiva quantidade de estanho deve-se ao fato do consumo cada vez maior de produtos enlatados. O estanho pode causar irritações gastrointestinais, diarreia, vômitos, náuseas, problemas renais e hepáticos, irritações na pele e olhos (Viau, 2005)

Ferro (Fe): o ferro é um dos elementos mais abundante, compondo $30 \%$ da massa total do planeta. A maior parte do ferro na crosta terrestre está presente como $\mathrm{Fe}^{+2}$, mas é rapidamente oxidado na superfície da Terra a $\mathrm{Fe}^{+3}$, forma insolúvel em água, nas condições normais de pH e EH (Azevedo \& Chain, 2003).

As fontes antrópicas de ferro são inúmeras como as indústrias de aço, ligas em geral, soldas, magnéticos, atividades de mineração, entre outras. Outra forma de adicionar ferro ao meio ambiente é o uso de lodo de esgoto, disposição de resíduos sólidos sobre superfícies e o uso excessivo de fertilizantes (Quináglia, 2006).

O ferro, elemento essencial a todas as formas de vida, é componente chave na manutenção da homeostase celular. A essencialidade desse metal deve-se à sua incorporação a um grande numero de enzimas e proteínas. Tanto a deficiência (causa anemia), como o excesso (pode causar hemossiderose e hemocromatose) são prejudiciais ao organismo humano. 
Manganês (Mn): este metal ocorre naturalmente em diversos tipos de rochas. O manganês metálico é usado principalmente na produção do aço, já o dióxido de manganês é utilizado na produção de baterias, palitos de fósforo, porcelanas e materiais à base de vidro e como substância precursora para a fabricação de outros compostos de manganês. O sulfato de manganês é usado como fertilizante e como suplemento, na fabricação de fungicidas, como desinfetante, agente anti-algas, agente de limpeza de metais e conservantes de folhas de frutas frescas (Azevedo \& Chain, 2003).

Os alvos primários da ação do manganês são os pulmões e o sistema nervoso central, embora efeitos em outros órgãos tenham sido observados, eventualmente (Azevedo \& Chain, 2003).

O pó de manganês causa inflamação pulmonar, principalmente para aqueles que trabalham em minerações. Existe relação positiva entre o excesso de manganês no organismo e a Síndrome de Parkinson, bem como psicoses, insônias e perda de peso facial A intoxicação por manganês pode causar efeitos neurológicos e, consequentemente, a falta de coordenação motora (Vaitsman et al, 2001 Apud Quináglia, 2006).

Mercúrio (Hg): o mercúrio é um metal de aspecto argênteo, inodoro. É normalmente encontrado em dois estados de oxidação $\left(\mathrm{Hg}^{0}\right.$ e $\left.\mathrm{Hg}^{+2}\right)$, sendo suas principais fontes antrópicas industriais de cloro e soda caustica que utilizam cátodos de mercúrio nas células eletrolíticas, fábricas de lâmpadas, retificadores, termômetros, tintas de impressão, pigmentos, produção de ácido acético, efluentes de muitos laboratórios analíticos e fotográficos, entre outras. Os sais de mercúrio têm efeito acumulativo e os seres humanos podem se contaminar com esse metal através da água, peixe, feridas na pele e respiração. (Quináglia, 2006).

O mercúrio é perigoso quando aquecido, pois evapora e o mercúrio em sua forma metálica é altamente tóxico. Os efeitos neurológicos, observados após a exposição aos vapores de mercúrio metálico, são atribuídos ao íon de mercúrio divalente formado por oxidação no tecido cerebral, mas ainda hoje muitos estudos têm avaliado os efeitos nocivos do $\mathrm{Hg}$ nos sistemas nervoso, reprodutivo, digestivo, cardíaco, imunológico, respiratório, entre outros. 
Molibdênio (Mo): seus sais são de baixa toxicidade e é um constituinte da enzima essencial xantina-oxidase e de flavoproteínas. Entretanto, seu excesso pode levar a perda de apetite, ao hipotireoidismo e esta ligado ao favorecimento de tumores da pele (sarcoma). Suas fontes antrópicas são indústrias nucleares, eletroeletrônicas, de esmaltes, construção de mísseis, lubrificantes, química fina, fertilizantes e outras (Quináglia, 2006).

Níquel (Ni): metal prateado que ocorre naturalmente na crosta terrestre, sendo dúctil e maleável. A utilização do níquel e de seus compostos na indústria é muito diversificada, como na galvanoplastia e na fabricação de margarinas. Seus compostos inorgânicos apresentam utilizações como: produção de ligas de níquel-cobre, galvanização, catálise, manufatura de baterias alcalinas (Ni-Cd), manufatura de moedas, pigmentos inorgânicos, eletrônica e próteses dentárias.

O níquel pode ser depositado nos sedimentos pelos seguintes processos: precipitação, complexação, adsorção sobre argila e também agregação à biota.

O níquel, assim como outros metais pesados, interage com receptores de íons em locais diferentes do organismo. O níquel causa efeitos imunológicos: a exposição incita resposta imune, resultando em dermatite de contato, mas os principais efeitos nocivos da exposição ocupacional são: rinite, sinusite, câncer das cavidades nasais, do pulmão e de outros órgãos (Azevedo \& Chain, 2003). A deficiência de níquel em nosso organismo causa degeneração do fígado, distúrbios no crescimento e reprodução, prejuízo na utilização do ferro e diminuição das concentrações de cálcio, magnésio, aumento de cobre e zinco no fêmur. Em excesso, se em contato com a pele provoca dermatites, infarto do miocárdio, etc. O maior perigo é que esse metal pode causar câncer de pulmão, dos seios e da face. (Vaitsman et al, 2001 Apud, Quináglia, 2006)

Selênio (Se): o selênio tem comportamento análogo ao do enxofre em muitas de suas propriedades e reações O selênio metálico é pouco tóxico e cancerígeno, enquanto o sulfito de selênio usado em xampu anticaspa não tem associação com risco de câncer. Como existe esta dualidade, é preciso analisar separadamente cada composto de selênio (Azevedo \& Chain, 2003).

O selênio pode ser encontrado em alguns alimentos como grãos, cebolas, carnes, como também em leite e vegetais combinado a substâncias orgânicas. Por outro 
lado, outros compostos de selênio são extremamente venenosos. Mesmo assim desde 1957 é conhecido como elemento essencial, por apresentar interação com a vitamina $\mathrm{E}$ e com os aminoácidos sulfurados, cujo mecanismo bioquímico não está ainda bem definido. $\mathrm{O}$ selênio reduz o envelhecimento e o endurecimento das artérias, já a sua deficiência causa cardiopatia endêmica e osteopatia (Quináglia, 2006).

Os principais usos do selênio ocorrem pelas suas características de material semicondutor na eletrônica e também na metalurgia, e na fabricação de pigmentos, vidros e cerâmicas.

Zinco (Zn): desde a mais remota antiguidade, o zinco era utilizado sob a forma de óxido de zinco para curar feridas e queimaduras. É um elemento essencial e benéfico ao nosso metabolismo, ao crescimento de plantas e animais.

O zinco é utilizado na formação de ligas com revestimento de ferro e outros metais para prevenir a corrosão, também para a produção de tintas brancas, cerâmicas, borrachas, tingimento de tecido, na produção de bloqueadores solares, desodorantes, xampus anti-caspa,

A deficiência desse elemento pode fazer com que alguns animais tenham de consumir até $50 \%$ a mais de alimentos para ter o mesmo peso.

O zinco é dos constituintes da insulina e cerca de 90 enzimas são ativadas por esse metal. A carência de zinco pode levar ao nanismo, anorexia, alopecia (queda de cabelos e barba), dificuldade de cicatrização. Seres humanos com leucemia, diabetes, problemas cardíacos, em geral, tem menos zinco que o normal. O zinco é encontrado nos tecidos humanos, no entanto, a maior concentração de zinco se localiza na próstata e retina; é encontrado em altas concentrações nas ostras, peixes, gengibre, condimentos e nas ervilhas. Seu grau de toxicidade é relativamente baixo, seu excesso está associado a casos de úlceras pancreáticas, anemias, má circulação sanguínea e a fibrose pulmonar.

\subsection{Fósforo em Sedimentos}

O ciclo do fósforo nos sedimentos pode ser dividido nos processos de deposição e liberação: 
* Deposição de fósforo no sedimento: A retenção de nutrientes em ecossistemas aquáticos se inicia com a decomposição de compostos em forma de partículas no sedimento. Três fatores parecem ser cruciais para a retenção do elemento no sedimento:

- Velocidade de deposição;

- Transformação dos compostos de fósforo na camada superficial de sedimento;

- Imobilização de compostos de fósforo nas camadas mais profundas do sedimento.

A capacidade dos sedimentos de absorver e reter o fosfato são fortemente influenciados pela composição mineral do mesmo. A presença de íons ferro, alumínio, sulfeto, compostos orgânicos, carbonatos, além do pH e das condições de oxi-redução no meio, interferem na precipitação e imobilização dos fosfatos no ambiente aquático.

* Liberação de fósforo do sedimento: Uma das formas de liberação do fósforo no corpo aquático é através da ressuspensão do sedimento. A mobilização dos diferentes tipos de fósforo dentro do sedimento para a água pode ocorrer via reações bioquímicas como a mineralização, autólise das células ou por dissolução. A liberação do íon fosfato para a coluna d'água ocorre mais facilmente em condições de baixas concentrações de oxigênio e, sobretudo em anaerobiose, não ocorre precipitação do fosfato pelo ferro, pois o mesmo se encontra no estado de oxidação como íon $\mathrm{Fe}^{2+}$; nessas condições o fosfato permanece solúvel (Borges, 1998). Estas características são frequentemente encontradas na parte inferior da coluna d'água, especialmente quando se encontra estratificada termicamente e o íon ferro encontra-se na forma reduzida $\left(\mathrm{Fe}^{2+}\right.$, ferroso). Nestas condições não ocorre precipitação de fosfato pelo ferro permanecendo, portanto solúvel (Esteves, 1988).

Em condições aeróbias, o sedimento apresenta uma camada de oxidação, geralmente de alguns milímetros (aproximadamente 2 a $5 \mathrm{~mm}$ em lagos tróficos), sobre uma camada reduzida (sem oxigênio). A camada oxidada funciona como uma barreira que impede a liberação do fósforo para a coluna d'água. No entanto à medida que o hipolímnio torna-se anaeróbio, em geral, quando o lago está estratificado termicamente, esta camada de oxidação torna-se menos espessa, podendo mesmo desaparecer. $\mathrm{O}$ sedimento apresentase então totalmente reduzido, condição favorável para a liberação do fosfato para a coluna d'água (Esteves, 1988). 


\subsection{Reservatório de Itupararanga}

O reservatório de Itupararanga foi construído pela LIGHT para gerar energia elétrica, iniciando suas operações em 1912. Este se localiza no alto curso do rio Sorocaba, maior afluente do rio Tietê pela margem esquerda, e situa-se na sub-bacia conhecida por Médio - Tietê. A bacia hidrográfica do rio Sorocaba, é a segunda maior do Médio - Tietê, sendo a do Piracicaba a maior. O reservatório é formado por uma barragem que represa as águas do rio Sorocaba, rio que possui como principais formadores os rios Sorocamirim, Sorocabuçu e Una, no município de Votorantim-SP. O reservatório possui uma área de drenagem de $936,51 \mathrm{~km}^{2}$, tendo aproximadamente $26 \mathrm{~km}$ de canal principal e $160 \mathrm{~km}$ de margens e ocupa, parcialmente, os seguintes municípios: Ibiúna, Piedade, São Roque, Cotia, Vargem Grande Paulista, Mairinque, Alumínio e Votorantim (CETESB, 2003).

A região onde se encontra a bacia da represa Itupararanga sofre fortes pressões ambientais, principalmente considerando-se que uma parte da área de drenagem da represa pertence à região metropolitana de São Paulo. Além disso, os rios formadores da bacia do Alto Sorocaba sofrem intensos impactos em todo seu percurso devido à poluição difusa da produção agrícola e à carga orgânica, ao atravessarem pequenos vilarejos ou mesmo cidades (V- Moschini-C, 2007).

O uso agrícola é intensivo e consta basicamente de pequenos proprietários (em média 4,5 alqueires/propriedade) que se dedicam ao cultivo de morango, cebola, batata, tomate e outras olerícolas, cultivos estes que envolvem a utilização intensiva de pesticidas e, em geral, são irrigadas. Nas margens da represa de Itupararanga, além do uso agropecuário, tem sido observado o aumento de áreas ocupadas por empreendimentos imobiliários, como chácaras e casas de recreio. A agricultura praticada na região é, em sua grande maioria, irrigada através do sistema de aspersão. Destacam-se também os plantios intensivos próximos aos corpos d'água sem a preocupação de práticas de conservação do solo, bem como a não observância do código florestal. Além disso, devido à intensa atividade de mineração de areia na região ocorrem altos níveis de assoreamento, principalmente nas cabeceiras da represa de Itupararanga, o que tem contribuído para o aumento do assoreamento dos corpos d'água na região. 
As águas da Represa Itupararanga são utilizadas para múltiplas finalidades, tais como: o abastecimento público, onde abastece cerca de 63\% da bacia do Rio Sorocaba, segundo o comitê de bacias hidrográficas além da geração de energia elétrica, e área de lazer das cidades próximas. Apesar de possuir um excelente manancial, com boa qualidade de águas, a represa está sofrendo sérios riscos ambientais devido ao uso e ocupação do solo. As principais atividades antrópicas que têm comprometido a qualidade ambiental da represa de Itupararanga são:

* Loteamentos que desconsideram critérios ambientais em sua implantação;

* Intensa atividade de mineração (areia);

* Uso intensivo para irrigação;

* Utilização indiscriminada de agrotóxicos.

* Falta de zoneamento territorial que discipline o uso e ocupação do solo

Estas atividades antrópicas são causadoras da eutrofização artificial. Ao atingir o estágio eutrófico, a água se torna imprópria para o abastecimento, mesmo com o tratamento convencional, em função da grande quantidade de substâncias tóxicas e odor desagradável excretadas pelas algas. É um processo de degradação que pode tornar o corpo d'água inaproveitável para o abastecimento.

A CETESB o classifica como classe 2 de acordo com o CONAMA 357/05 (CONAMA, 2005), sendo que este enquadramento é estabelecimento de uma meta ou objetivo de qualidade de água a ser alcançado ou mantido em um segmento de corpo d'água, de acordo com os usos pretendidos, ao longo do tempo. O fato de um trecho de rio estar enquadrado em determinada classe não significa, necessariamente, que esse seja o nível de qualidade que ele apresenta, mas sim aquele que se busca alcançar ou manter ao longo do tempo. O uso predominante para as águas de classe 2 são:

I. Ao abastecimento para consumo humano, após tratamento convencional;

II. Proteção das comunidades aquáticas;

III. À recreação de contato primário, tais como, natação, esqui aquático e mergulho, conforme CONAMA 274/2000;

IV. À irrigação de hortaliças e plantas frutíferas e de parques e jardins, campos de esporte e de lazer, com os quais o público possa vir a ter contato direto;

V. À aquicultura e à atividade de pesca. 
A bacia do Alto Sorocaba é composta por diversas estruturas geológicas, com período de formação desde o Proterozóico Médio-Superior até o Quaternário, destacandose os domínios São Roque e Embu conforme apresentado na FIG 1.3. O domínio São Roque apresenta rochas de baixo grau metamórfico do grupo São Roque (Godoy, Apud Sardinha et al., 2008).

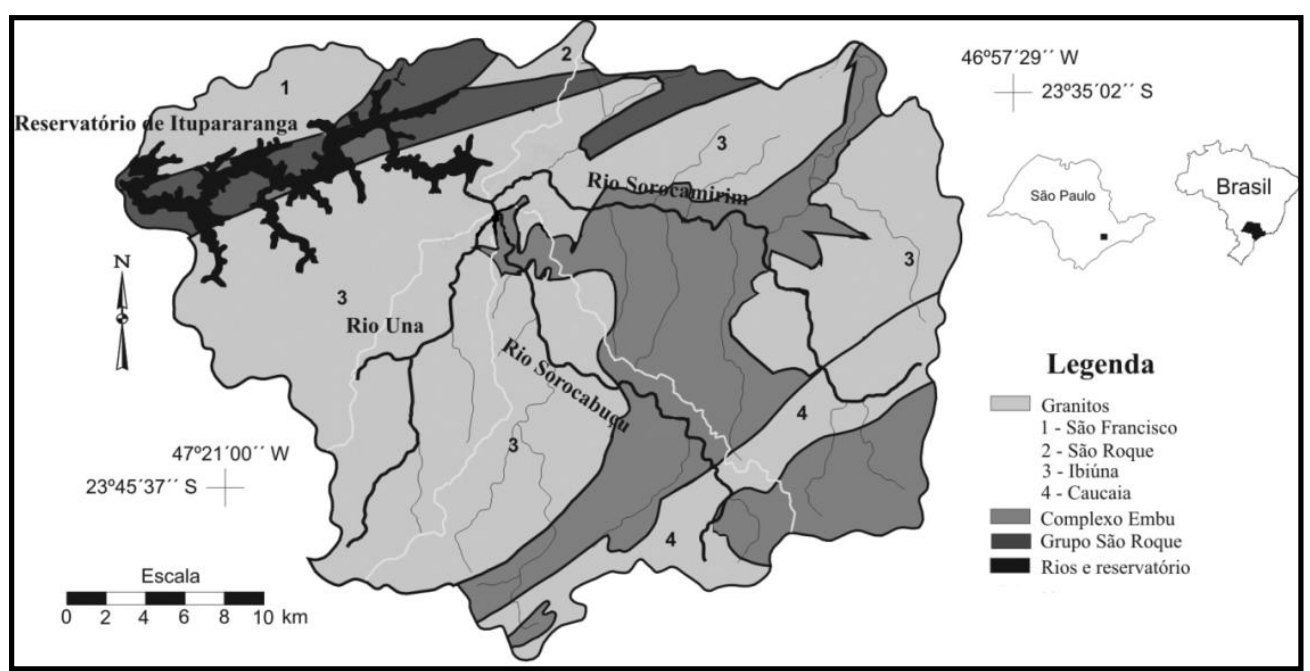

FIGURA 1.3 - Estruturas geológicas na região do reservatório de Itupararanga.

Fonte: Sardinha et al, 2008

\subsection{Histórico do monitoramento no reservatório de Iupararanga}

A CETESB, Companhia Ambiental do Estado de São Paulo, é a responsável pelo monitoramento da qualidade das águas do estado de São Paulo e possui um monitoramento da qualidade das águas deste reservatório. Em seus relatórios anuais, vêem chamando a atenção para os conflitos do uso deste manancial em função do uso do solo ao redor do reservatório de Itupararanga, o qual é predominante usado para empreendimentos imobiliários, lazer e cultivo sendo que para o cultivo se faz uso de defensores agrícolas e fertilizantes. Essas atividades antrópicas, acabam por comprometer a qualidade ambiental do reservatório, devido ao alto aporte de nutrientes e substâncias poluidoras no reservatório. 
As FIG 1.4 e 1.5 apresentam os pontos de amostragem atualmente utilizados pela CETESB para monitoramento no reservatório de Itupararanga e de seus formadores tanto a jusante como a montante.

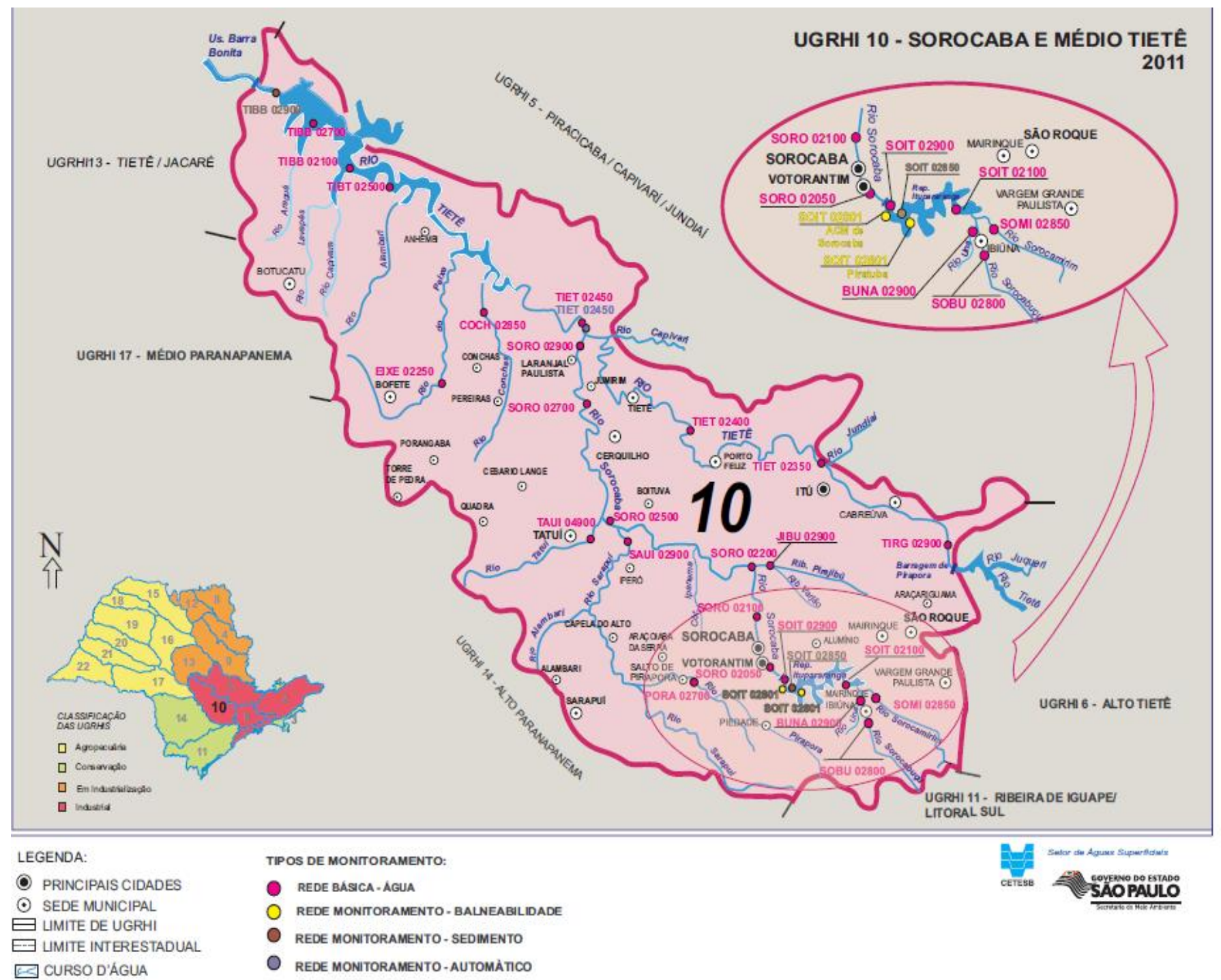

FIGURA 1.4 - Mapa esquemático contendo os principais corpos d'água, municípios e a localização dos pontos de amostragem da URGHI 10, tendo em destaque o Reservatório de Itupararanga. 


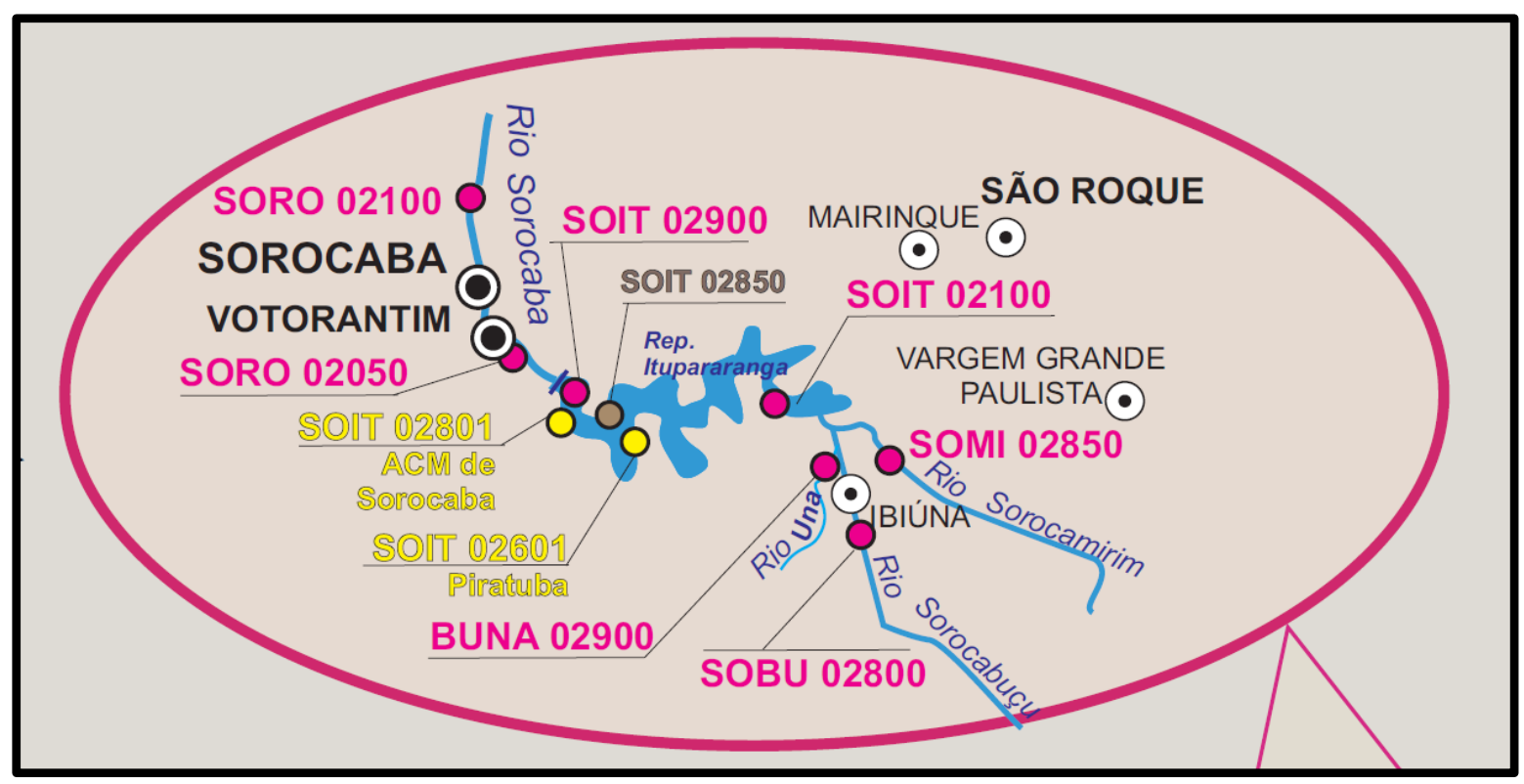

FIGURA 1.5 - Reservatório Itupararanga com seus pontos de monitoramento realizados anualmente pela CETESB.

Com um levantamento dos dados disponíveis, a partir dos relatórios anuais da qualidade das águas interiores do Estado de São Paulo entre os anos de 2000 e 2011, foi possível fazer um levantamento do monitoramento realizado em pontos do Reservatório de Itupararanga. Este levantamento foi compilado em forma gráfica, com o intuito de facilitar a visualização do comportamento ao longo dos anos no reservatório, estes resultados são apresentados nas FIG 1.6, 1.7, 1.8 e 1.9.

Como já citado para o cálculo do IQA, são consideradas variáveis de qualidade que indicam o lançamento de efluentes sanitários para o corpo d'água, fornecendo uma visão geral sobre as condições de qualidade das águas superficiais. A partir da FIG 1.6 que compila os valores médios de IQA desde o ano de 2000, pode-se verificar que há uma estabilidade na qualidade da água durante todos esses anos de monitoramento, tanto para o ponto SOIT 02100, localizado na entrada do reservatório, quanto para o ponto SOIT 02900, localizado na saída do reservatório (próximo à barragem). Isto mostra que os valores para o IQA, mantiveram sua classificação em ótimo durante todo este período.

Ainda na FIG 1.6, é apresentado que a partir de 2006 houve a inclusão de três novos pontos de monitoramento (SOMI 02850, BUNA 02900 e o SOBU 02800), pontos estes que se localizam no Rio Sorocamirim, Rio Una e Rio Sorocabuçu, respectivamente. A partir dos resultados das análises destes pontos que estão plotados na FIG 1.6, pode-se 
observar uma estabilidade também durante anos em que foram monitorados e durante este período, recebeu a classificação de boa, com uma ligeira melhora a partir do ano de 2009.

A partir destes dados pode-se concluir que segundo o índice de qualidade das águas, o Reservatório de Itupararanga possui águas com boa qualidade e esta classificação se mantém ao longo dos anos.

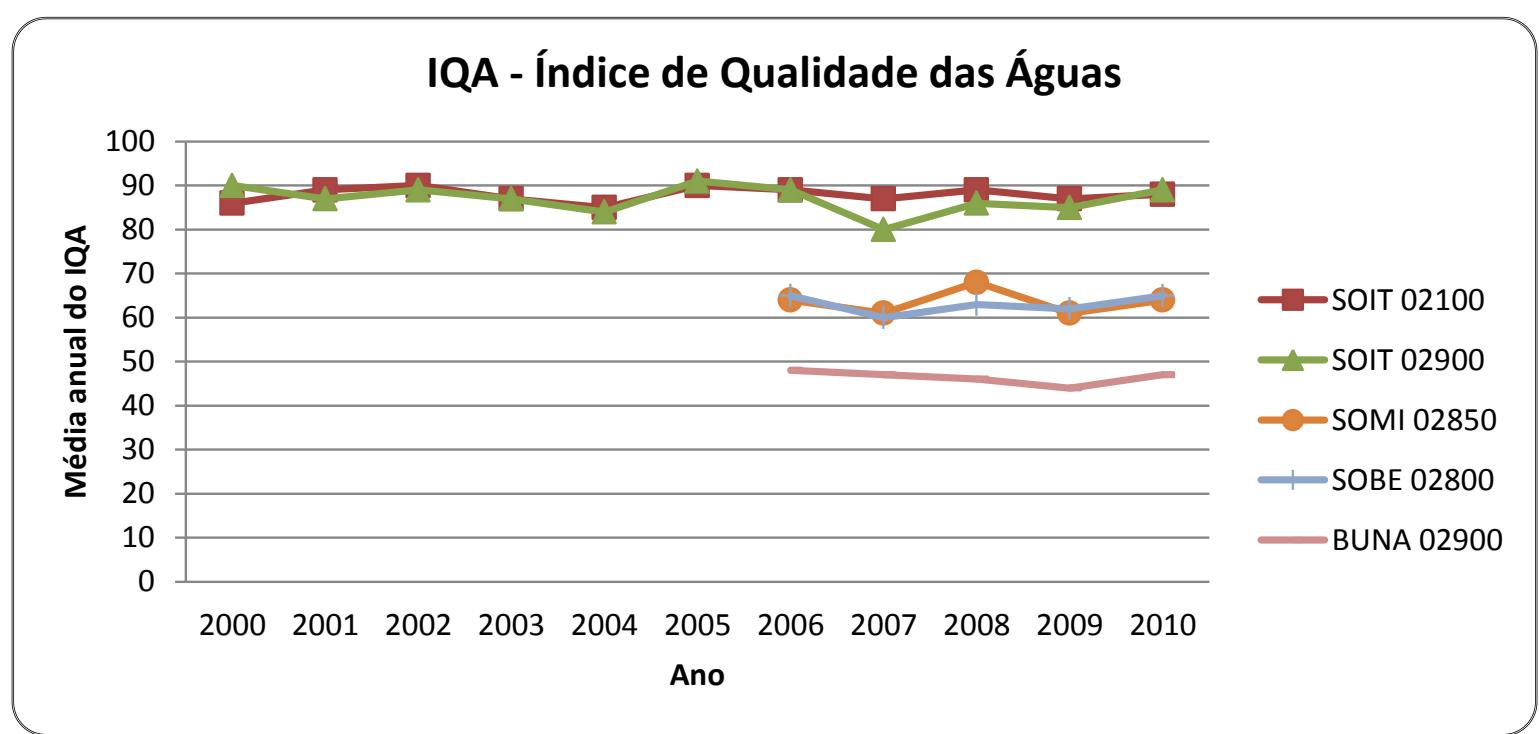

FIGURA 1.6 - Valores médios anuais do índice de qualidade da água no reservatório de Itupararanga, extraídos dos relatórios de qualidade das águas interiores do estado de São Paulo.

Na FIG 1.7, pode-se observar o gráfico que relaciona os valores médios anuais do índice de qualidade das águas para fins de abastecimento público, IAP, durante os anos de monitoramento. Pode-se observar que para o ponto SOIT 02100 houve uma queda nos valores nos anos de 2006 e 2007, e uma suspensão de seu monitoramento nos anos seguintes. Este ponto (SOIT 02100) nos primeiros anos de monitoramento apresentava uma classificação ótima segundo o IAP, mas nos anos de 2006 e 2007 esta classificação já havia caído para boa. O ponto SOIT 02900 sugere também uma tendência de diminuição da qualidade das águas pra fins de abastecimento público, sendo que no ano de 2005 sua classificação caiu de ótima para boa e no ano seguinte, em 2006, tendo voltado aos níveis anteriores. Esse ponto voltou a ter uma leve queda em 2007 e outra leve queda em 2009, mantendo-se constante no ano de 2010. Entretanto no ano de 2011 sofreu uma piora em 
sua qualidade, o que indica uma leve queda da qualidade das águas para fins de abastecimento público. Esta queda no ano de 2011 foi influenciada pela quantidade de cianobactérias encontradas no reservatório. Na FIG 1.7, nota-se também que houve a inclusão, em 2006, de dois novos pontos de monitoramento, incluindo-se pontos nos rios formadores do reservatório. Percebe-se também que estes rios possuem uma qualidade para o abastecimento inferior a da qualidade apresentada pelo reservatório. No ano de 2009, as águas dos rios Sorocabuçu e Sorocamirim foram classificadas como ruim e do rio Una, como regular sendo este um sinal de alerta para a qualidade da água nos rios formadores do reservatório e alertando para o futuro da qualidade das águas do reservatório. Entretanto, pode ser notada certa melhora na qualidade dos rios Sorocabuçu e Sorocamirim no ano de 2010, em relação ao ano de 2009. Todavia, esta melhora no ano de 2011 somente se manteve para o rio Sorocabuçu, pois o Sorocamirim sofre nova queda em sua classificação, queda esta bem semelhante à sofrida pelo Reservatório, podendo esta queda na qualidade do rio ter influenciado diretamente a qualidade do Reservatório.

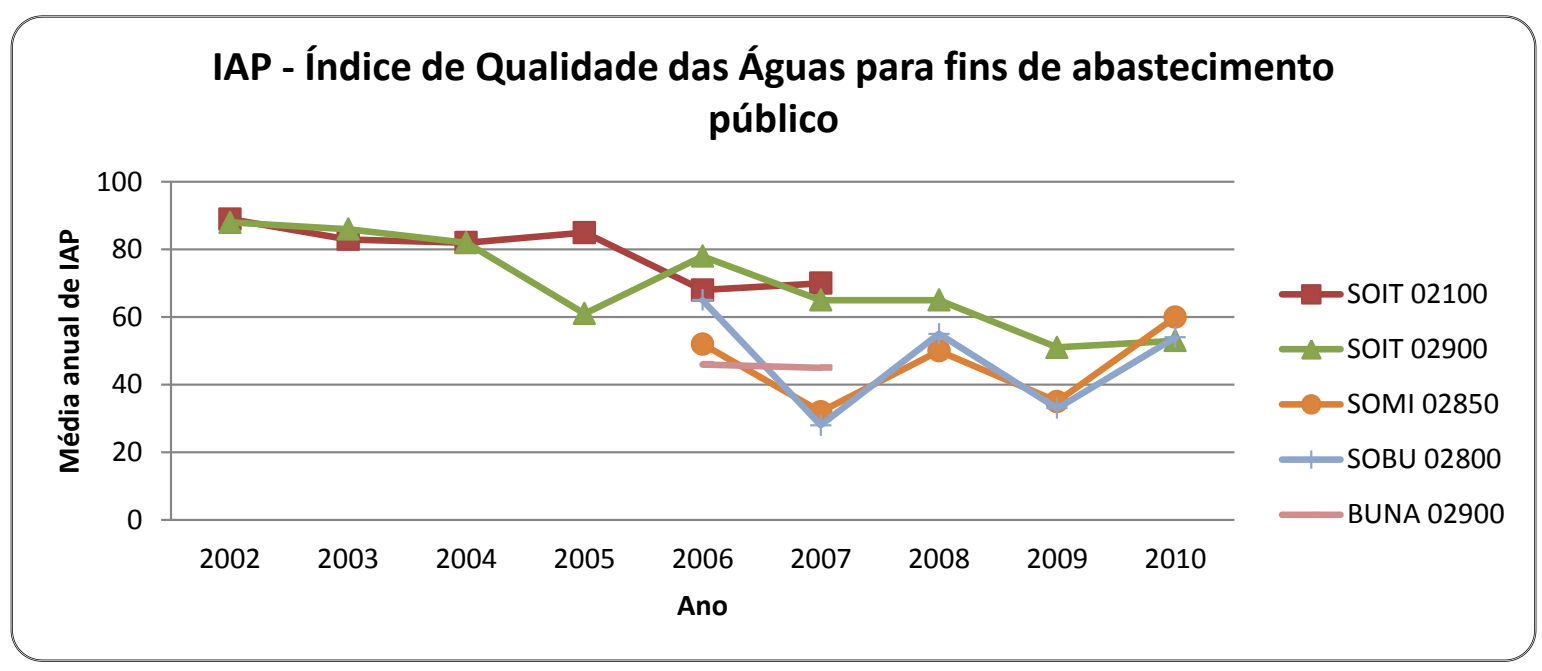

FIGURA 1.7 - Valores médios anuais do índice de qualidade das águas para fins de abastecimento público no reservatório de Itupararanga, extraídos dos relatórios de qualidade das águas interiores do estado de São Paulo.

Na FIG 1.8, apresenta-se os resultados anuais do índice de qualidade das águas para a proteção da vida aquática, a partir dos quais pode-se perceber que o ponto SOIT 02100 só apresentou uma elevação significante no ano de 2003, sofrendo uma queda em sua 
qualidade que foi de ótima para regular, permanecendo praticamente constante ao longo dos anos seguintes. O ponto SOIT 02900, praticamente oscilou da mesma forma que o ponto SOIT 02100, apresentando uma diferença no ano de 2009 onde a qualidade deste ponto foi classificada como ruim, tendo retornado a classificação anterior no ano de 2010 e 2011, voltando a ser classificado como ruim.

Entre os anos de 2006 à 2010 foram analisados o IVA do ponto BUNA 02900, ponto este localizado no rio Una, no qual a qualidade até 2008 era péssima e em 2009, 2010 e 2011, foi classificada como ruim apresentando uma melhora em sua qualidade para a proteção da vida aquática. Já o ponto SOMI 02850, que só foi analisado nos anos de 2009 a 2011, manteve-se constante em sua classificação de regular. O ponto do SOBU 02800, que em 2009 apresentou uma classificação regular, em 2010 melhorou a sua classificação para boa e em 2011, melhorou um pouco mais o IVA.

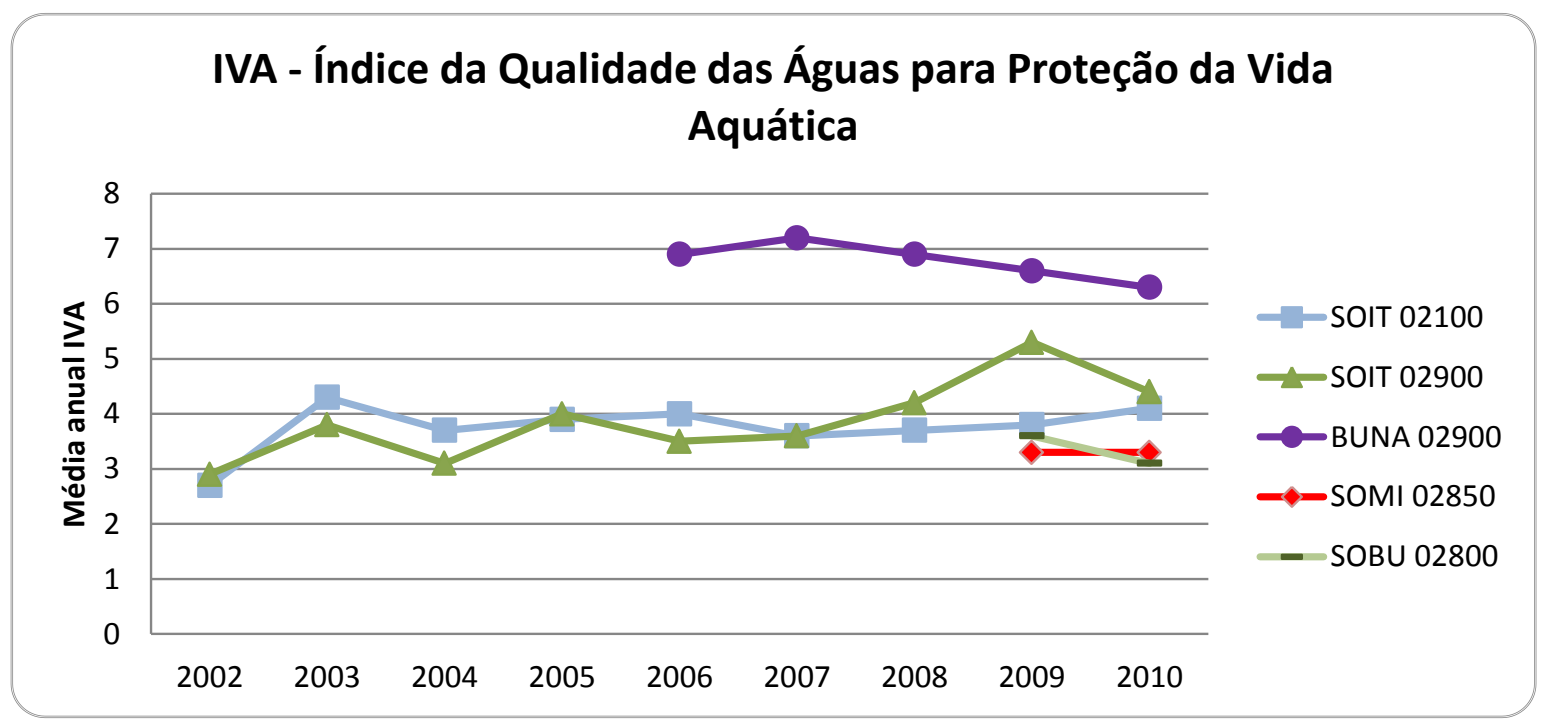

Figura 1.8 - Valores médios anuais do índice de qualidade da água para proteção da vida aquática no reservatório de Itupararanga, extraídos dos relatórios de qualidade das águas interiores do estado de São Paulo.

Na FIG 1.9, é possível verificar que o processo de eutrofização se apresenta crescente desde o ano de 2005, crescimento esse que embora pequeno, persiste ano a ano. O ponto SOIT 02100 apresenta estado Mesotrófico desde o ano de 2004, enquanto o ponto SOIT 02900 passou a apresentar esta classificação a partir de 2007. As análises dos pontos localizados nos rios formadores nos indicam que o rio Una já mostra um estado de 
eutrofização mesmo tendo apresentado uma leve melhora no ano de 2009, o qual permaceu no ano de 2010 e 2011. O rio Sorocabuçu apresentou uma leve piora em seu estado de eutrofização no ano de 2009, mas ainda sendo classificado como mesotrófico. Entretando, podemos notar uma leve melhora em 2010 em sua classificação, passando de mesotrófico para oligotrofico, voltando a ter uma piora no ano de 2011.

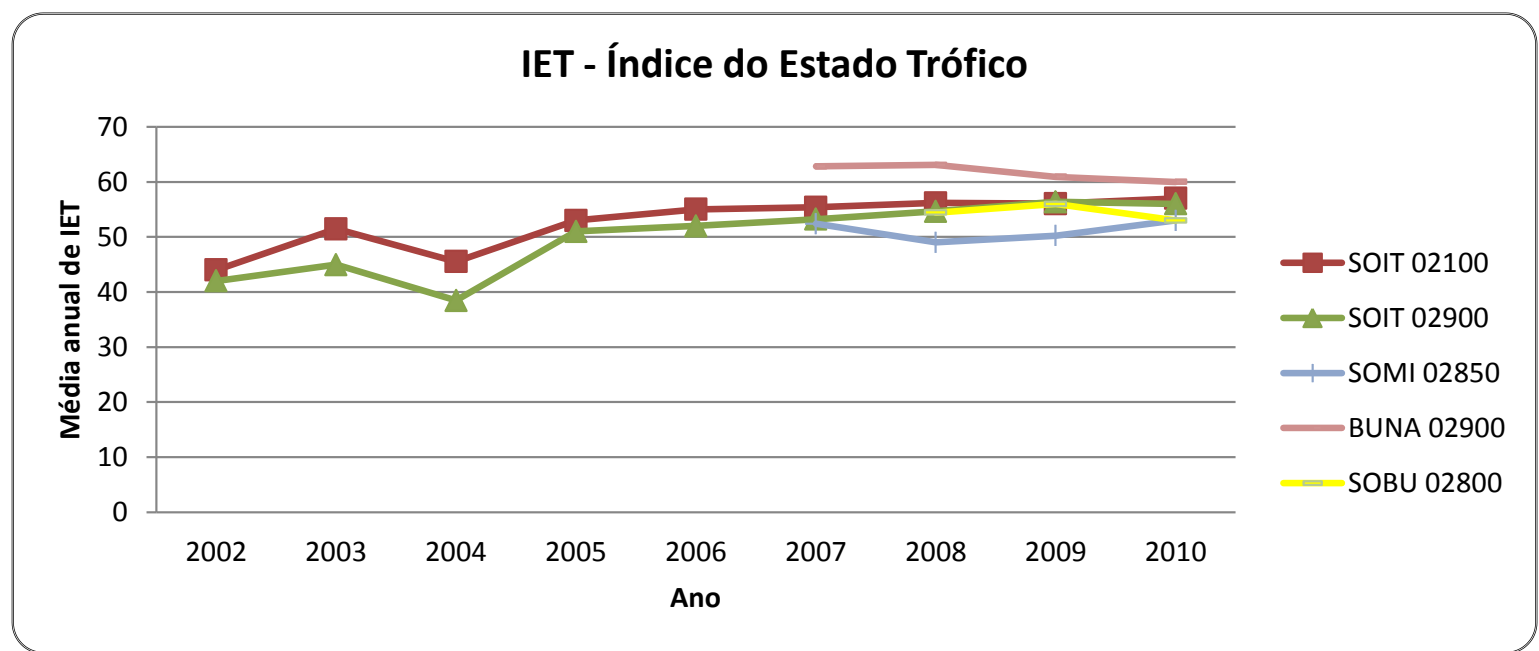

Figura 1.9 - Valores médios anuais do Índice de Estado Trófico no Reservatório de Itupararanga, extraídos dos relatórios de qualidade das águas interiores do estado de São Paulo.

Segundo os relatórios da CETESB, durante todo período de monitoramento, observa-se que o índice de balneabilidade sempre recebeu uma classificação de ótima. Entretanto, os relatórios a partir de 2004 apontam um aumento no IET do reservatório e a partir desse histórico, fica evidenciada a necessidade de maior atenção com relação à qualidade da água (CETESB, 2009).

No relatório de 2003 é apontado que o número de cianobactérias ultrapassou 10.000 céls $/ \mathrm{mL}$, em todos os meses de amostragem, na água bruta do Reservatório. Este valor é considerado pela legislação como sinal de alerta, recomendando-se assim cuidados especiais no tratamento realizado pelas empresas de saneamento, bem como o monitoramento de cianotoxinas nas águas tratadas. A frequente observação de efeitos tóxicos nas águas do reservatório de Itupararanga em 2003 (CETESB, 2003) já sugeria a necessidade de uma investigação mais detalhada da origem de tais efeitos. Entretanto, os 
aspectos negativos observados podem estar associados ao fato de que o volume do Reservatório esteve bastante reduzido ao longo do ano de 2003 (CETESB, 2003).

Em 2004, além das condições de trofia que variaram ao longo do ano de oligotrófico a eutrófico, foi constatado novamente um efeito tóxico crônico nos pontos SOIT 02900 (em janeiro e julho) e SOIT 02100 (em janeiro e julho) (CETESB, 2004). Para o ponto SOIT 02900, no mês de janeiro, registraram-se altas densidades de cianobactérias com presença do gênero Cylindrospermopsis, a qual segundo o relatório CETESB (2004) é considerada pela literatura como alga potencialmente tóxica. Para o ponto SOIT 02100, o diagnóstico foi ruim em janeiro pela alta densidade e dominância de cianobactérias, com grande quantidade de algas dos gêneros Microcystis, Aphanizomenon, Cylindropermopsis entre outras, sendo que para esta útima há registros de neurotoxicidade e hepatotoxicidade (CETESB, 2004). Em decorrência a esse processo ocorrido em 2004 e 2005, em 2006 a CETESB ampliou o monitoramento, com a instalação de novos pontos de monitoramento das águas dos rios formadores e um ponto no sedimento do reservatório.

Segundo o relatório de 2005, em alguns meses, foram detectados valores de cianobactérias que ultrapassaram o limite de 10.000 céls $/ \mathrm{mL}$ estabelecido pela legislação vigente para potabilidade (portaria 518/2004) (CONAMA, 2004). Vale ressaltar ainda que a toxicidade crônica à Ceriodaphnia dúbia foi detectada em quatro amostras do ponto SOIT 02900 (janeiro, maio, julho e setembro). Foi constatado também, efeito tóxico crônico nos pontos SOIT 02100 (julho e setembro). Os efeitos tóxicos observados, não se correlacionam com os resultados das análises químicas efetuadas e sua ocorrência pode estar associada a outras substâncias não avaliadas. Para a análise das comunidades fitoplanctônicas apesar da sua qualidade ter variado de ótima a boa, no ponto SOIT 02900 foi observado a presença de organismos pertencentes ao grupo de cianobatérias (Microcystis, Aphanocapsa e Aphanizomenon) em baixas densidades. Mas, segundo a literatura este grupo é problemático com relação à qualidade da água. Entretanto esta toxicidade crônica apresentada desde 2004, não pode ser relacionada com os resultados das análises químicas efetuadas (CETESB, 2006).

Em 2008 houve uma piora na qualidade das águas devido, principalmente, ao aumento da densidade no grupo de cianobactérias e a piora do IET. 
Em 2009 verificou-se um aumento na quantidade de cianobactérias em relação a 2008 e detectou-se a ocorrência do gênero de quironomídeos, da subfamília Tanypodinae, em densidades mais elevadas. Isto pode ser resultado da aceleração do processo de eutrofização em evolução neste ambiente (CETESB, 2009).

Já em 2010 foi notado o aparecimento do Dinofiageladoceratiumfurcoides, permanecendo o aumento na densidade das cianobacterias desde meados de 2007 atingindo 283.590 cels/mL, em dezembro de 2010.

No ultimo relatório de 2011, constatou-se que todas as amostras de água coletadas, nos dois pontos de monitoramento, eram tóxicas, sendo que na captação, próxima à barragem (SOIT 02900), em 50\% destas amostras a toxicidade encontrada foi aguda (CETESB, 2011)

Na FIG 1.10 podemos notar a evolução dos valores tanto de IET quanto do número de cianobactérias, nos dois pontos de monitoramento da CETESB neste reservatório, onde podemos notar um grande e significativo salto no número de cianobactérias no ponto SOIT02900, ponto este localizado próximo a barragem do reservatório.

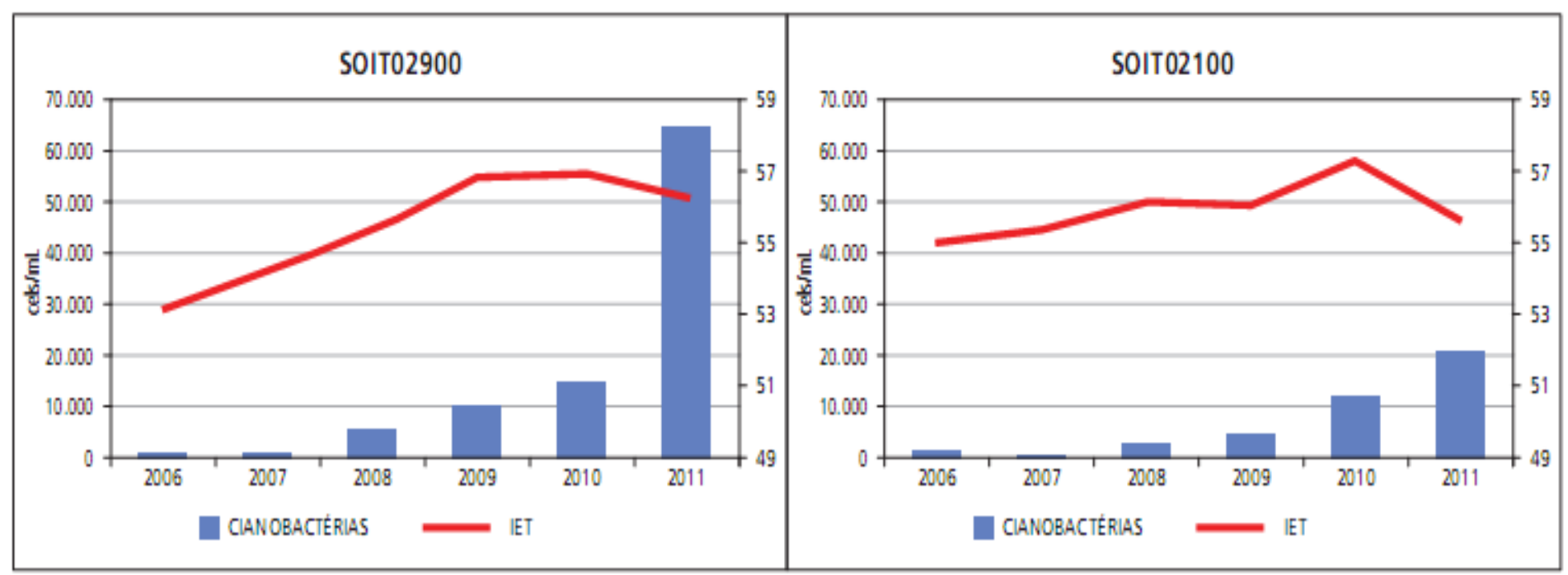

Figura 1.10 -Evolução do número de Cianobactérias e IET entre 2006 e 2011, nos pontos de monitoramento da CETESB 
Para as análises de sedimento no ano de 2008, os valores de resíduo volátil ( $8 \%$ e $15 \%$ ) e umidade ( $47 \%$ e $75 \%$ ) indicaram que existe um aporte significativo de matéria orgânica na área amostrada. Contudo a concentração de fósforo indicou a ocorrência de ligeiro acúmulo por este nutriente e, por conseguinte, indícios de geração de carga interna neste corpo d'água, fato que merece ser melhor investigado. Entretanto, esse sedimento foi classificado na categoria regular.

No ano de 2010 foram detectados valores para DDE (Dicloro Difenil Dicloro Etileno), o qual juntamente com o DDD (Dicloro Difenil Dicloro Etano), é um produto de degradação ambiental do DDT (Dicloro Difenil Triclooetano), acima de TEL (Threshold Effect Level) que representa a concentração abaixo da qual raramente são esperados efeitos adversos para os organismos, o que indica uma contaminação pretérita. Foram encontradas também concentrações de arsênio acima de PEL (Probable Effect Level), que representa a concentração acima da qual é frequentemente esperado o citado efeito adverso para os organismos, o qual levou o sedimento a apresentar uma classificação de péssima. (CETESB, 2010). Sendo que estes resultados se mantiveram no ano de 2011, com valores de Arsênio superior de PEL e DDE superior de TEL.

Segundo Smith et al. (2005), o reservatório Itupararanga apresentava um prognóstico desfavorável à manutenção do recurso hídrico bem como de sua qualidade. Dentre os fatores responsáveis, destacava-se o uso intenso do solo para agricultura, o que fazia com que muitas vezes a água retirada da represa para irrigação, retornasse ao manancial carregada de substâncias tóxicas, comprometendo a qualidade das suas águas; a degradação da vegetação ao redor do reservatório, como reflexo direto da implantação indiscriminada de loteamentos, e as agressivas atividades de extração de areia, resultaram no assoreamento do reservatório com diminuição do curso d'água e de seu abastecimento.

Em 2007, Smith et al., constataram que o reservatório passava por um processo de eutrofização.

Segundo Salles et al. (2008), a represa de Itupararanga ainda não sofria em toda a sua proporção os impactos detectados ao longo da bacia. Entretanto, merecia atenção especial, já que existia um baixo índice de tratamento de esgotos em sua bacia.

Segundo Sardinha et al. (2008), certos constituintes, como fosfato e nitrato, contribuem para a proliferação de macrófitas e algas, justamente na entrada do 
Reservatório de Itupararanga. Porém, no exutório deste reservatório, a água recupera sua qualidade, possivelmente pela sedimentação, absorção e/ou complexação dos elementos/compostos.

Taniwaki et al. (2011) sugeriu manejo e monitoramento constante no reservatório de Itupararanga, além de recomposição da vegetação ciliar em sua margem esquerda (sentido barragem) visando garantir proteção à vida aquática deste recurso hídrico, tendo em vista as condições preocupantes relativas ao grau de trófia desse reservatório.

Com isto, verifica-se que a maioria dos problemas ambientais na bacia do Alto Sorocaba, provocados por atividades antrópicas, tem como causas principais a sua má utilização e falta de planejamento.

\subsection{Objetivos}

Em vista do acima exposto, o presente trabalho pretendeu realizar um estudo da carga dos macros (Al, Fe, Mg, Ca, Na e K) e microconstituintes ( $\mathrm{Ag}, \mathrm{Al}, \mathrm{As}, \mathrm{Ba}, \mathrm{Be}, \mathrm{Br}$, Ce, Co, Cr, Cu, Cs, Eu, Fe, Hf, La, Li, Lu, Mg, Mn, Mo, Nd, Ni, P, Rb, Sc, Sm, Sn, Sr, Ta, Th, Ti, U, V, Yb e Zn) em 4 perfis sedimentares, coletados ao longo do reservatório Itupararanga. $\mathrm{O}$ conjunto de informações obtidas pela avaliação destes dados nas amostras de sedimento, recolhidos em pontos estratégicos selecionados do reservatório, possibilitou um diagnóstico da qualidade dos sedimentos e a carga de fósforo contida neste sedimento, direcionando para ações corretivas que antecipem um dano maior e gerando ações preventivas. O objeto do presente trabalho foi o estudo das condições ambientais da represa de Itupararanga. 


\subsection{Objetivos Específicos}

- Avaliação da concentração dos metais nos sedimentos (Ag, Al, Ba, Be, Ca, Co, Cr, $\mathrm{Cu}, \mathrm{Fe}, \mathrm{Li}, \mathrm{Mg}, \mathrm{Mn}, \mathrm{Mo}, \mathrm{Ni}, \mathrm{P}, \mathrm{Sn}, \mathrm{Ti}, \mathrm{V}$ e Zn) pela técnica de ICP OES;

- Avaliação da concentração dos metais nos sedimentos (As, Cd e Pb) por FG AAS e de $\mathrm{Hg}$ por Analisador Direto de Mercúrio;

- Avaliação da concentração dos elementos (As, Ba, Ca, Ce, Co, Cr, Cs, Eu, Fe, Hf, K, La, Lu, Na, Nd, Rb, Sb, Sc, Sm, Ta, Tb, Th, U, Yb e Zn), por ativação neutrônica instrumental (INAA) nos sedimentos (concentração total);

- A partir dos resultados obtidos, realizar um diagnóstico da qualidade dos sedimentos e levantamento da carga dos macro e microconstituintes do sedimento do reservatório Itupararanga;

- Comparar os valores de concentração de As e dos metais $\mathrm{Cd}, \mathrm{Cr}, \mathrm{Cu}, \mathrm{Hg}, \mathrm{Ni}, \mathrm{Pb}$ e Zn com os valores orientadores TEL e PEL do CCME (Canadian Council of Ministers of the Environment) e resolução CONAMA e com os valores da CETESB;

- Verificação da contaminação antrópica local, utilizando-se o fator de enriquecimento (EF) e o Índice de Geoacumulação (Igeo), como ferramentas geoquímicas de avaliação. 


\section{CAPÍTULO 2}

\section{METODOLOGIAS ANALÍTICAS}

\subsection{Técnicas analíticas para determinação de metais em sedimentos}

São várias as metodologias analíticas utilizadas para a determinação de metais e outros elementos de interesse em sedimentos, mas nesse capítulo foram feitas considerações teóricas somente sobre as técnicas analíticas utilizadas no presente estudo. As técnicas analíticas utilizadas foram as seguintes: Análise por Ativação Neutrônica Instrumental (INAA), Espectrometria de Emissão com Plasma Indutivamente Acoplado (ICP OES), Espectrometria de Absorção Atômica com atomização em forno de grafite (GF AAS) e Análise Direta de Mercúrio.

\subsubsection{Análise por Ativação com Nêutrons (INAA)}

Existem no mínimo 50 elementos de ocorrência natural que possuem isótopos radioativos, com um nêutron a mais que seus isótopos estáveis. Isto significa que espécies radioativas podem ser criadas por bombardeamento com nêutrons, sendo um procedimento tipicamente realizado em reator nuclear, apesar de serem usadas outras fontes de nêutrons em alguns casos. Um núcleo de interesse absorve um nêutron, tornando-se um núcleo radioativo. Através da deteç̧ão do decaimento deste núcleo, podendo ser feita com grande sensibilidade, pode-se medir a concentração do elemento de interesse na amostra (LBL, 2000).

A Análise por Ativação com Nêutrons Instrumental, INAA (Instrumental Neutron Activation Analysis), descoberta em 1936, é uma técnica analítica sensível e útil em análises multielementares qualitativas e quantitativas de elementos maiores, menores e traço, em amostras de quase todas as áreas científicas e técnicas. Para muitos elementos e 
aplicações, a INAA oferece sensibilidades superiores em relação a outros métodos. Devido à sua precisão e confiabilidade, a INAA é geralmente reconhecida como um método de referência quando novos procedimentos são desenvolvidos ou quando outros métodos produzem resultados não conformes (Glascock, 2010). Greenberg et al (2011) publicaram um artigo, citando que o método de NAA comparativo, apresentava todos os requisitos para ser considerado como método primário conforme definição do "Comité Consultatif pour La Quantité de Matière - Metrologie en Chimie" (CCQM). A tese dos autores é evidenciada nesse artigo em três capítulos, aonde foram discutidos todos os requisitos para que um método fosse considerado primário.

Os requisitos básicos necessários para analisar uma amostra por INAA são: uma fonte de nêutrons; instrumentos apropriados para a detecção de raios gama (detectores), e um conhecimento detalhado das reações nucleares que ocorrem quando os nêutrons interagem com os núcleos do alvo (Glascock, 2010).

A aplicação mundial da INAA é tão difundida que se estima aproximadamente 100.000 amostras submetidas à análise a cada ano (Glascock, 2010). Esta técnica vem sendo largamente utilizada para análises de solos e sedimentos e em exercícios de intercomparação para essas matrizes (Rezaee et al, 2011; Cristache et al, 2009; Lloyd et al, 2005; Al-Jundi \& Randle, 2001; Dinescu et al, 1998).

No Brasil essa técnica vem sendo utilizada em diferentes estudos e regiões pelo grupo de pesquisadores do Laboratório de Ativação Neutrônica (LAN) do IPEN/CNEN-SP (Amorim et al, 2007, 2008, 2009a; Fávaro et al, 2001; 2007; Figueiredo et al, 2009, Franklin et al, 2012; Guimarães et al, 2012; Larizzatti et al, 2001; Silva et al, 2011).

A INAA é um dos métodos mais importantes dentre os disponíveis para a determinação de elementos traço. A sua principal vantagem é a capacidade de determinação de muitos elementos com alta sensibilidade sendo possível a sua determinação em níveis de $\mu \mathrm{g} \mathrm{kg}^{-1}$ até \%, com exatidão e precisão. É uma técnica não destrutiva, que preenche dois requisitos básicos: a especificidade, que é a habilidade de correlacionar diretamente e de forma não ambígua o sinal obtido com o elemento procurado na presença de outros elementos que emitem sinais da mesma natureza e a seletividade, que vem a ser a possibilidade de medir o elemento em questão na presença de outros elementos que emitem sinais da mesma natureza. 
O método de análise por ativação com nêutrons consiste no bombardeamento com nêutrons em um dado material, o qual forma radionuclídeos artificiais, a partir de elementos estáveis (FIG 2.1) e o núcleo formado irá liberar a energia de excitação (raios gama), alcançando uma configuração mais estável quando emite fótons. A energia destes raios gamas e o tempo de meia vida $\left(\mathrm{T}_{1 / 2}\right)$ são característicos de cada elemento.

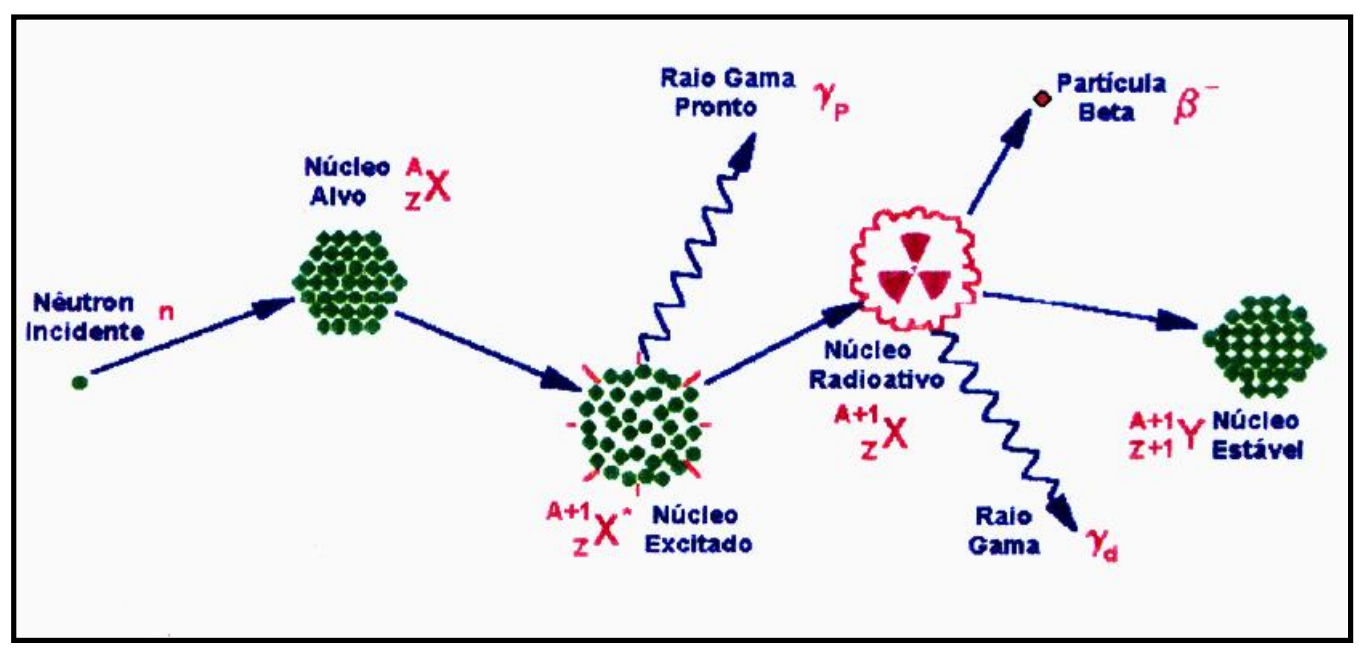

Figura 2.1 - Representação esquemática da interação do nêutron com um núcleo alvo.

No caso da INAA comparativa a amostra é irradiada juntamente com um padrão de composição o mais similar possível, nas mesmas condições. Após a irradiação, amostra e padrão são analisados no mesmo detector, o que permite que a massa desconhecida possa ser diretamente calculada a partir das taxas de contagens da amostra e do padrão e conhecendo-se a massa do padrão e da amostra.

A concentração dos elementos presentes na amostra é obtida pela comparação de áreas de picos referentes a padrões que são ativados juntamente com as amostras, utilizando-se para o cálculo a equação (2.1).

$$
\mathrm{C}_{\mathrm{a}}^{\mathrm{i}}=\frac{\left(\mathrm{Aa}^{\mathrm{i}} \mathrm{m}_{\mathrm{p}} \mathrm{c}_{\mathrm{p}}^{\mathrm{i}}\right) \mathrm{e}^{\lambda\left(\mathrm{t}_{\mathrm{a}}-\mathrm{t}_{\mathrm{p}}\right)}}{\mathrm{A}_{\mathrm{p}}^{\mathrm{i}} \mathrm{m}_{\mathrm{a}}}
$$

Onde:

$\mathrm{C}_{\mathrm{a}} \mathrm{i}$ : Concentração do elemento i na amostra

$\mathrm{C}_{\mathrm{p}} \mathrm{i}$ : Concentração do elemento i no padrão 
$\mathrm{A}_{\mathrm{a}} \mathrm{i}$ : Atividade do elemento i na amostra

$\mathrm{A}_{\mathrm{p}} \mathrm{i}:$ Atividade do elemento i no padrão

$\mathrm{m}_{\mathrm{a}}$ e $\mathrm{m}_{\mathrm{p}}$ : Massas da amostra e padrão, respectivamente

$\lambda$ : constante de decaimento do radioisótopo

$t_{a}:$ Tempo de resfriamento da amostra

$\mathrm{t}_{\mathrm{p}}$ : Tempo de resfriamento do padrão

\subsubsection{Espectrometria de Emissão com Plasma Indutivamente Acoplado (ICP OES)}

A espectrometria de emissão atômica com plasma indutivamente acoplado (ICP OES) vem sendo utilizada no Brasil desde 1976, quando foram instalados os primeiros equipamentos comerciais. A técnica foi muito bem sucedida em função da capacidade de análises multielementares em diversos tipos de amostras (Guiné, 1999).

A técnica de ICP OES aplica-se a uma grande faixa de metais, principalmente para os chamados refratários (que formam óxidos estáveis e não decompõem facilmente com a temperatura da chama). As altas temperaturas geradas nesta técnica nos fornecem excelentes sensibilidades para muitos elementos refratários, eliminando interferências químicas. Esta técnica usa plasma de argônio como fonte de excitação. A FIG 2.2, apresenta o esquema de funcionamento de ICP OES. 


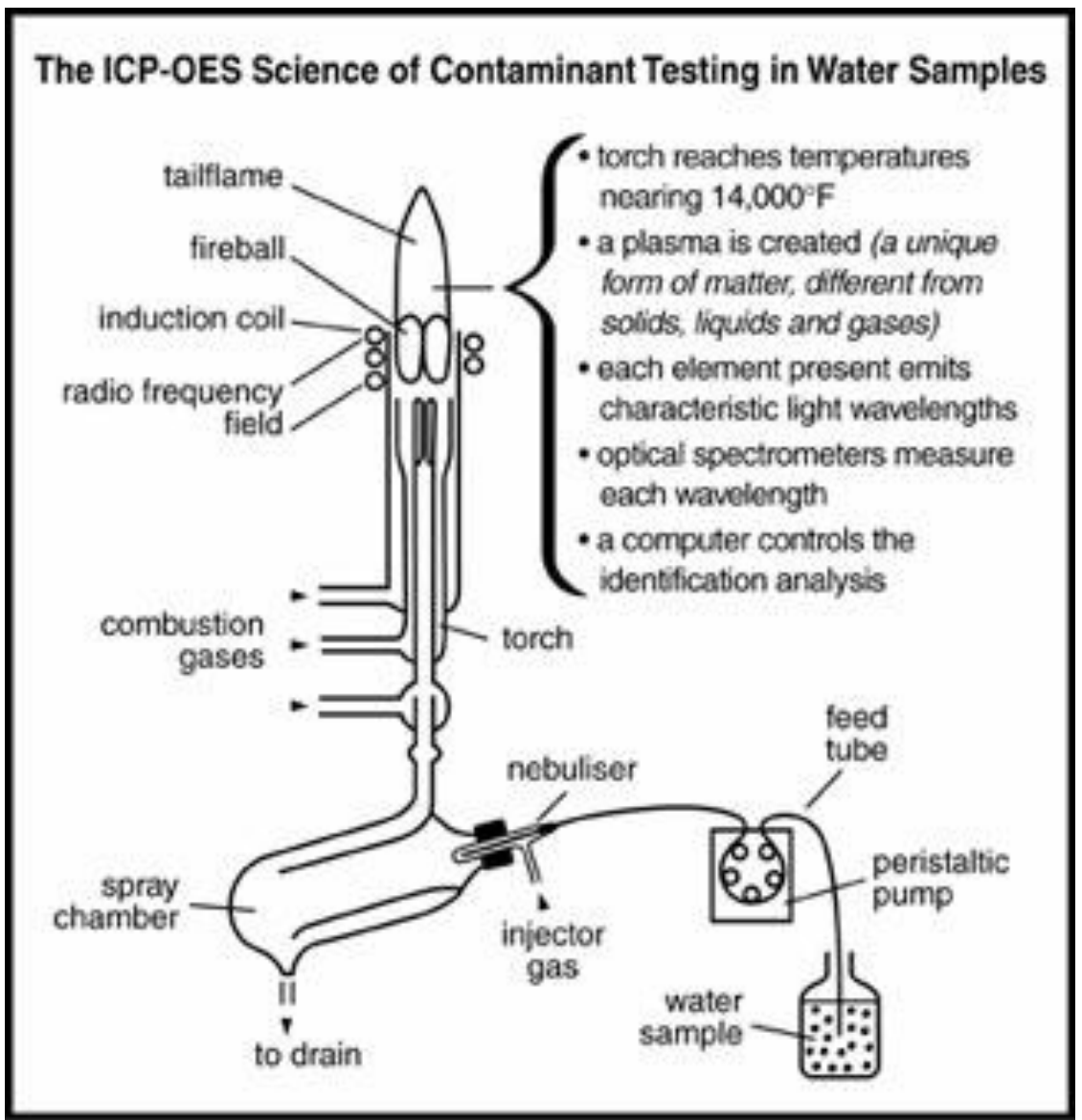

Figura 2.2 - Esquema de Análise de um ICP OES

O plasma de argônio é formado pela ação do campo magnético da bobina de radio frequência, sobre o argônio, na tocha. A tocha consiste de três tubos concêntricos de quartzo, com entradas independentes para cada seção anular. Na seção anular externa, o gás é introduzido tangencialmente, com fluxo superior a $12 \mathrm{~L} \mathrm{~min}{ }^{-1}$. Na seção anular intermediária entra o gás auxiliar, a uma vazão de $1 \mathrm{~L} \mathrm{~min}^{-1}$, necessário para estabilizar o plasma. Na seção interna ou tubo injetor, entra o aerossol da amostra, por arraste com gás em vazões abaixo de $1 \mathrm{~L} \mathrm{~min}^{-1}$ (Guiné, 1999).

Uma vez formado o plasma, procede-se à introdução do aerossol da amostra pelo tubo central.

Uma bomba peristáltica proporciona uma amostra aquosa em um nebulizador, onde é transformado em névoa e introduzido diretamente no interior do plasma. A amostra imediatamente colide com os elétrons e íons carregados no plasma e é ela própria dividida em íons carregados. As várias moléculas quebram-se em seus respectivos átomos que, em seguida, perdem elétrons e recombinam-se repetidamente no plasma, emitindo radiação nos comprimentos de onda característicos dos elementos envolvidos. 
Dentro da câmara óptica (s), após a luz ser separada nos seus comprimentos de onda diferentes (cores), a intensidade de luz é medida com um tubo fotomultiplicador ou tubos fisicamente posicionados. Esses tubos são usados para "visualizar" o comprimento de onda específico (s) para cada linha elemento envolvido, ou, em unidades mais modernas, as cores separadas caírem sobre um conjunto de detectores de fotos de semicondutores, tais como dispositivos de carga acoplada (CCDs). Nas unidades que utilizam estas matrizes de detectores, as intensidades de todos os comprimentos de onda (dentro do alcance do sistema) podem ser medidas simultaneamente, permitindo que o instrumento de análise possa medir cada elemento a que a unidade é sensível, ao mesmo tempo. Dessa forma, as amostras podem ser analisadas muito rapidamente.

A intensidade de cada linha é então comparada com intensidades previamente medidas de concentrações conhecidas dos elementos e as suas concentrações são, então, calculadas por interpolação ao longo das linhas de calibração. Além disso, o software especial geralmente corrige interferências provocadas pela presença de elementos diferentes dentro de uma matriz de uma dada amostra.

Entretanto, a amostra necessita passar previamente por digestão ácida assistida por aquecimento, para extração e solubilização dos elementos potencialmente extraíveis, ou disponíveis para o ambiente aquático.

A amostra, após digestão ácida, é introduzida dentro de uma câmara de mistura, onde é direcionada até o tubo central da tocha do ICP OES. Os átomos da amostra em contato com a energia da fonte de plasma produzem linhas de emissão específicas para cada elemento. A intensidade de cada linha é proporcional à concentração do elemento de interesse. A quantificação do metal se dá com a comparação do sinal analítico obtido na leitura da amostra, com uma curva analítica (Beat \& Kerber, 1993; STM, 1998; Baccan, 1994).

\subsubsection{Espectrometria de Absorção com Atomização em forno de grafite (GF AAS)}

A espetrometria de absorção atômica envolve a medida da absorção da intensidade da radiação eletromagnética, oriunda de uma fonte de radiação primária, por átomos gasosos no estado fundamental, essa medida é utilizada para que se determinem quantitativamente os elementos (metais, semimetais e alguns não metais). A técnica de 
Espectroscopia de Absorção Atômica com Forno de Grafite, GF AAS (Graphite Furnace Atomic Absorption Spectroscopy), aplica-se à determinação de vários elementos metálicos e é indicada, quando se deseja quantificar baixíssimas concentrações (inferiores a matriz, que pode ser minimizada, com o ajuste das temperaturas e modificadores químicos) (Beaty \& Kerber, 1993).

O espectrômetro de absorção atômica é um equipamento que permite a determinação quantitativa de elementos metálicos em soluções líquidas, gasosas e sólidas. Os componentes básicos de um espectrômetro incluem fonte de radiação, sistema de atomização, conjunto monocromador, detector e processador. Como fonte de radiação utiliza-se uma lâmpada, normalmente utiliza-se a lâmpada de cátodo oco.

O atomizador de forno de grafite simples é constituído por tubo de grafite, contatos elétricos, compartimento de água e controles dos gases inertes. O tubo de grafite é o elemento onde ocorrerá a atomização da amostra. Ele é horizontalmente alinhado no caminho óptico do espectrômetro, foi devidamente dimensionado ao longo dos anos porque o tempo de residência dos átomos dentro do tubo é proporcional ao quadrado do comprimento do tubo e inversamente proporcional ao coeficiente de difusão, supondo que as perdas sejam apenas por difusão. Uma alíquota da amostra é medida e dispensada, por um orifício no centro da parede de tubo, sobre a parede interna do tubo ou na plataforma de grafite. O tubo está entre dois cilindros de contato de grafite que fazem a conexão elétrica. Um potencial elétrico é aplicado aos contatos que percorre o tubo aquecendo o tubo e a amostra. O sistema elétrico controla a corrente elétrica provida ao tubo de grafite que gera o aquecimento. A temperatura do tubo é previamente especificada em um programa de temperatura. O programa tem uma sucessão de rampas de tempo versus de temperaturas selecionadas. O programa tem rampa para secagem, pirólise e atomização da amostra, e também pode incluir colocações para a taxa de fluxo de gás inerte interna e, em alguns casos, um gás alternado.

O vapor atômico resultante da atomização absorve a radiação monocromática, fornecida por uma lâmpada do metal e o detector fotoelétrico mede a intensidade da radiação transmitida. O inverso da transmitância é convertido logaritmicamente para absorvância, que é diretamente proporcional à densidade numérica de átomos no vapor, até uma concentração limite. A quantificação do metal se dá com a comparação do sinal analítico obtido na leitura da amostra, com uma curva analítica (Beaty \& Kerber, 1993). 


\subsubsection{Espectrometria de Absorção Atômica por Decomposição Térmica e Amalgamação}

A EPA USA - Environmental Protection Agency (US EPA, 2007) em seu método 7473 descreve uma metodologia para análises de amostras aquosas e sólidas de forma direta.

Este método é utilizado para determinação de mercúrio em amostras aquosas e sólidas. A decomposição térmica da amostra e a detecção por absorção atômica reduz o tempo total de análise, para a maioria das amostras, para menos de 5 minutos.

O DMA-80 (Direct Mercury Analyser) é um equipamento de termo decomposição e detecção por espectrometria de absorção atômica específica para determinação de mercúrio (Durão Junior, 2010). Na Erro! Fonte de referência não ncontrada., apresenta-se o esquema de Análise do DMA-80.

Nesta técnica a amostra é seca e depois decomposta em um forno com temperatura maior que $700^{\circ} \mathrm{C}$, sob uma atmosfera de oxigênio. $\mathrm{O}$ mercúrio e outros produtos de combustão são liberados da amostra e levados para a parte catalítica do forno, onde nitrogênio e enxofre oxidam, e também halogênios e outros interferentes são eliminados. O mercúrio é seletivamente capturado, em um forno separado, através de amalgamação com ouro e os produtos derivados da combustão, são eliminados. $\mathrm{O}$ forno de amalgamação é aquecido, o mercúrio é rapidamente liberado e arrastado pelo gás para o espectrofotômetro, que possui um exclusivo arranjo com duas ou três células de diferentes caminhos ópticos. A quantificação é realizada por absorção atômica a 253,65 nm. 


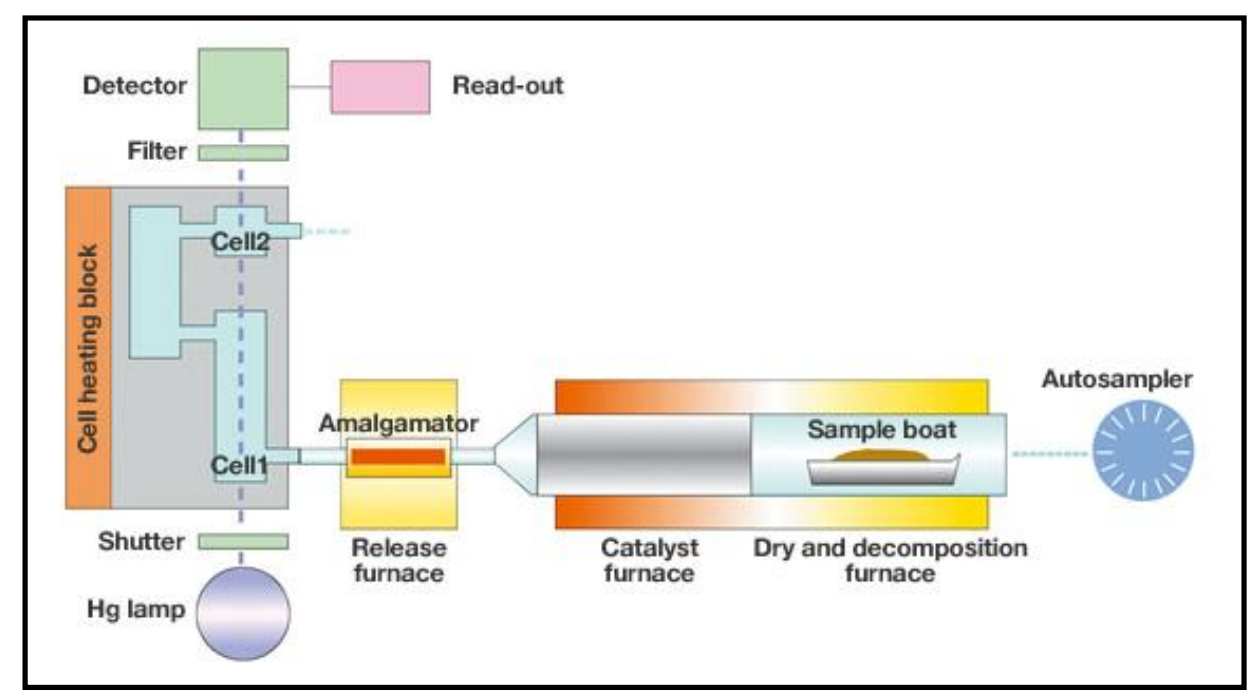

Figura 2.3 - Esquema de Análise da técnica de Análise direta de mercúrio

O método dispensa a etapa de pré-tratamento da amostra, ou seja, a amostra sólida não requer a conversão do $\mathrm{Hg}$ para o meio aquoso para determinar $\mathrm{Hg}$ (Ipolyi et al, Apud, Durão Junior, 2010). Além do mais, os produtos químicos gerados na preparação da amostra, na maioria das vezes são tóxicos e geram rejeitos que precisam ser tratados. 


\section{CAPÍTULO 3}

\section{MATERIAIS E MÉTODOS}

\subsection{Amostragem}

A amostragem foi realizada em quatro pontos ao longo do reservatório, sendo um ponto próximo à entrada do rio Sorocaba, dois pontos no corpo central do reservatório, sendo situados a montante e a jusante de um vilarejo localizado as margens do reservatório e o último ponto, próximo à barragem. Todos os pontos foram georeferênciados por meio de um GPS (Global Positioning System).

Para esta amostragem contou-se com os equipamentos e técnicos do Setor de Amostragem em Ambientes Aquáticos da Companhia Ambiental do Estado de São Paulo - CETESB. A definição dos pontos de amostragem foi feita, considerando-se a importância da localização dos mesmos para o estudo.

A TAB 3.1 apresenta os pontos de amostragem, com suas localizações a partir das coordenadas geográficas dadas por sistema GPS, a profundidade e a descrição da localidade de cada ponto de coleta. 


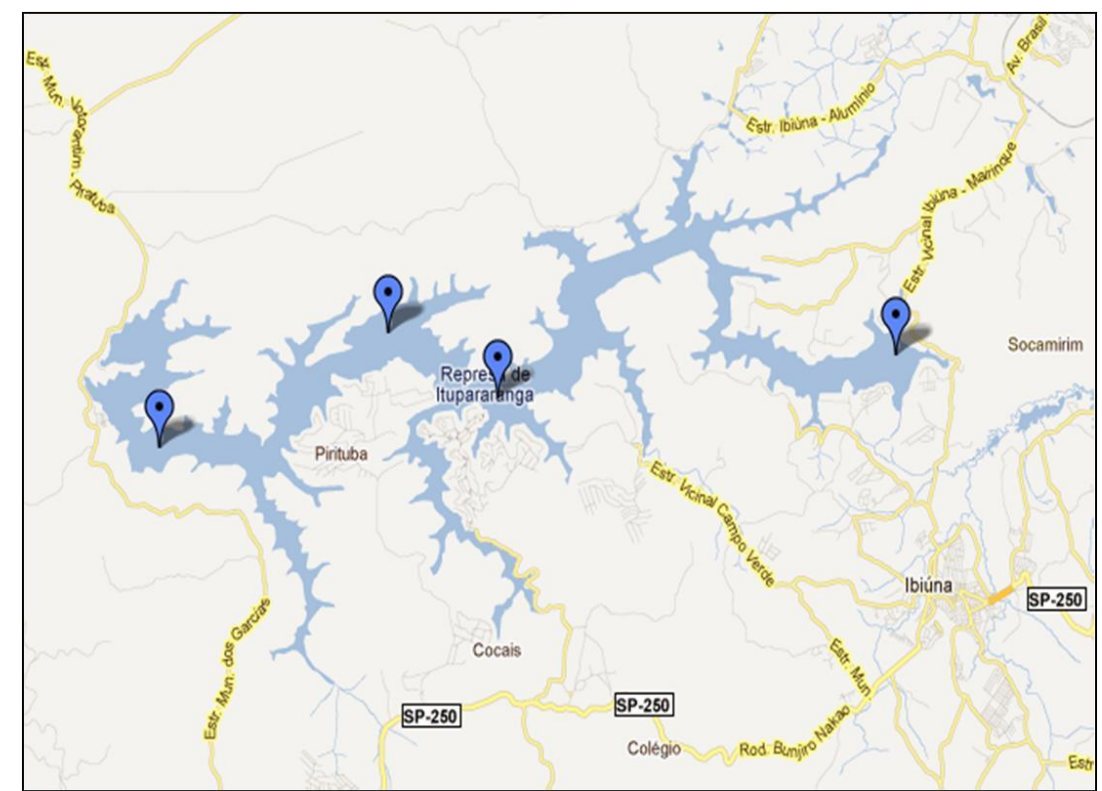

FIGURA 3.1- Localização dos pontos de amostragem no reservatório de Itupararanga

TABELA 3.1 - Descrição, localização e profundidades dos pontos amostrados

\begin{tabular}{|c|c|c|c|}
\hline Pontos & Descrição do local & $\begin{array}{c}\text { Localização } \\
\text { Geográfica } \\
\text { (GPS) }\end{array}$ & $\begin{array}{l}\text { Profundidade } \\
\text { (m) }\end{array}$ \\
\hline P-01 & A montante do Rio Sorocaba & 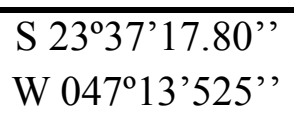 & 6,5 \\
\hline P-02 & Antes Vilarejo & $\begin{array}{l}\text { S } 23^{\circ} 37^{\prime} 14.10^{\prime \prime}, \\
\text { W } 047^{\circ} 18^{\prime} 313^{\prime},\end{array}$ & 14 \\
\hline P-03 & Após o Vilarejo & $\begin{array}{l}\text { S 233'ㄷ․ } 50^{\prime}, \\
\text { W } 04^{\circ} 20^{\prime} 188^{\prime},\end{array}$ & 16 \\
\hline P-04 & $\begin{array}{c}\text { No corpo central, a } 2 \mathrm{~km} \text { da } \\
\text { barragem }\end{array}$ & $\begin{array}{l}\text { S } 23^{\circ} 37^{\prime} 56,8^{\prime}, \\
\text { W } 047^{\circ} 23^{\prime} 105^{\prime},\end{array}$ & 17 \\
\hline
\end{tabular}

Ponto 01: localizado próximo à entrada do rio Sorocaba e pode ser considerado o inicio do reservatório, pois este é o rio formador deste reservatório, sendo sua coordenada geográfica S $23^{\circ} 37^{\prime} 17.80^{\prime \prime}$ W $047^{\circ} 13^{\prime} 525^{\prime}$ '. Neste ponto o reservatório apresenta uma profundidade de 6,5 metros. Pontos 02 e 03: estes pontos estão localizados no corpo central deste reservatório. O ponto 02 , coordenada geográfica S $23^{\circ} 37^{\prime} 14.10^{\prime \prime} \mathrm{W}$ 047 $18^{\prime} 313^{\prime}$, profundidade de 14 metros, está situado anterior a um vilarejo localizado 
bem as margens deste reservatório. O ponto 03, coordenada S 2336'5.50" W $047^{\circ} 20^{\prime} 188^{\prime \prime}$ e profundidade de 16 metros, está situado um pouco a frente deste vilarejo; estes pontos foram escolhidos para identificar uma possível contribuição antrópica gerada por este vilarejo.

Ponto 04: este último ponto foi escolhido por estar localizado próximo à

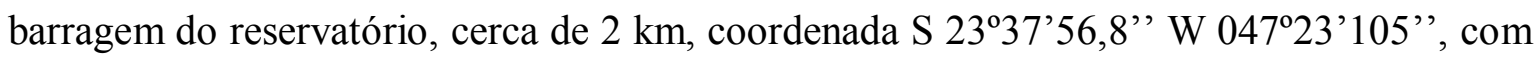
profundidade de 17 metros,

A amostragem foi realizada em 17 de junho de 2011, não havendo nenhuma ocorrência significativa em campo.

\subsubsection{Coleta e preparo das amostras de sedimentos}

Os testemunhos de sedimento foram coletados com o auxílio de um amostrador "core sample" (FIG 3.2), ao qual foi acoplado um tubo de PVC de $60 \mathrm{~cm}$ de comprimento e $60 \mathrm{~mm}$ de diâmetro, para a coleta dos perfis de sedimento.

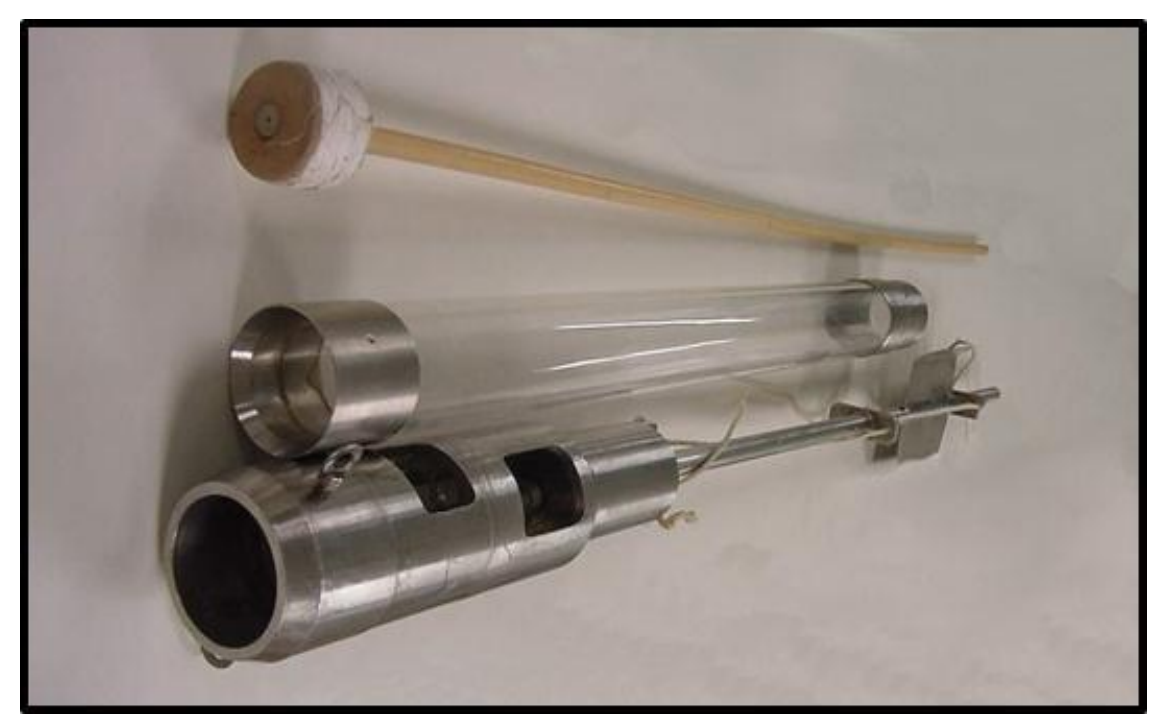

FIGURA 3.2 - Amostrador Core Sample

Logo após a coleta, ainda em campo, os testemunhos foram fracionados a cada $10 \mathrm{~cm}$, perfazendo-se um total de 19 amostras. Em seguida, as amostras foram acondicionadas em sacos plásticos com fechamento hermético, pré-lavados com solução de 
ácido nítrico e posteriormente lavados com água desmineralizada. As amostras foram acondicionadas sobre refrigeração durante todo o transporte.

Já no laboratório as amostras foram separadas em duas alíquotas onde uma delas, foi seca em estufa ventilada a $40^{\circ} \mathrm{C}$ até massa constante, macerada e peneirada a frações de $2 \mathrm{~mm}$. Uma fração foi destinada a Análise por: ICP OES (metais, fósforo), análise direta de mercúrio $(\mathrm{Hg})$, granulometria e Nitrogênio (NKT). A outra parte desta fração foi macerada para obter uma fração com granulometria de 200 mesh, a qual foi destinada a Análise por INAA (elementos traço e alguns elementos maiores).

A outra fração da amostra bruta foi seca a temperatura ambiente, macerada e peneirada a 35 mesh, fração esta que foi utilizada para determinação de carbono orgânico total (COT).

Por fim, as amostras na forma de pó, foram acondicionadas em recipientes de polietileno previamente descontaminados, estando assim prontas para as análises químicas.

\subsection{Análises Laboratoriais}

As amostras foram enviadas ao laboratório, onde foram realizadas as Análises para os seguintes parâmetros: umidade, granulometria, carbono orgânico total (COT), nitrogênio, metais (ICP OES, DMA, GF AAS e INAA).

\subsubsection{Umidade}

A umidade representa o teor de água no sedimento. Diversas metodologias analíticas nem sempre são executadas diretamente na matriz seca e são executadas em matriz úmida. Para uma correta interpretação do resultado este deve ser corrigido pela umidade da amostra. A umidade foi determinada pelo aquecimento de uma alíquota de amostra a cerca de $40^{\circ} \mathrm{C}$ até massa constante. 


\subsubsection{Análise Granulométrica}

A análise granulométrica foi realizada de acordo com a norma CETESB L 6.160 (CETESB, 1995). A amostra deve ser previamente tratada com $\mathrm{H}_{2} \mathrm{O}_{2}$ a quente para remoção da matéria orgânica, em seguida acerta-se o pH para evitar floculação durante a execução do ensaio e finalmente, a amostra é seca e macerada com pistilo de borracha para proceder-se ao peneiramento. Nessa etapa, separam-se e pesam-se as frações de areia mais grossa antes da execução do ensaio de sedimentação para determinação das frações de silte e argila. Para tal, avoluma-se uma massa conhecida da amostra em proveta de 1L, e adiciona-se previamente um sal para desagregação das partículas e depois, executa-se o ensaio de sedimentação para quantificação de silte e argila, para posteriormente separar as frações de areias mais finas. Estas determinações foram executadas pelo laboratório da Agência Ambiental de Limeira, da CETESB.

\subsubsection{Carbono Orgânico Total (COT)}

Para análise de COT as amostras foram secas a temperatura ambiente, maceradas e peneiradas em uma peneira de 35 mesh. A determinação foi realizada segundo o método de Gaudette et al (1974) no qual a amostra é seca a temperatura ambiente, macerada e peneirada a 35 mesh, malha com 500 milímetros de abertura. Uma massa conhecida desta amostra já seca é colocada para reagir com uma quantidade conhecida de $\mathrm{K}_{2} \mathrm{Cr}_{2} \mathrm{O}_{7}$, em meio fortemente ácido $\left(\mathrm{H}_{2} \mathrm{SO}_{4}\right.$ e $\left.\mathrm{H}_{3} \mathrm{PO}_{4}\right)$, sendo posteriormente titulado o excesso de $\mathrm{K}_{2} \mathrm{Cr}_{2} \mathrm{O}_{7}$, que não reagiu com carbono, com uma solução de sulfato ferroso amoniacal, na presença de solução indicadora de difenilamina. O teor de carbono orgânico total é calculado a partir do volume de sulfato ferroso amoniacal consumido.

\subsubsection{Nitrogênio (NKT)}

O termo nitrogênio Kjeldahl total (NKT) refere-se à combinação da amônia e do nitrogênio orgânico. A determinação de NKT é um método de referência para a determinação do nitrogênio, sendo o método clássico Kjeldahl satisfatório para a análise de 
$\mathrm{N}_{\text {total }}$ para a maioria dos compostos nitrogenados que ocorrem nos solos e plantas (Cotta et al., 2006).

O método utilizado nas Análises de nitrogênio é baseado no método 4500-Norg C Semi-Micro-Kjeldahl Method, (Standard Methods, 1998), onde a determinação de nitrogênio é realizada a partir da determinação de nitrogênio Kjeldahl total. Inicialmente, procede-se a digestão de uma alíquota de aproximadamente $0,25 \mathrm{~g}$ da massa úmida, que é transferida com o mínimo de água necessária para um tubo de quartzo. Em seguida, adiciona-se solução digestora (sulfato de potássio, sulfato de cobre e ácido sulfúrico) e essa solução é levada para um bloco digestor a $180^{\circ} \mathrm{C}$ por duas horas e meia, aumentando-se a temperatura para $380^{\circ} \mathrm{C}$, por mais duas horas e meia. Depois de frio, solubiliza-se com um pouco de água destilada e avoluma-se para balão volumétrico de $50 \mathrm{~mL}$.

Após esta digestão as amostras foram destiladas utilizando um destilador Bucchi k360 , onde o volume final da digestão é destilado por um minuto e trinta segundos em potência de $95 \%$, para que a amônia seja liberada e acrescenta-se uma solução de hidróxido de sódio. O destilado é recolhido em uma solução ácida e posteriormente levado para Análise em cromatógrafo iônico onde determina-se o NKT.

Para o cálculo dos resultados finais levam-se em conta os valores de umidade e o resultado final é expresso na base seca.

\subsubsection{Metais e fósforo - ICP OES e FG AAS}

Para as análises por ICP OES e FG AAS é necessário que se faça um prétratamento nas amostras. Este pré-tratamento consiste de uma digestão ácida, em sistema fechado, que se faz necessário para a solubilização dos elementos em estudo, conforme recomendado pela Agência Americana de Proteção Ambiental - método US EPA 3051A (US EPA, 2007). Com esse procedimento, analisa-se a concentração extraível de metais nos sedimentos. 


\subsubsection{Digestão das amostras de sedimentos (ICP OES, GF AAS)}

Para a determinação de metais e fósforo realizadas por ICP OES e para as determinações de $\mathrm{Cd}, \mathrm{Pb}$ e $\mathrm{As}$, por GF $\mathrm{AAS}$, as amostras passaram pelo processo de secagem a $40{ }^{\circ} \mathrm{C}$ em estufa com circulação de ar, separadas em frações de até $2 \mathrm{~mm}$ e em seguida, maceradas com gral e pistilo de ágata, antes de serem analisadas. As amostras foram digeridas segundo o método US EPA 3051A (US EPA, 2007), fazendo dois processos de digestão, onde para os elementos $\mathrm{Al}, \mathrm{Ba}, \mathrm{Be}, \mathrm{Cr}, \mathrm{Fe} \mathrm{Mg}, \mathrm{Ag}, \mathrm{V}$ e $\mathrm{Sn}$, pesou-se aproximadamente $0,50 \mathrm{~g}$ de amostra, adicionou-se $3 \mathrm{~mL}$ de $\mathrm{HCl}$ e $9 \mathrm{~mL}$ de $\mathrm{HNO}_{3}$ concentrado e, em seguida, digeriu-se a amostra em forno de micro-ondas para o restante dos elementos analisados a digestão foi realizada com aproximadamente de $0,50 \mathrm{~g}$ de amostra na qual foi adicionada $10 \mathrm{~mL}$ de $\mathrm{HNO}_{3}$ e digerida em digestor de micro-ondas; para estas digestões foi utilizado um digestor de micro-ondas da marca CEM, modelo 2100. Após a digestão o conteúdo foi filtrado em papel filtro Whatman 40 e avolumado em balão volumétrico de $50 \mathrm{~mL}$.

Posteriormente, as amostras digeridas foram encaminhadas para Análise nos equipamentos ICP OES e GF AAS.

\subsection{Determinação por ICP OES (fósforo e metais)}

As análises foram realizadas por meio da técnica de ICP OES, onde foi utilizado o equipamento ICP OES modelo Spectro flame Modula S, da SPETRO, equipamento pertencente ao Laboratório de Química Inorgânica (ELAI - CETESB). Para as determinações de fósforo utilizou-se a linha de $178 \mathrm{~nm}$, que foi escolhida por possuir somente o iodo como interferente e apresentar uma maior sensibilidade.

Antes do inicio das análises o equipamento passou por um ajuste dos parâmetros de medidas e um alinhamento das energias de emissão.

O equipamento utilizado para as análises por ICP OES possui um plasma de argônio com configuração radial, células fotomultiplicadoras, amostrador automático, o qual é equipado com uma bomba peristáltica para inserção da amostra no equipamento, gerador de potência de $1200 \mathrm{WRF}$ de 27,12 MHz e também uma câmara de nebulização, que tem o papel de conduzir a amostra até a tocha. 
Para a realização de determinações de elementos de forma eficiente, é necessário otimizar as condições do plasma para que ele trabalhe no chamado modo robusto. A robustez é a capacidade do sistema ICP para aceitar uma mudança na concentração dos principais elementos, ácidos e outros elementos sem qualquer variação significativa na intensidade da linha dos analítos.

Foi verificado também o tempo de aquecimento recomendado para que o equipamento dê respostas satisfatórias. Este tempo está relacionado com a estabilização do gerador de frequência e com o plasma, a partir do ponto do qual ele é ligado. O RSD e as contagens por segundo obtidas para o $\mathrm{Ba}(\mathrm{II})$ 405, o $\mathrm{Ar}$ 404, o Ni(II) 231 e o Zn(II) 206 são bons indicativos para a avaliação deste tempo, que nos instrumentos mais novos raramente excede 15 minutos.

Estas linhas também servem para evidenciar a estabilidade do instrumento a longo prazo, que se estiverem em um patamar de desvios inferior a 3\% indicam que não há necessidade de recalibração do instrumento.

O nível de radiação de fundo e a relação deste com o sinal analítico também devem ser verificados com uma linha em Baixa UV e outra dentro dos comprimentos de UV, para o qual foi utilizado P a $179 \mathrm{~nm}$ e o Mn a $253 \mathrm{~nm}$.

Após este ajuste, realizou-se uma calibração utilizando-se soluções com concentrações conhecidas obtidas a partir da diluição de uma solução padrão rastreável e com concentração certificada. A calibração foi feita para cada conjunto de elementos determinados, Para a leitura utilizou-se as condições de operação para cada elemento determinado, conforme descrito na TAB 3.2. 
TABELA 3.2-Condição de operação do ICP OES: elementos e as respectivas linhas de emissão e os valores de limite de detecção (LD) da técnica

\begin{tabular}{cccccc}
\hline Elemento & $\begin{array}{c}\text { Linha de emissão } \\
(\mathbf{n m})\end{array}$ & $\begin{array}{c}\text { LD } \\
\left(\mathbf{m g ~ k g} \mathbf{~}^{-\mathbf{1}}\right)\end{array}$ & Elemento & $\begin{array}{c}\text { Linha emissão } \\
(\mathbf{n m})\end{array}$ & $\begin{array}{c}\text { LD } \\
\left(\mathbf{m g ~ k g}^{-\mathbf{1}}\right)\end{array}$ \\
\hline $\mathbf{A l}$ & 308,215 & 0,03 & $\mathrm{Fe}$ & 259,940 & 0,009 \\
$\mathbf{B e}$ & 313,042 & 0,0004 & $\mathrm{Mg}$ & 279,079 & 0,02 \\
$\mathbf{B a}$ & 455,403 & 0,001 & $\mathrm{Mn}$ & 257,610 & 0,0007 \\
$\mathbf{C a}$ & 317,933 & 0,15 & $\mathrm{Mo}$ & 202,030 & 0,008 \\
$\mathbf{C r}$ & 267,716 & 0,007 & $\mathrm{Ni}$ & 231,604 & 0,005 \\
$\mathbf{C o}$ & 228,616 & 0,005 & $\mathrm{~V}$ & 292,402 & 0,008 \\
$\mathbf{C u}$ & 324,754 & 0,002 & $\mathrm{Zn}$ & 213,856 & 0,002 \\
\hline
\end{tabular}

Para a calibração do equipamento, foi construída a curva analítica preparada a partir de três soluções, S1, S2 e S3 - estas preparadas a partir de soluções de referência certificadas - e o branco, que foram submetidos ao mesmo procedimento de digestão que as amostras. Feito isto, levantou-se as curvas de calibração construídas com um branco e três soluções (S1, S2 e S3), para cada elemento. Para a preparação desta curva foram preparadas soluções com concentrações pré-determinadas a partir de uma solução padrão certificada.

A verificação da precisão e exatidão da metodologia para a determinação de Fósforo e metais foi realizada por meio da Análise dos seguintes materiais de referência certificados: WQB-3 (Lake Ontario Blended Sediment for Trace Elements Environmental Canada), NIST SRM 2710A (Montana Soil) e SRM 1646 (Estuarine sediment) que possuem valores certificados de concentração para os elementos Ag, Al, Ba, Be, Ca, Cd, Co, Cr, Cu, Fe, Li, Mg, Mn, Mo, Ni, P, Pb, Sc, Sr, Sn, Ti, V, Zn.

\subsection{Análise por GF AAS}

Por meio da técnica GF AAS foram determinados os elementos $\mathrm{Cd}, \mathrm{Pb}$ e As. Utilizou-se o equipamento de GF AAS, modelo Analyst 600, da Perkin Elmer.

Antes de iniciar as análises das amostras foi realizado o ajuste do equipamento, o levantamento das curvas analíticas, para as quais se utilizaram soluções diluídas 
preparadas a partir de uma solução estoque padrão certificada conforme TAB 3.3, onde estão descritas as concentrações das soluções utilizadas para calibração do GF AAS.

TABELA 3.3 - Soluções utilizadas na construção da curva de calibração para as determinações por meio da técnica GF AAS

\begin{tabular}{cccc}
\hline \multirow{2}{*}{$\begin{array}{c}\text { Soluções de } \\
\text { calibração }\end{array}$} & \multicolumn{3}{c}{$\begin{array}{c}\text { Concentração Calculada } \\
\left(\boldsymbol{\mu g} \mathbf{~ L}^{-\mathbf{1}}\right)\end{array}$} \\
\cline { 2 - 4 } & $\mathbf{A s}$ & $\mathbf{C d}$ & $\mathbf{P b}$ \\
\hline Branco & 0 & 0 & 0 \\
S1 & 10 & 0,5 & 5 \\
S2 & 50 & 2,5 & 25 \\
S3 & 100 & 5,0 & 50 \\
\hline
\end{tabular}

Conforme recomendação do fabricante do equipamento de GF AAS (Perkin Elmer), foi utilizada solução de modificador químico de 0,005 mg Pd + 0,003 mg $\mathrm{Mg}\left(\mathrm{NO}_{3}\right)_{2}$. O sinal analítico foi determinado a partir da área do pico de absorção, onde se utilizou o modo de regressão linear para o ajuste da curva. A TAB 3.4 apresenta os parâmetros de determinação de $\mathrm{As}, \mathrm{Cd}$ e $\mathrm{Pb}$ utilizados no equipamento.

TABELA 3.4 - Parâmetros de determinação de As, Cd e Pb ajustados para análise por GF AAS

\begin{tabular}{cccc}
\hline Parâmetros de determinação & $\mathrm{As}$ & $\mathrm{Cd}$ & $\mathrm{Pb}$ \\
\hline Comprimento de onda (nm) & 193,7 & 228,8 & 283,3 \\
Fenda (nm) & 0,7 & 0,7 & 0,7 \\
\hline
\end{tabular}

A verificação da precisão e exatidão da metodologia para a determinação dos elementos $\mathrm{As}, \mathrm{Cd} \mathrm{e} \mathrm{Pb}$, foi realizada por meio da Análise dos seguintes materiais de referência certificados: WQB-3 (Lake Ontario Blended Sediment for Trace Elements - 
Environmental Canada), NIST SRM 2710A (Montana Soil) e SRM 1646 (Estuarine sediment), que possuem valores certificados de concentração para esses elementos.

\subsection{Método direto de Análise de mercúrio}

O mercúrio total foi determinado por meio da técnica de análise direto de mercúrio, nas amostras de sedimento. Essa técnica não necessita de nenhum pré-tratamento das amostras, entretanto as amostras utilizadas nesta Análise foram secas a $40^{\circ} \mathrm{C}$ e passadas em peneira de $2 \mathrm{~mm}$. Em seguida, as amostras foram pesadas e uma massa conhecida, cerca de 0,05g, foi encaminhada para Análise no equipamento de Análise direta de mercúrio, da marca Millestone modelo DMA-80.

A verificação da precisão e exatidão da metodologia para a determinação de Hg foi feita por meio da análise dos materiais de referência certificados NIST SRM 2702 (Inorganics in Marine Sediment), SRM 2709 (San Joaquim Soil) e o IAEA 405 (Trace and Major Elements in Estuarine Sediment), que possuem valores certificados para $\mathrm{Hg}$ total.

\subsection{Aceitação dos resultados (ICP OES, FG AAS, método direto de Análise de mercúrio)}

Segundo o INMETRO (2010), sempre que possível, os materiais de referência certificados (MRC) devem ser utilizados no processo de validação de um método de ensaio.

Os processos normalmente utilizados para avaliar a tendência de um método incluem, entre outros, o uso de materiais de referência. A tendência, quando aplicada a uma série de resultados de ensaio, implica numa combinação de componentes de erro aleatórios e sistemáticos. A determinação da tendência com relação aos valores de referência apropriados é importante no estabelecimento de erros aleatórios e sistemáticos (INMETRO, 2010), sendo que tendência é uma avaliação numérica da exatidão.

O uso correto dos MRC consiste em sua utilização para avaliar o desempenho do laboratório. Na avaliação da tendência utilizando um MRC, os valores obtidos pelo 
laboratório devem ser comparados com os valores certificados no material de referência. Para esta comparação podem ser utilizados diversos critérios de decisão, entre os quais:

* Erro relativo;

* Índice $\mathrm{z}$-score;

* Erro normalizado.

Já a precisão, normalmente é determinada para circunstâncias específicas de medição e as três formas mais comuns de expressá-la são: por meio da repetitividade, precisão intermediaria e da reprodutividade, sendo usualmente expressa pelo desvio padrão e coeficiente de variação, sendo este ultimo conhecido como desvio padrão relativo (DPR) (INMETRO, 2010).

O critério de aceitação dos resultados baseia-se no fato de que a partir dos materiais de referências certificados (MRC), podemos calcular tanto a precisão como a exatidão do método analítico.

Segundo o INMETRO (2010), uma forma de se avaliar a exatidão do método é por meio do cálculo do erro relativo. Logo para verificar a exatidão dos métodos utilizados foi calculado o erro relativo, dado em porcentagem, conforme equação 3.1, para o qual foi utilizado o valor médio determinado e o valor certificado do material de referência utilizado.

$$
E_{r e l}(\%)=\frac{X_{L a b}-X_{w}}{X_{w}} \times 100
$$

Onde:

$\mathrm{E}_{\text {rel }}$ - erro relativo calculado $(\%)$;

$\mathrm{X}_{\mathrm{lab}}$ - valor obtido experimentalmente;

$\mathrm{X}_{\mathrm{v}}$ - valor aceito como verdadeiro (valor certificado do material de referência)

Ainda segundo o INMETRO (2010), a avaliação da precisão do método das medições pode ser realizada por meio do desvio padrão relativo (DPR), expresso em porcentagem e que foi empregado no presente trabalho. O DPR é calculado a partir da equação 3.2 . 


$$
D P R=\frac{D P}{C M D} \times 100
$$

Onde:

DP - desvio-padrão;

CMD - concentração média determinada

\subsection{Limites de Detecção (LD) e Quantificação (LQ) dos métodos ICP OES, GF AAS e determinação direta de mercúrio}

Quando são realizadas medidas em amostras com baixos níveis do analíto ou de uma propriedade, como por exemplo, análise de traços, é importante saber qual o menor valor de concentração do analíto ou da propriedade que pode ser detectado pelo método (INMETRO, 2010).

Para qualquer método quantitativo, existe uma faixa de concentrações do analíto ou valores da propriedade no qual o método pode ser aplicado. Todo experimento de determinação da faixa de trabalho é iniciado pela escolha de uma faixa preliminar. A faixa de trabalho deve cobrir a faixa de aplicação para a qual o ensaio vai ser usado (INMETRO, 2010).

O limite de detecção é definido como a concentração mínima de uma substância medida e declarada com $95 \%$ ou $99 \%$ de confiança de que a concentração do analíto é maior que zero. O limite de Quantificação é a menor concentração do analíto que pode ser quantificada com um nível aceitável de precisão e veracidade. A diferença entre os Limites de Detecção (LD) e Quantificação (LQ) é a ordem de grandeza das incertezas associadas (Bostelmann, 2006).

Analisando-se, por exemplo, sete replicatas, têm-se 7-1=6 graus de liberdade de uma matriz de branco da amostra com adição da menor concentração aceitável do analíto. Assim, com o valor de t unilateral para 99\% de confiança, o LD é igual a 3,143 vezes o desvio padrão amostral.

O Limite de Quantificação (LQ) corresponde, normalmente, ao padrão de calibração de menor concentração (excetuando-se o branco). Em geral, é considerado como média do branco mais 5, 6 ou 10 vezes o desvio padrão (INMETRO, 2010). 
Este processo foi utilizado para o cálculo dos limites de Quantificação para as técnicas: ICP OES, FG AAS e Análise direta de mercúrio.

\subsection{Análise por Ativação com Nêutrons Instrumental (INAA)}

A INAA constitui-se numa técnica comparativa, na qual a amostra e materiais de referência são irradiados conjuntamente e as medidas da atividade gama, são realizadas nas mesmas condições. Os resultados fornecem a concentração total dos elementos determinados.

A TAB 3.5 apresenta os radioisótopos utilizados na quantificação dos elementos de interesse pela técnica de INAA, bem como as suas respectivas energias gama de decaimento e tempos de meia-vida. 
TABELA 3.5 - Radioisótopos identificados nos espectros de emissão gama utilizados para determinação dos elementos de interesse pela técnica de INAA, suas respectivas energias e meias-vidas $\left(\mathbf{T}_{1 / 2}\right)$

\begin{tabular}{|c|c|c|c|c|c|}
\hline Radioisótopo & $\begin{array}{c}\text { Energia } \\
(\mathrm{keV})\end{array}$ & $\begin{array}{c}\text { Tempo de } \\
\text { Meia-vida }\end{array}$ & Radioisótopo & $\begin{array}{c}\text { Energia } \\
(\mathrm{keV})\end{array}$ & $\begin{array}{l}\text { Tempo de } \\
\text { Meia-vida }\end{array}$ \\
\hline${ }^{76} \mathrm{As}$ & 559,1 & 26,32 horas & ${ }^{147} \mathrm{Nd}$ & 91,1 & 10,98 dias \\
\hline${ }^{131} \mathbf{B a}$ & 496,26 & 11,8 dias & & 531,01 & \\
\hline \multirow[t]{2}{*}{${ }^{82} \mathrm{Br}$} & 554 & \multirow[t]{2}{*}{ 35,3 horas } & ${ }^{86} \mathbf{R b}$ & 1076,6 & 18,66 dias \\
\hline & 776,52 & & ${ }^{122} \mathrm{Sb}$ & 564,24 & 2,70 dias \\
\hline${ }^{47} \mathbf{C a}$ & 159 & 4,54 dias & ${ }^{124} \mathrm{Sb}$ & 1690,98 & 60,20 dias \\
\hline${ }^{141} \mathrm{Ce}$ & 145,4 & 32,5 dias & ${ }^{46} \mathrm{Sc}$ & 889,28 & 83,81 dias \\
\hline \multirow[t]{2}{*}{${ }^{60} \mathrm{Co}$} & 1173,2 & 5,27 anos & & 1120 & \\
\hline & 1332,5 & & ${ }^{75} \mathrm{Se}$ & 264,6 & 119,77 dias \\
\hline${ }^{57} \mathrm{Cr}$ & 320,1 & 27,7 dias & ${ }^{153} \mathrm{Sm}$ & 103,18 & 46,27 horas \\
\hline${ }^{134} \mathrm{Cs}$ & 795,85 & 2,06 anos & ${ }^{160} \mathrm{~Tb}$ & 879,38 & 72,3 dias \\
\hline${ }^{152} \mathbf{E u}$ & $\begin{array}{c}121 \\
1408\end{array}$ & 13,33 anos & ${ }^{233} \mathbf{P a}$ & $\begin{array}{c}312,01 \\
340\end{array}$ & 27 dias \\
\hline${ }^{59} \mathrm{Fe}$ & $\begin{array}{c}1099,25 \\
1291,6\end{array}$ & 44,5 dias & ${ }^{139} \mathbf{N p}$ & $\begin{array}{c}228,18 \\
277,6\end{array}$ & 2,36 dias \\
\hline${ }^{42} \mathbf{K}$ & $\begin{array}{c}1524 \\
328,7\end{array}$ & 12,36 horas & ${ }^{169} \mathrm{Yb}$ & $\begin{array}{l}177,21 \\
197,96\end{array}$ & 32,02 dias \\
\hline${ }^{140} \mathrm{La}$ & $\begin{array}{c}487 \\
1596,21\end{array}$ & 40,27 horas & ${ }^{175} \mathrm{Yb}$ & $\begin{array}{l}282,52 \\
396,33\end{array}$ & 4,19 dias \\
\hline${ }^{177} \mathbf{L u}$ & 208,36 & 6,71 dias & ${ }^{65} \mathrm{Zn}$ & 1115,5 & 243,9 dias \\
\hline${ }^{24} \mathrm{Na}$ & 1368,6 & 14,96 horas & & & \\
\hline
\end{tabular}

\subsubsection{Irradiação e contagem}

As amostras e materiais de referência foram pesados (cerca de $150 \mathrm{mg}$ cada) em balança analítica SHIMADZU modelo LIBROR série AEL-40SM - e acondicionados em pequenos invólucros de duplo polietileno previamente descontaminados com $\mathrm{HNO}_{3}$ diluído e água ultra pura (Milli-Q).

Amostras de sedimento (duplicata) e materiais de referência, após pesagem, foram irradiadas por oito horas, sob um fluxo de nêutrons térmicos de 1 a $5 \times 10^{12} \mathrm{ncm}^{-2} \mathrm{~s}^{-1}$, no Reator de Pesquisa IEA-R1 do IPEN/CNEN-SP. A primeira contagem foi realizada após um tempo de decaimento de 5 a 7 dias, por aproximadamente uma hora para amostras 
e materiais de referência. Os seguintes radioisótopos de $\mathrm{T}^{1 / 2}$ (meia-vida) intermediária: ${ }^{76} \mathrm{As},{ }^{82} \mathrm{Br},{ }^{42} \mathrm{~K},{ }^{140} \mathrm{La},{ }^{24} \mathrm{Na},{ }^{147} \mathrm{Nd},{ }^{239} \mathrm{~Np},{ }^{122} \mathrm{Sb},{ }^{153} \mathrm{Sm}$ e ${ }^{175} \mathrm{Yb}$ foram determinados.

A segunda contagem foi realizada após um tempo de decaimento de quinze a vinte dias, e um tempo de contagem idêntico ao utilizado na primeira contagem. Os seguintes radioisótopos de $\mathrm{T} 1 / 2$ longa: ${ }^{131} \mathrm{Ba},{ }^{141} \mathrm{Ce},{ }^{60} \mathrm{Co},{ }^{57} \mathrm{Cr},{ }^{134} \mathrm{Cs},{ }^{152} \mathrm{Eu},{ }^{59} \mathrm{Fe},{ }^{181} \mathrm{Hf}$, ${ }^{177} \mathrm{Lu},{ }^{233} \mathrm{~Pa},{ }^{86} \mathrm{Rb},{ }^{124} \mathrm{Sb},{ }^{46} \mathrm{Sc},{ }^{75} \mathrm{Se},{ }^{182} \mathrm{Ta},{ }^{160} \mathrm{~Tb},{ }^{169} \mathrm{Yb}$ e ${ }^{65} \mathrm{Zn}$, foram determinados.

Para a contagem das amostras e materiais de referência, utilizou-se detector de cristal semicondutor de germânio hiperpuro para a medida dos raios gama, associado a sistema eletrônico de aquisição de dados com analisador multicanal e computador. A resolução dos detectores é uma medida da habilidade em separar picos muito próximos em um espectro. Em geral, a resolução do detector é especificada em termos da largura na meia-altura dos fotopicos de 121,97 keV do Co-57 e 1332,49 keV do Co-60 (Glascock, 2010). No presente estudo, as resoluções foram de $0,9 \mathrm{keV}$ e $1,8 \mathrm{keV}$, respectivamente.

\subsubsection{Validação da metodologia de INAA}

Para verificação da precisão e exatidão do método foram analisados os materiais de referência certificados BEN (Basalt-IWG-GIT), WQB-3 (Lake Ontario Blended Sediment for Trace Elements - Environmental Canada) e SL 01 (Lake sediment, IAEA), que possuem valores certificados para quase todos os elementos determinados.

\subsubsection{Aceitação dos resultados de INAA}

Para a validação dos resultados obtidos pela técnica de INAA, é frequentemente utilizado o critério de Z-score (Bode, 1996). O cálculo da diferença padronizada ou valor de $\mathrm{Z}$ de um resultado analítico é dado pela equação 3.3.

$$
Z=\frac{C_{\tilde{i}}-C_{\text {ref }}}{\sqrt{\sigma_{\tilde{i}}^{2}+\sigma_{\text {ref }}^{2}}}
$$


Onde:

$\mathrm{C}_{\mathrm{i}}$ - concentração do elemento i na análise do MR;

$\mathrm{C}_{\text {ref- }}$ valor certificado de concentração ou de consenso para o elemento i;

$\sigma_{\mathrm{i}}$ - incerteza da concentração do elemento i na análise do MR;

$\sigma_{\text {ref }}-$ incerteza do valor de consenso certificado para o elemento i.

Segundo Bode (1996), o uso do valor de Z para aprovação dos resultados considera que se $|Z| \leq 3$, o resultado de concentração do elemento individual no material de referência que esta sendo analisado deve estar dentro de $99 \%$ do intervalo de confiança do valor esperado.

\subsubsection{Limites de Detecção (LD) e Quantificação (LQ)}

Para a técnica de INAA, o cálculo do limite de detecção foi realizado a partir da equação 3.4, na qual o valor de LD é dado em contagens por segundo (cps), valor convertido para a unidade de concentração $\left(\mathrm{mg} \mathrm{kg}^{-1}\right)$, por meio da equação 3.5.

$$
\begin{gathered}
\text { Atividade }(\text { cps })=\left(\frac{3 \sqrt{B G}}{T_{\text {vivo }}}\right) \\
L D_{\left(m g k g^{-1}\right)}=\left(\frac{3 \sqrt{B G}}{T_{\text {vivo }}}\right) \frac{U * m_{a}}{A}
\end{gathered}
$$

Onde:

BG - background do fotópico do elemento de interesse no espectro do material de referência;

$\mathrm{T}_{\text {vivo }}$ - tempo vivo do espectro do material de referência;

$\mathrm{U}$ - valor certificado no material de referência.

A - atividade, de um dado elemento no espectro do material de referência. 


\section{$\mathrm{m}_{\mathrm{a}}-$ massa da amostra $(\mathrm{g})$}

Já o limite de quantificação (LQ) foi calculado a partir do valor do limite de detecção, conforme equação 3.6.

$$
\mathrm{LQ}=3 \times \mathrm{LD}
$$

\subsection{Fator de Enriquecimento (EF)}

O fator de enriquecimento $(\mathrm{EF})$, definido como a dupla razão normalizada para um elemento de referência, é um índice usado como uma ferramenta para avaliar a extensão da poluição por metais (Audry et. al., 2004). Os metais Fe, Al e Sc são os mais usados para propósitos de normalização (Gomes et. al., 2009) e no presente estudo, utilizou-se o Sc como elemento normalizador. Os valores de referencia utilizados para sedimento no presente estudo foram os valores de UCC (Wedepohl,1995), NASC (Taylor \& Mclennan, 1985) e a concentração dos mesmos elementos na base de um dos perfis coletados (ponto 03) no presente estudo. Os valores de Sc foram aqueles obtidos por INAA (Tabela 4.24) e os demais valores, foram aqueles obtidos por INAA e pelas outras técnicas analíticas.

Para cálculo do FE utilizou-se a Equação 3.7, conforme Dickinson et al (1996), Hornung et al (1989) e Abrahim et al (2005) (apud Rezaee, 2011).

$$
\mathrm{FE}=\frac{\left(\frac{\text { elemento }]}{[\mathrm{Sc}]}\right)_{\text {amostra }}}{\left(\frac{[\text { elemento }]}{[\mathrm{Sc}]}\right)_{\text {referência }}}
$$

Onde:

$([\text { elemento }] /[\mathrm{Sc}])_{\text {amostra }}=$ razão entre a concentração do elemento de interesse e a concentração de Sc na amostra.

$\left([\text { elemento] } /[\mathrm{Sc}])_{\text {referência }}=\right.$ razão entre a concentração de referência do elemento de interesse e a concentração de referência do Sc. 
Por convenção, se o valor de $0,5<\mathrm{EF}<1,5$, considera-se que os metais traço são provenientes totalmente de contribuição crustal (por exemplo, produto de intemperismo) e um valor de $\mathrm{EF}>1,5$, é indicativo de que a fonte principal é de contribuição antrópica. Quanto maior o valor de EF, maior o grau de poluição de origem antrópica (Zhang \& Liu, 2002).

\subsection{0. Índice de Geoacumulação (IGeo)}

O índice de geoacumulação é utilizado desde a década de 60 e é largamente empregado em estudos de metais traço na Europa (Yaqin et al, 2008). Para o presente estudo, foram calculados os Índices de Geoacumulação (Igeo) para os resultados de concentração das amostras obtidos pelas técnicas analíticas, adotando os mesmos valores de referência utilizados para os cálculos de EF (UCC, NASC e base do perfil). Para o cálculo do Igeo, foi utilizada a equação 3.8, conforme Müller (1969), Stoffers et al (1986) e Abrahim et al (2005) (apud Rezaee, 2011).

$$
\text { Igeo }=\log _{2}\left(\frac{C_{u m}}{1,5 C_{r e f}}\right)
$$

Onde:

$C_{a m}=$ concentração do elemento de interesse na amostra;

$C_{r e f}=$ concentração de referência do elemento de interesse.

O Igeo é associado com uma escala qualitativa de intensidade de poluição, descrita na Tabela 3.6, desenvolvida também por G. Muller (1969), Stoffers et al (1986) e Abrahim et al (2005) (apud Rezaee et al, 2011). 
TABELA 3.6 - Classificação do nível de poluição a partir dos valores de IGeo calculados

\begin{tabular}{cc}
\hline IGeo & Nível de poluição \\
\hline$<\mathbf{0}$ & Não contaminados \\
0 a $\mathbf{1}$ & Não contaminado a moderadamente \\
$\mathbf{1}$ a 2 & Moderadamente contaminado \\
& Moderadamente a fortemente \\
$\mathbf{2}$ a 3 & contaminado \\
\hline $\mathbf{3}$ a 4 & Fortemente contaminado \\
\hline $\mathbf{4}$ a 5 & Muito fortemente contaminado \\
\hline$>\mathbf{5}$ & \\
\hline
\end{tabular}

\subsection{Tratamento estatístico dos dados - Análise estatística multivariada}

Uma análise estatística descritiva da amostra é fundamental para resumir algumas informações, e estas informações são utilizadas muitas vezes para tomada de decisões e formação de modelos estatísticos, mas para que se obtenham bons resultados numa análise estatística, é necessário também que se tenha clareza dos conceitos envolvidos e por isto a seguir são apresentados os conceitos utilizados.

\subsubsection{Análise Fatorial}

A Estatística Multivariada permite o estudo de fenômenos complexos, pois realiza o tratamento de diversas variáveis simultaneamente, mesmo quando não se conhece o modelo teórico das relações entre as variáveis. A análise fatorial, uma das técnicas da estatística multivariada, pode ser aplicada quando há uma grande quantidade de dados e 
busca-se a sua sumarização, com fatores latentes, que são definidos através de comportamento semelhante entre variáveis.

A análise fatorial inclui a análise de componentes principais e análise de fatores comuns. A principal função das diferentes técnicas de análise fatorial é reduzir uma grande quantidade de variáveis observadas a um número reduzido de fatores. Os fatores representam as dimensões latentes (construtos) que resumem ou explicam o conjunto de variáveis observadas (Hair et al, 2005, Apud Figueiredo Filho, 2010)

Em termos gerais, a análise fatorial aborda o problema de analisar a estrutura das inter-relações (correlações) entre um grande número de variáveis, assim a análise fatorial permite ao pesquisador identificar as dimensões separadas da estrutura e então determinar o grau em que cada variável é explicada por cada dimensão.

A análise fatorial é uma técnica de interdependência nas quais todas as variáveis são simultaneamente consideradas, cada uma relacionada com todas as outras, empregando ainda o conceito de variável estatística e a composição linear de variáveis. Estas variáveis estatísticas (fatores) são formadas para maximizar seu poder de explicação do conjunto inteiro de variáveis e não para prever uma variável dependente (Costa, 2006).

Há, basicamente, quatro passos na condução da análise fatorial: (Costa, 2006)

a) Entrada de dados - geralmente tomam forma de um conjunto de valores de variáveis para cada objeto na amostra;

b) Cálculo das correlações entre as variáveis - para este passo podem ser utilizadas duas abordagens: análise fatorial Q (entre casos) ou R (entre variáveis), onde se procura agrupar as diferentes variáveis em alguns fatores específicos;

c) Extração inicial dos fatores - o objetivo da extração é encontrar um conjunto de fatores que formem uma combinação linear das variáveis originais ou da matriz de correlação;

d) Rotação da matriz - é necessária para ajudar na interpretação dos fatores. Há duas formas de fazer esta rotação: a rotação ortogonal (Varimax), que mantém os fatores não correlacionados e a rotação oblíqua, que torna os fatores correlacionados entre si. 


\subsubsection{Análise de Agrupamento (Cluster Analysis)}

Análise de Cluster é um grupo de técnicas multivariadas cujo objetivo primário é reunir objetos baseando-se nas características que eles possuem. A análise de cluster é comparável a análise fatorial em seu objetivo de agrupar estrutura, no entanto se diferem pelo fato da análise em cluster agrupar objetos, ao passo que a análise fatorial é primariamente voltada para o agrupamento de variáveis. Adicionalmente, a análise fatorial faz os agrupamentos baseada em padrões de variação (correlação) nos dados enquanto que a análise em cluster faz os agrupamentos com base em distância (proximidade) (Hair Júnior et al., 2010).

A análise de cluster classifica objetos, em uma disposição de característica selecionada pelo usuário. Os clusters resultantes devem exibir alta homogeneidade interna (within-cluster) e uma alta heterogeneidade externa (between-cluster). Portanto, se a classificação for bem sucedida, os objetos dentro do cluster estarão bem próximos quando plotados, e clusters diferentes estarão bastante distanciados. (Hair Júnior et al., 2010)

O objetivo primário da análise de cluster é definir a estrutura dos dados através da colocação das observações mais similares em grupos. Para cumprir esta tarefa precisamos sanar três questões básicas, segundo Hair Junior et al.,(2010).

a) Como medir a similaridade? É requerido o método de simultaneamente comparar observações em duas variáveis $\left(\mathrm{V}_{1}\right.$ e $\left.\mathrm{V}_{2}\right)$. Muitos métodos são possíveis, incluindo a correlação entre objetos, ou talvez uma medida de sua proximidade em um espaço bidimensional, de modo que a distância entre observações indique similaridade.

b) Como formar clusters? Não importa quanta similaridade é medida, o procedimento precisa agrupar aquelas observações que sejam mais similares em um cluster, logo determinar a qual cluster pertence cada observação para cada conjunto de clusters formados.

c) Quantos grupos formar? A tarefa final é selecionar um grupo de clusters como a solução final. Tendo feito isto, o pesquisador encara uma troca: menos clusters e menos homogeneidade interna versus um grande número de clusters e mais homogeneidade interna. Uma estrutura simples, apontada em direção a parcimônia reflete-se em se ter quanto menos clusters possíveis. Ainda conforme o número de clusters 
diminui, a heterogeneidade dentro dos clusters necessariamente aumenta. Ainda, um equilíbrio deve ser feito entre definir a estrutura mais básica (menos clusters) que ainda assim alcance um nível aceitável de heterogeneidade entre os cluters. 


\section{CAPÍTULO 4}

\section{RESULTADOS E DISCUSSÃO}

São apresentados a seguir, os resultados das determinações obtidos pelas técnicas de INAA, ICP OES, GF AAS, método direto de análise de mercúrio, nitrogênio, análise granulométrica, umidade e carbono orgânico total (COT), nas amostras de sedimentos coletadas no reservatório Itupararanga.

\subsection{Análise Granulométrica, Conteúdo de Matéria Orgânica (MO) e Nitrogênio Kjeldahl Total}

Os resultados de análise granulométrica, realizado no laboratório da CETESB em Limeira e carbono orgânico total, realizados no Laboratório da CETESB em São Paulo, são apresentados na TAB 4.1 .

A análise granulométrica das amostras (TAB 4.1 e FIG 4.1), mostra que o ponto Pt 01, apresenta grande quantidade de areia, sendo classificado como areia-síltica. Podemos observar também que há uma redução significativa da porcentagem de areia para a segunda fração (de 60,1 para 26,15\%) onde a classificação passa a ser argilo-arenosa. Este ponto se difere bastante em relação aos outros pontos quanto à classificação granulométrica. Nos demais pontos de amostragem têm-se uma predominância de argila síltica para quase todas as frações analisadas, sendo as únicas exceções as frações P2-50 e P4-30, onde a classificação foi de silte-argiloso. 
A granulometria dos sedimentos é de grande interesse para a compreensão da hidrodinâmica dos lagos (Amorim, 2009). Uma maior quantidade de finos, representados por elevadas quantidades de silte e argila e menor de areia, configuram uma significativa possibilidade de se encontrar contaminantes que possibilitam verificar a qualidade do sedimento presente naquele corpo hídrico. (CESTEB, 2008)

Mudroch e Macknight (1997 - apud Quináglia, 2006) citam que muitos estudos apontam para uma correlação entre a concentração de metais e o tamanho das partículas do sedimento, que sugerem concentrações mais elevadas nas partículas finas. Entretanto Quináglia (2006), aponta que outras frações granulométricas também são utilizadas com diversos propósitos e que comparações de resultados em diferentes tamanhos de partículas podem ser questionáveis, já que a distribuição de metais é variável.

A alta concentração da fração areia observada no ponto Pt 01, classificado como areia síltica, sugere a possibilidade de uma diminuição na concentração de alguns elementos metálicos no sedimento localizado na região deste ponto de coleta.

Em contrapartida, os altos teores de argila encontrados nos pontos Pt 02, Pt 03 e Pt 04, sugerem uma maior concentração de alguns metais no sedimento localizado na região destes pontos, em relação ao Pt01.

A caracterização do material orgânico sedimentar é de grande importância e utilidade para se conhecer a origem e os processos aos quais os ambientes estiveram submetidos em um passado recente ou mais antigo (Amorim et al., 2009b). Segundo Dias (2004), o método de Gaudette, trata-se de uma avaliação quantitativa baseada na ocorrência de certa quantidade de matéria orgânica presente na amostra. Por essa razão, o que se determina é o parâmetro denominado por "carbono orgânico", que vem a ser o constituinte maior (em geral, considerado 85\%) da matéria orgânica.

O teor de matéria orgânica (MO) foi calculado a partir da porcentagem de carbono orgânico (COT), segundo a equação (Meguro, 2000 Apud, Padial, 2008) realizada pela equação 4.1 ,

$$
\operatorname{MO}(\%)=\operatorname{COT}(\%) * 1,8
$$

Este cálculo pressupõe que a matéria orgânica possui $58 \%$ de carbono. 
Quanto aos teores de Nitrogênio e o Carbono Orgânico Total (COT) (Tabela 4.1) podemos observar que no Pt 01 , ocorreu um aumento de concentração de $\mathrm{N}$ da fração P1-10 para a fração P1-20 e uma diminuição no teor de COT. No Pt 02, os valores das concentrações de ambos variaram minimamente, com exceção do P2-20. Para os pontos Pt 03 e Pt 04, os valores de COT e Nitrogênio apresentaram uma queda acentuada do topo para o fundo dos testemunhos, sendo que para o Pt 03, observou-se uma elevação destas concentrações na última fração (P3-60). Os valores elevados de nitrogênio provavelmente estão ligados ao uso agrícola da bacia.

Os valores de matéria orgânica e carbono orgânico total encontrados no presente estudo podem parecer valores altos, mas Bottino (2011), ao analisar a camada superior do sedimento do reservatório de Itupararanga sazonalmente, ao longo das quatro estações, encontrou valores entre 2,0 e $26,0 \%$ de matéria orgânica e para os valores de nitrogênio, uma variação de 270 a $4648 \mu \mathrm{g} \mathrm{g}^{-1}$.

A matéria orgânica nos sedimentos pode ser originada de fontes naturais (autóctone) e antrópicas (alóctone). O carbono orgânico alóctone possui grande importância para o metabolismo dos sistemas aquáticos, sendo que em concentrações elevadas pode causar prejuízos a esses sistemas (Bottino, 2011).

Diversos tipos de traçadores de matéria orgânica são utilizados para identificar as prováveis origens e os processos a que esta matéria esteve sujeita durante sua formação. Segundo Meyers \& Ishiwatary (1993, Apud, Amorim et al, 2009b) a razão carbono/nitrogênio $(\mathrm{C} / \mathrm{N})$ é um dos marcadores mais confiáveis para a indicação de fonte de matéria orgânica para um ecossistema. As relações molares $\mathrm{C} / \mathrm{N}$ com valores de 10 a 1000 caracterizam origem terrígena (ou continental) da matéria orgânica, de 6,6 (relação de Redfield) origem autóctone (aquela gerada dentro do próprio sistema) e valores entre 6,6 e 10, origem terrígena e aquático (Barreto, 2002).

Podemos observar na TAB 4.1, que a razão C/N, oscila entre 3,90 a 19,24, sendo o menor valor na base de um dos perfis (P3-60) e o maior valor, na base de outro perfil sedimentar (P1-20). Mas, como era de se esperar, observou-se que os valores superficiais sempre são superiores aos valores da base dos perfis. Esta variação nos valores da relação $\mathrm{C} / \mathrm{N}$, nos indica que a matéria orgânica nos sedimentos do Pt 01 (superfície) e Pt 02, que apresentam a razão $\mathrm{C} / \mathrm{N}$ maior que 10 indica origem Alóctone, que é típica de 
bacia de contribuição, ou seja, de origem terrígena (os sedimentos terrígenos são constituídos essencialmente por grãos de minerais, resultantes da erosão das rochas), já os Pt 03 e Pt 04, origem terrígena e aquática.

Entretanto, essa relação $(\mathrm{C} / \mathrm{N})$ deve ser utilizada com cuidado, uma vez que, para sedimentos mais arenosos e com baixos teores de matéria orgânica, os valores de $\mathrm{C} / \mathrm{N}$ são, geralmente, altos, o que pode levar a atribuições errôneas. Isso pode ser explicado devido ao sequestro preferencial do nitrogênio durante o início da decomposição da matéria orgânica. (Senatore, 2010)

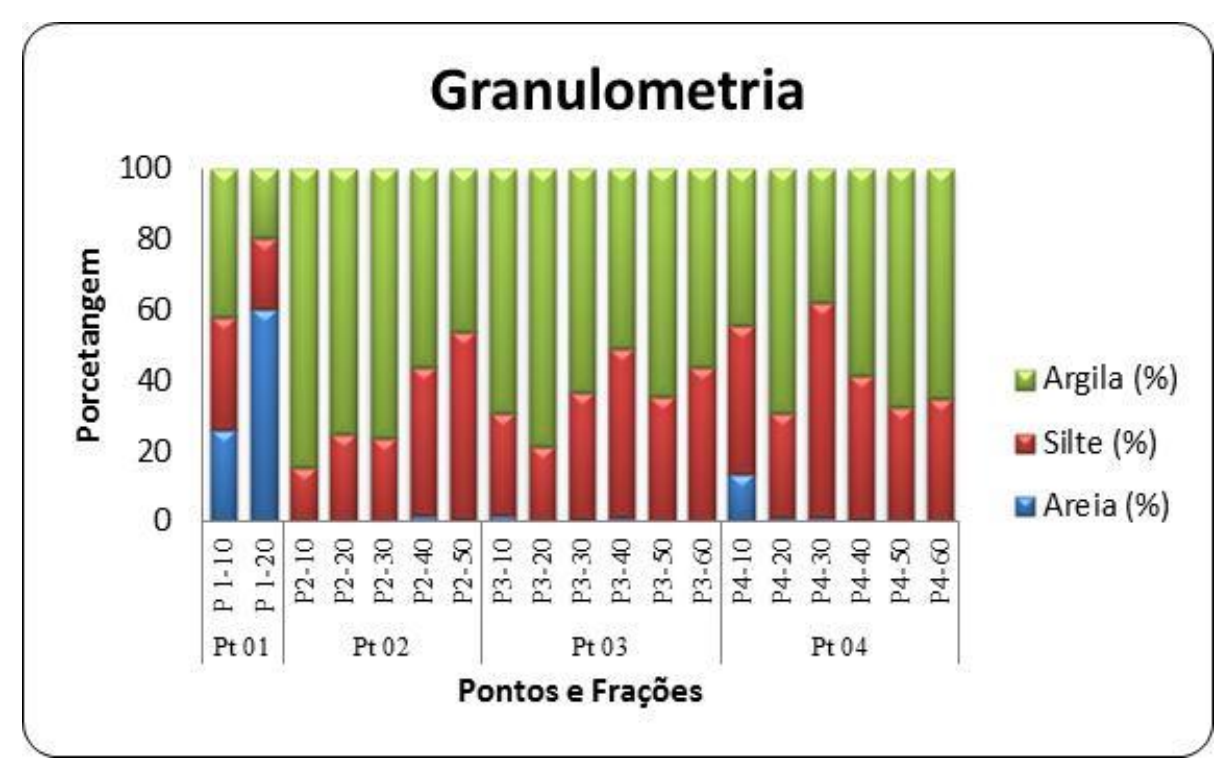

FIGURA 4.1 Porcentagem de Argila, Silte e Areia em cada fração das amostras de sedimento, por ponto amostrado 
TABELA 4.1- Resultados das análises granulométricas, umidade, Carbono Orgânico Total (COT), Nitrogênio (NKT) e relação COT/NKT

\begin{tabular}{|c|c|c|c|c|c|c|c|c|c|c|}
\hline Ponto & Amostra & $\begin{array}{c}\text { Areia } \\
(\%)\end{array}$ & $\begin{array}{l}\text { Silte } \\
(\%)\end{array}$ & $\begin{array}{c}\text { Argila } \\
(\%)\end{array}$ & $\begin{array}{c}\text { Classificação } \\
\text { Textural }\end{array}$ & $\begin{array}{c}\text { Umidade } \\
(\%)\end{array}$ & $\begin{array}{c}\text { NKT } \\
\left(\mathrm{mg} \mathrm{L}^{-1}\right)\end{array}$ & $\begin{array}{l}\text { COT } \\
(\%)\end{array}$ & $\begin{array}{c}\text { Matéria } \\
\text { orgânica } \\
(\%)\end{array}$ & COT/NKT \\
\hline \multirow{2}{*}{ Pt 01} & P $1-10$ & 26,15 & 31,89 & 41,96 & $\begin{array}{c}\text { Argila } \\
\text { Arenosa }\end{array}$ & 45,40 & 1715 & 3,30 & 5,94 & 19,24 \\
\hline & P $1-20$ & 60,10 & 20,14 & 19,76 & Areia siltica & 37,30 & 1281 & 1,68 & 3,02 & 13,11 \\
\hline \multirow{5}{*}{ Pt 02} & $\mathrm{P} 2-10$ & 0,18 & 15,40 & 84,42 & Argila Siltica & 52,30 & 2482 & 3,69 & 6,64 & 14,87 \\
\hline & P2-20 & 0,05 & 24,78 & 75,16 & Argila Siltica & 70,30 & 4116 & 4,41 & 7,94 & 10,71 \\
\hline & P2-30 & 0,05 & 23,47 & 76,47 & Argila Siltica & 75,00 & 2928 & 3,20 & 5,76 & 10,93 \\
\hline & $\mathrm{P} 2-40$ & 1,82 & 42,05 & 56,12 & Argila Siltica & 76,10 & 2691 & 3,52 & 6,34 & 13,08 \\
\hline & $P 2-50$ & 0,35 & 53,29 & 46,36 & Silte Argiloso & 74,50 & 2956 & 3,12 & 5,62 & 10,55 \\
\hline \multirow{6}{*}{ Pt 03} & P3-10 & 1,81 & 28,98 & 69,21 & Argila Siltica & 67,20 & 8307 & 7,93 & 14,27 & 9,55 \\
\hline & P3-20 & 0,10 & 21,39 & 78,51 & Argila Siltica & 73,10 & 5855 & 4,69 & 8,44 & 8,01 \\
\hline & P3-30 & 0,36 & 36,17 & 63,46 & Argila Siltica & 74,10 & 3190 & 3,45 & 6,21 & 10,82 \\
\hline & P3-40 & 1,01 & 47,93 & 51,06 & Argila Siltica & 75,60 & 3334 & 2,11 & 3,80 & 6,33 \\
\hline & P3-50 & 0,30 & 35,02 & 64,68 & Argila Siltica & 75,70 & 3913 & 2,13 & 3,83 & 5,44 \\
\hline & P3-60 & 0,23 & 43,56 & 56,21 & Argila Siltica & 84,30 & 6596 & 2,57 & 4,63 & 3,90 \\
\hline \multirow{6}{*}{ Pt 04} & P4-10 & 13,47 & 42,33 & 44,20 & Argila Siltica & 58,50 & 6939 & 7,48 & 13,46 & 10,78 \\
\hline & $\mathrm{P} 4-20$ & 0,95 & 29,96 & 69,09 & Argila Siltica & 67,20 & 4140 & 3,42 & 6,16 & 8,26 \\
\hline & P4-30 & 1,30 & 61,07 & 37,62 & Silte Argiloso & 71,50 & 4718 & 2,82 & 5,08 & 5,98 \\
\hline & $\mathrm{P} 4-40$ & 0,68 & 40,90 & 58,43 & Argila Siltica & 71,50 & 2867 & 2,50 & 4,50 & 8,72 \\
\hline & $\mathrm{P} 4-50$ & 0,16 & 32,09 & 67,75 & Argila Siltica & 73,10 & 3508 & 2,20 & 3,96 & 6,27 \\
\hline & P4-60 & 0,24 & 34,52 & 65,25 & Argila Siltica & 78,20 & 3215 & 2,06 & 3,71 & 6,41 \\
\hline
\end{tabular}

\subsection{Análises dos Sedimentos pelas Técnicas ICP OES, FG AAS e Análise Direta} de Mercúrio.

Os resultados das concentrações para os elementos determinados por ICP OES, FG AAS e Análise direta de mercúrio, nas amostras dos perfis sedimentares são apresentadas a seguir, bem como os resultados da validação e os limites de detecção e de quantificação do método e os resultados dos tratamentos estatísticos dos dados. 


\subsubsection{Validação da metodologia de ICP OES, FG AAS e Análise Direta de Mercúrio}

A validação destas metodologias foi realizada com a utilização de materiais de referência certificados, onde tanto para a determinação de metais por ICP OS e FG AAS, como para a ddeterminação de fósforo, foram analisados os materiais de referência certificados: WQB-3 (Lake Ontario Blended Sediment for Trace Elements Environmental Canada), NIST SRM 2710a (Montana Soil) e SRM 1646 (Estuarine sediment). Para a Análise direta de mercúrio utilizou-se os materiais de referência: NIST SRM 2702 (Inorganics in Marine Sediment), SRM 2709 (San Joaquim Soil) e o IAEA 405 (Trace and Major Elements in Estuarine Sediment).

A partir dos resultados das análises dos materiais de referência foram calculados os Erros Relativos (ER) e Desvio Padrão Relativo (DPR), que se encontram apresentados nas TAB 4.2, 4.3 e 4.4.

A partir dos dados da TAB 4.2, pode-se verificar em relação aos valores certificados, que o elemento $\mathrm{Mg}$, apresentou um resultado insatisfatório (valor de ER $>25 \%$ ), para o material WQB-3. Para o material NIST SRM 1646 (Tabela 4.3), somente o Mn apresentou resultado insatisfatório, valor que foi aceito porque tal erro pode ser devido ao erro que a diluição da amostra possa ter acrescentado ao erro. Além disso, apresentou valor satisfatório para o material SRM 2710 a

A partir dos dados da TAB $4.4\left(\right.$ SRM $\left.2710^{\mathrm{a}}\right)$, pode-se notar que somente o elemento Co apresentou resultado insatisfatório (valor de ER>25\%).

A partir da Análise destes materiais de referência pode-se dizer que, em geral, os valores obtidos na análise desses materiais mostraram-se bons para quase todos os elementos determinados, com erros relativos inferiores a $25 \%$. Entretanto a determinação de Sr, presente apenas no material WQB-3 não foi satisfatória, apresentando valores bastante divergentes em relação aos valores certificados.

Segundo a TAB 4.5, onde se encontram os resultados obtidos nas análises dos materiais de referência para a validação da Análise de fósforo por ICP OES, podemos considerar que todos os resultados foram satisfatórios, com erros relativos inferiores a 
$25 \%$.

A partir dos resultados da TAB 4.6, pode-se verificar em relação aos valores certificados, que os elementos $\mathrm{As}, \mathrm{Cd}$ e $\mathrm{Pb}$, apresentaram resultados satisfatórios (valores de $\mathrm{ER}<25 \%$ ). A partir da Análise destes materiais de referência pode-se dizer que, os valores obtidos na análise desses materiais mostraram-se bons para todos os elementos determinados, com erros relativos inferiores a $25 \%$.

Para a validação da metodologia de Análise direta de mercúrio, TAB 4.7, todos os resultados obtidos para $\mathrm{Hg}$ total apresentaram valores de $\mathrm{ER}<25 \%$ e, portanto, foram considerados resultados satisfatórios.

TABELA 4.2 - Resultados das análises do material de referência WQB-3 por ICP OES

\begin{tabular}{ccccc}
\hline \multicolumn{5}{c}{ WQB-3 } \\
\hline Elemento & $\begin{array}{c}\text { Valor informação } \\
\left(\mathbf{m g ~ K g ~}^{-1}\right)\end{array}$ & $\begin{array}{c}\text { Valor } \\
\text { encontrado } \\
\left(\mathbf{m g ~ k g}^{-1}\right)\end{array}$ & RSD & ER \\
\hline Co & 13,4 & $14,8 \pm 0,5$ & 3,5 & $(\boldsymbol{\%})$ \\
$\mathbf{L i}$ & 32,9 & $39,6 \pm 1,3$ & 3,3 & 20,5 \\
$\mathbf{M g}$ & 14329 & $18000 \pm 65$ & 0,4 & 25,6 \\
\hline
\end{tabular}

TABELA 4.3 - Resultados das análises do material de referência SRM 1646 por ICP OES

\begin{tabular}{cccccc}
\hline \multicolumn{7}{c}{$\mathbf{1 6 4 6}$ a } \\
\hline Elemento & $\begin{array}{c}\text { Valor certificado } \\
\left(\mathbf{m g ~ k g}^{-\mathbf{1}}\right)\end{array}$ & $\begin{array}{c}\text { Valor encontrado } \\
\left(\mathbf{m g ~ k g}^{-\mathbf{1}}\right)\end{array}$ & $\begin{array}{c}\text { RSD } \\
\text { \% }\end{array}$ & $\begin{array}{c}\text { ER } \\
\text { \% }\end{array}$ \\
\hline $\mathbf{A l}$ & $22970 \pm 180$ & $23073 \pm 133$ & 0,6 & 0,4 \\
$\mathbf{C a}$ & $5190 \pm 200$ & $4589 \pm 210$ & 4,6 & 11,6 \\
$\mathbf{C r}$ & $40,9 \pm 1,9$ & $43,2 \pm 0,6$ & 1,4 & 5,6 \\
$\mathbf{C u}$ & $10,01 \pm 0,34$ & $10,9 \pm 0,5$ & 5,0 & 8,6 \\
$\mathbf{F e}$ & $20080 \pm 390$ & $17046 \pm 1332$ & 7,8 & 15,1 \\
$\mathbf{M n}$ & $234,5 \pm 2,8$ & $122,5 \pm 2,8$ & 2,3 & 47,8 \\
$\mathbf{M g}$ & $3880 \pm 90$ & $3806 \pm 15$ & 0,4 & 1,9 \\
$\mathbf{T i}$ & $4560 \pm 210$ & $3782 \pm 10$ & 0,3 & 17,1 \\
$\mathbf{V}$ & $44,84 \pm 0,76$ & $34,9 \pm 0,3$ & 0,9 & 22,2 \\
$\mathbf{Z n}$ & $48,9 \pm 1,6$ & $39,2 \pm 6,4$ & 16,3 & 19,9 \\
\hline
\end{tabular}


TABELA 4.4 - Resultados das análises do material de referência SRM 2710a por ICP OES

\begin{tabular}{|c|c|c|c|c|}
\hline \multicolumn{5}{|c|}{$2710 \mathrm{a}$} \\
\hline Elemento & $\begin{array}{l}\text { Valor certificado } \\
\quad\left(\mathrm{mg} \mathrm{kg}^{-1}\right)\end{array}$ & $\begin{array}{c}\text { Valor encontrado } \\
\quad\left(\mathrm{mg} \mathrm{kg}^{-1}\right)\end{array}$ & $\begin{array}{c}\text { RSD } \\
\%\end{array}$ & $\begin{array}{c}\text { ER } \\
\%\end{array}$ \\
\hline Al & $10100 \pm 500$ & $9943 \pm 281$ & 2,8 & 1,6 \\
\hline Ag & $35 \pm 4$ & $29,9 \pm 1,0$ & 3,5 & 14,6 \\
\hline $\mathbf{B a}$ & $515 \pm 25$ & $497 \pm 12$ & 2,4 & 3,6 \\
\hline Be & $0,38 \pm 0,13$ & $0,42 \pm 0,01$ & 3,0 & 10,5 \\
\hline $\mathbf{C a}$ & $1850 \pm 150$ & $2282 \pm 13$ & 0,6 & 23,4 \\
\hline $\mathrm{Cr}$ & $10,1 \pm 0,9$ & $12,1 \pm 0,4$ & 3,5 & 19,8 \\
\hline Co & $4 \pm 1,2$ & $5,02 \pm 0,5$ & 10,6 & 25,5 \\
\hline $\mathbf{C u}$ & $3300 \pm 200$ & $3355 \pm 22$ & 0,7 & 1,7 \\
\hline $\mathbf{F e}$ & $33000 \pm 3000$ & $27376 \pm 164$ & 0,6 & 17,0 \\
\hline Mn & $1650 \pm 150$ & $1763 \pm 82$ & 4,7 & 6,8 \\
\hline Mg & $3400 \pm 200$ & $3382 \pm 56$ & 1,7 & 0,5 \\
\hline $\mathbf{N i}$ & $5,4 \pm 0,6$ & $6,6 \pm 0,4$ & 6,3 & 21,7 \\
\hline $\mathbf{V}$ & $39 \pm 2$ & $48,2 \pm 1,2$ & 2,5 & 23,6 \\
\hline Zn & $3850 \pm 559$ & $4600 \pm 163$ & 3,5 & 19,5 \\
\hline
\end{tabular}

TABELA 4.5 - Resultados das análises dos materiais de referência para a determinação de Fósforo, por ICP OES

\begin{tabular}{|c|c|c|c|c|}
\hline \multicolumn{5}{|c|}{ WQB -3 } \\
\hline Elemento & $\begin{array}{c}\text { Valor ce rtificado } \\
\qquad\left(\mathbf{m g ~ K g ^ { - 1 } )}\right.\end{array}$ & $\begin{array}{c}\text { Valor Encontrado } \\
\quad\left(\mathbf{m g ~ K g ^ { - 1 }}\right)\end{array}$ & RSD & ER \\
\hline $\mathbf{P}$ & $1371 \pm 106$ & $1100 \pm 49$ & 4,5 & 19,8 \\
\hline \multicolumn{5}{|c|}{ 2710a } \\
\hline Elemento & $\begin{array}{c}\text { Valor certificado } \\
\quad\left(\mathrm{mg} \mathrm{Kg}^{-1}\right)\end{array}$ & $\begin{array}{c}\text { Valor Encontrado } \\
\quad\left(\mathrm{mg} \mathrm{Kg}^{-1}\right)\end{array}$ & RSD & ER \\
\hline $\mathbf{P}$ & $1050 \pm 40$ & $1148 \pm 12$ & 1,0 & 9,3 \\
\hline \multicolumn{5}{|c|}{$1646 a$} \\
\hline Elemento & $\begin{array}{c}\text { Valor ce rtificado } \\
\qquad(\mathrm{mg} \mathrm{Kg} \\
\left.\mathbf{H}^{-1}\right)\end{array}$ & $\begin{array}{l}\text { Valor Encontrado } \\
\qquad\left(\mathrm{mg} \mathrm{Kg}^{-1}\right)\end{array}$ & RSD & ER \\
\hline $\mathbf{P}$ & $270 \pm 10$ & $239,8 \pm 1,8$ & 0,8 & 11,2 \\
\hline
\end{tabular}


TABELA 4.6 - Resultados das análises dos materiais de referência para a determinação de As, Cd e Pb, por FG AAS

\begin{tabular}{|c|c|c|c|c|}
\hline \multicolumn{5}{|c|}{$1646 \mathrm{a}$} \\
\hline Elemento & $\begin{array}{c}\text { Valor certificado } \\
\left(\mathrm{mg} \mathrm{Kg} \mathrm{Kg}^{-1}\right)\end{array}$ & $\begin{array}{c}\text { Valor encontrado } \\
\left(\mathrm{mg} \mathrm{kg}^{-1}\right) \\
\end{array}$ & $\begin{array}{c}\text { RSD } \\
\% \\
\end{array}$ & $\begin{array}{c}\mathbf{E R} \\
\% \\
\end{array}$ \\
\hline As & $6,23 \pm 0,21$ & $7,07 \pm 0,25$ & 3,5 & 13,4 \\
\hline $\mathbf{P b}$ & $11,7 \pm 1,2$ & $12,6 \pm 2,0$ & 15,8 & 7,7 \\
\hline \multicolumn{5}{|c|}{2710 a } \\
\hline Elemento & $\begin{array}{c}\text { Valor certificado } \\
\left(\mathrm{mg} \mathrm{Kg} \mathrm{g}^{-1}\right) \\
\end{array}$ & $\begin{array}{c}\text { Valor encontrado } \\
\left(\mathrm{mg} \mathrm{kg}^{-1}\right) \\
\end{array}$ & $\begin{array}{c}\text { RSD } \\
\% \\
\end{array}$ & $\begin{array}{c}\mathbf{E R} \\
\% \\
\end{array}$ \\
\hline As & $1540 \pm 10$ & $1420 \pm 2$ & 0,1 & 7,8 \\
\hline Cd & $12,3 \pm 0,3$ & $10,30 \pm 0,01$ & 0,1 & 16,3 \\
\hline $\mathbf{P b}$ & $5520 \pm 30$ & $5338 \pm 9$ & 0,2 & 3,3 \\
\hline
\end{tabular}

TABELA 4.7 - Resultados de Hg total nos materiais de referência pela metodologia de Análise Direta de Mercúrio

\begin{tabular}{|c|c|c|c|c|}
\hline \multicolumn{5}{|c|}{ SRM 2702} \\
\hline Elemento & $\begin{array}{c}\text { Valor certificado } \\
\mathrm{mg} / \mathrm{Kg}\end{array}$ & $\begin{array}{c}\text { Valor } \\
\text { encontrado } \\
\text { mg kg }^{-1}\end{array}$ & $\begin{array}{c}\text { RSD } \\
\%\end{array}$ & $\begin{array}{c}\text { RE } \\
\%\end{array}$ \\
\hline Hg & $0,428 \pm 0,024$ & $0,39 \pm 0,09$ & 23,1 & 8,9 \\
\hline \multicolumn{5}{|c|}{ IAEA 405} \\
\hline Elemento & $\begin{array}{c}\text { Valor certificado } \\
\mathrm{mg} / \mathrm{Kg}\end{array}$ & $\begin{array}{c}\text { Valor } \\
\text { encontrado } \\
\mathrm{mg} \mathrm{kg}^{-1}\end{array}$ & $\begin{array}{c}\text { RSD } \\
\%\end{array}$ & $\begin{array}{c}\text { RE } \\
\%\end{array}$ \\
\hline $\mathbf{H g}$ & $0,77 \pm 0,85$ & $0,69 \pm 0,09$ & 13,7 & 10,4 \\
\hline \multicolumn{5}{|c|}{ SRM 2709} \\
\hline Elemento & $\begin{array}{c}\text { Valor certificado } \\
\mathrm{mg} / \mathrm{Kg}\end{array}$ & $\begin{array}{c}\text { Valor } \\
\text { encontrado } \\
\mathrm{mg} \mathrm{kg}^{-1}\end{array}$ & $\begin{array}{c}\text { RSD } \\
\%\end{array}$ & $\begin{array}{c}\text { RE } \\
\%\end{array}$ \\
\hline Hg & $1,40 \pm 0,08$ & $1,07 \pm 0,09$ & 8,7 & 23,6 \\
\hline
\end{tabular}

\subsubsection{Limites de Detecção (LD) e Limite de Quantificação (LQ)}

Os limites de detecção e quantificação, para as técnicas de ICP OES, FG AAS e Análise direta de mercúrio, foram calculados conforme descrito no item 3.3.9, para cada um dos elementos determinados por essas técnicas. Na TAB 4.8 se encontram apresentados os valores de LD e LQ. 
TABELA 4.8 - Valores de LQ e LD $\left(\mathrm{mg} \mathrm{L}^{-1}\right)$, determinados pelas técnicas ICP OES, GF AAS e Análise Direta de Mercúrio

\begin{tabular}{cccc}
\hline \multicolumn{1}{l}{ Técnica Elemento } & LD & LQ \\
\hline & $\mathrm{Ag}$ & 0,003 & 0,01 \\
& $\mathrm{Al}$ & 0,03 & 0,1 \\
& $\mathrm{Ba}$ & 0,001 & 0,004 \\
& $\mathrm{Be}$ & 0,0004 & 0,001 \\
& $\mathrm{Ca}$ & 0,15 & 0,5 \\
& $\mathrm{Co}$ & 0,005 & 0,01 \\
& $\mathrm{Cr}$ & 0,007 & 0,02 \\
& $\mathrm{Cu}$ & 0,002 & 0,008 \\
& $\mathrm{Fe}$ & 0,009 & 0,03 \\
ICP OES & $\mathrm{Li}$ & 0,0007 & 0,002 \\
& $\mathrm{Mg}$ & 0,02 & 0,07 \\
& $\mathrm{Mn}$ & 0,0007 & 0,002 \\
& $\mathrm{Mo}$ & 0,002 & 0,03 \\
& $\mathrm{Ni}$ & 0,05 & 0,01 \\
& $\mathrm{P}$ & 0,01 & 0,04 \\
& $\mathrm{Sn}$ & 0,01 & 0,05 \\
& $\mathrm{Ti}$ & 0,001 & 0,004 \\
& $\mathrm{~V}$ & 0,002 & 0,03 \\
direta & $\mathrm{Zn}$ & 0,002 & 0,006 \\
\hline FG AAS & $\mathrm{As}$ & 0,0004 & 0,0014 \\
& $\mathrm{Cd}$ & 0,00002 & 0,00005 \\
& $\mathrm{~Pb}$ & 0,0004 & 0,0013 \\
\hline \multirow{6}{*}{ Analise } & 0,015 & 0,051 \\
\hline
\end{tabular}

\subsubsection{Resultados obtidos para as amostras de sedimento pela técnica de ICP OES}

Os resultados encontrados nas análises das amostras de sedimento pela técnica de ICP OES com suas respectivas incertezas encontram-se na TAB 4.9. Pelos resultados obtidos observa-se uma grande variação de concentração nas frações, para todos os elementos, para todos os pontos. Os elementos Ag e Mo não foram quantificados, por suas concentrações estarem abaixo do limite de quantificação do método. As análises dos pontos e suas respectivas frações foram feitas tomando-se como referencial a base do sedimento, para se avaliar a presença de contribuição antrópica pelo ambiente. 
Para o ponto Pt 01, podemos observar que houve um decréscimo de concentração para todos os elementos determinados, quando comparados os valores das frações P1-10 e P1-20 (base do perfil).

Em geral, para alguns dos elementos determinados, em todos os pontos, observou-se o comportamento de maior concentração na superfície e menor concentração na base. Os elementos que apresentaram comportamento diferente (maior concentração na base e menor na superfície ou demais frações) foram:

- $\quad \mathrm{Al}, \mathrm{Ba}, \mathrm{Be}, \mathrm{Ca}, \mathrm{Cr}, \mathrm{Mg}, \mathrm{Ni}, \mathrm{Sn}, \mathrm{V}$ e $\mathrm{Zn}$, no ponto 02 ;

- $\quad \mathrm{Ba}, \mathrm{Be}, \mathrm{Li}, \mathrm{Mg}, \mathrm{Ni}$ e Ti, no ponto 03;

- $\quad \mathrm{Cu}, \mathrm{Li}$, Ni e Zn, no ponto 04.

Com o intuito de facilitar a visualização do comportamento de distribuição para cada um dos elementos determinados ao longo do perfil, foram construídos os gráficos apresentados na FIG 4.2, com os dados de concentrações em mg kg-1 versus as frações de cada um dos perfis de sedimento amostrado no reservatório de Itupararanga. Em destaque, em linha vermelha, estão apresentados os valores limites de TEL, para os elementos que possuem esses valores.

A TAB 4.10 apresenta os resultados obtidos para $\mathrm{P}$ total nas amostras de sedimentos. Em geral, os valores de concentração foram maiores na superfície do que na base, para todos os pontos, sendo a única exceção o ponto Pt 03, onde ocorreu uma inversão, com o maior valor de concentração encontrado na base do perfil. Um fato não esperado foi a concentração de fósforo nos sedimentos do ponto 03 ser inferior ao do ponto 2. O ponto 3 se localiza após um vilarejo e dessa forma, esperava-se o recebimento de uma grande carga antrópica principalmente de esgotos não tratados e, portanto, uma concentração de fósforo maior que a do ponto 2 , o que acabou não acontecendo.

A resolução CONAMA 344, que estabelece a diretriz geral e os procedimentos mínimos para avaliação do material a ser dragado, limita a concentração de fósforo a $2000 \mathrm{mg} \mathrm{kg}^{-1}$ (CONAMA, 2004).

Os valores orientadores utilizados pela província de Ontário, no Canadá, para nutrientes em sedimentos para fósforo é de $600 \mathrm{mg} \mathrm{kg}^{-1}$ (níveis de menores efeitos 
adversos à biota) a $2000 \mathrm{mg} \mathrm{kg}^{-1}$ (níveis de severo efeito adverso à biota). (MOE, 2003 Apud, Quináglia, 2006)

Os valores de P total encontrados no presente estudo variaram de 543 a 2011 $\mathrm{mg} \mathrm{kg}^{-1}$. Analisando-se os dados da TAB 4.10 verificou-se que todos os pontos, com exceção do ponto 1 e fração P4-60, apresentaram concentrações de fósforo que ultrapassaram os valores orientadores da província de Ontário e/ou o valor orientador do CONAMA 344/2004, o que justifica o alerta que vem sendo aplicado pela CETESB para esse reservatório, que em seu monitoramento indica um constante aumento apresentando um valor médio, nos pontos 3 e 4, de $1000 \mathrm{mg} \mathrm{kg}^{-1}$, valor este que já indica um estado de alerta quanto ao futuro deste reservatório, principalmente levando-se em conta a expansão que ocorre nas áreas plantadas e empreendimentos imobiliários ao redor do reservatório, os quais são grandes fontes de fósforo. 
Tabela 4.9 - Resultados $\left(\mathrm{mg} \mathrm{kg}^{-1}\right)$ das análise das amostras de sedimentos por ICP OES

\begin{tabular}{|c|c|c|c|c|c|c|c|c|c|c|c|c|c|c|c|c|c|c|c|c|c|}
\hline \multirow{2}{*}{$\frac{\text { Ponto }}{\text { Amostra }}$} & \multicolumn{2}{|c|}{ Pt 01} & \multicolumn{5}{|c|}{$\mathrm{Pt} 02$} & \multicolumn{6}{|c|}{$\mathrm{Pt} 03$} & \multicolumn{6}{|c|}{$\mathrm{Pt} 04$} & \multirow{2}{*}{$\mathrm{UCC}$} & \multirow{2}{*}{ NASC } \\
\hline & P1-10 & P1-20 & P2-10 & P2-20 & P2.30 & P2-40 & P2.50 & P3-10 & P3-20 & P3-30 & P3-40 & P3.50 & P3-60 & P4-10 & P4-20 & P4-30 & P4-40 & P4.50 & P4.60 & & \\
\hline $\mathrm{Ag}$ & $<0,200$ & $<0,200$ & $<0,200$ & $<0,200$ & $<0,200$ & $<0,200$ & $<0,200$ & $<0,200$ & $<0,200$ & $<0,200$ & $<0,200$ & $<0,200$ & $<0,200$ & $<0,200$ & $<0,200$ & $<0,200$ & $<0,200$ & $<0,200$ & $<0,200$ & 0,055 & .. \\
\hline $\operatorname{Al}(\%)$ & $6,9 \pm 0,6$ & $5,19 \pm 0,7$ & $2,4 \pm 0,1$ & $7,7 \pm 2,1$ & $7,0 \pm 1,7$ & $4,8 \pm 0,5$ & $6,7 \pm 0,7$ & $9,3 \pm 5,1$ & $1,1 \pm 1,6$ & $7,4 \pm 1,5$ & $7,4 \pm 1,3$ & $7,6 \pm 1,0$ & $7,9 \pm 1,5$ & $11,6 \pm 4,2$ & $10,1 \pm 1,4$ & $10,9 \pm 1,6$ & $8,3 \pm 1,1$ & $7,6 \pm 1,9$ & $5,6 \pm 1,1$ & 77440 & $8,95(\%)$ \\
\hline $\mathrm{Ba}$ & $235 \pm 6$ & $174 \pm 5$ & $179 \pm 6$ & $191 \pm 1$ & $209 \pm 3$ & $186 \pm 2$ & $222 \pm 7$ & $184 \pm 1$ & $221 \pm 9$ & $193 \pm 5$ & $202 \pm 1$ & $192 \pm 3$ & $234 \pm 1$ & $229 \pm 4$ & $197 \pm 1$ & $194 \pm 4$ & $186 \pm 5$ & $181 \pm 3$ & $145 \pm 3$ & 668 & 584 \\
\hline $\mathrm{Be}$ & $2,4 \pm 0,1$ & $1,8 \pm 0,1$ & $0,94 \pm 0,05$ & $2,2 \pm 0,1$ & $1,91 \pm 0,11$ & $1,50 \pm 0,01$ & $2,1 \pm 0,1$ & $1,9 \pm 0,1$ & $2,8 \pm 0,1$ & $2,05 \pm 0,1$ & $2,0 \pm 0,1$ & $2,2 \pm 0,1$ & $3,12 \pm 0,05$ & $1,5 \pm 0,1$ & $1,8 \pm 0,1$ & $1,5 \pm 0,1$ & $1,6 \pm 0,1$ & $1,4 \pm 0,1$ & $1,2 \pm 0,1$ & 3,1 & .. \\
\hline $\mathrm{Ca}$ & $594 \pm 5$ & $592 \pm 3$ & $360 \pm 9$ & $430 \pm 10$ & $466 \pm 7$ & $384 \pm 6$ & $542 \pm 7$ & $483 \pm 3$ & $430 \pm 1$ & $421 \pm 3$ & $421 \pm 3$ & $394 \pm 5$ & $439 \pm 6$ & $508 \pm 13$ & $439 \pm 6$ & $444 \pm 1$ & $388 \pm 7$ & $362 \pm 5$ & $375 \pm 8$ & 29450 & $2,59(\%)$ \\
\hline $\mathrm{Cr}$ & $36 \pm 2$ & $30 \pm 1$ & $43,0 \pm 0,2$ & $44,0 \pm 0,1$ & $45,0 \pm 0,3$ & $37,0 \pm 0,2$ & $46 \pm 4$ & $45 \pm 2$ & $52,20,6$ & $43,8 \pm 0,4$ & $41 \pm 0,8$ & $44 \pm 0,8$ & $32 \pm 1$ & $56 \pm 3$ & $53,1 \pm 0,5$ & $50,7 \pm 0,1$ & $60 \pm 3$ & $44 \pm 1$ & $33,9 \pm 0,1$ & 35 & 126 \\
\hline $\mathrm{Cu}$ & $8,11 \pm 0,9$ & $6,4 \pm 0,8$ & $75,3 \pm 0,9$ & $16,8 \pm 0,2$ & $20,7 \pm 0,1$ & $22,7 \pm 2,3$ & $20,8 \pm 1,0$ & $21,4 \pm 0,4$ & $18,2 \pm 0,4$ & $19,5 \pm 0,3$ & $21,50,2$ & $37,1 \pm 0,7$ & $13,3 \pm 0,3$ & $11,3 \pm 0,1$ & & $20,1 \pm 0,3$ & $19,2 \pm 0,1$ & $22,3 \pm 0,5$ & $26,2 \pm 1,0$ & 14,3 & .. \\
\hline $\mathrm{Fe}(\%)$ & $1,9 \pm 0,6$ & $1,8 \pm 0,2$ & $5,0 \pm 0,9$ & $5,5 \pm 0,1$ & $6,4 \pm 0,3$ & $3,5 \pm 0,2$ & $3,9 \pm 0,7$ & $7,7 \pm 0,9$ & $5,9 \pm 0,2$ & $6,1 \pm 1,0$ & $5,4 \pm 0,5$ & $4,1 \pm 0,9$ & $1,5 \pm 0,2$ & $8,3 \pm 0,8$ & $6,7 \pm 0,2$ & $8,6 \pm 0,2$ & $7,3 \pm 2,2$ & $4,1 \pm 0,1$ & $1,34 \pm 0,04$ & 30890 & 43200 \\
\hline $\mathrm{Li}$ & $22,6 \pm 0,5$ & $16,3 \pm 0,4$ & $27,7 \pm 0,7$ & $23,9 \pm 0,6$ & $20,4 \pm 0,5$ & $16,3 \pm 0,3$ & $21,9 \pm 0,6$ & $21,1 \pm 0,4$ & $30,5 \pm 0,7$ & $20,5 \pm 0,7$ & $20,6 \pm 0,6$ & $21,2 \pm 0,3$ & $30,9 \pm 0,4$ & $25,4 \pm 0,4$ & $26,1 \pm 0,7$ & $23,8 \pm 0,5$ & $24,1 \pm 0,8$ & $29,9 \pm 0,8$ & $64,6 \pm 0,6$ & 22 & .. \\
\hline $\mathrm{Mg}$ & $1807 \pm 38$ & $1557 \pm 12$ & $597 \pm 2$ & $829 \pm 27$ & $791 \pm 20$ & $610 \pm 13$ & $787 \pm 7$ & $758 \pm 13$ & $941 \pm 15$ & $792 \pm 14$ & $775 \pm 10$ & $742 \pm 3$ & $1029 \pm 13$ & $884 \pm 35$ & $739 \pm 20$ & $796 \pm 15$ & $758 \pm 13$ & $713 \pm 10$ & $791 \pm 13$ & 13510 & 22000 \\
\hline Mn & $147 \pm 5$ & $133 \pm 1$ & $313 \pm 12$ & $331 \pm 10$ & $381 \pm 1$ & $314 \pm 2$ & $252 \pm 9$ & $503 \pm 23$ & $342 \pm 32$ & $443 \pm 11$ & $433 \pm 11$ & $542 \pm 19$ & $358 \pm 12$ & $566 \pm 34$ & $505 \pm 12$ & $670 \pm 1$ & $409 \pm 24$ & $251 \pm 5$ & $219 \pm 3$ & 527 & 716 \\
\hline Mo & $<1,00$ & $<1,00$ & $<1,00$ & $<1,00$ & $<1,00$ & $<1,00$ & $<1,00$ & $<1,00$ & $<1,00$ & $<1,00$ & $<1,00$ & $<1,00$ & $<1,00$ & $<1,00$ & $<1,00$ & $<1,00$ & $<1,00$ & $<1,00$ & $<1,00$ & 1,4 & .. \\
\hline Sn & $2,1 \pm 0,5$ & $1,5 \pm 0,5$ & $<0,4$ & $<0,4$ & $<0,4$ & $<0,4$ & $2,2 \pm 0,2$ & $1,0 \pm 0,2$ & $4,4 \pm 0,1$ & $2,8 \pm 0,7$ & $1,27 \pm 0,04$ & $<0,4$ & $0,8 \pm 0,3$ & $1,1 \pm 0,1$ & $1,42 \pm 0,2$ & $2,4 \pm 0,2$ & $<0,4$ & $<0,4$ & $<0,4$ & 2,5 & .. \\
\hline $\mathrm{Ti}$ & $726 \pm 8$ & $394 \pm 7$ & $253 \pm 8$ & $268 \pm 4$ & $253 \pm 2$ & $113 \pm 4$ & $251 \pm 1$ & $308 \pm 0,4$ & $557 \pm 4$ & $442 \pm 2$ & $393 \pm 2$ & $298 \pm 1$ & $371 \pm 1$ & $414 \pm 7$ & $356 \pm 5$ & $391 \pm 1$ & $339 \pm 2$ & $242 \pm 8$ & $161 \pm 2$ & 3117 & 4010 \\
\hline V & $41,7 \pm 0,9$ & $31,7 \pm 0,9$ & $45,4 \pm 0,8$ & $76 \pm 4$ & $72 \pm 2$ & $59 \pm 2$ & $77 \pm 1$ & $93 \pm 2$ & $95 \pm 4$ & $90 \pm 2$ & $81 \pm 4$ & $89 \pm 2$ & $39,5 \pm 0,5$ & $96 \pm 1$ & $92 \pm 1$ & $92 \pm 2$ & $82 \pm 6$ & $75 \pm 1$ & $36 \pm 1$ & 53 & 98 \\
\hline $\mathrm{Zn}$ & $50,9 \pm 0,3$ & $43,8 \pm 0,8$ & $49,9 \pm 8,8$ & $59,0 \pm 0,9$ & $61,8 \pm 1,7$ & $50,3 \pm 0,2$ & $53,0 \pm 0,5$ & $58 \pm 2$ & $63 \pm 2$ & $65 \pm 1,3$ & $57,1 \pm 1,0$ & $94,3 \pm 0,7$ & $58,5 \pm 0,1$ & $27,6 \pm 0,4$ & $49 \pm 1$ & $54 \pm 1$ & $49 \pm 1$ & $55 \pm 1$ & $56 \pm 1$ & 52 & 65 \\
\hline
\end{tabular}

-- Não tabelado 

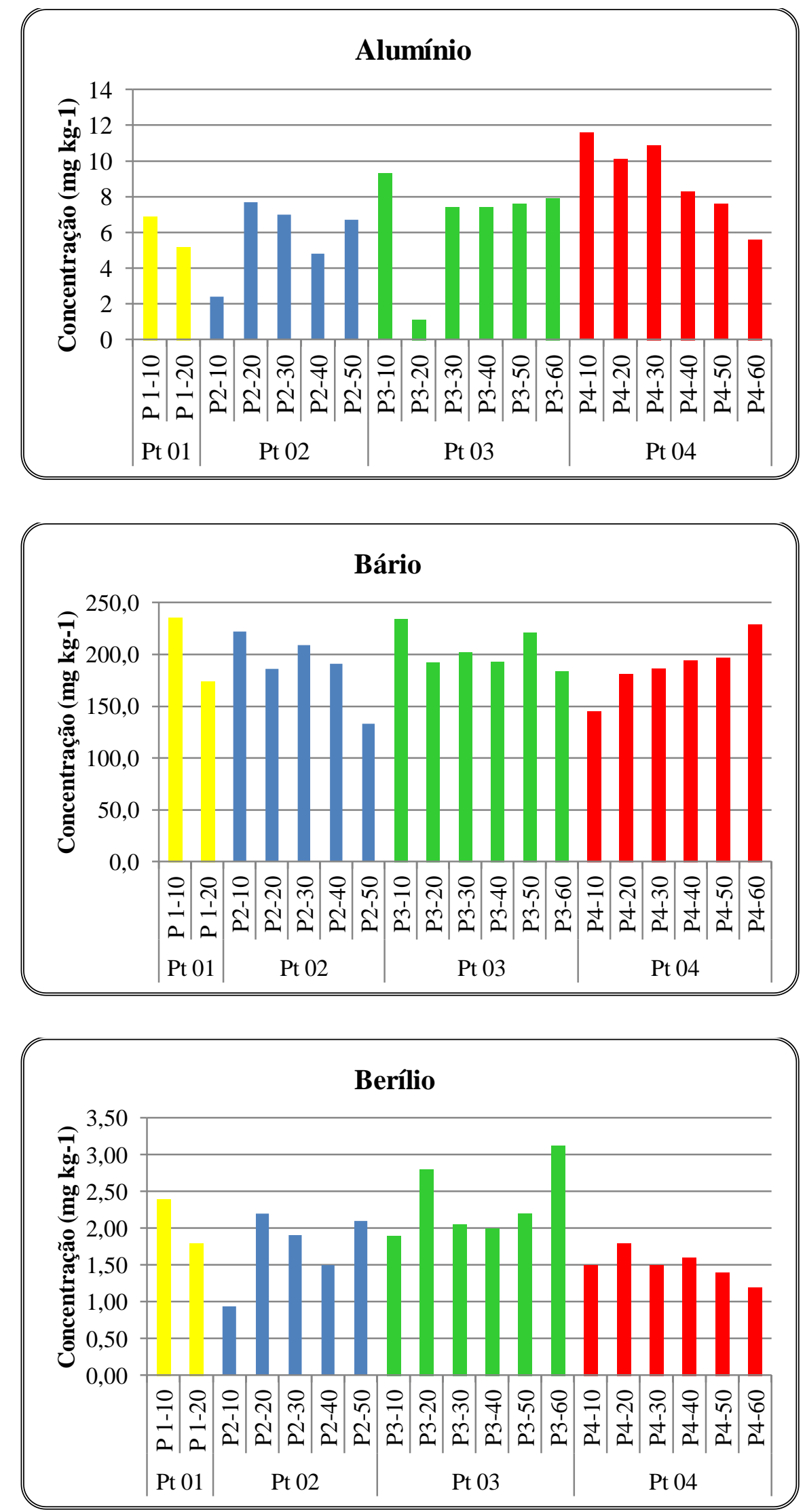

FIGURA 4.2 Distribuição dos elementos analisados por ICP OES (mg kg $\left.{ }^{-1}\right)$, em cada fração de sedimento, para cada ponto amostrado 


\section{Cálcio}
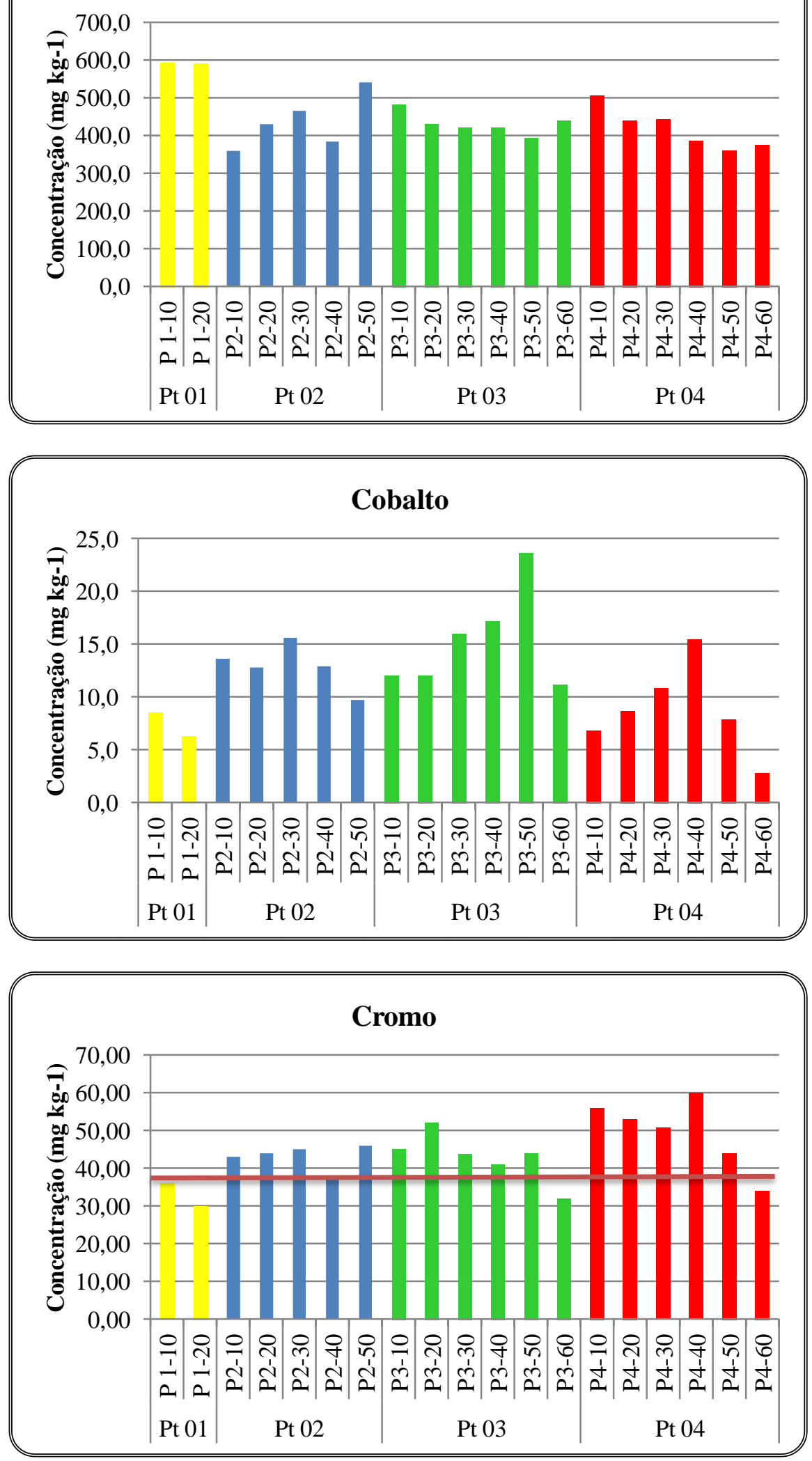

FIGURA 4.2 Continuação 


\section{Cobre}

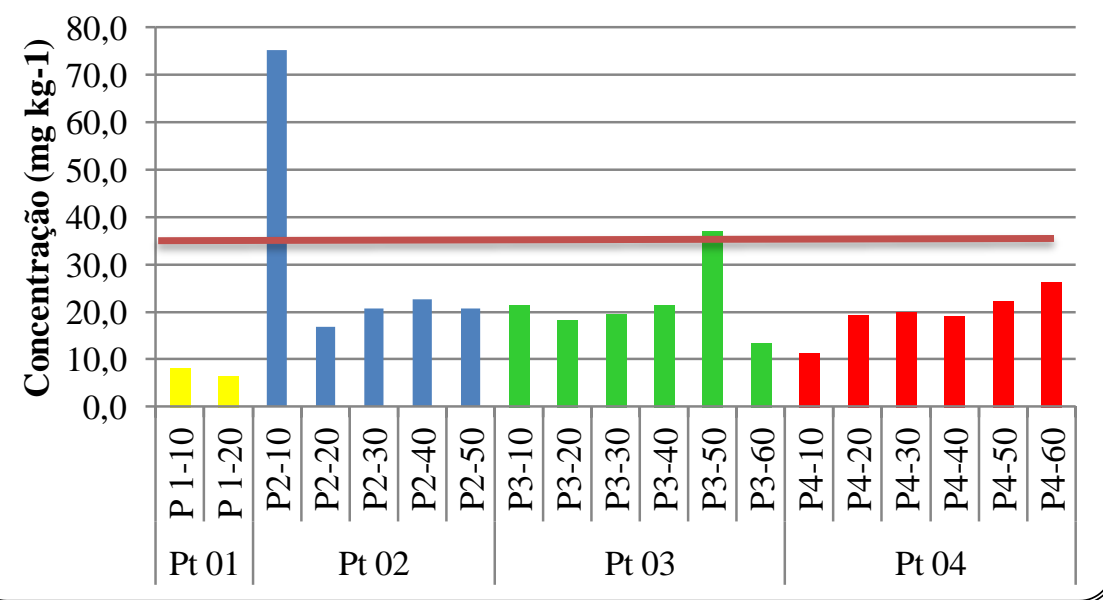

\section{Estanho}

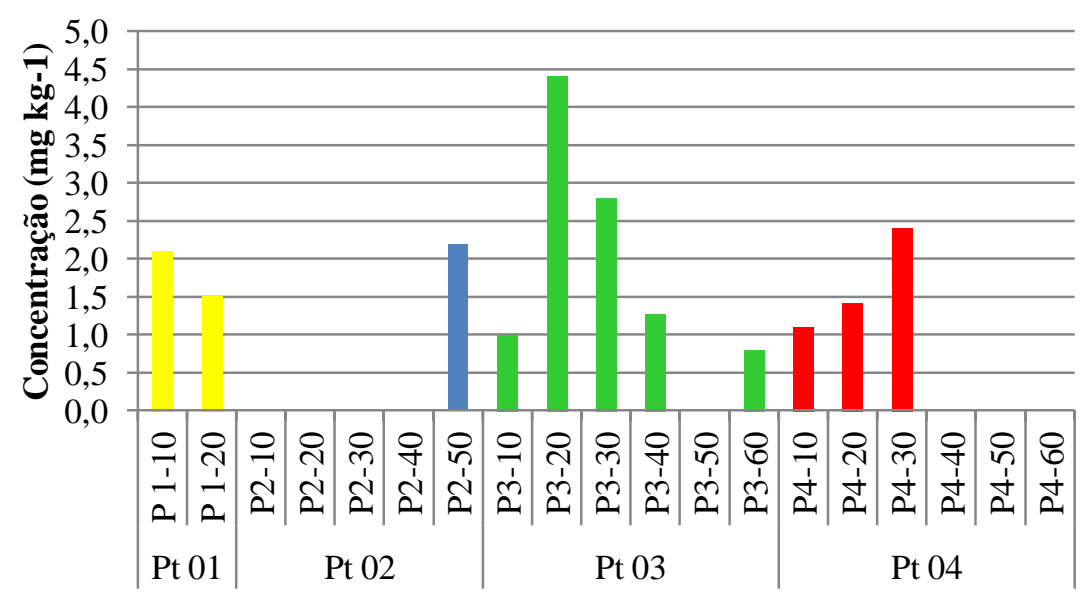

\section{Ferro}

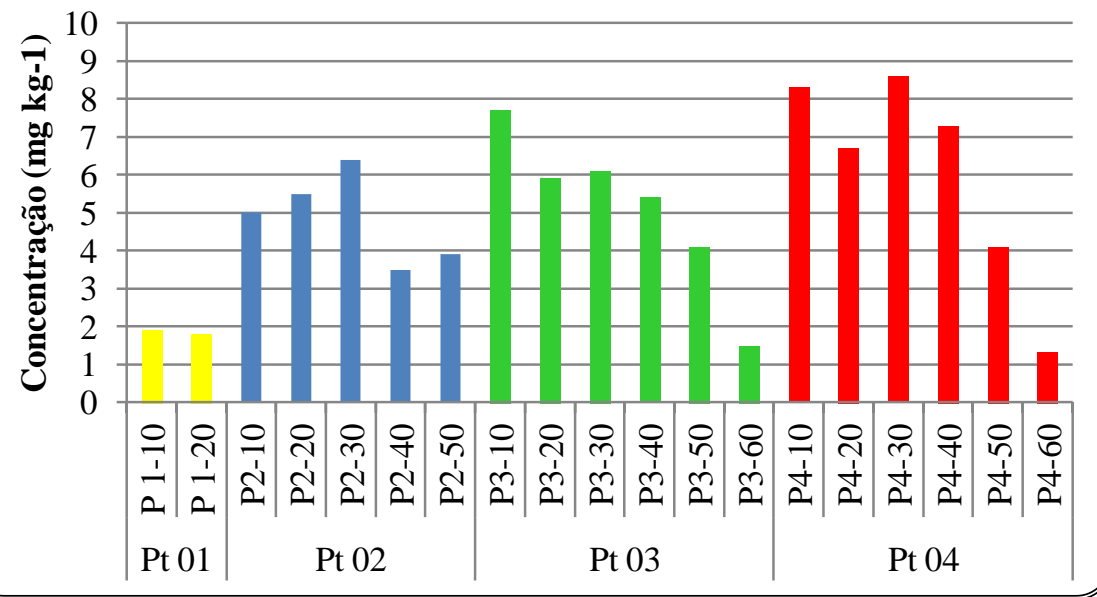

FIGURA 4.2 Continuação 

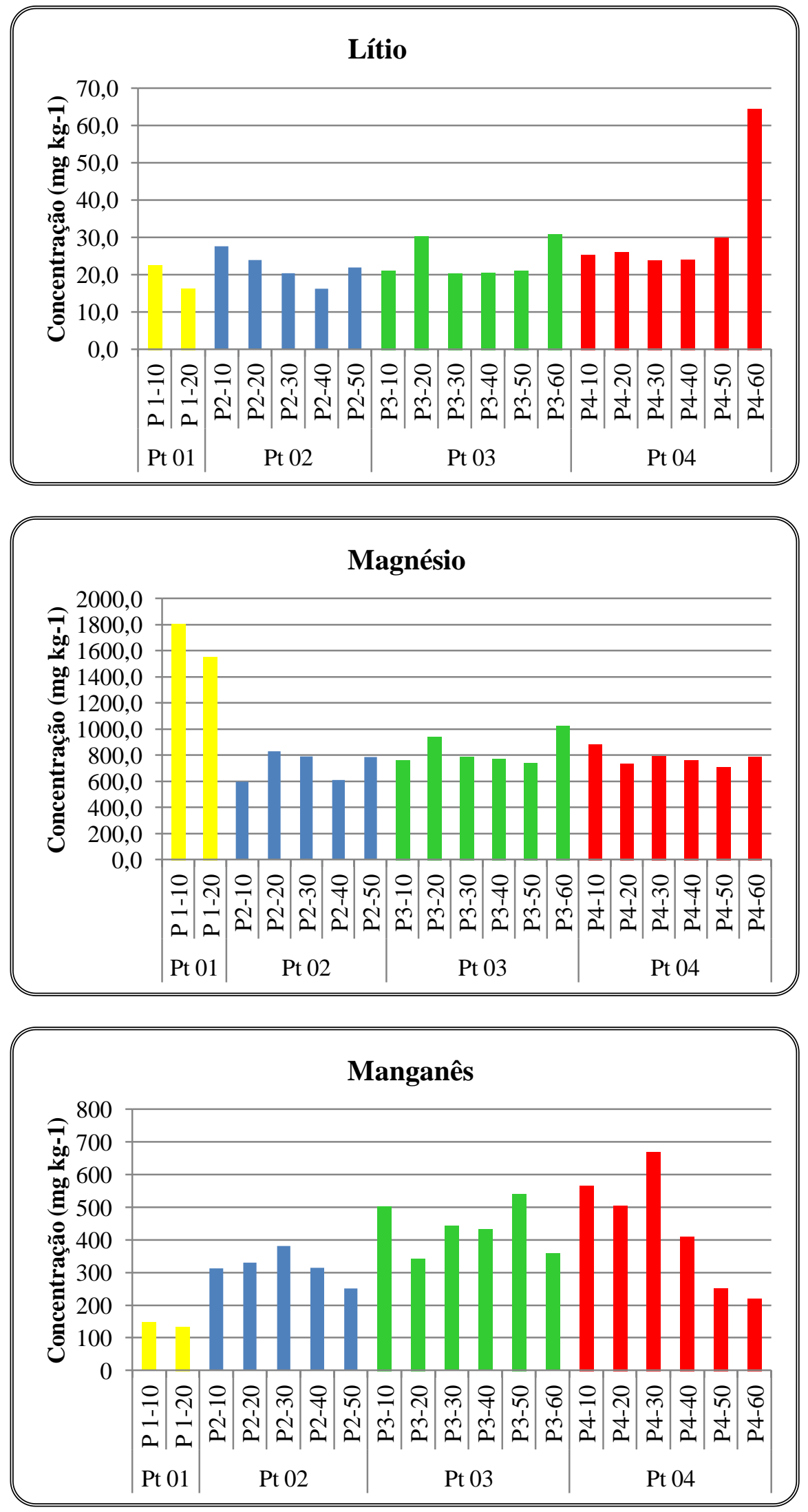

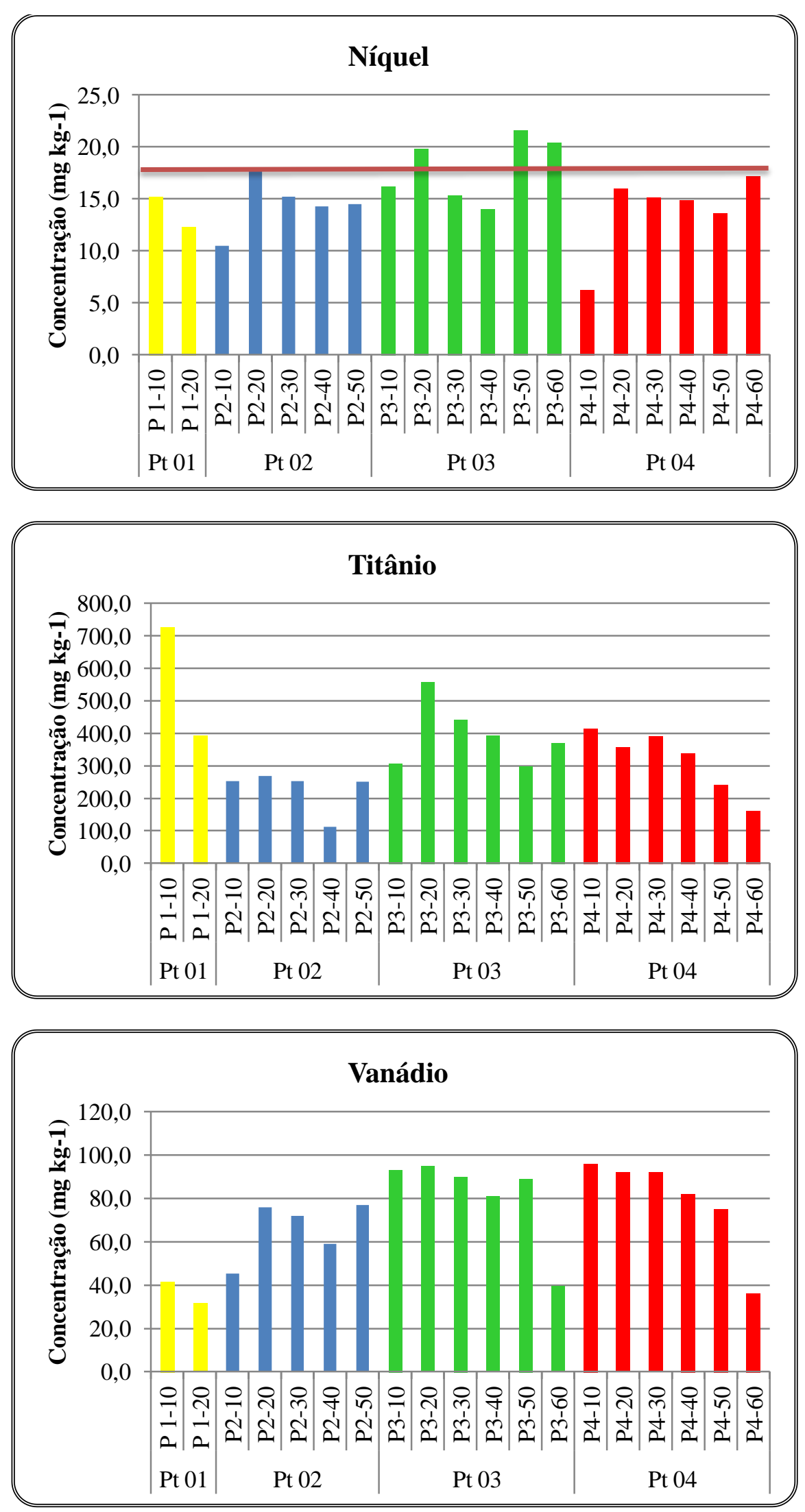

FIGURA 4.2 Continuação 


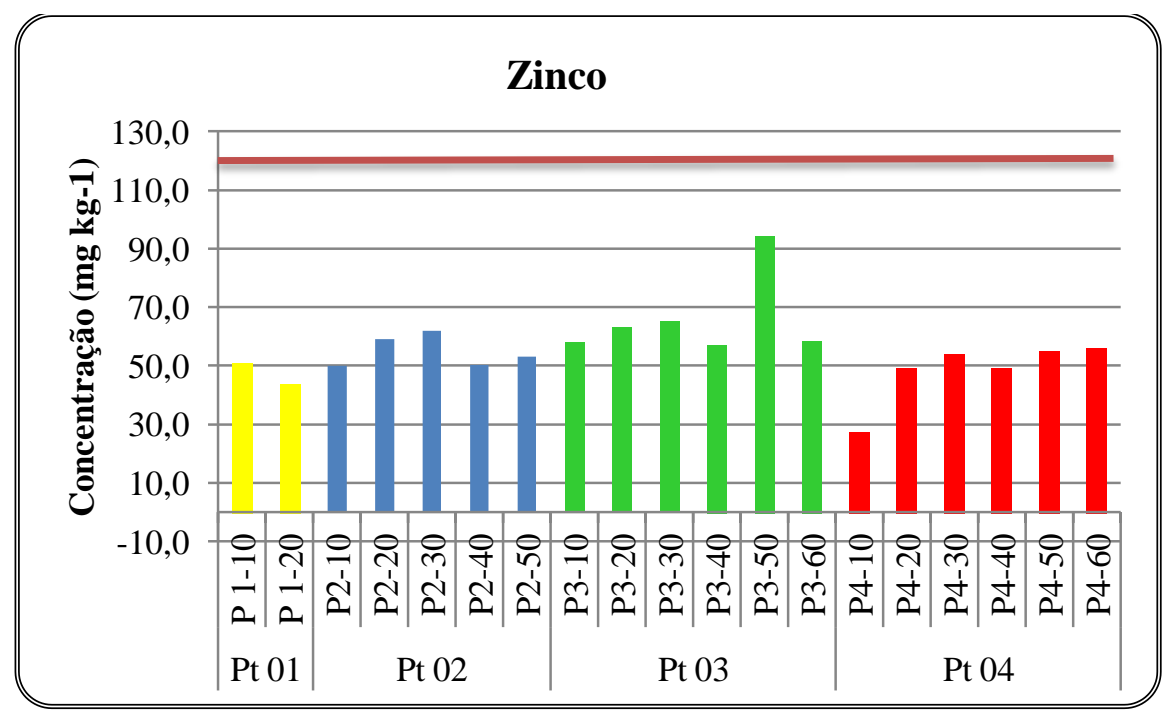

FIGURA 4.2 - Distribuição dos elementos analisados por ICP OES ( $\left.\mathrm{mg} \mathrm{kg}^{-1}\right)$, em cada fração de sedimento, para cada ponto amostrado

TABELA 4.10 - Resultados das determinações de fósforo por ICP OES, nas amostras de sedimento

\begin{tabular}{ccc}
\hline Ponto & Amostra & P $\left(\mathbf{m g ~ k g}^{-\mathbf{1}}\right)$ \\
\hline \multirow{2}{*}{ Pt 01 } & P 1-10 & $574 \pm 6$ \\
& P 1-20 & $543 \pm 2$ \\
& P2-10 & $1198 \pm 40$ \\
& P2-20 & $1008 \pm 30$ \\
Pt 02 & P2-30 & $922 \pm 6$ \\
& P2-40 & $866 \pm 11$ \\
& P2-50 & $1080 \pm 25$ \\
& P3-10 & $935 \pm 13$ \\
& P3-20 & $995 \pm 11$ \\
Pt 03 & P3-30 & $1007 \pm 33$ \\
& P3-40 & $817 \pm 3$ \\
& P3-50 & $1383 \pm 25$ \\
& P3-60 & $2011 \pm 6$ \\
& P4-10 & $650 \pm 6$ \\
& P4-20 & $781 \pm 45$ \\
Pt 04 & P4-30 & $792 \pm 15$ \\
& P4-40 & $702 \pm 26$ \\
& P4-50 & $719 \pm 38$ \\
& P4-60 & $557 \pm 9$ \\
\hline
\end{tabular}




\subsubsection{Resultados obtidos para as amostras de sedimento pela técnica de GF}

\section{AAS}

Os resultados encontrados nas análises das amostras de sedimento pela técnica de FG AAS com suas respectivas incertezas encontram-se na TAB 4.11. Pelos resultados obtidos para As, pode-se observar uma grande variação de concentração nas frações, onde há uma variação entre 3,4 a 17,6 $\mathrm{mg} \mathrm{kg}^{-1}$, sendo que o valor de alerta para metais, em solo adotado pela CETESB, é de $15 \mathrm{mg} \mathrm{kg}^{-1}$ (CETESB, 2001b), valor este que foi ultrapassado para as frações P2-10, P4-20 e P4-30.

Para o elemento $\mathrm{Pb}$, podemos observar um acréscimo nas frações superficiais, tendo este ficado sempre abaixo do valor orientador para solo que é de $100 \mathrm{mg} \mathrm{kg}^{-1}$ (CETESB, 2001). Já o elemento Cd não foi quantificado, por suas concentrações encontrarem-se abaixo do limite de quantificação do GF AAS. As análises dos pontos e suas frações respectivas foram feitas tomando-se como referencial a base do sedimento, para se avaliar a presença de contribuição antrópica pelo ambiente. 
TABELA 4.11 - Resultados $\left(\mathrm{mg} \mathrm{kg}^{-1}\right)$ das análises de sedimentos por GF AAS

\begin{tabular}{ccccc}
\hline Ponto & Amostra & As & Cd & Pb \\
\hline \multirow{2}{*}{ Pt 01 } & P1-10 & $3,4 \pm 0,1$ & $<0,04$ & $23 \pm 1$ \\
& P1-20 & $4,4 \pm 0,1$ & $<0,04$ & $18,5 \pm 0,9$ \\
& P2-10 & $17,6 \pm 0,5$ & $<0,04$ & $63 \pm 2$ \\
& P2-20 & $8,7 \pm 0,4$ & $<0,04$ & $37 \pm 2$ \\
Pt 02 & P2-30 & $5,3 \pm 0,1$ & $<0,04$ & $32 \pm 2$ \\
& P2-40 & $6,2 \pm 0,2$ & $<0,04$ & $29 \pm 2$ \\
& P2-50 & $6,1 \pm 0,1$ & $<0,04$ & $29 \pm 2$ \\
& P3-10 & $8,6 \pm 0,4$ & $<0,04$ & $30 \pm 2$ \\
& P3-20 & $8,2 \pm 0,3$ & $<0,04$ & $33 \pm 2$ \\
Pt 03 & P3-30 & $8,2 \pm 0,5$ & $<0,04$ & $37 \pm 2$ \\
& P3-40 & $8,00 \pm 0,6$ & $<0,04$ & $47 \pm 2$ \\
& P3-50 & $10,5 \pm 0,4$ & $<0,04$ & $47 \pm 2$ \\
& P3-60 & $7,4 \pm 0,3$ & $<0,04$ & $34 \pm 2$ \\
& P4-10 & $9,8 \pm 0,5$ & $<0,04$ & $30 \pm 2$ \\
& P4-20 & $15,6 \pm 0,5$ & $<0,04$ & $30 \pm 2$ \\
Pt 04 & P4-30 & $15,7 \pm 0,3$ & $<0,04$ & $30 \pm 2$ \\
& P4-40 & $10,0 \pm 0,4$ & $<0,04$ & $30 \pm 2$ \\
& P4-50 & $8,5 \pm 0,4$ & $<0,04$ & $27 \pm 2$ \\
& P4-60 & $6,6 \pm 0,3$ & $<0,04$ & $18 \pm 2$ \\
\hline
\end{tabular}

\subsubsection{Resultados de $\mathrm{Hg}$ total obtidos por análise direta de mercúrio}

Os resultados das determinações de mercúrio estão apresentados na TAB 4.12. Pode-se observar a partir dos resultados, baixa concentração de $\mathrm{Hg}$ em todos os pontos, com pequena variação de concentração nas frações. A exceção foi o ponto P3-50, que apresentou a maior concentração de mercúrio $\left(0,11 \pm 0,01 \mathrm{mg} \mathrm{kg}^{-1}\right)$. 
TABELA 4.12 - Resultados $\left(\mathrm{mg} \mathrm{kg}^{-1}\right)$ de mercúrio total obtidos por Análise Direta de Mercúrio, nas amostras de sedimentos

\begin{tabular}{ccc}
\hline Ponto & Amostra & $\mathbf{H g}\left(\mathbf{m g ~ k g}^{-\mathbf{1}}\right)$ \\
\hline \multirow{2}{*}{ Pt 01 } & P 1- 10 & $0,04 \pm 0,01$ \\
& P 1-20 & $0,04 \pm 0,01$ \\
& P2-10 & $0,07 \pm 0,01$ \\
& P2-20 & $0,08 \pm 0,01$ \\
Pt 02 & P2-30 & $0,07 \pm 0,01$ \\
& P2-40 & $0,08 \pm 0,01$ \\
& P2-50 & $0,09 \pm 0,01$ \\
& P3-10 & $0,05 \pm 0,01$ \\
& P3-20 & $0,06 \pm 0,01$ \\
Pt 03 & P3-30 & $0,09 \pm 0,01$ \\
& P3-40 & $0,07 \pm 0,01$ \\
& P3-50 & $0,09 \pm 0,01$ \\
& P3-60 & $0,11 \pm 0,01$ \\
& P4-10 & $0,05 \pm 0,01$ \\
& P4-20 & $0,06 \pm 0,01$ \\
Pt 04 & P4-30 & $0,07 \pm 0,01$ \\
& P4-40 & $0,07 \pm 0,01$ \\
& P4-50 & $0,05 \pm 0,01$ \\
& P4-60 & $0,05 \pm 0,01$ \\
\hline
\end{tabular}

\subsubsection{Variação de concentração dos elementos analisados por ICP OES e}

\section{AAS nas amostras de sedimentos - Gráficos Box Plot}

Para a verificação da variação de concentração, a partir dos dados obtidos pelas técnicas de ICP OES e AAS, foram confeccionados gráficos "box plot" para cada elemento determinado, a partir das representações dos quartis e da mediana, além dos limites mínimos e máximos para cada elemento.

As FIG 4.3 a 4.6 apresentam os "Box plot" para os elementos analisados, agrupados por ordem de concentração.

A FIG 4.3 apresenta os "box plot" para os elementos Be, $\mathrm{Hg}$ e Sn. Os elementos Be e $\mathrm{Hg}$ apresentaram pequena variação de concentração, porém Be apresentou um valor de "outlier" (P3-60). O Sn apresentou uma maior variação de concentração, sem valores "outliers" ou extremos. 


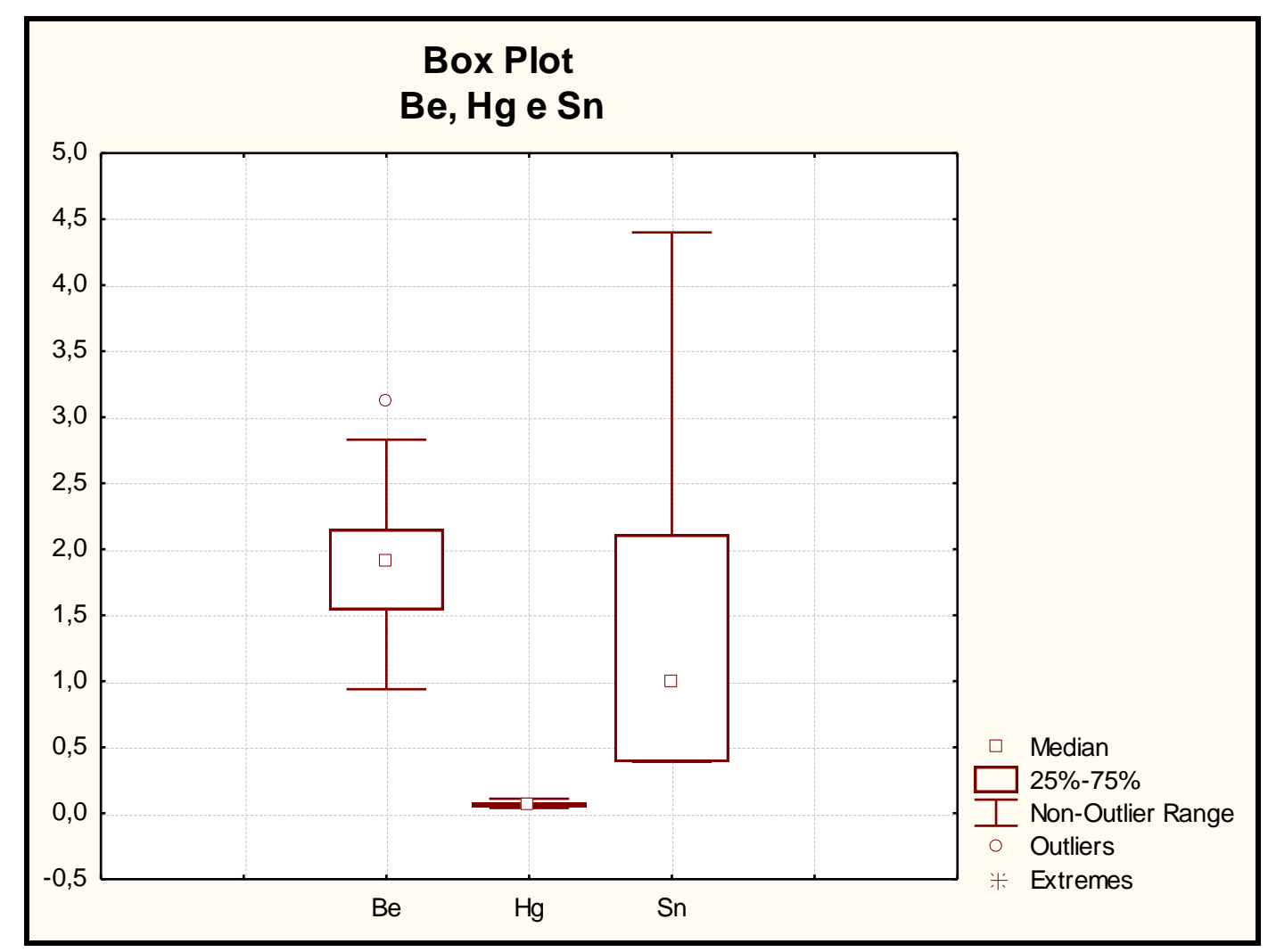

FIGURA 4.3 - Box plot dos elementos Be, Hg e Sn

A FIG 4.4 apresenta os "box plot" para os elementos Al, As, Co, Cu, Fe e Ni. Os elementos $\mathrm{Fe}$ e Co apresentaram pequena variação de concentração nas amostras de sedimentos e todos os valores ficaram dentro do intervalo de $25-75 \%$ dos quartis e não apresentaram valores "outliers" ou extremos. Já os elementos Al e Ni apresentaram pequena variação de concentração, entretanto tiveram valores "outliers" abaixo da mediana, amostras P2-10 para o Al e P4-10 para o Ni. O elemento $\mathrm{Cu}$ apresentou 2 valores "outliers" abaixo da mediana e um acima, P1-10, P1-20 e P2-10, respectivamente. O elemento As também apresentou pequena variação de concentração, porém um valor “outlier' correspondente à amostra P2-50. 


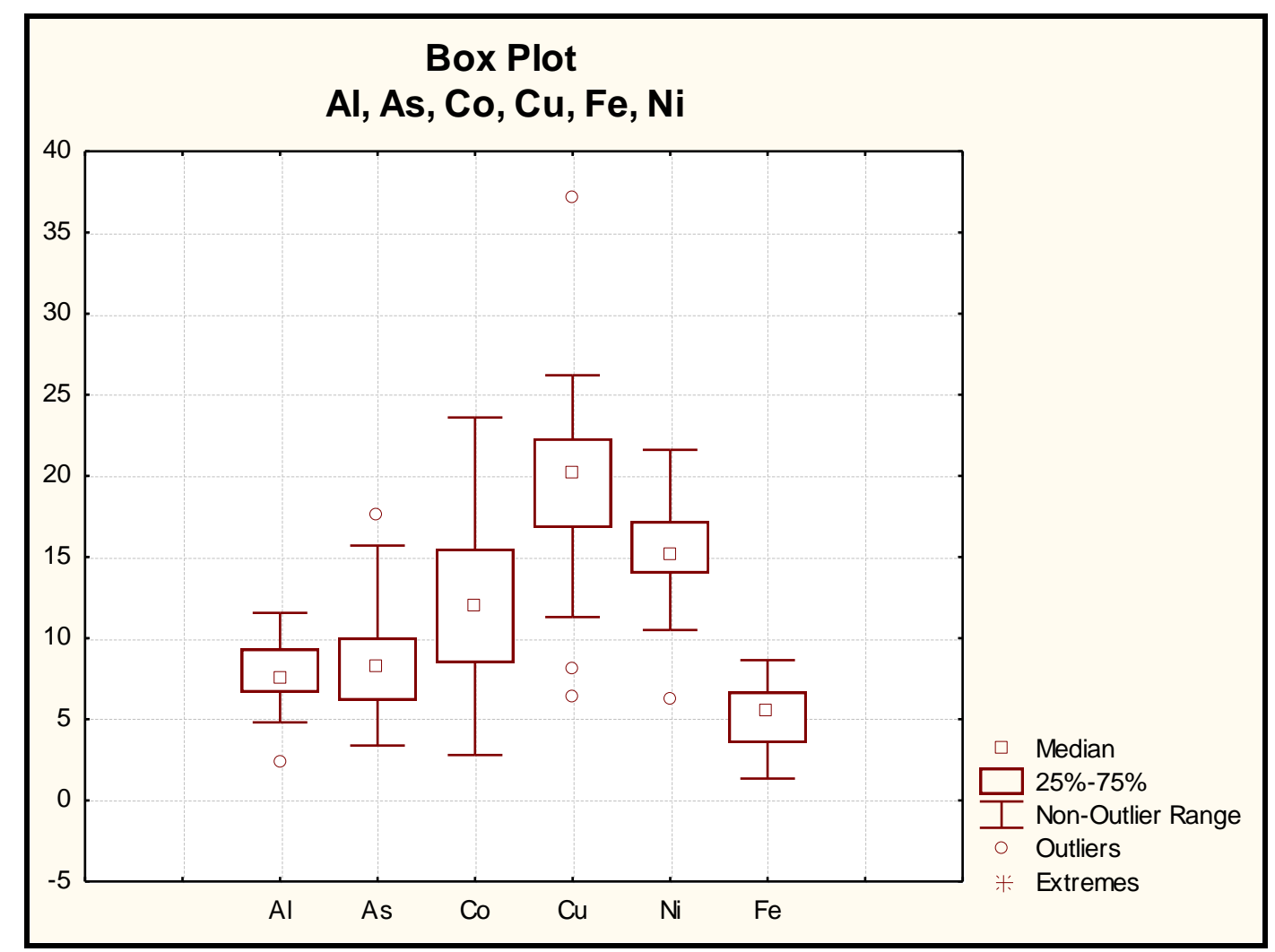

FIGURA 4.4 - Box plot dos elementos Al, As, Co, Cu, Fe e Ni

A FIG 4.5 apresenta os "box plot" para os elementos $\mathrm{Cr}, \mathrm{Li}, \mathrm{Pb}, \mathrm{Zn}$ e V. Os elementos $\mathrm{Cr}, \mathrm{Li}, \mathrm{Pb}$ e $\mathrm{Zn}$ apresentaram pequena variação de concentração entretanto apresentaram valores "outliers" ou extremos, com exceção do elemento Cr. O elemento V apresentou uma maior variação de concentração nas amostras de sedimentos, porém sem valores "outliers" ou extremos. 


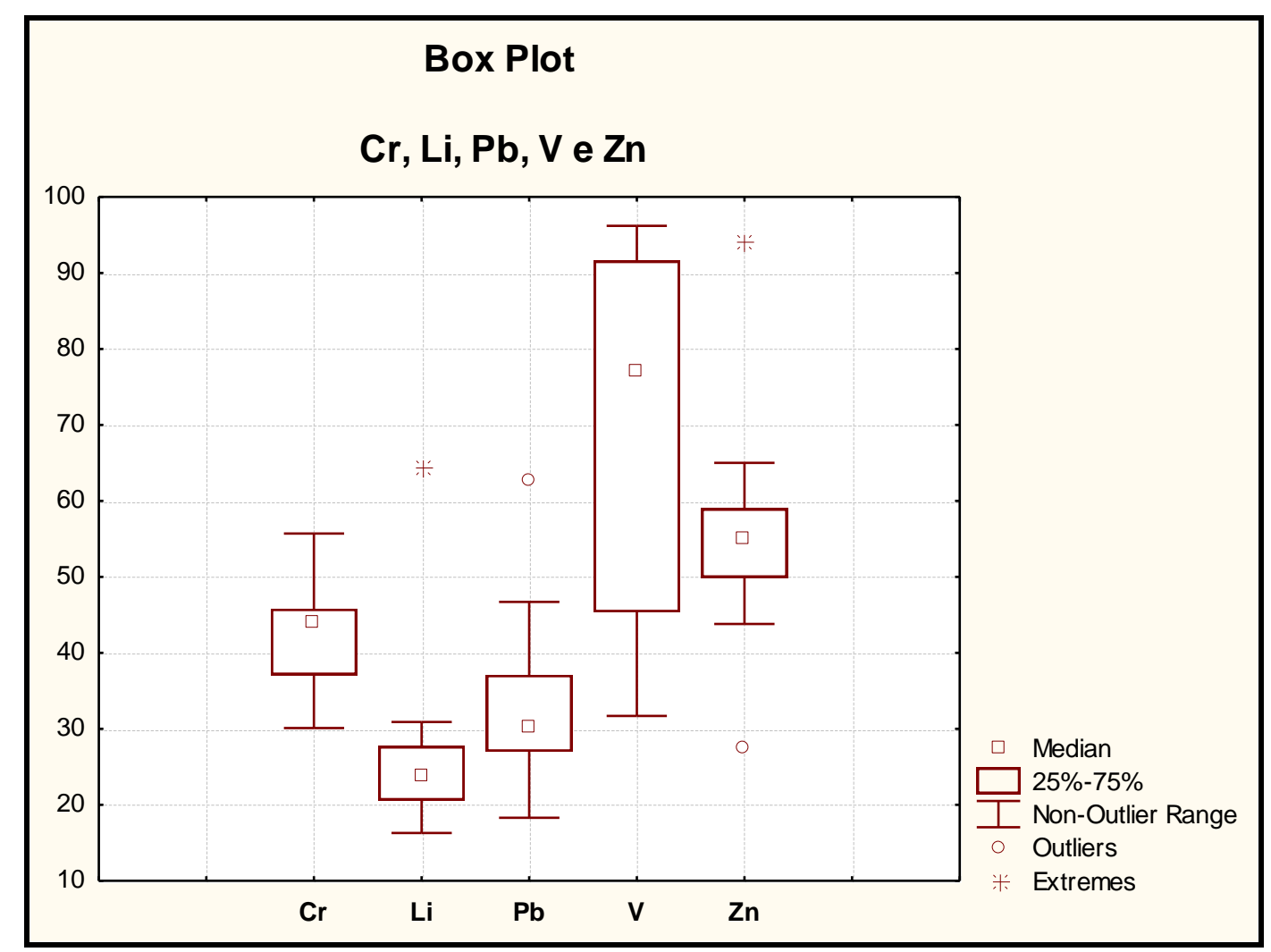

FIGURA 4.5 - Box plot dos elementos $\mathrm{Cr}$, Li, Pb, Zn e V

A FIG 4.6 apresenta os "box plot" para os elementos Ba, Ca, Mg, Mn, P e Ti. Os elementos $\mathrm{Ba}, \mathrm{Ca}$ e $\mathrm{Mn}$, apresentaram pequena variação de concentração nas amostras de sedimentos. O elemento Ti apresentou um valor anômalo (P1-10) e o elemento $\mathrm{Mg}$, dois valores "outlier" (P1-10 e P1-20). O elemento P apresentou valores de concentração dentro da faixa de não “outliers", mas apresentou um valor extremo (P3-60). 


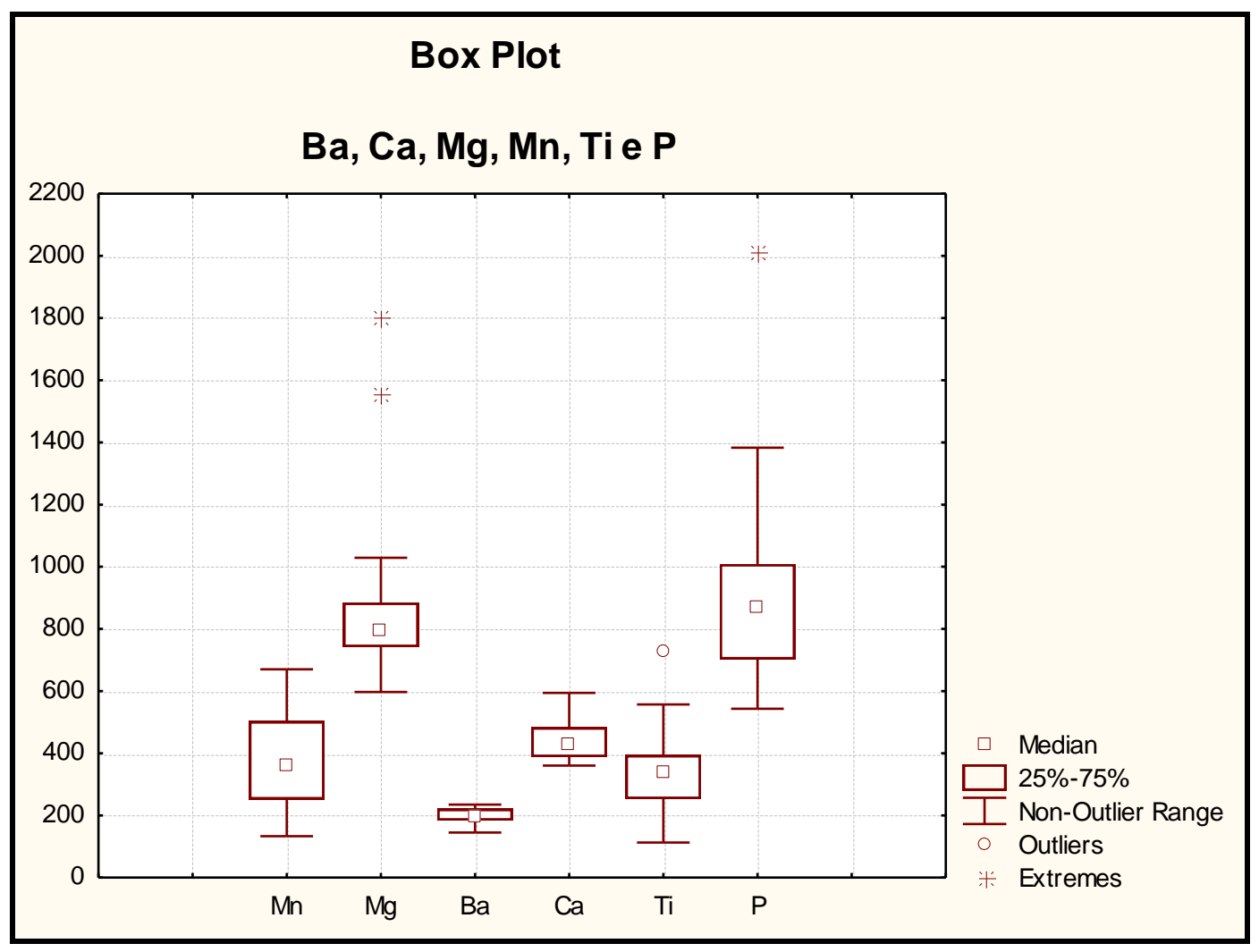

FIGURA 4.6 - Box plot dos elementos Ba, Ca, Mg, Mn, P e Ti

\subsubsection{Comparação dos resultados de concentração para alguns metais, com os valores de TEL e PEL (CCME, 2001)}

A TAB 4.13 apresenta os resultados dos elementos determinados no presente estudo comparados com os valores de TEL e PEL do CCME (2001).

Os valores encontrados para o elemento As, excederam os valores de TEL em todos os pontos, com exceção do ponto 01 .

Os elementos $\mathrm{Cd}, \mathrm{Hg}$ e $\mathrm{Zn}$ não excederam os valores de TEL em nenhum dos pontos analisados. $\mathrm{O}$ elemento $\mathrm{Pb}$, excedeu o valor TEL, no ponto 02 , nas frações $\mathrm{P} 2-20 \mathrm{e}$ P2-10 e no ponto 3, nas frações de P3-50 a P3-30. O elemento $\mathrm{Cr}$ excedeu o valor TEL praticamente em todas as frações dos pontos 02,03 e $04 . \mathrm{O}$ elemento Ni excedeu o TEL somente em algumas frações do ponto 03. 
TABELA 4.13 - Comparação dos resultados de ICP OES, FG AAS e análise direta de mercúrio com os valores de TEL e PEL

\begin{tabular}{cccccccccc}
\hline \multicolumn{2}{c}{ Frações } & As & Cd & Pb & Cu & Cr & Hg & Ni & Zn \\
\hline \multirow{2}{*}{ Pt 01 } & P1- 10 & 3,38 & $<0,04$ & 23,1 & 8,11 & 35,80 & 0,04 & 15,20 & 50,90 \\
& P1-20 & 4,38 & $<0,04$ & 18,5 & 6,41 & 30,10 & 0,04 & 12,32 & 43,80 \\
& P2-10 & $\mathbf{1 7 , 5 7}$ & $<0,04$ & $\mathbf{6 2 , 7}$ & 24,10 & $\mathbf{4 3 , 0 0}$ & 0,07 & 10,50 & 49,9 \\
& P2-20 & $\mathbf{8 , 7 5}$ & $<0,04$ & $\mathbf{3 7 , 5}$ & 16,80 & $\mathbf{4 4 , 0 0}$ & 0,08 & 17,70 & 59,00 \\
Pt 02 & P2-30 & $\mathbf{5 , 3 4}$ & $<0,04$ & 32,4 & 20,70 & $\mathbf{4 5 , 3 0}$ & 0,07 & 15,20 & 61,80 \\
& P2-40 & $\mathbf{6 , 1 7}$ & $<0,04$ & 28,6 & 22,70 & 37,10 & 0,08 & 14,30 & 50,30 \\
& P2-50 & $\mathbf{6 , 0 6}$ & $<0,04$ & 28,8 & 20,80 & $\mathbf{4 5 , 8 0}$ & 0,09 & 14,50 & 53,00 \\
& P3-10 & $\mathbf{8 , 6 3}$ & $<0,04$ & 30,4 & 21,40 & $\mathbf{4 5 , 4 0}$ & 0,05 & 16,20 & 58,00 \\
& P3-20 & $\mathbf{8 , 1 9}$ & $<0,04$ & 33,0 & 18,20 & $\mathbf{5 2 , 2 0}$ & 0,06 & $\mathbf{1 9 , 8 0}$ & 62,60 \\
Pt 03 & P3-30 & $\mathbf{8 , 2 3}$ & $<0,04$ & $\mathbf{3 7 , 1}$ & 19,50 & $\mathbf{4 3 , 8 0}$ & 0,09 & 15,30 & 65,00 \\
& P3-40 & $\mathbf{8 , 0 0}$ & 0,05 & $\mathbf{4 6 , 7}$ & 21,50 & $\mathbf{4 1 , 0 0}$ & 0,07 & 14,00 & 57,10 \\
& $\mathbf{P 3 - 5 0}$ & $\mathbf{1 0 , 2 5}$ & 0,05 & $\mathbf{4 6 , 5}$ & $\mathbf{3 7 , 1 0}$ & $\mathbf{4 3 , 9 0}$ & 0,09 & $\mathbf{2 1 , 6 0}$ & 94,30 \\
& P3-60 & $\mathbf{7 , 3 8}$ & $<0,04$ & 34,1 & 13,30 & 32,20 & 0,11 & $\mathbf{2 0 , 3 5}$ & 58,50 \\
& P4-10 & $\mathbf{9 , 7 9}$ & $<0,04$ & 20,3 & 11,30 & $\mathbf{5 5 , 7 0}$ & 0,05 & 6,16 & 27,60 \\
& P4-20 & $\mathbf{1 5 , 5 9}$ & $<0,04$ & 30,0 & 19,30 & $\mathbf{5 3 , 1 0}$ & 0,06 & 16,00 & 49,40 \\
Pt 04 & P4-30 & $\mathbf{1 5 , 7 1}$ & $<0,04$ & 29,8 & 20,10 & $\mathbf{5 0 , 7 0}$ & 0,07 & 15,10 & 54,30 \\
& P4-40 & $\mathbf{1 0 , 0 3}$ & $<0,04$ & 30,1 & 19,20 & $\mathbf{4 5 , 4 0}$ & 0,07 & 14,90 & 49,00 \\
& P4-50 & $\mathbf{8 , 4 7}$ & $<0,04$ & 27,0 & 22,30 & $\mathbf{4 4 , 4 0}$ & 0,05 & 13,60 & 55,00 \\
& P4-60 & $\mathbf{6 , 6 0}$ & $<0,04$ & 18,3 & 26,20 & 33,90 & 0,05 & 17,20 & 56,40 \\
\hline TEL & $\mathbf{5 , 9}$ & $\mathbf{0 , 6}$ & $\mathbf{3 5}$ & $\mathbf{3 5 , 7}$ & $\mathbf{3 7 , 3}$ & $\mathbf{0 , 1 7}$ & $\mathbf{1 8}$ & $\mathbf{1 2 3}$ \\
PEL & $\mathbf{1 7}$ & $\mathbf{3 , 5}$ & $\mathbf{9 1 , 3}$ & $\mathbf{1 9 7}$ & $\mathbf{9 0}$ & $\mathbf{0 , 4 8 6}$ & $\mathbf{3 5 , 9}$ & $\mathbf{3 1 5}$ \\
\hline
\end{tabular}

\subsubsection{Fator de Enriquecimento (FE)}

O fator de enriquecimento, para os resultados de ICP OES, FG AAS e análise direta de mercúrio, foi calculado conforme descrito no item 3.9. Para este cálculo foram utilizados os valores de concentração determinado para cada um dos elementos de interesse e os valores de referência. Como valores de referência foram utilizados os valores de UCC (Upper Continental Crust), NASC (North American Shale Composite) e a concentração dos elementos na base do perfil do ponto 3. Esse perfil, aparentemente, parece ter chegado até a base pré-alagamento do reservatório, conforme mostrado na imagem do perfil apresentada na FIG 4.7, onde podemos observar uma diferença em sua base com uma coloração mais escura e com presença de pedaços de folhas e galhos de árvore. Em vista disto e por falta de informações sobre o solo da região do reservatório, escolhemos a base deste perfil para ser usado como valor de referência para os cálculos do EF e Igeo. Como elemento normalizador para estes cálculos foi escolhido o Sc, por ser considerado 
conservativo e distribuído de forma ampla na crosta terrestre. Os valores de Sc, utilizados para os cálculos foram determinados pela técnica INAA e seus valores encontram-se na Tabela 4.23.

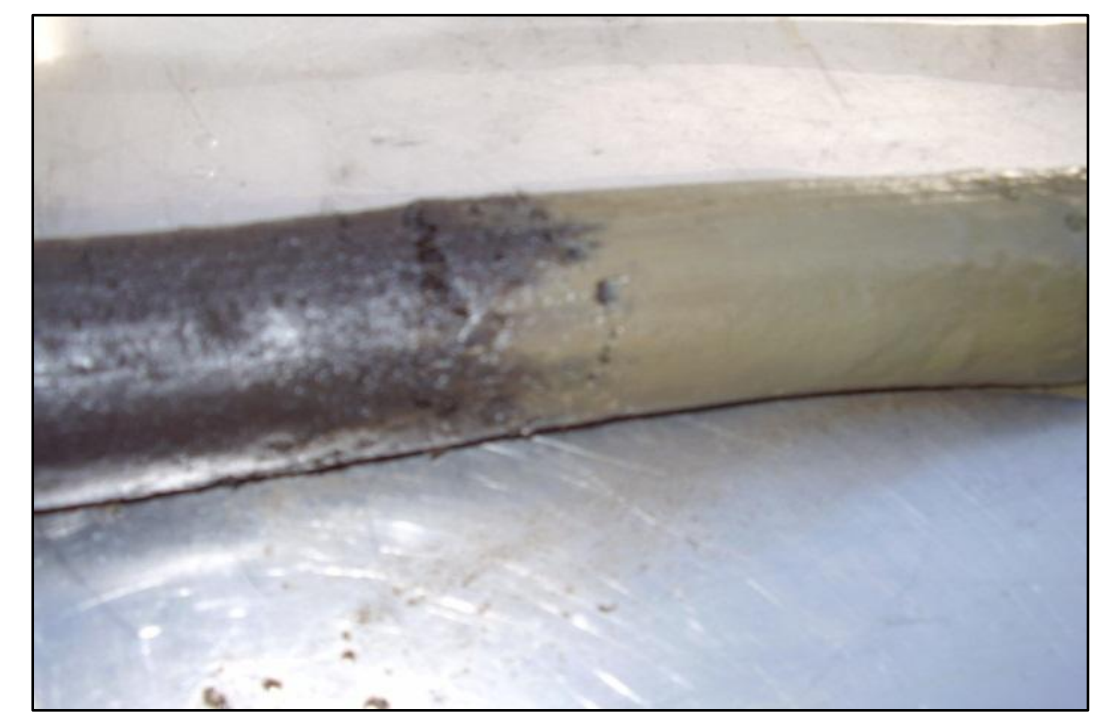

FIGURA 4.7 - Foto do perfil sedimentar do ponto 03

Por convenção, se o valor de FE está entre 0,5 e 1,5, considera-se que metais traço são provenientes totalmente de contribuição crustal (por exemplo, produto de intemperismo) e o valor de FE > 1,5, é indicativo de que a fonte principal é de contribuição antrópica. Quanto maior o valor de FE, maior o grau de poluição de origem antrópica (ZHANG \& LIU, 2002).

As TAB 4.14, 4.15 e 4.16, apresentam os resultados obtidos para o FE, para os elementos As, Ba, Ca, Co, Cr, Fe, Hg, Mg, Mn, Ti, V e Zn, em todos os pontos. Estes elementos foram escolhidos por serem dentre os analisados por ICP OES, os elementos com valores tabelados para UCC e NASC.

Em relação aos três valores de referência utilizados (UCC, NASC e base do perfil), verifica-se que os valores de FE, para a maioria dos elementos analisados, se encontraram entre 0,5 e 1,5, indicando uma contribuição crustal.

Quando os valores de referência foram os valores de UCC, o elemento As 
apresentou valores de FE>1,5 para o ponto 2 nas frações superficiais, e em todas as frações dos pontos 3 e 4 .

Quando os valores de referência foram os valores do NASC, o elemento As apresentou valores de $\mathrm{FE}>1,5$, para todos os pontos. O Fe apresentou valores de $\mathrm{FE}>1,5$ nas superfícies dos pontos 3 e 4. Já o elemento $\mathrm{Hg}$ apresentou $\mathrm{FE}>1$,5, na superfície do ponto 2 e base dos pontos 3 e 4 .

$\mathrm{O}$ elemento $\mathrm{Pb}$ apresentou $\mathrm{FE}>1,5$, nas frações P2-10, P2-20 e P2-30 e no ponto 3, P3-20 a P3-60.

Quando os valores de referência foram os valores da base do perfil o elemento Fe apresentou valores de $\mathrm{FE}>1,5$, nos pontos 2, 3 e 4, com exceção dos valores da base do perfil e o elemento $\mathrm{Cu}$, na fração $\mathrm{P} 4-60$

Os maiores valores de FE foram observados para o As principalmente em relação aos valores de UCC e NASC. Entretanto, quando os valores de referência foram os valores da base do perfil, não foram verificados valores de $\mathrm{FE}>1,5$, para nenhuma das frações em nenhum dos pontos indicando que, provavelmente, a concentração basal desse elemento é mais alta do que os valores de UCC e NASC.

Analisando-se os valores do elemento Fe parece haver uma contaminação por origem antrópica para esse elemento, que aparece como enriquecido quando se analisa tomando-se como referência os valores do NASC e base do perfil para as camadas mais superficiais dos pontos 3 e 4, o que indica que o sedimento deste reservatório começa a sofrer enriquecimento de Fe de origem antrópica. 
TABELA 4.14 - Valores de FE, tendo Sc como elemento normalizador e valores de concentração do UCC como valores de referência

\begin{tabular}{|c|c|c|c|c|c|c|c|c|c|c|c|c|c|c|c|c|}
\hline \multicolumn{17}{|c|}{ Normalização com UCC } \\
\hline Ponto & Amostra & As & Ba & $\mathrm{Ca}$ & Co & $\mathrm{Cr}$ & $\mathrm{Cu}$ & $\mathbf{F e}$ & $\mathrm{Hg}$ & Mg & Mn & $\mathrm{Ni}$ & $\mathbf{P b}$ & Ti & V & $\mathrm{Zn}$ \\
\hline \multirow{2}{*}{ Pt 01} & P1-10 & 0,86 & 0,18 & 0,01 & 0,37 & 0,52 & 0,29 & 0,32 & 0,36 & 0,07 & 0,14 & 0,41 & 0,69 & 0,12 & 0,40 & 0,50 \\
\hline & -20 & 1,24 & 0,15 & 0,01 & 0,31 & 0,49 & 0,25 & 0,33 & 0,40 & 0,07 & 0,14 & 0,37 & 0,61 & 0,07 & 0,34 & 0,48 \\
\hline \multirow{5}{*}{ Pt 02} & P2-10 & 2,04 & 0,11 & 0,01 & 0,50 & 0,52 & 0,71 & 0,69 & 0,53 & 0,02 & 0,25 & 0,24 & 1,56 & 0,03 & 0,36 & 0,41 \\
\hline & P2-20 & 1,80 & 0,12 & 0,01 & 0,45 & 52 & 48 & 0,73 & 0,59 & 0,03 & 0,26 & 0,39 & 0,91 & 0,04 & 0,59 & 0,47 \\
\hline & P2-30 & 1,28 & 0,15 & 0,01 & 0,65 & 0,62 & 0,70 & 1,00 & 0,60 & 0,03 & 0,35 & 0,39 & 0,92 & 0,04 & 0,66 & 0,57 \\
\hline & P2-40 & 1,22 & 0,11 & 0,01 & 0,44 & 0,42 & 0,63 & 0,45 & 0,56 & 0,02 & 0,24 & 0,30 & 0,67 & 0,01 & 0,44 & 0,38 \\
\hline & $\mathrm{P} 2-50$ & 0,86 & 0,09 & 0,00 & 0,24 & 0,37 & 0,41 & 0,36 & 0,46 & 0,02 & 0,14 & 0,22 & 0,48 & 0,02 & 0,41 & 0,29 \\
\hline \multirow{6}{*}{ Pt 03} & P3-10 & 1,68 & 0,11 & 0,01 & 0,40 & 0,50 & 0,58 & 0,97 & 0,35 & 0,02 & 0,37 & 0,34 & 0,70 & 0,04 & 0,68 & 0,43 \\
\hline & P3-20 & 1,68 & 0,14 & 0,01 & 0,43 & 0,61 & 0,52 & 0,79 & 0,44 & 0,03 & 0,27 & 0,44 & 0,80 & 0,07 & 0,74 & 0,50 \\
\hline & P3-30 & 1,76 & 0,12 & 0,01 & 0,59 & 0,53 & 0,58 & 0,84 & 0,46 & 0,03 & 0,36 & 0,35 & 0,93 & 0,06 & 0,72 & 0,53 \\
\hline & P3-40 & 1,77 & 0,13 & 0,01 & 0,66 & 0,52 & 0,67 & 0,78 & 0,71 & 0,03 & 0,36 & 0,33 & 1,22 & 0,06 & 0,68 & 0,49 \\
\hline & & 1,98 & 0,11 & 0,01 & 0,79 & 0,48 & 1,00 & 0,51 & 0,62 & 0,02 & 0,40 & 0,45 & 1,06 & 0,04 & 0,65 & 0,70 \\
\hline & & 2,46 & 0,23 & 0,01 & 0,64 & 0,61 & 0,62 & 0,32 & 1,31 & 0,05 & 0,45 & 0,73 & 1,34 & 0,08 & 0,50 & 0,75 \\
\hline \multirow{6}{*}{ Pt 04} & & 1,68 & 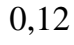 & 0,0 & 0,20 & 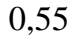 & 0,27 & 0, & 0,31 & 0,02 & 0,37 & 0,11 & 0,41 & 0,05 & 0,62 & 0,18 \\
\hline & & 2,96 & 0,11 & 0,01 & 0,28 & 0,58 & 0,51 & 0,83 & 0,41 & 0,02 & 0,36 & 0,33 & 0,67 & 0,04 & 0,66 & 0,36 \\
\hline & P4-30 & 2,76 & 0,10 & 0,01 & 0,33 & 0,51 & 0,49 & 0,99 & 0,44 & 0,02 & 0,45 & 0,29 & 0,62 & 0,04 & 0,61 & 0,37 \\
\hline & P4-40 & 1,77 & 0,10 & 0,00 & 0,47 & 0,46 & 0,47 & 0,83 & 0,44 & 0,02 & 0,27 & 0,28 & 0,63 & 0,04 & 0,55 & 0,33 \\
\hline & P4-50 & 1,74 & 0,11 & 0,01 & 0,28 & 0,52 & 0,64 & 0,55 & 0,37 & 0,02 & 0,20 & 0,30 & 0,65 & 0,03 & 0,58 & 0,44 \\
\hline & P4-60 & 2,17 & 0,14 & 0,01 & 0,16 & 0,64 & 1,21 & 0,29 & 0,59 & 0,04 & 0,27 & 0,61 & 0,71 & 0,03 & 0,45 & 0,71 \\
\hline
\end{tabular}

TABELA 4.15 - Valores de FE, tendo Sc como elemento normalizador e valores de concentração do NASC como valores de referência

\begin{tabular}{|c|c|c|c|c|c|c|c|c|c|c|c|c|c|c|c|c|}
\hline \multicolumn{17}{|c|}{ Normalização com NASC } \\
\hline Ponto & Amostra & As & Ba & $\mathbf{C a}$ & Co & $\mathrm{Cr}$ & $\mathrm{Cu}$ & $\mathrm{Fe}$ & $\mathrm{Hg}$ & Mg & Mn & $\mathrm{Ni}$ & $\mathbf{P b}$ & Ti & V & $\mathbf{Z n}$ \\
\hline \multirow{2}{*}{ Pt 01} & P1-10 & 2,30 & 0,47 & 0,02 & 0,41 & 0,33 & - & 0,52 & 1,16 & 0,10 & 0,24 & 0,30 & 1,34 & 0,21 & 0,49 & 0,91 \\
\hline & P1-20 & 3,33 & 0,38 & 0,02 & 0,34 & 0,31 & -- & 0,54 & 1,29 & 0,09 & 0,24 & 0,27 & 1,19 & 0,13 & 0,42 & 0,87 \\
\hline \multirow{5}{*}{ Pt 02} & P2-10 & 5,5 & 0,30 & 0,01 & 0,55 & 0,33 & -- & 1,12 & 1,70 & 0,03 & 0,42 & 0,18 & 3,04 & 0,06 & 0,45 & 0,74 \\
\hline & $\mathrm{P} 2-20$ & 4,84 & 0,31 & 0,01 & 0,50 & 0,33 & -- & 1,19 & 1,88 & 0,04 & 0,43 & 0,29 & 1,76 & 0,06 & 0,73 & 0,85 \\
\hline & $\mathrm{P} 2-30$ & 3,45 & 0,39 & 0,01 & 0,71 & 0,40 & -- & 1,63 & 1,92 & 0,04 & 0,59 & 0,29 & 1,78 & 0,07 & 0,81 & 1,05 \\
\hline & P2-40 & 3,28 & 0,29 & 0,01 & 0,49 & 0,27 & -- & 0,74 & 1,81 & 0,03 & 0,40 & 0,22 & 1,29 & 0,03 & 0,54 & 0,70 \\
\hline & P2-50 & 2,31 & 0,25 & 0,01 & 0,26 & 0,24 & -- & 0,59 & 1,46 & 0,02 & 0,23 & 0,16 & 0,93 & 0,04 & 0,51 & 0,53 \\
\hline \multirow{6}{*}{ Pt 03} & P3-10 & 4,51 & 0,28 & 0,01 & 0,44 & 0,32 & -- & 1,58 & 1,11 & 0,03 & 0,62 & 0,25 & 1,35 & 0,07 & 0,84 & 0,79 \\
\hline & P3-20 & 4,53 & 0,36 & 0,01 & 0,47 & 0,39 & -- & 1,29 & 1,41 & 0,04 & 0,45 & 0,32 & 1,55 & 0,13 & 0,91 & 0,91 \\
\hline & P3-30 & 4,72 & 0,32 & 0,01 & 0,65 & 0,34 & -- & 1,38 & 1,46 & 0,04 & 0,60 & 0,26 & 1,81 & 0,11 & 0,89 & 0,98 \\
\hline & P3-40 & 4,76 & 0,35 & 0,01 & 0,72 & 0,33 & -- & 1,27 & 2,28 & 0,04 & 0,61 & 0,24 & 2,36 & 0,10 & 0,84 & 0,89 \\
\hline & P3-50 & 5,32 & 0,29 & 0,01 & 0,87 & 0,31 & -- & 0,84 & 1,98 & 0,03 & 0,67 & 0,33 & 2,05 & 0,07 & 0,80 & 1,28 \\
\hline & P3-60 & 6,62 & 0,61 & 0,02 & 0,71 & 0,39 & -- & 0,53 & 4,19 & 0,07 & 0,76 & 0,53 & 2,60 & 0,14 & 0,61 & 1,37 \\
\hline \multirow{6}{*}{ Pt 04} & & 4,5 & & & 0,22 & 0, & -- & 1,51 & 0,98 & 0,03 & 0,62 & 0,08 & 0,79 & 0,08 & 0,77 & 0,33 \\
\hline & & 7,9 & 0,2 & & 0,31 & 0 , & -- & 1,3 & 1,30 & 0,03 & 0,61 & 0,24 & 1,30 & 0,08 & 0,81 & 0,66 \\
\hline & & 7,43 & 0,27 & 0,0 & 0,36 & 0,32 & -- & 1,61 & 1,41 & 0,03 & 0,75 & 0,21 & 1,20 & 0,08 & 0,76 & 0,67 \\
\hline & & 4,77 & 0,26 & 0,0 & 0,52 & 0,29 & -- & 1,36 & 1,41 & 0,03 & 0,46 & 0,21 & 1,22 & 0,07 & 0,68 & 0,61 \\
\hline & & 4,69 & 0,29 & 0,0 & 0,31 & 0,33 & -- & 0,90 & 1,18 & 0,03 & 0,33 & 0,22 & 1,27 & 0,06 & 0,72 & 0,80 \\
\hline & P4-60 & 5,84 & 0,37 & 0,01 & 0,18 & 0,40 & -- & 0,47 & 1,88 & 0,05 & 0,46 & 0,45 & 1,38 & 0,06 & 0,55 & 1,30 \\
\hline
\end{tabular}


TABELA 4.16 - Valores de FE tendo Sc como elemento normalizador e valores de concentração da base do perfil como valores de referência

\begin{tabular}{|c|c|c|c|c|c|c|c|c|c|c|c|c|c|c|c|c|}
\hline \multicolumn{17}{|c|}{ Normalização com Base do Perfil } \\
\hline Ponto & mostra & As & $\mathbf{B a}$ & $\mathrm{Ca}$ & Co & $\mathrm{Cr}$ & $\mathrm{Cu}$ & $\mathrm{Fe}$ & $\mathbf{H g}$ & $\mathbf{M g}$ & Mn & $\mathbf{N i}$ & $\mathbf{P b}$ & $\mathbf{T i}$ & V & $\mathbf{Z n}$ \\
\hline \multirow{2}{*}{ Pt 01} & $\overline{P 1-10}$ & 0,35 & 0,76 & 1,03 & 0,58 & 0,84 & 0,46 & 0,98 & 0,28 & 1,33 & 0,31 & 0,57 & 0,51 & 1,49 & 0,80 & 0,66 \\
\hline & -20 & 0,50 & 0,63 & 1,14 & 48 & 0,79 & 11 & 1,03 & 0,31 & 1,28 & 0,31 & 0,51 & 0,46 & 0,90 & 0,68 & 0,63 \\
\hline \multirow{5}{*}{ Pt 02} & P2-10 & 0,83 & 0,49 & 0,52 & 0,77 & 0,85 & 1,15 & 2,13 & 0,40 & 0,37 & 0,56 & 0,33 & 1,17 & 0,43 & 0,73 & 0,54 \\
\hline & -20 & 0,73 & 0,50 & 0,60 & 0,71 & 0,84 & 0,78 & 2,27 & 0,45 & 0,50 & 0,57 & 0,54 & 0,68 & 0,45 & 1,18 & 0,62 \\
\hline & P2-30 & 0,52 & 0,64 & 0,77 & 1,01 & 1,02 & 1,12 & 3,10 & 0,46 & 0,55 & 0,77 & 0,54 & 0,69 & 0,49 & 1,32 & 0,76 \\
\hline & P2-40 & 0,50 & 0,47 & 0,52 & 0,68 & 0,68 & 1,01 & 1,41 & 0,43 & 0,35 & 0,52 & 0,42 & 0,50 & 0,18 & 0,89 & 0,51 \\
\hline & 50 & 0,35 & 0,40 & 0,34 & 0,37 & 0,60 & 0,66 & 1,12 & 0,35 & 0,32 & 0,30 & 0,30 & 0,36 & 0,29 & 0,83 & 0,38 \\
\hline \multirow{6}{*}{ Pt 03} & P3-10 & 0,68 & 0,46 & 0,64 & 0,63 & 0,82 & 0,94 & 3,00 & 0,27 & 0,43 & 0,82 & 0,46 & 0,52 & 0,48 & 1,37 & 0,58 \\
\hline & P3-20 & 0,68 & 0,58 & 0,60 & 0,66 & 1,00 & 0,84 & 2,45 & 0,34 & 0,56 & 0,59 & 0,60 & 0,60 & 0,93 & 1,49 & 0,66 \\
\hline & P3-30 & 0,71 & 0,53 & 0,61 & 0,91 & 0,87 & 0,94 & 2,62 & 0,35 & 0,49 & 0,79 & 0,48 & 0,70 & 0,76 & 1,46 & 0,71 \\
\hline & P3-40 & 0,72 & 0,57 & 0,64 & 1,02 & 0,85 & 1,07 & 2,42 & 0,54 & 0,50 & 0,80 & 0,46 & 0,91 & 0,70 & 1,36 & 0,65 \\
\hline & & 0,80 & 0,47 & 0,52 & 1,22 & 0,79 & 1,61 & 1,59 & 0,47 & 0,42 & 0,88 & 0,61 & 0,79 & 0,46 & 1,30 & 0,93 \\
\hline & & 1,00 & 1,00 & 1,00 & 1,00 & 1,00 & 1,00 & 1,00 & 1,00 & 1,00 & 1,00 & 1,00 & 1,00 & 1,00 & 1,00 & 1,00 \\
\hline \multirow{6}{*}{ Pt 04} & & 0,68 & 0,5 & 0,59 & 0,31 & 0,89 & 0,44 & 2,86 & 0,23 & 0,44 & 0,81 & 0,16 & 0,31 & 0,57 & 1,25 & 0,24 \\
\hline & P4-20 & 1,21 & 0,48 & 0,57 & 0,44 & 0,94 & 0,83 & 2,56 & 0,31 & 0,41 & 0,80 & 0,45 & 0,50 & 0,55 & 1,32 & 0,48 \\
\hline & P4-30 & 1,12 & 0,44 & 0,53 & 0,51 & 0,83 & 0,80 & 3,06 & 0,34 & 0,41 & 0,99 & 0,39 & 0,46 & 0,56 & 1,23 & 0,49 \\
\hline & P4-40 & 0,72 & 0,42 & 0,47 & 0,73 & 0,75 & 0,77 & 2,58 & 0,34 & 0,39 & 0,61 & 0,39 & 0,47 & 0,48 & 1,11 & 0,44 \\
\hline & P4-50 & 0,71 & 0,48 & 0,51 & 0,44 & 0,85 & 1,04 & 1,72 & 0,28 & 0,43 & 0,43 & 0,41 & 0,49 & 0,40 & 1,17 & 0,58 \\
\hline & P4-60 & 0,88 & 0,61 & 0,84 & 0,25 & 1,04 & 1,94 & 0,89 & 0,45 & 0,76 & 0,60 & 0,83 & 0,53 & 0,43 & 0,90 & 0,95 \\
\hline
\end{tabular}

\subsection{9. Índice de Geoacumulação (Igeo)}

O índice de geoacumulação foi calculado conforme descrito no item 3.10 e para este cálculo foram utilizados os valores de concentração determinados para cada um dos elementos de interesse da amostra e os valores de referência. Para tal foram utilizados os valores de UCC, NASC e base do perfil, neste caso utilizando-se a base do perfil (mesmo utilizado para o cálculo do FE).

Nas TAB. 4-17, 4-18 e 4-19 se encontram apresentados os valores de Igeo obtidos para os elementos, a partir dos respectivos valores de referência UCC, NASC e base do perfil. A partir dos resultados, podemos observar que para o valor de referência UCC foram encontrados valores de $\mathbf{1}<$ Igeo $<2$ para o elemento As, para a maioria das amostras dos pontos 2, 3 e 4 e para o elemento $\mathrm{Pb}$ no ponto 2 (P2-10), com indicação de nível moderadamente poluído para esses elementos, segundo a TAB 3.6 de classificação do Igeo. Valores de $2<$ Igeo 3 foram encontrados somente para as amostras P2-10, P4-20 e P4-30, com classificação de sedimento moderadamente a poluído para esse elemento. 
Quando os valores de referência foram os dados do NASC (Tabela 4.18), se repetiram os mesmos resultados encontrados para o elemento As e para o elemento $\mathrm{Pb}$ somente a fração P2-10 apresentou valor de Igeo $>1$.

Entretanto, quando os valores de referência foram os valores da base do perfil (TAB 4.19), foram encontrados valores de $1<$ Igeo $<2$ somente para o elemento $\mathrm{Fe}$, para algumas amostras do ponto 2 (P2-10 a 30), do ponto 3 (P3-10 a 40) e do ponto 4 (P4-10 a 40), com indicação de sedimento moderadamente poluído.

Os valores de Igeo $<0$ encontrados para a maioria dos elementos, são indicativos de não contaminados e valores de $0<\operatorname{Igeo}<1$, de sedimentos não contaminados a moderadamente contaminados.

TABELA 4.17 - Valores de Igeo obtidos a partir dos valores de concentração do UCC

\begin{tabular}{|c|c|c|c|c|c|c|c|c|c|c|c|c|c|c|c|c|}
\hline \multicolumn{17}{|c|}{ Normalização com UCC } \\
\hline Ponto & mostra & As & $\mathbf{B a}$ & $\mathbf{C a}$ & Co & $\mathrm{Cr}$ & $\mathbf{C u}$ & $\mathbf{F e}$ & $\mathrm{Hg}$ & Mg & Mn & $\mathbf{N i}$ & $\mathbf{P b}$ & $\mathbf{T i}$ & $\mathbf{V}$ & $\mathbf{Z n}$ \\
\hline \multirow{2}{*}{ Pt 01} & 0 & 0,2 & $-2,1$ & $-6,2$ & $-1,0$ & $-0,6$ & $-1,4$ & $-1,3$ & $-1,1$ & $-3,5$ & $-2,4$ & $-0,9$ & $-0,1$ & $-2,7$ & $-0,9$ & $-0,6$ \\
\hline & 20 & 0,5 & $-2,5$ & $-6,2$ & $-1,5$ & $-0,8$ & $-1,7$ & $-1,4$ & $-1,1$ & $-3,7$ & $-2,6$ & $-1,2$ & $-0,5$ & $-3,6$ & $-1,3$ & $-0,8$ \\
\hline \multirow{5}{*}{ Pt 02} & 20 & 2,6 & $-2,5$ & $-6,9$ & $-0,4$ & $-0,3$ & 0,2 & 0,1 & $-0,3$ & $-5,1$ & $-1,3$ & $-1,4$ & 1,3 & $-4,2$ & $-0,8$ & $-0,6$ \\
\hline & 20 & 1,5 & $-2,4$ & $-6,7$ & $-0,4$ & $-0,3$ & $-0,4$ & 0,2 & $-0,1$ & $-4,6$ & $-1,3$ & $-0,7$ & 0,6 & $-4,1$ & $-0,1$ & $-0,4$ \\
\hline & P2-30 & 0,8 & $-2,3$ & $-6,6$ & $-0,2$ & $-0,2$ & $-0,1$ & 0,5 & $-0,3$ & $-4,7$ & $-1,1$ & $-0,9$ & 0,3 & $-4,2$ & $-0,1$ & $-0,3$ \\
\hline & & 1,0 & $-2,4$ & $-6,8$ & $-0,4$ & $-0,5$ & 0,1 & $-0,4$ & $-0,1$ & $-5,1$ & $-1,3$ & $-1,0$ & 0,2 & $-5,4$ & $-0,4$ & $-0,6$ \\
\hline & & 1,0 & $-2,2$ & $-7,0$ & $-0,8$ & $-0,2$ & 0,0 & $-0,2$ & 0,1 & $-4,7$ & $-1,6$ & $-0,9$ & 0,2 & $-4,2$ & 0,0 & $-0,6$ \\
\hline \multirow{6}{*}{ Pt 03} & 10 & 1,5 & $-2,4$ & $-6,5$ & $-0,5$ & $-0,2$ & 0,0 & 0,7 & $-0,7$ & $-4,7$ & $-0,7$ & $-0,8$ & 0,3 & $-3,9$ & 0,2 & $-0,4$ \\
\hline & P3-20 & 1,4 & $-2,2$ & $-6,7$ & $-0,5$ & 0,0 & $-0,2$ & 0,4 & $-0,5$ & $-4,4$ & $-1,2$ & $-0,5$ & 0,4 & $-3,1$ & 0,3 & $-0,3$ \\
\hline & P3 & 1,5 & $-2,4$ & $-6,7$ & $-0,1$ & $-0,3$ & $-0,1$ & 0,4 & $-0,5$ & $-4,7$ & $-0,8$ & $-0,9$ & 0,5 & $-3,4$ & 0,2 & $-0,3$ \\
\hline & P3-40 & 1,4 & $-2,3$ & $-6,7$ & 0,0 & $-0,4$ & 0,0 & 0,2 & 0,1 & $-4,7$ & $-0,9$ & $-1,0$ & 0,9 & $-3,6$ & 0,0 & $-0,4$ \\
\hline & & 1,8 & $-2,4$ & $-6,8$ & 0,4 & $-0,3$ & 0,8 & $-0,2$ & 0,1 & $-4,8$ & $-0,5$ & $-0,4$ & 0,9 & $-4,0$ & 0,2 & 0,3 \\
\hline & P3-60 & 1,3 & $-2,1$ & $-6,7$ & $-0,6$ & $-0,7$ & $-0,7$ & $-1,6$ & 0,4 & $-4,3$ & $-1,1$ & $-0,5$ & 0,4 & $-3,7$ & $-1,0$ & $-0,4$ \\
\hline \multirow{6}{*}{ Pt 04} & & 1,7 & $-2,1$ & $-6,4$ & $-1,4$ & 0,1 & $-0,9$ & 0,8 & $-0,7$ & $-4,5$ & $-0,5$ & $-2,2$ & $-0,3$ & $-3,5$ & 0,3 & $-1,5$ \\
\hline & & 2,4 & $-2,3$ & $-6,7$ & $-1,0$ & 0,0 & $-0,2$ & 0,5 & $-0,5$ & $-4,8$ & $-0,6$ & $-0,8$ & 0,2 & $-3,7$ & 0,2 & $-0,7$ \\
\hline & P4-30 & 2,4 & $-2,4$ & $-6,6$ & $-0,7$ & $-0,1$ & $-0,1$ & 0,9 & $-0,3$ & $-4,7$ & $-0,2$ & $-0,9$ & 0,2 & $-3,6$ & 0,2 & $-0,5$ \\
\hline & P4-40 & 1,7 & $-2,4$ & $-6,8$ & $-0,2$ & $-0,2$ & $-0,2$ & 0,7 & $-0,3$ & $-4,7$ & $-1,0$ & $-0,9$ & 0,2 & $-3,8$ & 0,1 & $-0,7$ \\
\hline & & 1,5 & $-2,5$ & $-6,9$ & $-1,1$ & $-0,2$ & 0,1 & $-0,2$ & $-0,7$ & $-4,8$ & $-1,7$ & $-1,0$ & 0,1 & $-4,3$ & $-0,1$ & $-0,5$ \\
\hline & P4-60 & 1,1 & $-2,8$ & $-6,9$ & $-2,6$ & $-0,6$ & 0,3 & $-1,8$ & $-0,7$ & $-4,7$ & $-1,9$ & $-0,7$ & $-0,5$ & $-4,9$ & $-1,1$ & $-0,5$ \\
\hline
\end{tabular}


TABELA 4.18 - Valores de Igeo obtidos a partir dos valores de concentração do NASC

Normalização com NASC

\begin{tabular}{|c|c|c|c|c|c|c|c|c|c|c|c|c|c|c|c|}
\hline Ponto & Amostra & As & $\mathbf{B a}$ & $\mathbf{C a}$ & Co & $\mathrm{Cr}$ & $\mathbf{C u}$ & $\mathbf{F e}$ & $\mathbf{H g}$ & Mg Mn & $\mathbf{N i}$ & $\mathbf{P b}$ & $\mathbf{T i}$ & $\mathbf{V}$ & $\mathbf{Z n}$ \\
\hline \multirow{2}{*}{ Pt 01} & P1-10 & 0,4 & $-1,9$ & $-6,6$ & $-2,1$ & $-2,4$ & -- & $-1,7$ & $-0,6$ & $\begin{array}{ll}-4,2 & -2,9\end{array}$ & $-2,5$ & $-0,4$ & $-3,1$ & $-1,8$ & $-0,9$ \\
\hline & P1-20 & 0,8 & $-2,3$ & $-6,6$ & $-2,5$ & $-2,7$ & -- & $-1,8$ & $-0,6$ & $-4,4 \quad-3,0$ & $-2,8$ & $-0,7$ & $-3,9$ & $-2,2$ & $-1,2$ \\
\hline \multirow{5}{*}{ Pt 02} & P2-10 & 2,8 & $-2,3$ & $-7,3$ & $-1,4$ & $-2,1$ & -- & $-0,4$ & 0,2 & $\begin{array}{lll}-5,8 & -1,8\end{array}$ & $-3,1$ & 1,1 & $-4,6$ & $-1,7$ & $-1,0$ \\
\hline & $\mathrm{P} 2-20$ & 1,8 & $-2,2$ & $-7,1$ & $-1,5$ & $-2,1$ & -- & $-0,2$ & 0,4 & $-5,3-1,7$ & $-2,3$ & 0,3 & $-4,5$ & $-1,0$ & $-0,7$ \\
\hline & $\mathrm{P} 2-30$ & 1,1 & $-2,1$ & $-7,0$ & $-1,2$ & $-2,1$ & -- & 0,0 & 0,2 & $-5,4-1,5$ & $-2,5$ & 0,1 & $-4,6$ & $-1,0$ & $-0,7$ \\
\hline & $\mathrm{P} 2-40$ & 1,3 & $-2,2$ & $-7,2$ & $-1,5$ & $-2,3$ & -- & $-0,9$ & 0,4 & $-5,8-1,8$ & $-2,6$ & $-0,1$ & $-5,7$ & $-1,3$ & $-1,0$ \\
\hline & $\mathrm{P} 2-50$ & 1,2 & $-2,0$ & $-7,4$ & $-1,9$ & $-2,0$ & -- & $-0,7$ & 0,6 & $\begin{array}{ll}-5,4 & -2,1\end{array}$ & $-2,6$ & $-0,1$ & $-4,6$ & $-0,9$ & $-0,9$ \\
\hline \multirow{6}{*}{ Pt 03} & P3-10 & 1,8 & $-2,3$ & $-6,9$ & $-1,6$ & $-2,1$ & -- & 0,2 & $-0,3$ & $-5,4-1,1$ & $-2,4$ & 0,0 & $-4,3$ & $-0,7$ & $-0,7$ \\
\hline & P3-20 & 1,7 & $-2,0$ & $-7,1$ & $-1,6$ & $-1,9$ & -- & $-0,1$ & 0,0 & $-5,1 \quad-1,7$ & $-2,1$ & 0,1 & $-3,4$ & $-0,6$ & $-0,6$ \\
\hline & P3-30 & 1,7 & $-2,2$ & $-7,1$ & $-1,2$ & $-2,1$ & -- & $-0,1$ & 0,0 & $-5,4-1,3$ & $-2,5$ & 0,3 & $-3,8$ & $-0,7$ & $-0,6$ \\
\hline & P3-40 & 1,6 & $-2,1$ & $-7,1$ & $-1,1$ & $-2,2$ & -- & $-0,3$ & 0,6 & $-5,4-1,3$ & $-2,6$ & 0,6 & $-3,9$ & $-0,9$ & $-0,8$ \\
\hline & P3-50 & 2,0 & $-2,2$ & $-7,2$ & $-0,6$ & $-2,1$ & -- & $-0,7$ & 0,6 & $-5,5-1,0$ & $-2,0$ & 0,6 & $-4,3$ & $-0,7$ & 0,0 \\
\hline & P3-60 & 1,5 & $-1,9$ & $-7,0$ & $-1,7$ & $-2,6$ & -- & $-2,1$ & 0,9 & $\begin{array}{lll}-5,0 & -1,6\end{array}$ & $-2,1$ & 0,2 & $-4,0$ & $-1,9$ & $-0,7$ \\
\hline \multirow{6}{*}{ Pt 04} & P4-10 & 1,9 & $-1,9$ & $-6,8$ & $-2,4$ & $-1,8$ & -- & 0,4 & $-0,3$ & $-5,2 \quad-0,9$ & $-3,8$ & $-0,6$ & $-3,9$ & $-0,6$ & $-1,8$ \\
\hline & P4-20 & 2,6 & $-2,2$ & $-7,0$ & $-2,1$ & $-1,8$ & -- & 0,0 & 0,0 & $-5,5-1,1$ & $-2,4$ & 0,0 & $-4,1$ & $-0,7$ & $-1,0$ \\
\hline & P4-30 & 2,6 & $-2,2$ & $-7,0$ & $-1,7$ & $-1,9$ & -- & 0,4 & 0,2 & $-5,4-0,7$ & $-2,5$ & 0,0 & $-3,9$ & $-0,7$ & $-0,8$ \\
\hline & $\mathrm{P} 4-40$ & 2,0 & $-2,2$ & $-7,2$ & $-1,2$ & $-2,1$ & -- & 0,2 & 0,2 & $-5,4-1,4$ & $-2,5$ & 0,0 & $-4,1$ & $-0,8$ & $-1,0$ \\
\hline & $\mathrm{P} 4-50$ & 1,7 & $-2,3$ & $-7,3$ & $-2,2$ & $-2,1$ & -- & $-0,6$ & $-0,3$ & $-5,5 \quad-2,1$ & $-2,7$ & $-0,2$ & $-4,6$ & $-1,0$ & $-0,8$ \\
\hline & P4-60 & 1,4 & $-2,6$ & $-7,3$ & $-3,7$ & $-2,5$ & -- & $-2,3$ & $-0,3$ & $-5,4-2,3$ & $-2,3$ & $-0,7$ & $-5,2$ & $-2,0$ & $-0,8$ \\
\hline
\end{tabular}

TABELA 4.19 - Valores de Igeo obtidos a partir dos valores de concentração da base do perfil sedimentar

Normalização com Base do Perfil

\begin{tabular}{ccccccccccccccccc}
\hline Ponto & Amostra & As & Ba & Ca & Co & Cr & Cu & Fe & Hg & Mg & Mn & Ni & Pb & Ti & $\mathbf{V}$ & $\mathbf{Z n}$ \\
\hline \multirow{2}{*}{ Pt 01 } & P1-10 & $-1,7$ & $-0,6$ & $-0,1$ & $-1,0$ & $-0,4$ & $-1,3$ & $-0,2$ & $-2,0$ & 0,2 & $-1,9$ & $-1,0$ & $-1,1$ & 0,4 & $-0,5$ & $-0,8$ \\
& P1-20 & $-1,3$ & $-1,0$ & $-0,2$ & $-1,4$ & $-0,7$ & $-1,6$ & $-0,3$ & $-2,0$ & 0,0 & $-2,0$ & $-1,3$ & $-1,5$ & $-0,5$ & $-0,9$ & $-1,0$ \\
& $\mathrm{P} 2-10$ & 0,7 & $-1,0$ & $-0,9$ & $-0,3$ & $-0,2$ & 0,3 & 1,2 & $-1,2$ & $-1,4$ & $-0,8$ & $-1,5$ & 0,3 & $-1,1$ & $-0,4$ & $-0,8$ \\
& $\mathrm{P} 2-20$ & $-0,3$ & $-0,9$ & $-0,6$ & $-0,4$ & $-0,1$ & $-0,2$ & 1,3 & $-1,0$ & $-0,9$ & $-0,7$ & $-0,8$ & $-0,4$ & $-1,1$ & 0,4 & $-0,6$ \\
Pt 02 & $\mathrm{P} 2-30$ & $-1,1$ & $-0,7$ & $-0,5$ & $-0,1$ & $-0,1$ & 0,1 & 1,5 & $-1,2$ & $-1,0$ & $-0,5$ & $-1,0$ & $-0,7$ & $-1,1$ & 0,3 & $-0,5$ \\
& $\mathrm{P} 2-40$ & $-0,8$ & $-0,9$ & $-0,8$ & $-0,4$ & $-0,4$ & 0,2 & 0,7 & $-1,0$ & $-1,3$ & $-0,8$ & $-1,1$ & $-0,8$ & $-2,3$ & 0,0 & $-0,8$ \\
& $\mathrm{P} 2-50$ & $-0,9$ & $-0,7$ & $-0,9$ & $-0,8$ & $-0,1$ & 0,1 & 0,8 & $-0,9$ & $-1,0$ & $-1,1$ & $-1,1$ & $-0,8$ & $-1,1$ & 0,4 & $-0,7$ \\
& $\mathrm{P} 3-10$ & $-0,4$ & $-0,9$ & $-0,4$ & $-0,5$ & $-0,1$ & 0,1 & 1,8 & $-1,7$ & $-1,0$ & $-0,1$ & $-0,9$ & $-0,8$ & $-0,9$ & 0,7 & $-0,6$ \\
& $\mathrm{P} 3-20$ & $-0,4$ & $-0,7$ & $-0,6$ & $-0,5$ & 0,1 & $-0,1$ & 1,4 & $-1,5$ & $-0,7$ & $-0,7$ & $-0,6$ & $-0,6$ & 0,0 & 0,7 & $-0,5$ \\
Pt 03 & $\mathrm{P} 3-30$ & $-0,4$ & $-0,9$ & $-0,6$ & $-0,1$ & $-0,1$ & 0,0 & 1,4 & $-1,5$ & $-1,0$ & $-0,3$ & $-1,0$ & $-0,5$ & $-0,3$ & 0,6 & $-0,4$ \\
& $\mathrm{P} 3-40$ & $-0,5$ & $-0,8$ & $-0,6$ & 0,0 & $-0,2$ & 0,1 & 1,3 & $-0,9$ & $-1,0$ & $-0,3$ & $-1,1$ & $-0,1$ & $-0,5$ & 0,5 & $-0,6$ \\
& $\mathrm{P} 3-50$ & $-0,1$ & $-0,9$ & $-0,7$ & 0,5 & $-0,1$ & 0,9 & 0,9 & $-0,9$ & $-1,1$ & 0,0 & $-0,5$ & $-0,1$ & $-0,9$ & 0,6 & 0,1 \\
& $\mathrm{P} 3-60$ & $-0,6$ & $-0,6$ & $-0,6$ & $-0,6$ & $-0,6$ & $-0,6$ & $-0,6$ & $-0,6$ & $-0,6$ & $-0,6$ & $-0,6$ & $-0,6$ & $-0,6$ & $-0,6$ & $-0,6$ \\
& $\mathrm{P} 4-10$ & $-0,2$ & $-0,6$ & $-0,4$ & $-1,3$ & 0,2 & $-0,8$ & 1,9 & $-1,7$ & $-0,8$ & 0,1 & $-2,3$ & $-1,3$ & $-0,4$ & 0,7 & $-1,7$ \\
& $\mathrm{P} 4-20$ & 0,5 & $-0,8$ & $-0,6$ & $-1,0$ & 0,1 & 0,0 & 1,6 & $-1,5$ & $-1,1$ & $-0,1$ & $-0,9$ & $-0,8$ & $-0,6$ & 0,6 & $-0,8$ \\
Pt 04 & $\mathrm{P} 4-30$ & 0,5 & $-0,9$ & $-0,6$ & $-0,6$ & 0,1 & 0,0 & 1,9 & $-1,2$ & $-1,0$ & 0,3 & $-1,0$ & $-0,8$ & $-0,5$ & 0,6 & $-0,7$ \\
& $\mathrm{P} 4-40$ & $-0,1$ & $-0,9$ & $-0,8$ & $-0,1$ & $-0,1$ & $-0,1$ & 1,7 & $-1,2$ & $-1,0$ & $-0,4$ & $-1,0$ & $-0,8$ & $-0,7$ & 0,5 & $-0,8$ \\
& $\mathrm{P} 4-50$ & $-0,4$ & $-1,0$ & $-0,9$ & $-1,1$ & $-0,1$ & 0,2 & 0,9 & $-1,7$ & $-1,1$ & $-1,1$ & $-1,2$ & $-0,9$ & $-1,2$ & 0,3 & $-0,7$ \\
& $\mathrm{P} 4-60$ & $-0,7$ & $-1,3$ & $-0,8$ & $-2,6$ & $-0,5$ & 0,4 & $-0,7$ & $-1,7$ & $-1,0$ & $-1,3$ & $-0,8$ & $-1,5$ & $-1,8$ & $-0,7$ & $-0,6$ \\
\hline
\end{tabular}




\subsubsection{Tratamento estatístico dos dados de ICP OES e AAS}

Os resultados obtidos pelas técnicas de ICP OES, AAS (GF AAS e CV AAS), granulometria, COT e NKT foram reunidos e submetidos a tratamento estatístico sendo apresentados a seguir.

\subsubsection{Análise Fatorial}

Foi efetuada a Análise de Fatores com extração de Componentes Principais e Rotação Varimax normalizada, utilizando-se os resultados das amostras de sedimento e os elementos determinados pelas técnicas de ICP OES e AAS e também os dados de granulometria, conteúdo de MO e NKT. Foi utilizado o programa Statistica 7.0 (STATSOFT). Os resultados estão apresentados na TAB 4.20 e estão marcados os valores > /0,6/. A extração de Componentes Principais é apresentada na TAB 4.21.

Segundo Einax et al. (1999), a análise de fatores é um método estatístico multivariado que pode examinar correlações entre diversas variáveis, de modo a verificar similaridades em um conjunto de dados.

Verificou-se a partir dos dados da TAB 4.20 que 5 fatores puderam ser extraídos, respondendo por 82,5\% da variância observada. O Fator 1 explica 31,0\% da variância total; o Fator 2 é responsável por 20,0\%; o Fator 3 por 14,9\%; o Fator 4, por $9,8 \%$ e finalmente, o Fator 5 , por $6,7 \%$.

O Fator 1 compreende o elemento $\mathrm{Cu}$ e a fração silte+argila e inversamente correlacionados estão os elementos $\mathrm{Mg}, \mathrm{Ba}, \mathrm{Ca}$, Ti e areia; o Fator 2, apresentou correlação positiva entre os elementos $\mathrm{Al}, \mathrm{Fe}, \mathrm{Mn}, \mathrm{V}, \mathrm{Cr}$, NKT e COT; o Fator 3, apresentou correlação positiva para os elementos Ni, Be e P; Fator 4, apresentou correlação positiva entre os elementos $\mathrm{Sn}$ e $\mathrm{Pb}$ e o Fator 5, o elemento Co inversamente correlacionado com Li. 
TABELA 4.20 - Resultado da Análise Fatorial utilizando Rotação Varimax com

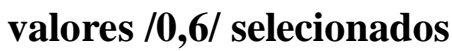

\begin{tabular}{|c|c|c|c|c|c|}
\hline & Fator 1 & Fator 2 & Fator 3 & Fator 4 & Fator 5 \\
\hline Al & $-0,181206$ & 0,834782 & 0,189111 & $-0,384687$ & $-0,117648$ \\
\hline $\mathbf{F e}$ & 0,081302 & 0,907435 & $-0,254280$ & 0,143687 & 0,178823 \\
\hline Mn & 0,229238 & 0,813825 & 0,055408 & 0,039472 & 0,229310 \\
\hline Co & 0,213618 & 0,165106 & 0,338299 & 0,215048 & 0,834516 \\
\hline $\mathbf{N i}$ & 0,271967 & $-0,147100$ & 0,768269 & $-0,324058$ & 0,230520 \\
\hline $\mathbf{C u}$ & 0,843197 & 0,052590 & 0,133183 & 0,042043 & 0,369951 \\
\hline $\mathbf{Z n}$ & 0,398982 & $-0,120095$ & 0,567574 & $-0,147931$ & 0,592013 \\
\hline Be & $-0,443683$ & 0,038726 & 0,843697 & $-0,197574$ & 0,088562 \\
\hline Mg & $-0,831174$ & $-0,390494$ & 0,032413 & $-0,245691$ & $-0,072752$ \\
\hline $\mathbf{V}$ & 0,146768 & 0,903513 & 0,018288 & $-0,110616$ & 0,311416 \\
\hline $\mathrm{Cr}$ & 0,095909 & 0,898015 & $-0,128742$ & 0,100065 & 0,053530 \\
\hline Sn & 0,034228 & $-0,127171$ & $-0,124628$ & 0,915887 & $-0,038938$ \\
\hline $\mathbf{B a}$ & $-0,634539$ & 0,329045 & 0,493527 & 0,085558 & $-0,009308$ \\
\hline $\mathbf{C a}$ & $-0,872776$ & $-0,049154$ & $-0,079831$ & $-0,206995$ & $-0,057773$ \\
\hline $\mathbf{T i}$ & $-0,760880$ & 0,161842 & 0,205550 & $-0,035181$ & 0,063283 \\
\hline $\mathbf{L i}$ & 0,496423 & $-0,240449$ & 0,075184 & $-0,186852$ & $-0,659544$ \\
\hline As & 0,367938 & 0,426410 & $-0,178890$ & 0,533307 & 0,037913 \\
\hline $\mathbf{P b}$ & 0,306705 & 0,006287 & 0,243805 & 0,756488 & 0,469714 \\
\hline Hg & 0,329491 & 0,376926 & 0,109705 & 0,445858 & 0,207906 \\
\hline $\mathbf{P}$ & 0,135968 & $-0,048898$ & 0,804232 & 0,364099 & 0,088802 \\
\hline areia & $-0,719108$ & $-0,410092$ & $-0,381109$ & $-0,172466$ & 0,004290 \\
\hline silte+argila & 0,719183 & 0,410023 & 0,381102 & 0,172425 & $-0,004434$ \\
\hline COT & $-0,197513$ & 0,680447 & 0,001551 & 0,206711 & $-0,337049$ \\
\hline NKT & 0,041585 & 0,695424 & 0,430961 & 0,011986 & $-0,382030$ \\
\hline Expl.Var & 5,422710 & 5,845564 & 3,417693 & 2,682310 & 2,424993 \\
\hline Prp.Total & 0,225946 & 0,243565 & 0,142404 & 0,111763 & 0,101041 \\
\hline
\end{tabular}


TABELA 4.21 - Resultado da Análise Fatorial com extração de Componentes Principais

\begin{tabular}{c|c|c|c|c}
\hline & AutoValor & $\begin{array}{c}\text { Variância } \\
\text { Total (\%) }\end{array}$ & $\begin{array}{c}\text { Autovalor } \\
\text { Cumulativo }\end{array}$ & $\begin{array}{c}\text { Cumulativo } \\
(\%)\end{array}$ \\
\hline $\mathbf{1}$ & 7,45 & 31,04 & 7,45 & 31,04 \\
\hline $\mathbf{2}$ & 4,80 & 20,02 & 12,25 & 51,06 \\
\hline $\mathbf{3}$ & 3,57 & 14,88 & 15,83 & 65,94 \\
\hline $\mathbf{4}$ & 2,35 & 9,79 & 18,18 & 75,73 \\
\hline $\mathbf{5}$ & 1,62 & 6,74 & 19,79 & 82,47 \\
\hline
\end{tabular}

\subsubsection{Análise de Agrupamentos}

Para os resultados obtidos pelas técnicas de ICP OES e AAS, dados da composição granulométrica, COT e NKT foi realizada a Análise de Agrupamento (Cluster Analysis), utilizando-se o método de Ward e as distâncias Euclidianas. O objetivo dessa análise foi verificar possíveis semelhanças entre os pontos de amostragem (FIG 4.8) e entre os elementos analisados e os demais parâmetros (FIG 4.9) 


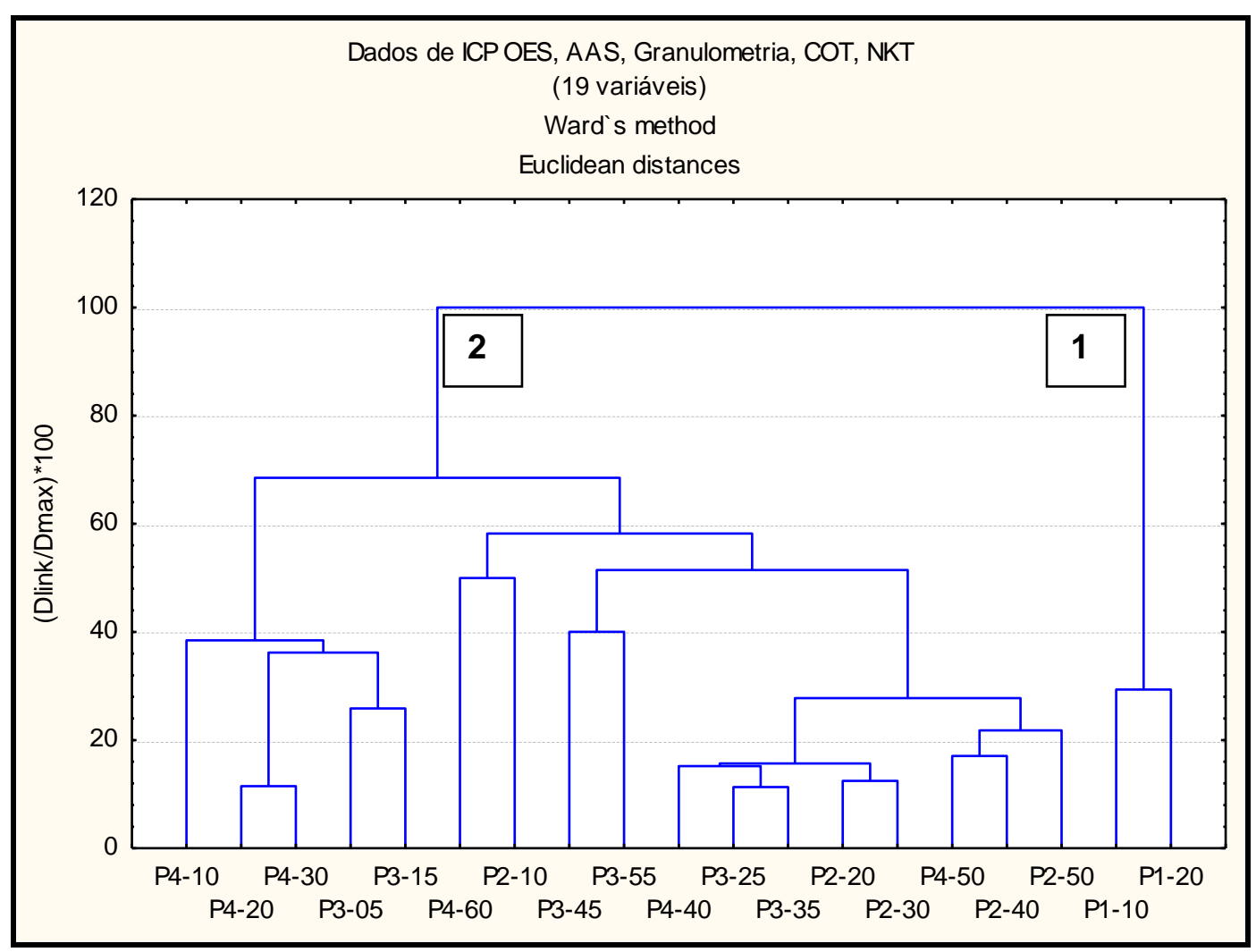

FIGURA 4.8 - Dendrograma resultante da Análise de Agrupamento, variáveis: pontos de amostragem

Verificou-se que o ponto 1 formou um grupo separado dos demais pontos (grupo 1). O grupo 2 foi formado pelas demais amostras e se dividiu, em geral, em 2 subgrupos:

- sub-grupo 1: formado pelos pontos P4-10, P4-20, P4-30 e P3-10, P3-20 (amostras superficiais e intermediárias dos pontos 3 e 4);

- sub-grupo 2 : constituído pelos demais pontos de amostragem

O grupo 1 apresentou as menores concentrações principalmente para os metais $\mathrm{Fe}, \mathrm{Mn}, \mathrm{Cu}, \mathrm{V}, \mathrm{Cr}$, As e $\mathrm{Pb}$, maiores concentrações para $\mathrm{Mg}$ e Ti e maiores teores de areia, o que fez com que essas amostras apresentassem um comportamento bastante diferente das demais.

O sub-grupo 1 do grupo 2, constituído pelas amostras mais superficiais dos pontos 3 e 4, apresentaram concentrações similares para alguns parâmetros como $\mathrm{Al}, \mathrm{Fe}$, $\mathrm{Zn}, \mathrm{Mg}, \mathrm{V}, \mathrm{Cr}, \mathrm{Ba}, \mathrm{Ca}$, Li e Pb. 
O sub-grupo 2 é formado pelas demais amostras correspondentes as de maior profundidade, com exceção da amostra P2-10.

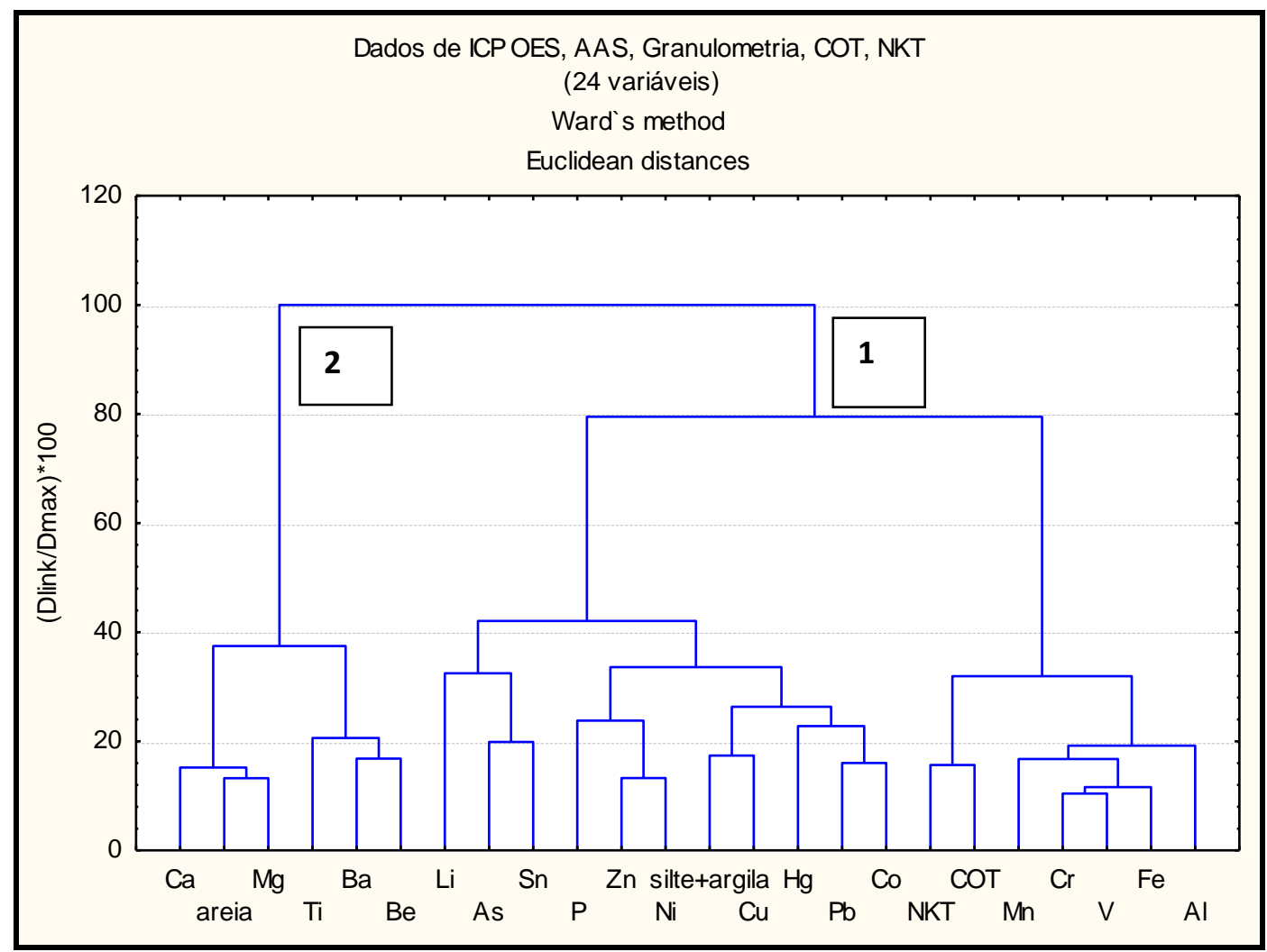

FIGURA 4.9 - Dendrograma resultante da Análise de Agrupamento, variáveis: parâmetros analisados

Quando a mesma base de dados foi rodada considerando-se os elementos e os parâmetros analisados como variáveis, também houve a formação de 2 grupos. O grupo 2 foi formado pelos elementos $\mathrm{Ca}, \mathrm{Mg}, \mathrm{Ti}, \mathrm{Ba}, \mathrm{Be}$ e teor de areia.

O grupo 1 se subdividiu em 2 grandes sub-grupos:

- sub-grupo 1: formado por silte, argila e os metais $\mathrm{Li}, \mathrm{Sn}, \mathrm{P}, \mathrm{Zn}, \mathrm{Ni}, \mathrm{Cu}, \mathrm{Hg}$, $\mathrm{Co}, \mathrm{Pb}$ e o semi-metal As

- sub-grupo 2: teores de NKT, COT, Mn, Cr, V, Fe e Al (elementos ligados ao $\mathrm{Fe})$.

O grupo 2 se constituiu dos elementos alcalino-terrosos ( $\mathrm{Ca}, \mathrm{Mg}, \mathrm{Be}, \mathrm{Ba})$, Ti e areia. O grupo 1 foi formado por silte+argila, conteúdo de MO, conteúdo de $\mathrm{N}$ e dos 
principais metais e elementos ligados ao $\mathrm{Fe}(\mathrm{Mn}, \mathrm{Cr}, \mathrm{V}$ e $\mathrm{Al})$ e o semi-metal As. Esse resultado indica que a distribuição dos elementos é controlada, principalmente, pelas frações granulométricas e que o conteúdo de MO está estreitamente relacionado ao teor de silte+argila e dos principais metais.

\subsection{Análise por Ativação Neutrônica Instrumental (INAA)}

Os resultados das concentrações para os elementos determinados por INAA nas amostras dos perfis sedimentares são apresentadas a seguir, bem como os resultados da validação e os limites de Detecção e Limites de Quantificação do método e os resultados do tratamento estatístico dos dados.

\subsubsection{Validação da metodologia de INAA}

Foram analisados os materiais de referência certificados BEN (Basalt-IWGGIT) e SL 01 (Lake sediment, IAEA). Para a validação da metodologia foram feitos os cálculos de Z-score (FIG 4-10 e 4.11) para os resultados obtidos nas análises dos materiais de referência certificados, assumindo o critério de $|\mathrm{Z}|<3$ - resultados satisfatórios, conforme já descrito no item 3.4.2.

Pelas FIG 4-10 e 4-11 pode-se observar que para todos os elementos determinados o valor de Z-score ficou entre 2 e -2 , ou seja, que todos os resultados foram satisfatórios e se encontraram no do intervalo de $\mid Z /<3$. Se o $|Z|<3$, significa que o resultado individual da amostra controle (material de referência) está dentro do intervalo de confiança de $99 \%$ do valor verdadeiro (ou aceito). Os resultados obtidos são as médias de 3 determinações para cada material de referência. 


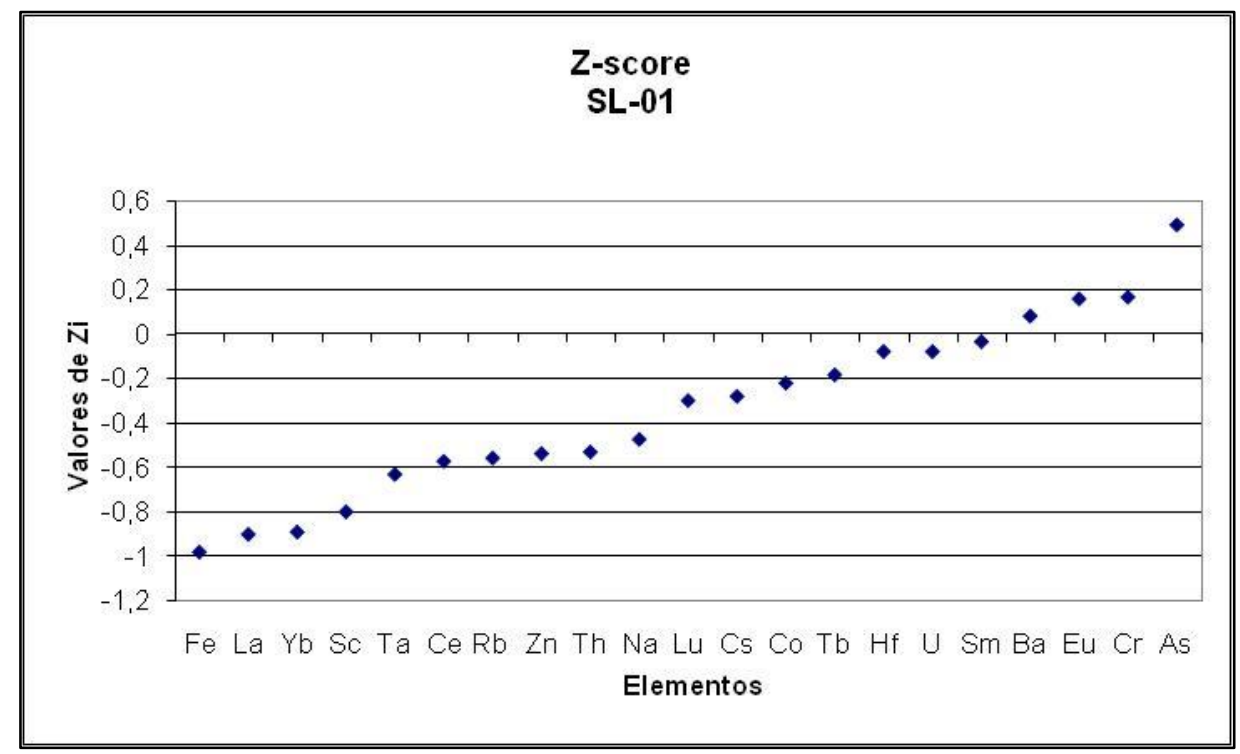

FIGURA 4.10 - Z-score obtido para os resultados do material de referência SL-01, por INAA

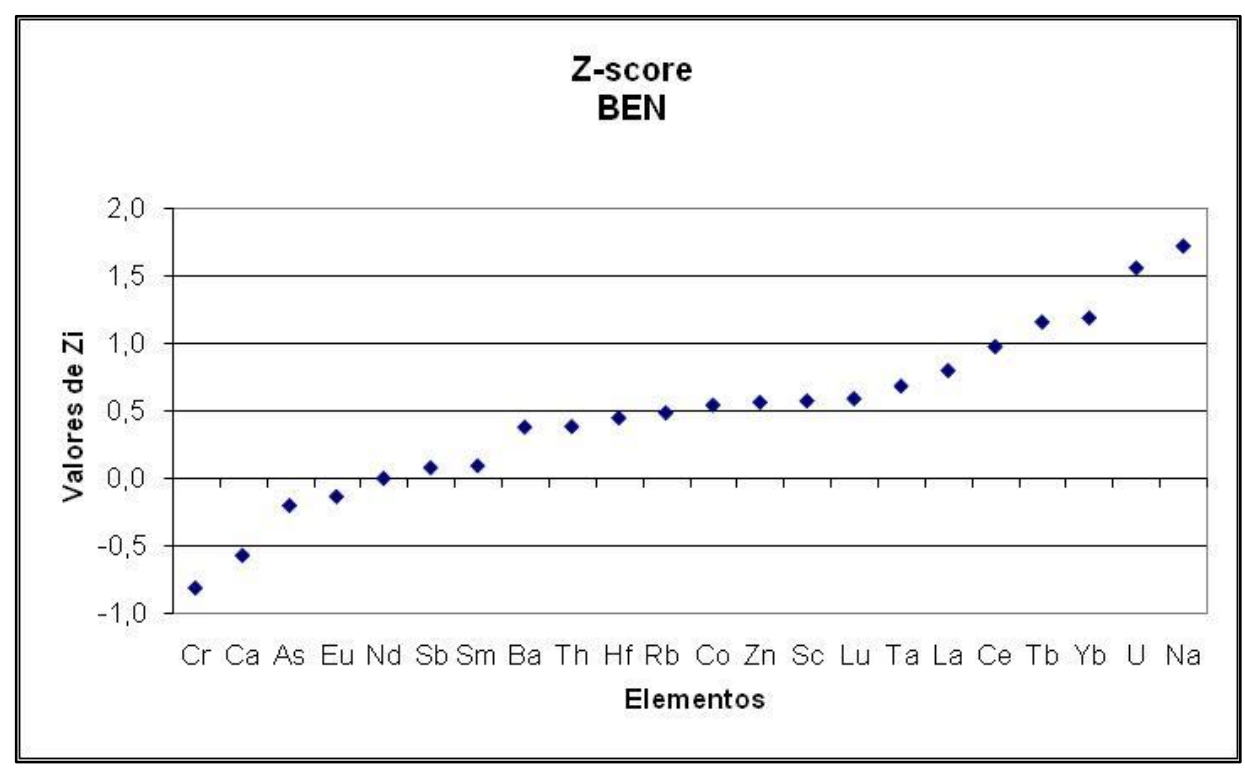

FIGURA 4.11 - Z-score obtido para os resultados do material de referência BENBasalt, por INAA 


\subsubsection{Limites de Detecção (LD) e Limites de Quantificação (LQ)}

Conforme descrito no item 3.8.4, foram realizados os cálculos para a determinação dos valores dos Limites de Detecção e Limites de Quantificação para cada um dos elementos determinados pela técnica de INAA, nos materiais de referência WQB-3 e BEN-Basalt. A TAB 4-22 apresenta os valores de LD e LQ, obtidos pela técnica de INAA, para todos os elementos determinados.

Tabela 4.22 - Valores de LD e LQ $\left(\mathrm{mg} \mathrm{kg}^{-1}\right)$ para os materiais de referencia analisados por INAA

\begin{tabular}{c|cc|cc}
\hline & \multicolumn{2}{c}{ WQB-3 } & \multicolumn{2}{c}{ BEN - Basalt } \\
\hline Elemento & LD & LQ & LD & LQ \\
\hline $\mathrm{As}$ & 0,9 & 2,8 & 1,1 & 3,2 \\
$\mathrm{Ba}$ & 212 & 637 & 135 & 405 \\
$\mathrm{Ce}$ & 2,4 & 7,1 & 1,6 & 4,9 \\
$\mathrm{Co}$ & 0,3 & 0,8 & 0,31 & 0,94 \\
$\mathrm{Cr}$ & 2,0 & 6,0 & 3,7 & 11,0 \\
$\mathrm{Cs}$ & 0,9 & 2,6 & 0,5 & 1,5 \\
$\mathrm{Eu}$ & 0,1 & 0,3 & 0,09 & 0,26 \\
$\mathrm{Fe}(\%)$ & 0,02 & 0,07 & 0,03 & 0,08 \\
$\mathrm{Hf}$ & 0,2 & 0,6 & 0,38 & 1,13 \\
$\mathrm{La}$ & 0,2 & 0,7 & 0,21 & 0,64 \\
$\mathrm{Lu}$ & 0,04 & 0,11 & 0,03 & 0,08 \\
$\mathrm{Na}(\%)$ & 0,005 & 0,001 & 0,006 & 0,017 \\
$\mathrm{Nd}$ & & & 4,3 & 13,0 \\
$\mathrm{Rb}$ & 16 & 49 & 11 & 34 \\
$\mathrm{Sb}$ & 0,05 & 0,16 & & \\
$\mathrm{Sc}$ & 0,08 & 0,24 & 0,02 & 0,05 \\
$\mathrm{Sm}$ & 0,07 & 0,20 & 0,08 & 0,23 \\
$\mathrm{Ta}$ & 3,4 & 10,1 & 0,28 & 0,84 \\
$\mathrm{~Tb}$ & 0,77 & 2,32 & 0,32 & 0,96 \\
$\mathrm{Th}$ & 0,4 & 1,3 & 0,3 & 1,0 \\
$\mathrm{U}$ & 1,0 & 2,9 & 0,49 & 1,47 \\
$\mathrm{Yb}$ & & & 0,17 & 0,51 \\
$\mathrm{Zn}$ & 3 & 8 & 14 & 43 \\
\hline
\end{tabular}




\subsubsection{Resultados obtidos nas análises das amostras de sedimentos por INAA}

Os resultados obtidos pela técnica de INAA encontram-se na TAB 4.23, onde pode-se verificar os valores de concentração encontrados e seus respectivos desvios associados. A FIG 4.12 apresenta os gráficos de concentração dos elementos determinados por INAA ( $\mathrm{mg} \mathrm{kg}^{-1}$ ), em cada fração de sedimento, para cada ponto amostrado, sendo que para os elementos em que há valores tabelados para TEL, estes são apresentados nos gráficos por uma linha horizontal vermelha.

$\mathrm{Na} \mathrm{TAB} 4.23$, podemos perceber uma grande oscilação nas concentrações das frações, para a maioria dos pontos, para todos os elementos. Assim optou-se em fazer uma comparação entre as variações das concentrações das frações de todos os pontos para cada elemento, tomando como base para esta comparação dados da base do perfil, fração mais profunda do perfil coletado, para a superfície do perfil.

No ponto Pt 01 observa-se que os elementos $\mathrm{Co}, \mathrm{Cr}, \mathrm{Cs}, \mathrm{Fe}, \mathrm{Sb}$, Sc e $\mathrm{Zn}$ apresentaram concentrações maiores na fração P1-10 (superfície) em relação a fração P120. Os demais elementos analisados apresentaram concentrações mais altas na fração P120.

Em geral, pode-se observar que para os demais pontos, houve um decréscimo de concentração da base para a superfície, mesmo este aumento não sendo constante para todas as frações, para todos os elementos analisados.

Pode-se observar algumas exceções (acréscimo de concentração da base para a superfície) para os elementos:

- As, Ba, Ca, Fe, Rb, Th e ETR (Lu, Nd, Sm) no ponto 02,

- As, Co, Cr, Fe, Na, Rb, Sb, Sc, Th, U e ETR (Ce, Lu, Yb) no ponto 03,

- As, Ba, Co, Cr, Fe, Na, Rb, Sb, Sc, Ta, Th, U e ETR (Ce, Eu, La, Lu, Nd, $\mathrm{Sm}, \mathrm{Tb})$, no ponto 04

Um fato que acaba chamando atenção e pode ser observado na FIG 4-12, a qual apresenta gráficos de concentração versus frações dos perfis, são as altas concentrações dos elementos (Ba, Ca, Hf, Na, Ta, Th, U e ETR (Ce, La, Lu, Nd, Yb e Sm), no ponto 1 . Um outro fato que chama atenção é a concentração de urânio que ficou acima 
do esperado. Os valores da crosta terrestre (Wedepohl, 1995) para urânio é de 1,7 $\mathrm{mg} \mathrm{kg}^{-1}$, entretanto o valor encontrado para as amostras do ponto $1\left(10,3 \mathrm{e} 14,4 \mathrm{mg} \mathrm{kg}^{-1}\right)$ foram bem superiores. Quando se utiliza a técnica de NAA na análise de solos e sedimentos e são encontrados altos teores de $\mathrm{U}$, pode-se ter valores mais altos de $\mathrm{Ba}, \mathrm{La}, \mathrm{Ce}, \mathrm{Nd}$ e $\mathrm{Sm}$ como consequência da fissão do $\mathrm{U}$ durante a irradiação e formação dos radioisótopos ${ }^{141} \mathrm{Ba}$, ${ }^{140} \mathrm{La},{ }^{141} \mathrm{Ce},{ }^{147} \mathrm{Nd} \mathrm{e}{ }^{153} \mathrm{Sm}$, como produtos de fissão. A interferência dos produtos de fissão do U, depende da relação entre as concentrações de U e ETR, bem como das condições de irradiação e, no caso específico do La, do tempo de decaimento. (Maria, 2000).

Na comparação dos resultados deste trabalho com os resultados encontrados por Arine (2000), o qual fez análises de água superficial e sedimento de rios da região de Iperó, verificou-se que para os elementos: $\mathrm{Cr}, \mathrm{Eu}, \mathrm{Fe}$ (base do perfil de Itupararanga), Lu, $\mathrm{Na}, \mathrm{Nd}, \mathrm{Rb}, \mathrm{Sb}, \mathrm{Ta}, \mathrm{Th}, \mathrm{U}, \mathrm{Yb}$ e $\mathrm{Zn}$ as concentrações encontradas foram semelhantes. 
Tabela 4.23 - Resultados $\left(\mathrm{mg} \mathrm{kg}^{-1}\right)$ das análises das amostras de sedimentos por INAA

\begin{tabular}{|c|c|c|c|c|c|c|c|c|c|c|c|c|c|c|c|c|c|c|c|c|c|}
\hline \multirow{2}{*}{$\frac{\text { Ponto }}{\text { Amostra }}$} & \multicolumn{2}{|c|}{ Pt 01} & \multicolumn{5}{|c|}{ Pt 02} & \multicolumn{6}{|c|}{ Pt 03} & \multicolumn{6}{|c|}{ Pt 04} & \multirow{2}{*}{ UCC } & \multirow{2}{*}{ NASC } \\
\hline & P 1-10 & P $1-20$ & P2-10 & 20 & P2-30 & P2-40 & P2-50 & -10 & -20 & P3-30 & P3-40 & -50 & 60 & P4-10 & P4-20 & P4-30 & P4-40 & P4-50 & P4-60 & & \\
\hline As & -- & -- & $3 \pm 0,3$ & $5,14 \pm 0,3$ & $5,30 \pm 0,3$ & $5,68 \pm 0,4$ & $5,27 \pm 0,4$ & $9,09 \pm 0,5$ & $6,28 \pm 0,5$ & $8,08 \pm 0,9$ & $6,14 \pm 0,7$ & $5,43 \pm 0,4$ & $3,50 \pm 0,2$ & $19,1 \pm 1,6$ & $15,0 \pm 0,6$ & $18,1 \pm 1,5$ & $12,0 \pm 0,7$ & $9,32 \pm 0,5$ & $5,34 \pm 0,4$ & 2 & 2 \\
\hline $\mathrm{Ba}$ & $817 \pm 32$ & $1090 \pm 42$ & $523 \pm 44$ & $601 \pm 43$ & $485 \pm 42$ & $452 \pm 24$ & $483 \pm 25$ & $358 \pm 34$ & $427 \pm 42$ & $303 \pm 36$ & $313 \pm 22$ & $458 \pm 42$ & $521 \pm 37$ & $479 \pm 47$ & $512 \pm 49$ & $571 \pm 54$ & $345 \pm 30$ & $407 \pm 23$ & $246 \pm 26$ & 68 & 636 \\
\hline $\mathrm{Ca}(\%)$ & $1,10 \pm 0,05$ & $1,25 \pm 0,06$ & $0,41 \pm 0,10$ & $1,08 \pm 0,06$ & $0,66 \pm 0,14$ & $0,48 \pm 0,04$ & $0,13 \pm 0,08$ & $0,80 \pm 0,04$ & $0,89 \pm 0,06$ & $0,96 \pm 0,05$ & $0,73 \pm 0,04$ & $0,75 \pm 0,14$ & $0,99 \pm 0,05$ & $0,77 \pm 0,04$ & $0,57 \pm 0,09$ & $0,74 \pm 0,04$ & $0,56 \pm 0,06$ & $0,63 \pm 0,04$ & $0,74 \pm 0,09$ & 2,95 & 2,59 \\
\hline $\mathrm{Ce}$ & $237 \pm 9$ & $264 \pm 10$ & $107 \pm 6$ & $103 \pm 6$ & $64,8 \pm 4,2$ & $150 \pm 6$ & $182 \pm 7$ & $174 \pm 10$ & $179 \pm 10$ & $161 \pm 13$ & $135 \pm 4$ & $162 \pm 3$ & $42,4 \pm 3,1$ & $129 \pm 5$ & $134 \pm 7$ & $147 \pm 6$ & $140 \pm 8$ & $114 \pm 4$ & $57,1 \pm 5,4$ & 65,7 & 73 \\
\hline Co & $11,8 \pm 0,2$ & $8,47 \pm 0,15$ & $14,3 \pm 0,3$ & $17,0 \pm 0,4$ & $11,5 \pm 0,3$ & $12,6 \pm 0,4$ & $17,5 \pm 0,4$ & $12,5 \pm 0,3$ & $12,6 \pm 0,3$ & $15,2 \pm 0,5$ & $16,4 \pm 0,4$ & $16,4 \pm 0,6$ & $10,4 \pm 0,3$ & $9,29 \pm 0,23$ & $8,90 \pm 0,23$ & $11,5 \pm 0,3$ & $16,6 \pm 0,6$ & $8,01 \pm 0,19$ & $3,50 \pm 0,17$ & 11,6 & 28 \\
\hline $\mathrm{Cr}$ & $68,8 \pm 2,5$ & $60,5 \pm 2,2$ & $63,0 \pm 2,8$ & $68,2 \pm 3,0$ & $56,6 \pm 2,1$ & $69,3 \pm 2,0$ & $68,5 \pm 2,0$ & $66,7 \pm 2,0$ & $80,0 \pm 2,7$ & $64,1 \pm 3,2$ & $58,9 \pm 1,7$ & $69,0 \pm 2,9$ & $47,0 \pm 1,4$ & $78,2 \pm 2,3$ & $17,2 \pm 1,2$ & $74,7 \pm 2,2$ & $68,5 \pm 2,8$ & $65,5 \pm 1,9$ & 54,0 & & 25 \\
\hline Cs & $6,23 \pm 0,35$ & $4,56 \pm 0,26$ & $5,93 \pm 0,36$ & $7,39 \pm 0,44$ & $5,56 \pm 0,33$ & $7,24 \pm 0,39$ & $9,99 \pm 0,53$ & $6,12 \pm 0,35$ & $5,83 \pm 0,33$ & $4,76 \pm 0,73$ & $5,41 \pm 0,33$ & $6,52 \pm 0,55$ & $6,91 \pm 0,40$ & $9,27 \pm 0,55$ & $7,28 \pm 0,52$ & $8,52 \pm 0,51$ & $9,17 \pm 0,69$ & $10,7 \pm 0,6$ & $14,2 \pm 1,4$ & , & 5,2 \\
\hline Eu & $2,13 \pm 0,11$ & $2,38 \pm 0,13$ & $1,38 \pm 0,11$ & $1,13 \pm 0,13$ & $1,01 \pm 0,11$ & $1,36 \pm 0,15$ & $1,81 \pm 0,20$ & $1,38 \pm 0,11$ & $1,50 \pm 0,12$ & $1,20 \pm 0,14$ & $1,02 \pm 0,08$ & $1,26 \pm 0,14$ & $1,68 \pm 0,14$ & $0,94 \pm 0,08$ & $1,04 \pm 0,08$ & $1,05 \pm 0,08$ & $0,92 \pm 0,14$ & $0,90 \pm 0,10$ & $0,77 \pm 0,12$ & 0,95 & 1,24 \\
\hline $\mathrm{Fe}(\%)$ & $2,99 \pm 0,03$ & $2,50 \pm 0,02$ & $6,32 \pm 0,08$ & $6,24 \pm 0,08$ & $3,88 \pm 0,05$ & $4,58 \pm 0,06$ & $2,93 \pm 0,04$ & $7,52 \pm 0,09$ & $6,28 \pm 0,07$ & $7,15 \pm 0,08$ & $5,37 \pm 0,07$ & $4,74 \pm 0,08$ & $2,32 \pm 0,03$ & $7,33 \pm 0,09$ & $6,85 \pm 0,05$ & $7,80 \pm 0,09$ & $7,30 \pm 0,13$ & $4,08 \pm 0,05$ & $1,82 \pm 0,02$ & 3,09 & 4 \\
\hline $\mathrm{Hf}$ & $38,3 \pm 1,1$ & $99,6 \pm 2,6$ & $3,79 \pm 0,16$ & $4,74 \pm 0,19$ & $4,47 \pm 0,18$ & $5,14 \pm 0,19$ & $3,88 \pm 0,15$ & $5,03 \pm 0,19$ & $3,87 \pm 0,15$ & $4,62 \pm 0,27$ & $5,42 \pm 0,21$ & $6,15 \pm 0,34$ & $5,05 \pm 0,23$ & $8,35 \pm 0,39$ & $7,00 \pm 0,21$ & $6,24 \pm 0,27$ & $8,35 \pm 0,44$ & $9,64 \pm 0,35$ & $13,4 \pm 0,8$ & 8 & 6,3 \\
\hline $\mathrm{La}$ & $115 \pm 2$ & $125 \pm 2$ & $66,4 \pm 0,9$ & $8 \pm 0,7$ & $39,5 \pm 0,6$ & $48,7 \pm 0,9$ & $0,0 \pm 1,4$ & $53,5 \pm 0,7$ & $56,8 \pm 1,1$ & $59,6 \pm 1,0$ & $41,3 \pm 0,6$ & $49,7 \pm 1,0$ & $65,8 \pm 0,9$ & $37,5 \pm 0,5$ & $39,1 \pm 0,5$ & $41,9 \pm 0,6$ & $39,4 \pm 0,7$ & $34,6 \pm 0,6$ & $18,3 \pm 0,6$ & כ, & 2 \\
\hline $\mathrm{Lu}$ & $0,77 \pm 0,07$ & $1,47 \pm 0,11$ & $0,32 \pm 0,04$ & $0,30 \pm 0,03$ & $0,36 \pm 0,04$ & $0,34 \pm 0,04$ & $0,28 \pm 0,03$ & $0,32 \pm 0,04$ & $0,30 \pm 0,04$ & $0,33 \pm 0,05$ & $0,27 \pm 0,03$ & $0,34 \pm 0,05$ & $0,25 \pm 0,04$ & $0,64 \pm 0,09$ & $0,42 \pm 0,03$ & $0,59 \pm 0,08$ & $0,53 \pm 0,08$ & $0,58 \pm 0,06$ & $0,46 \pm 0,06$ & 0,27 & 0,48 \\
\hline $\mathrm{Na}$ & $1151 \pm 32$ & $1577 \pm 40$ & $431 \pm 9$ & $560 \pm 10$ & $600 \pm 10$ & $682 \pm 18$ & $533 \pm 18$ & $404 \pm 16$ & $389 \pm 16$ & $481 \pm 17$ & $532 \pm 12$ & $601 \pm 19$ & $381 \pm 8$ & $829 \pm 14$ & $666 \pm 13$ & $820 \pm 14$ & $1162 \pm 25$ & $1014 \pm 22$ & $348 \pm 15$ & 2,5 & 0,75 \\
\hline Nd & $85,6 \pm 6,0$ & $112 \pm 8$ & $64,3 \pm 6,2$ & $51,9 \pm 7,0$ & $38,6 \pm 5,2$ & $41,9 \pm 4,1$ & $53,2 \pm 4,4$ & $39,4 \pm 1,8$ & $36,3 \pm 2,4$ & $46,5 \pm 4,5$ & $44,2 \pm 2,2$ & $56,5 \pm 5,1$ & $59,7 \pm 3,0$ & $32,7 \pm 4,3$ & $23,2 \pm 2,6$ & $38,6 \pm 2,8$ & $27,5 \pm 3,3$ & $23,8 \pm 3,1$ & $27,6 \pm 7,5$ & 25,9 & 27,4 \\
\hline $\mathbf{R b}$ & $82,6 \pm 3,8$ & $93,2 \pm 4,2$ & $89,3 \pm 5,6$ & $90,3 \pm 5,6$ & $88,4 \pm 5,4$ & $108 \pm 8$ & $76,9 \pm 5,6$ & $64,2 \pm 3,9$ & $58,0 \pm 3,3$ & $42,7 \pm 5,1$ & $102 \pm 9$ & $70,2 \pm 7,1$ & $36,5 \pm 2,7$ & $116 \pm 15$ & $91,3 \pm 8,0$ & $113 \pm 11$ & $119 \pm 12$ & $111 \pm 8$ & $72,1 \pm 6,0$ & 10 & 125 \\
\hline Sb & $0,22 \pm 0,02$ & $0,13 \pm 0,03$ & $0,56 \pm 0,04$ & $0,62 \pm 0,05$ & $0,70 \pm 0,06$ & $0,95 \pm 0,06$ & $0,65 \pm 0,04$ & $0,78 \pm 0,07$ & $0,57 \pm 0,07$ & $1,09 \pm 0,18$ & $0,67 \pm 0,04$ & $0,98 \pm 0,08$ & $0,46 \pm 0,03$ & $1,72 \pm 0,13$ & $0,89 \pm 0,11$ & $1,51 \pm 0,11$ & $1,66 \pm 0,09$ & $1,63 \pm 0,09$ & $0,78 \pm 0,07$ & 0,31 & 2,09 \\
\hline Sc & $13,8 \pm 0,3$ & $12,4 \pm 0,3$ & $16,7 \pm 0,6$ & $17,0 \pm 0,6$ & $14,6 \pm 0,5$ & $17,7 \pm 0,6$ & $24,7 \pm 0,7$ & $18,0 \pm 0,6$ & $17,0 \pm 0,6$ & $16,4 \pm 0,8$ & $15,8 \pm 0,5$ & $18,1 \pm 0,8$ & $10,5 \pm 0,3$ & $20,4 \pm 0,7$ & $18,4 \pm 0,5$ & $19,9 \pm 0,7$ & $19,8 \pm 0,7$ & $17,0 \pm 0,6$ & $10,6 \pm 0,4$ & 7 & 15 \\
\hline $\mathrm{Sm}$ & $14,50 \pm 0,3$ & $17,2 \pm 0,4$ & $8,07 \pm 0,18$ & $6,23 \pm 0,14$ & $5,30 \pm 0,12$ & $6,33 \pm 0,14$ & $4,41 \pm 0,13$ & $7,30 \pm 0,16$ & $7,53 \pm 0,24$ & $7,34 \pm 0,17$ & $5,76 \pm 0,13$ & $6,71 \pm 0,21$ & $9,61 \pm 0,21$ & $5,57 \pm 0,12$ & $4,88 \pm 0,23$ & $6,01 \pm 0,14$ & $5,03 \pm 0,11$ & $4,56 \pm 0,10$ & $4,61 \pm 0,23$ & 4,7 & $\mathbf{5 , 7}$ \\
\hline Ta & $2,78 \pm 0,12$ & $3,13 \pm 0,15$ & $1,46 \pm 0,10$ & $1,30 \pm 0,09$ & $0,91 \pm 0,07$ & $1,66 \pm 0,16$ & $1,94 \pm 0,14$ & $1,62 \pm 0,12$ & $1,26 \pm 0,07$ & $1,43 \pm 0,14$ & $1,46 \pm 0,11$ & $1,44 \pm 0,16$ & $1,73 \pm 0,15$ & $2,71 \pm 0,43$ & $1,70 \pm 0,32$ & $2,47 \pm 0,40$ & $1,58 \pm 0,17$ & $1,91 \pm 0,14$ & $2,01 \pm 0,40$ & 1,5 & 1,1 \\
\hline $\mathrm{Tb}$ & $1,56 \pm 0,22$ & $2,09 \pm 0,22$ & $0,77 \pm 0,13$ & $0,56 \pm 0,11$ & $0,76 \pm 0,18$ & $0,99 \pm 0,17$ & $1,53 \pm 0,23$ & $0,59 \pm 0,12$ & $0,65 \pm 0,10$ & $0,54 \pm 0,18$ & $0,52 \pm 0,30$ & $2,86 \pm 1,06$ & $0,94 \pm 0,21$ & $1,01 \pm 0,13$ & $1,00 \pm 0,22$ & $0,70 \pm 0,19$ & $1,38 \pm 0,38$ & $1,13 \pm 0,26$ & $0,93 \pm 0,25$ & 0,5 & 0,85 \\
\hline Th & $29,6 \pm 0,8$ & $41,0 \pm 1,1$ & $23,5 \pm 0,8$ & $19,5 \pm 0,7$ & $15,5 \pm 0,5$ & $18,5 \pm 0,6$ & $20,4 \pm 0,7$ & $22,1 \pm 0,8$ & $22,0 \pm 0,8$ & $19,8 \pm 1,0$ & $16,3 \pm 0,6$ & $19,1 \pm 0,9$ & $17,2 \pm 0,9$ & $23,6 \pm 0,8$ & $22,5 \pm 0,9$ & $23,9 \pm 0,8$ & $21,5 \pm 1,1$ & $19,3 \pm 0,7$ & $14,9 \pm 1,2$ & 10,3 & 12 \\
\hline $\mathbf{U}$ & $10,32 \pm 0,6$ & $14,4 \pm 0,8$ & $4,06 \pm 0,23$ & $3,19 \pm 0,20$ & $3,12 \pm 0,20$ & $3,96 \pm 0,33$ & $6,24 \pm 0,55$ & $5,41 \pm 0,34$ & $5,38 \pm 0,53$ & $3,29 \pm 0,21$ & $4,23 \pm 0,22$ & $3,57 \pm 0,21$ & $3,519 \pm 0,20$ & $5,38 \pm 0,29$ & $3,74 \pm 0,31$ & $4,90 \pm 0,27$ & $5,48 \pm 0,46$ & $6,42 \pm 0,42$ & $3,66 \pm 0,48$ & 2,5 & 2,7 \\
\hline Yb & $5,01 \pm 0,26$ & $9,38 \pm 0,49$ & $1,66 \pm 0,17$ & $1,66 \pm 0,16$ & $1,90 \pm 0,14$ & $2,54 \pm 0,19$ & $2,18 \pm 0,16$ & $2,01 \pm 0,17$ & $1,85 \pm 0,14$ & $2,15 \pm 0,29$ & $2,39 \pm 0,26$ & $2,49 \pm 0,37$ & $1,49 \pm 0,20$ & $2,58 \pm 0,25$ & $2,46 \pm 0,16$ & $2,97 \pm 0,31$ & $3,41 \pm 0,34$ & $3,52 \pm 0,25$ & $3,42 \pm 0,34$ & 1,5 & 3,1 \\
\hline $\mathrm{Zn}$ & $71,5 \pm 3,6$ & $58,8 \pm 3,1$ & $86,1 \pm 6,3$ & $83,2 \pm 5,9$ & $117 \pm 6$ & $65,9 \pm 2,8$ & $127 \pm 5$ & $53,4 \pm 2,8$ & $69,5 \pm 3,4$ & $88,2 \pm 7,4$ & $79,4 \pm 6,1$ & $152 \pm 9$ & $85,3 \pm 6,3$ & $55,2 \pm 3,0$ & $63,2 \pm 3,7$ & $55,0 \pm 3,1$ & $52,3 \pm 3,5$ & $53,8 \pm 2,5$ & $79,5 \pm 5,2$ & 52 & 85 \\
\hline
\end{tabular}

-- Não determinado 

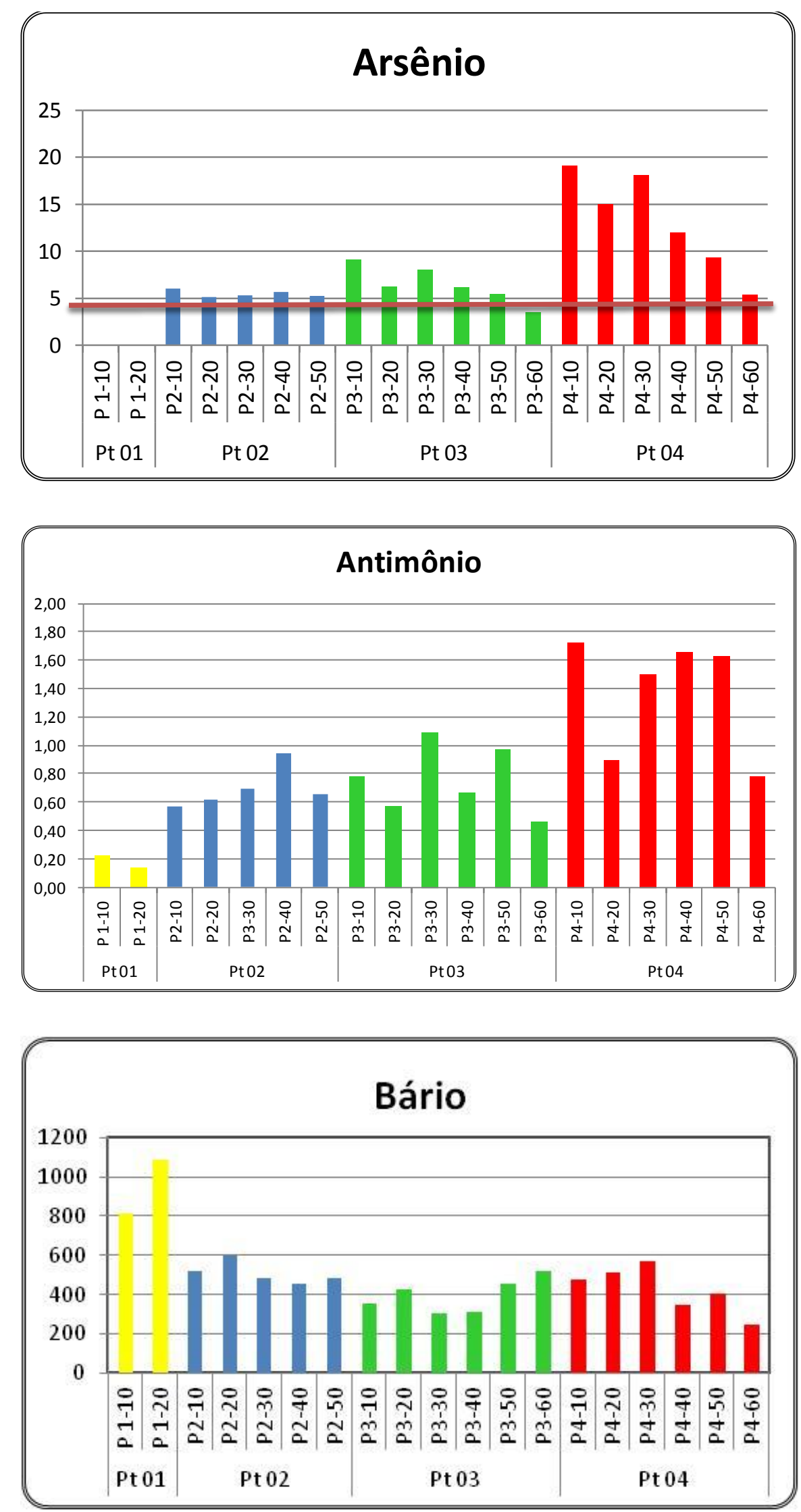

Figura 4.12 Distribuição dos elementos analisados por INAA $\left(\mathrm{mg} \mathrm{kg}^{-1}\right)$, em cada fração de sedimento, para cada ponto amostrado 

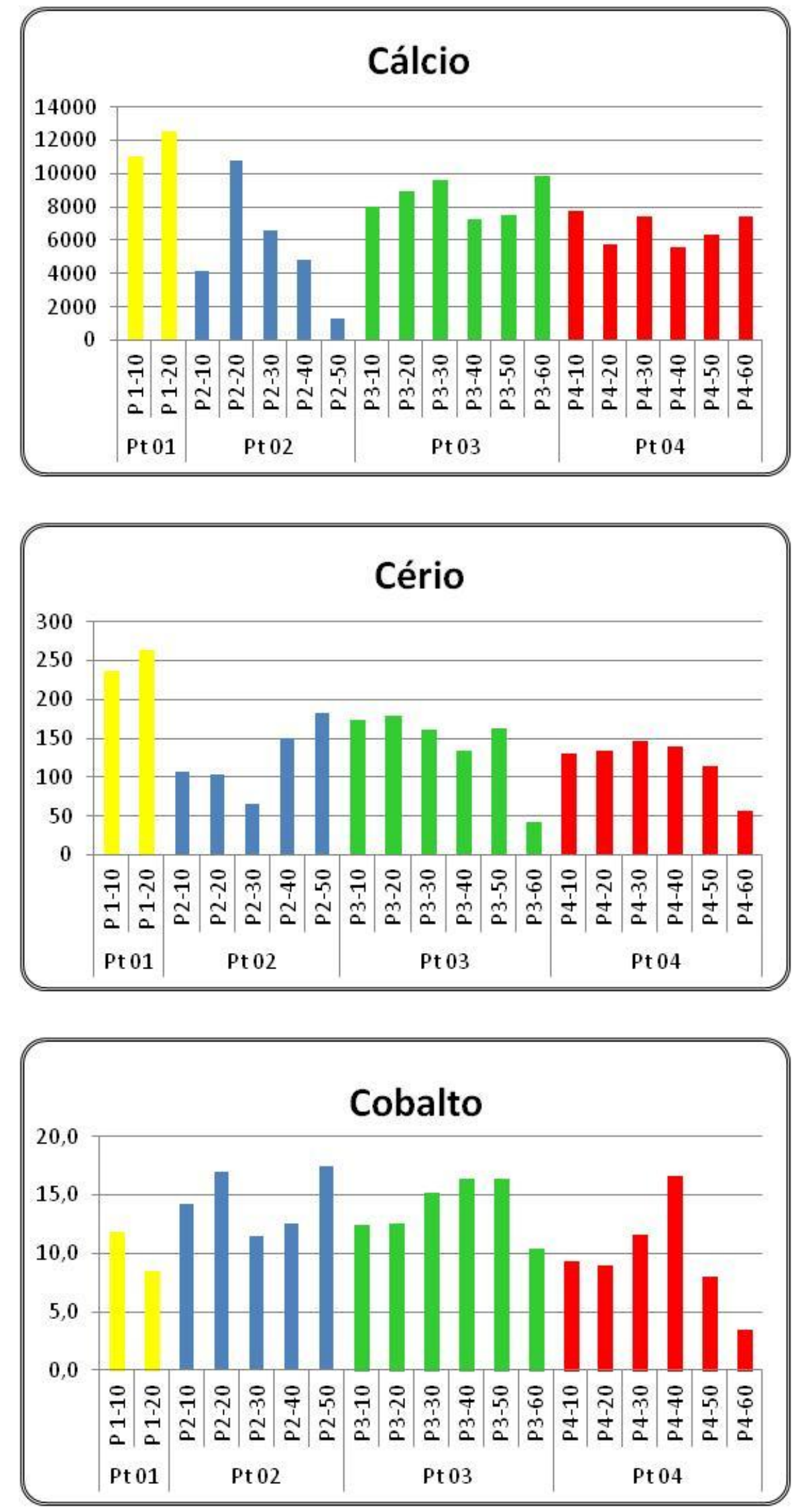

FIGURA 4-12 Continuação 

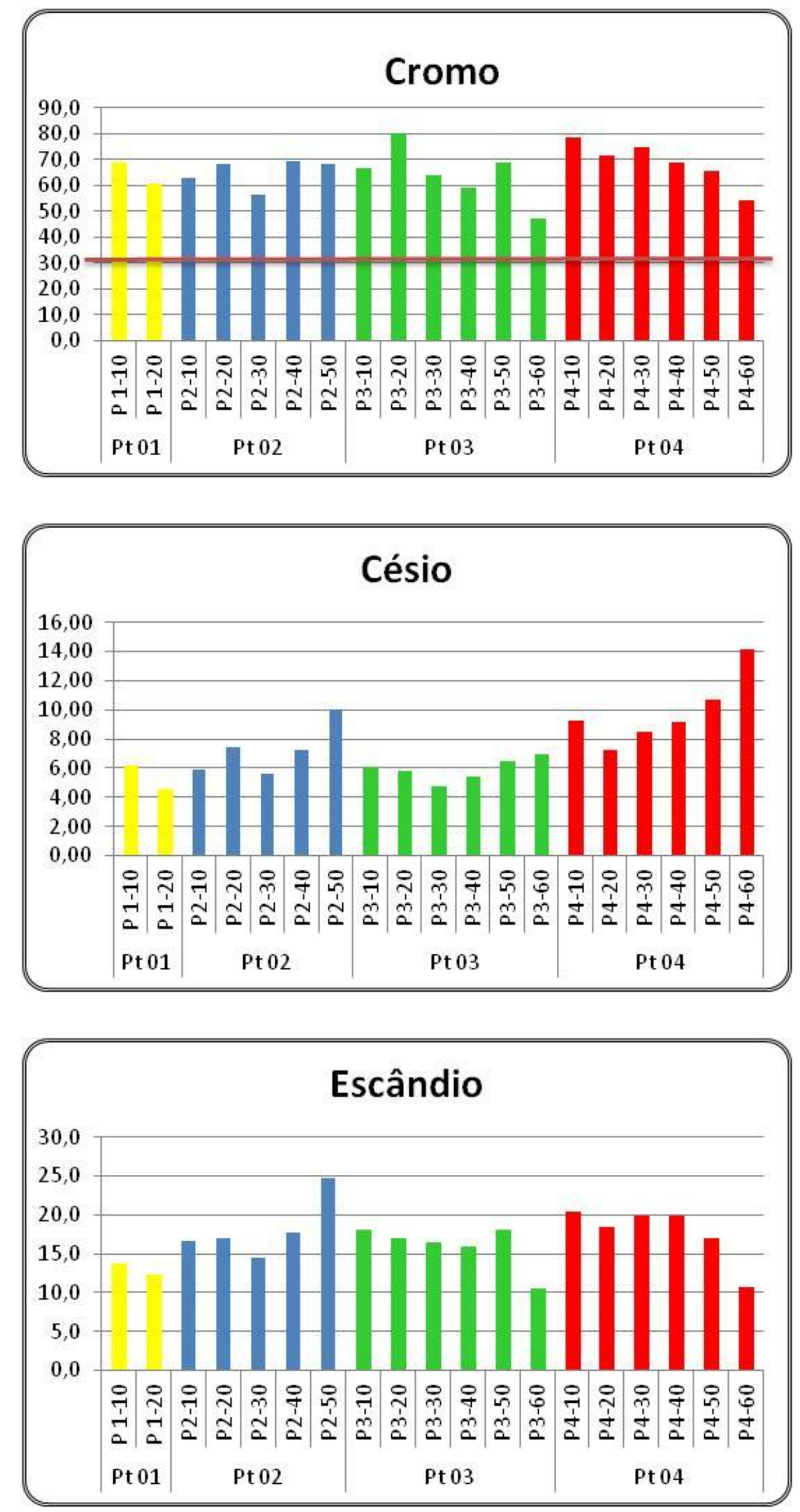

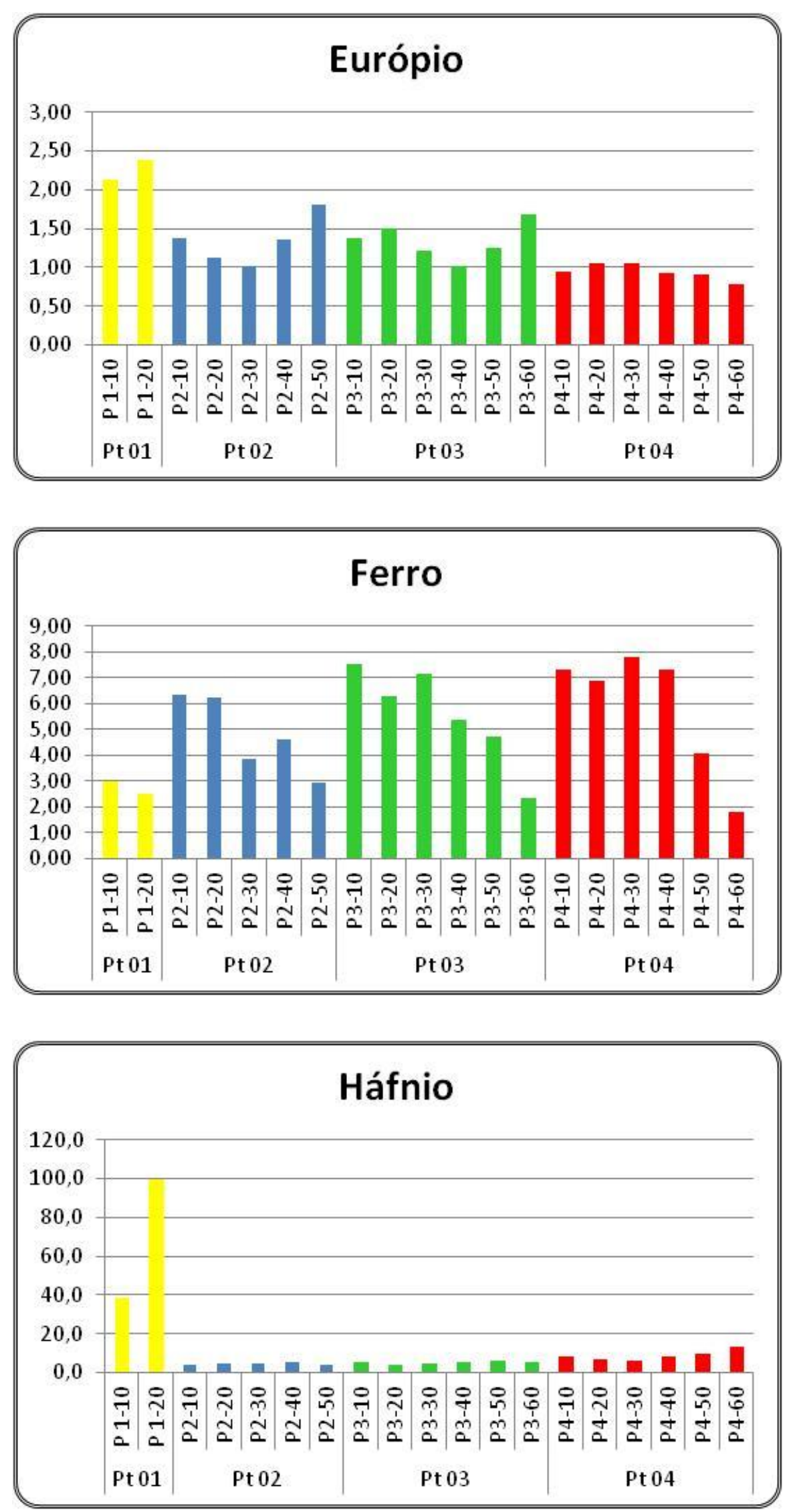

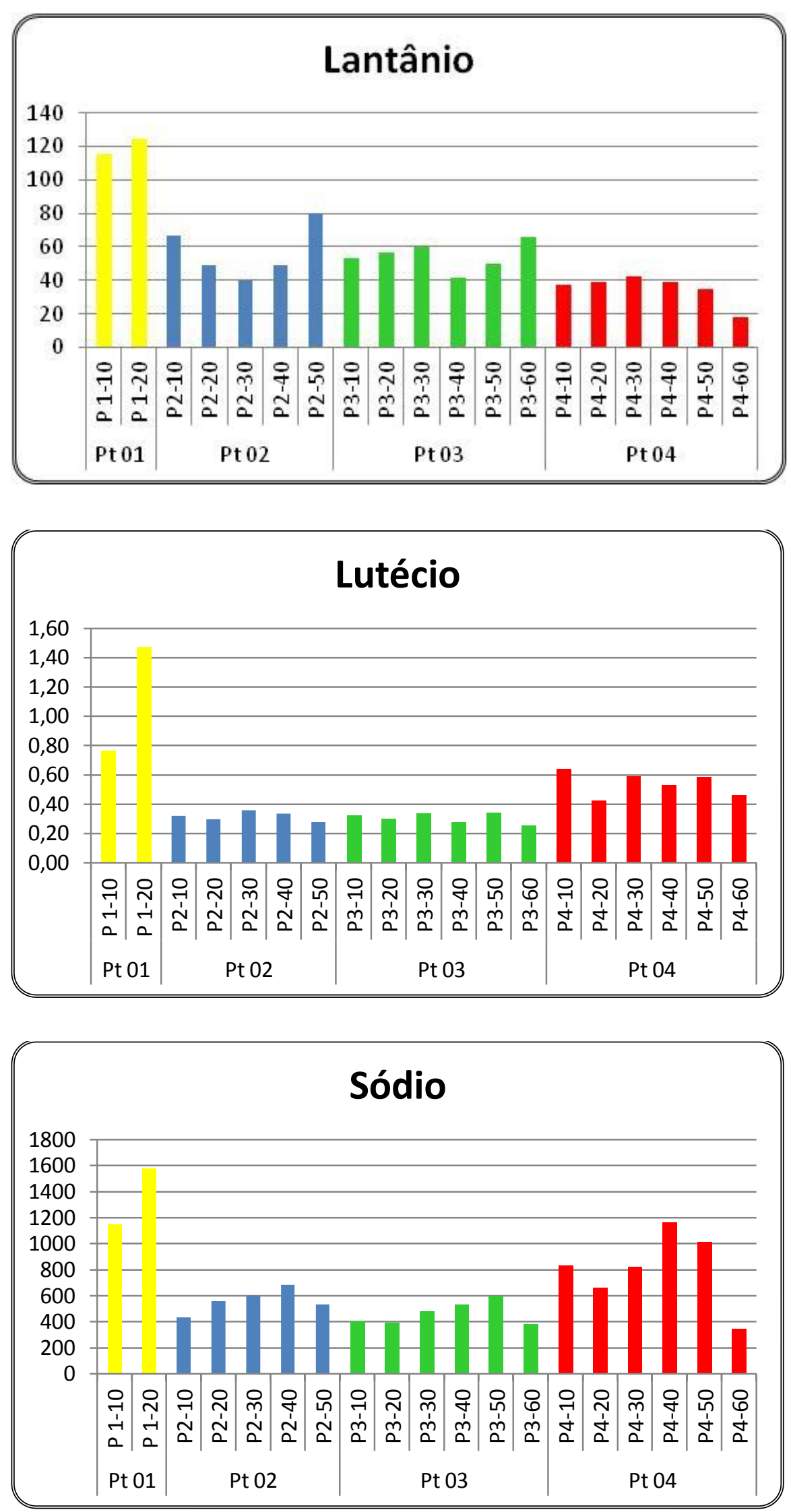

FIGURA 4-12 Continuação 

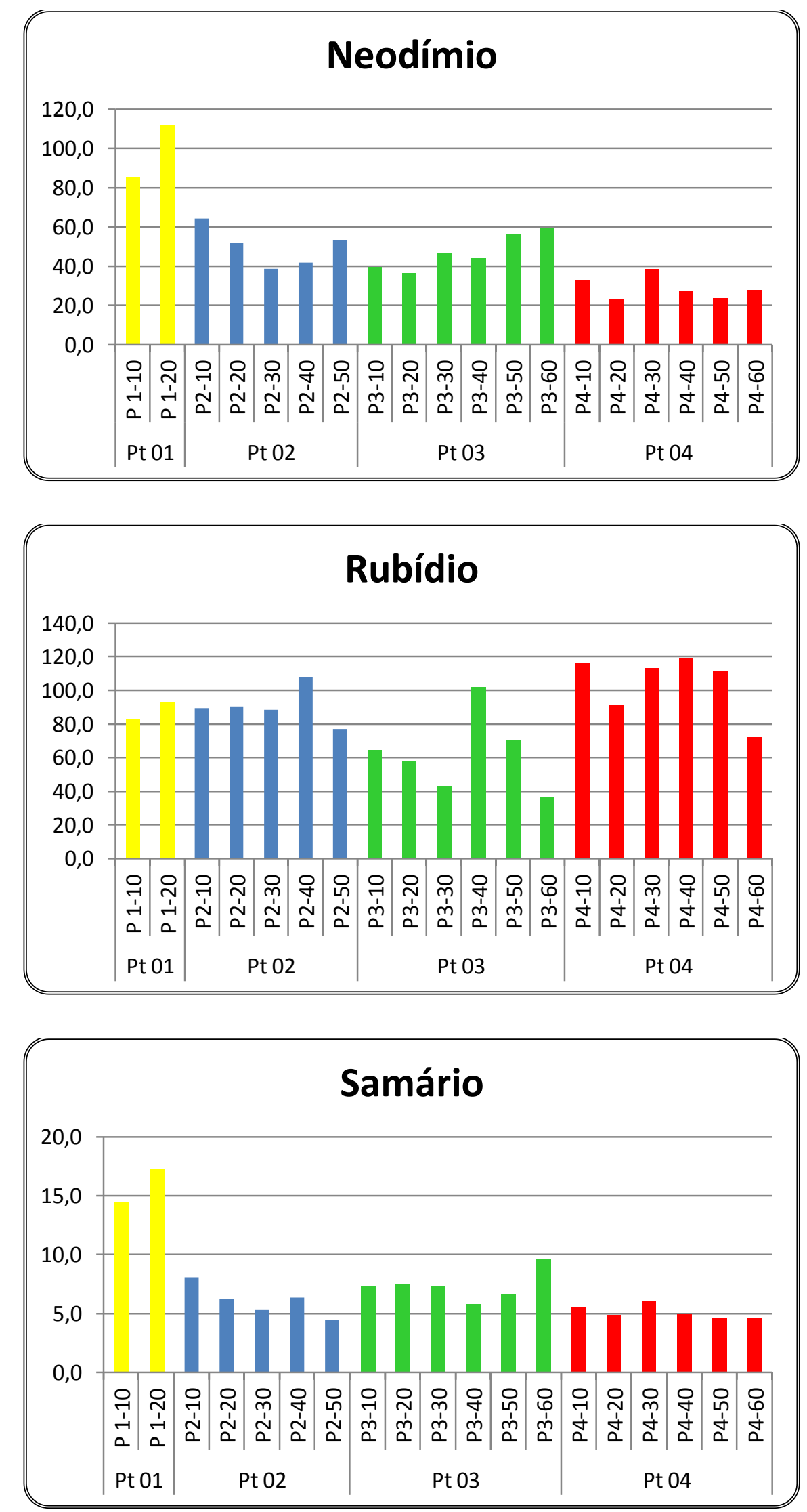

FIGURA 4-12 Continuação 

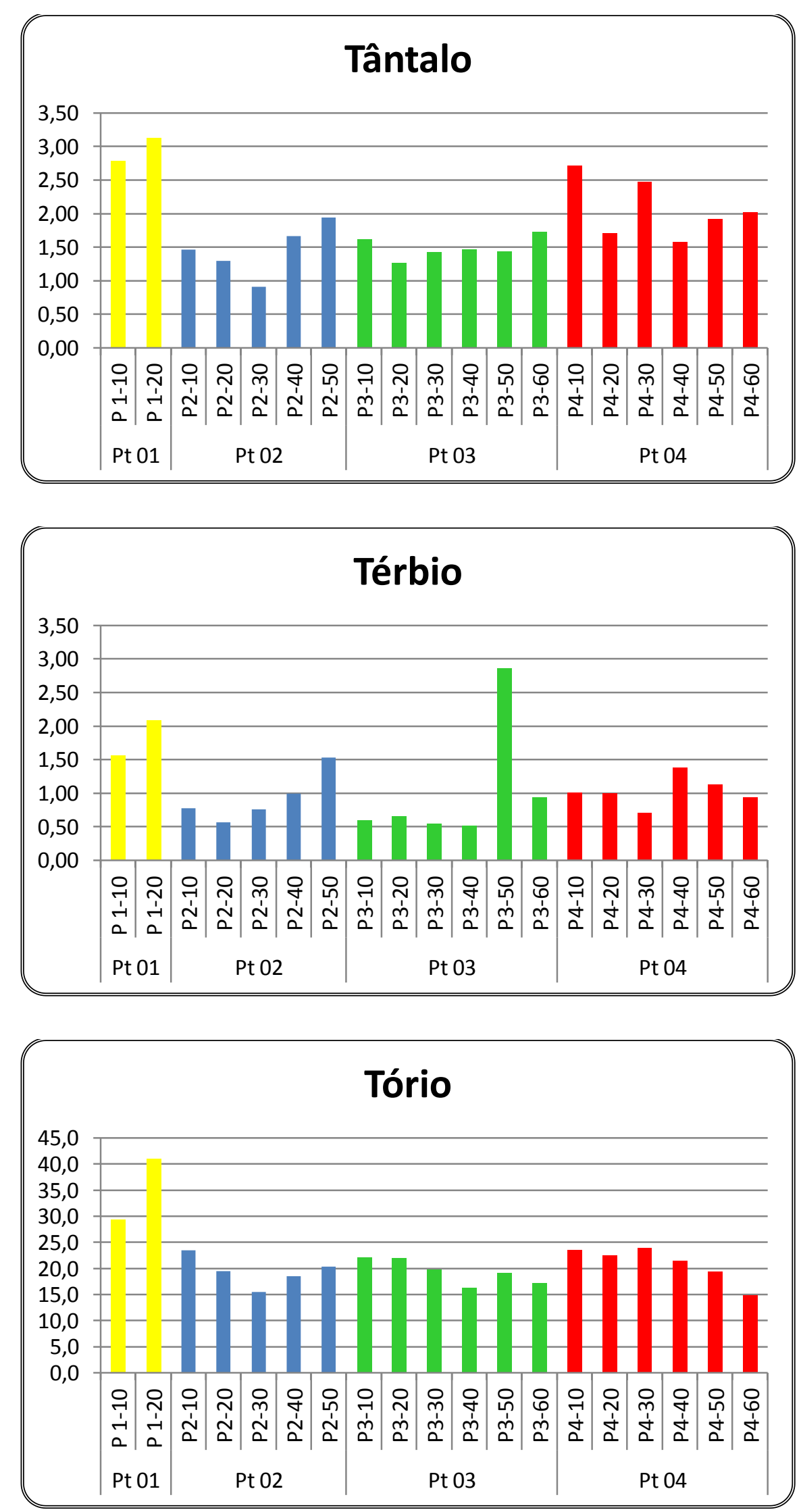

FIGURA 4-12 Continuação 

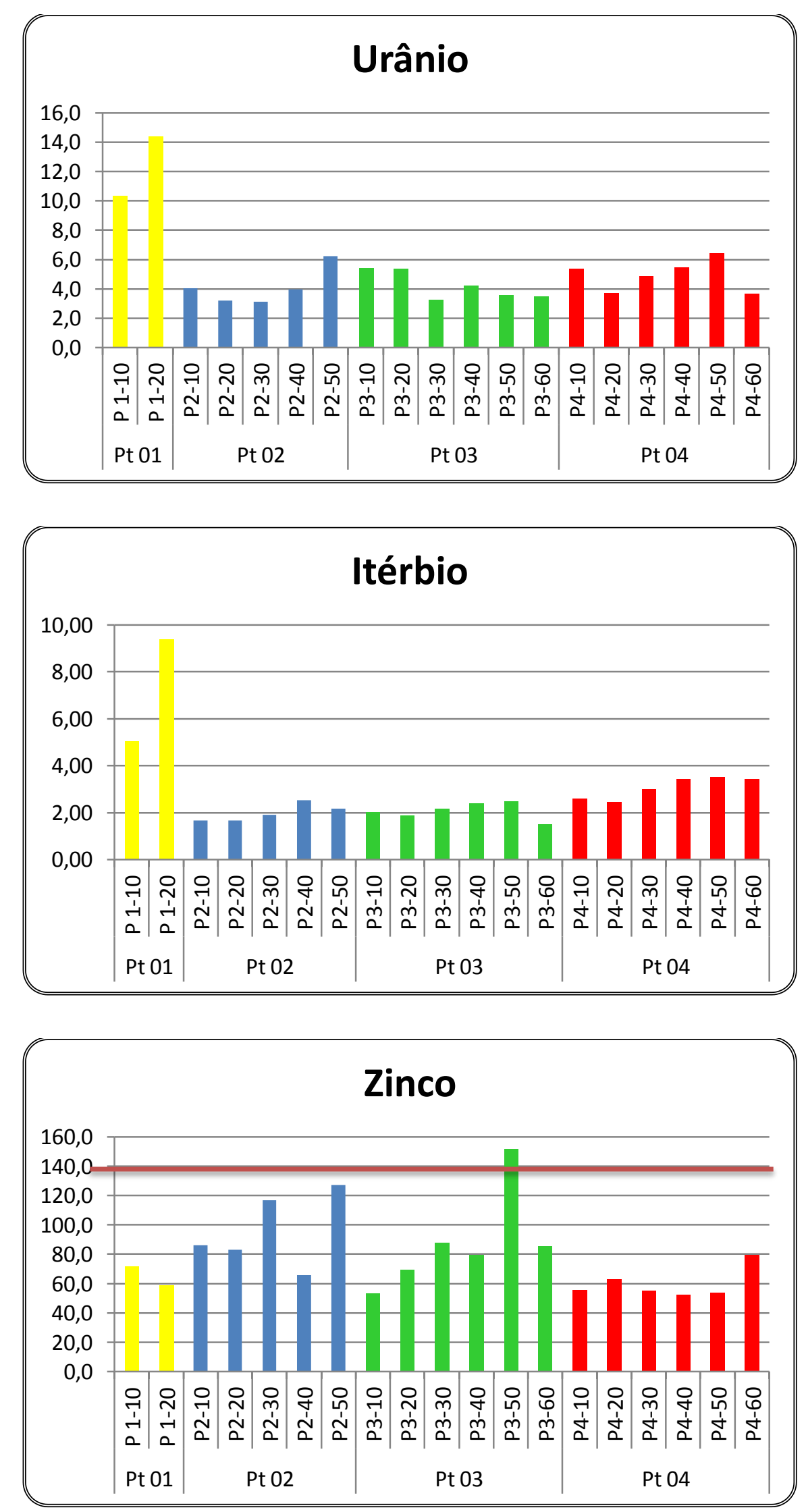

FIGURA 4-12 Distribuição dos elementos analisados por INAA (mg $\mathrm{kg}^{-1}$ ), em cada fração de sedimento, para cada ponto amostrado 


\subsubsection{Variação de concentração dos elementos determinados por INAA nas amostras de sedimentos - Gráficos "Box Plot"}

Para a verificação da variação de concentração, a partir dos dados obtidos pela técnica de INAA, valores de COT, NKT e de granulometria foram confeccionados gráficos "box plot" para cada elemento analisado, a partir das representações dos quartis e da mediana, além dos limites mínimos e máximos para cada elemento.

As FIG 4.13 a 4.18 apresentam os "box plot" para os elementos determinados os demais parâmetros, agrupados por ordem de concentração.

A partir dos "box plot" da FIG 4.13 pode-se verificar que os elementos $\mathrm{Ca}$, Co, $\mathrm{Cs}, \mathrm{Fe}$ e $\mathrm{Sb}$ apresentaram pequena variação de concentração com valores na faixa de não“outliers". A amostra P1-10 apresentou valores "outliers" e/ou extremos para os elementos As, Ta, Th e U e a amostra P1-20, apresentou valores "outliers" para os elementos As, Sc e U.

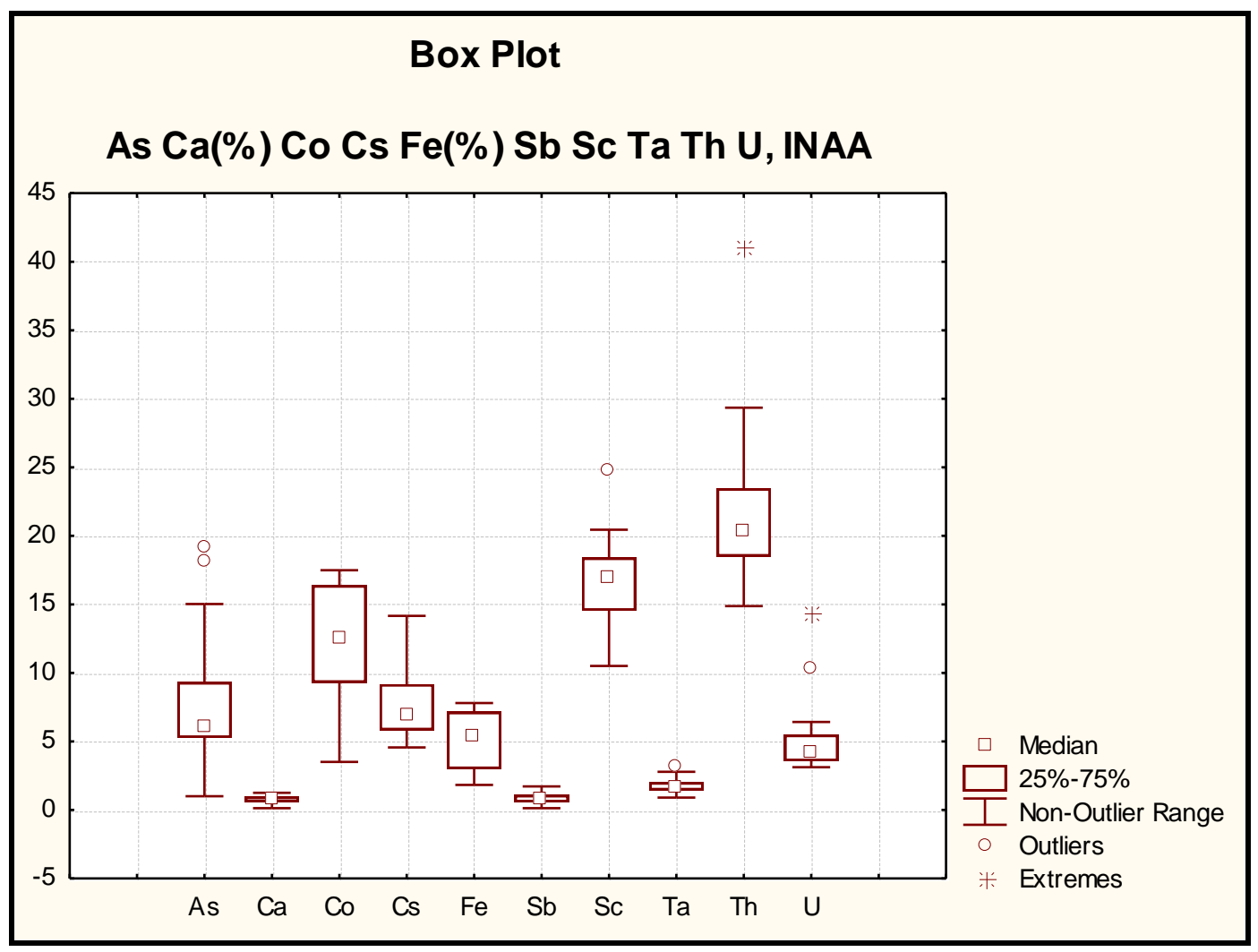

FIGURA 4.13 - Box plot dos elementos As, Ca, Co, Cs, Fe, Sb, Sc, Ta, Th e U 
A FIG 4.14 apresenta os "box plot" para os elementos Cr, Hf, Rb e Zn. Em geral, todos os elementos apresentaram pequena variação de concentração nas amostras analisadas, porém somente o elemento Rb não apresentou valores "outliers" ou extremos. O elemento $\mathrm{Cr}$ apresentou um valor "outlie"r abaixo da mediana (P4-50), o Zn um “outlier” (P2-10) e o Hf, 2 valores extremos, ambos no ponto 1 (P1-10 e 20).

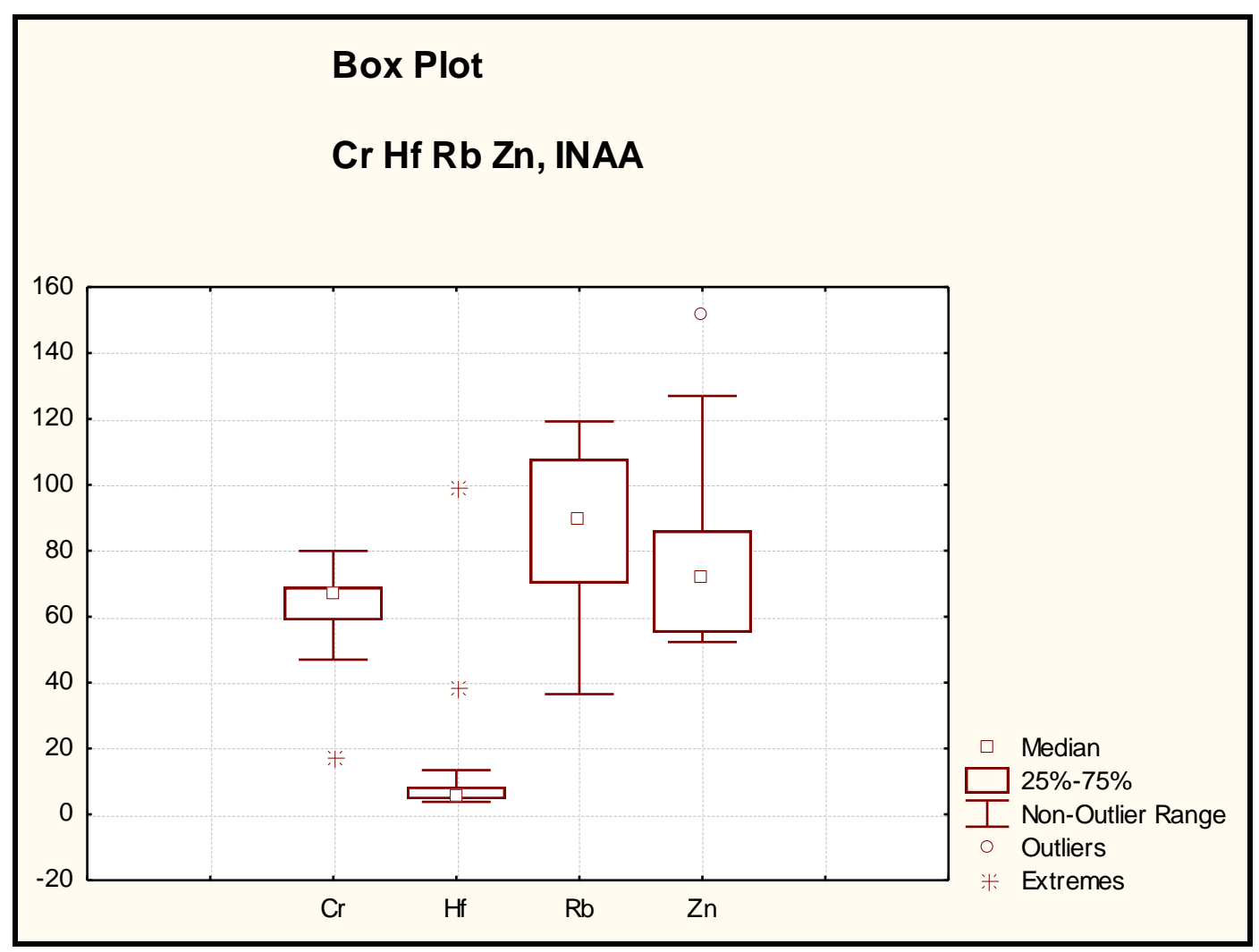

FIGURA 4.14 - Box plot dos elementos Cr, Hf, Rb e Zn 


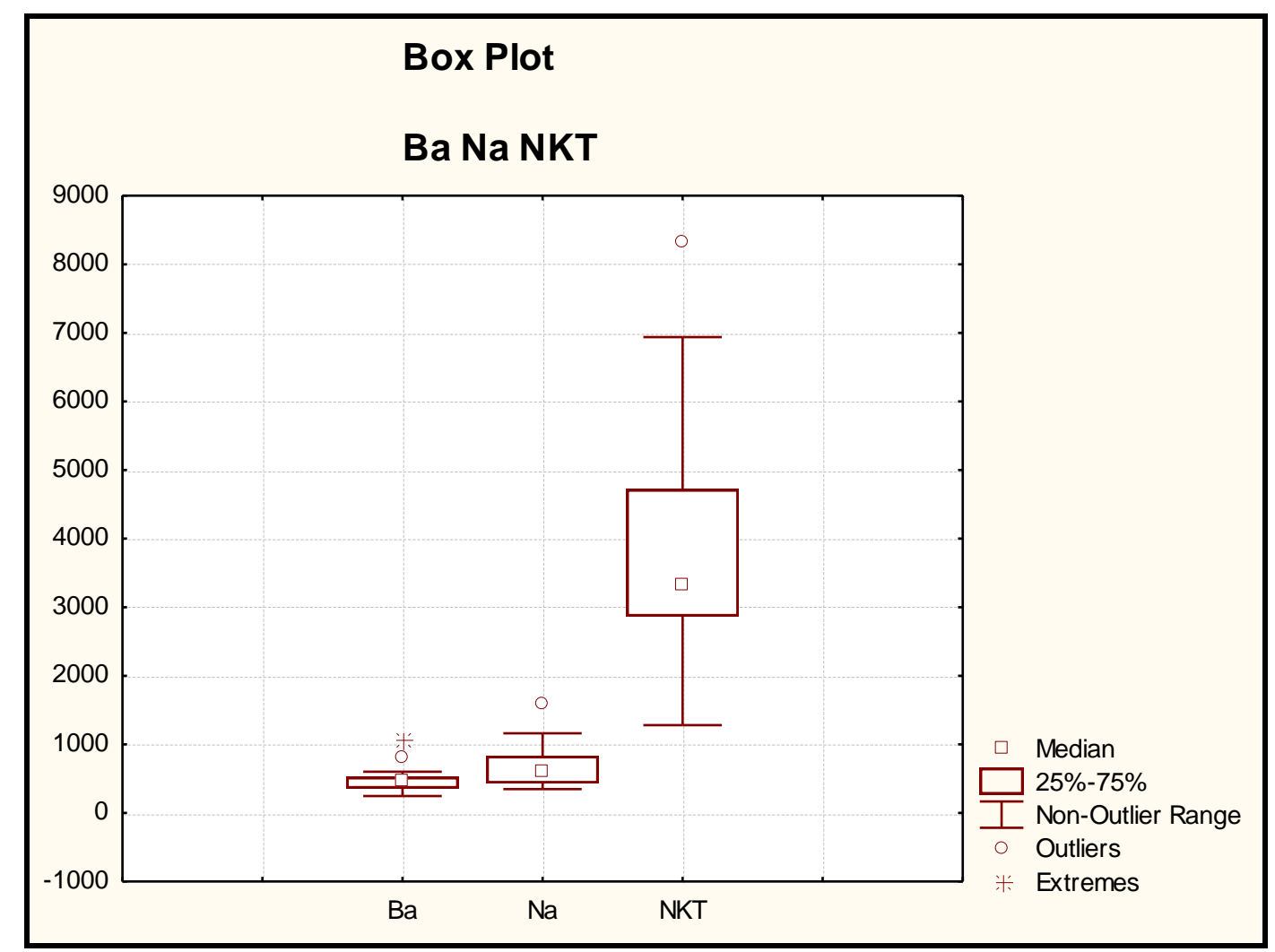

FIGURA 4.15 - Box plot dos elementos Ba, Na e NKT

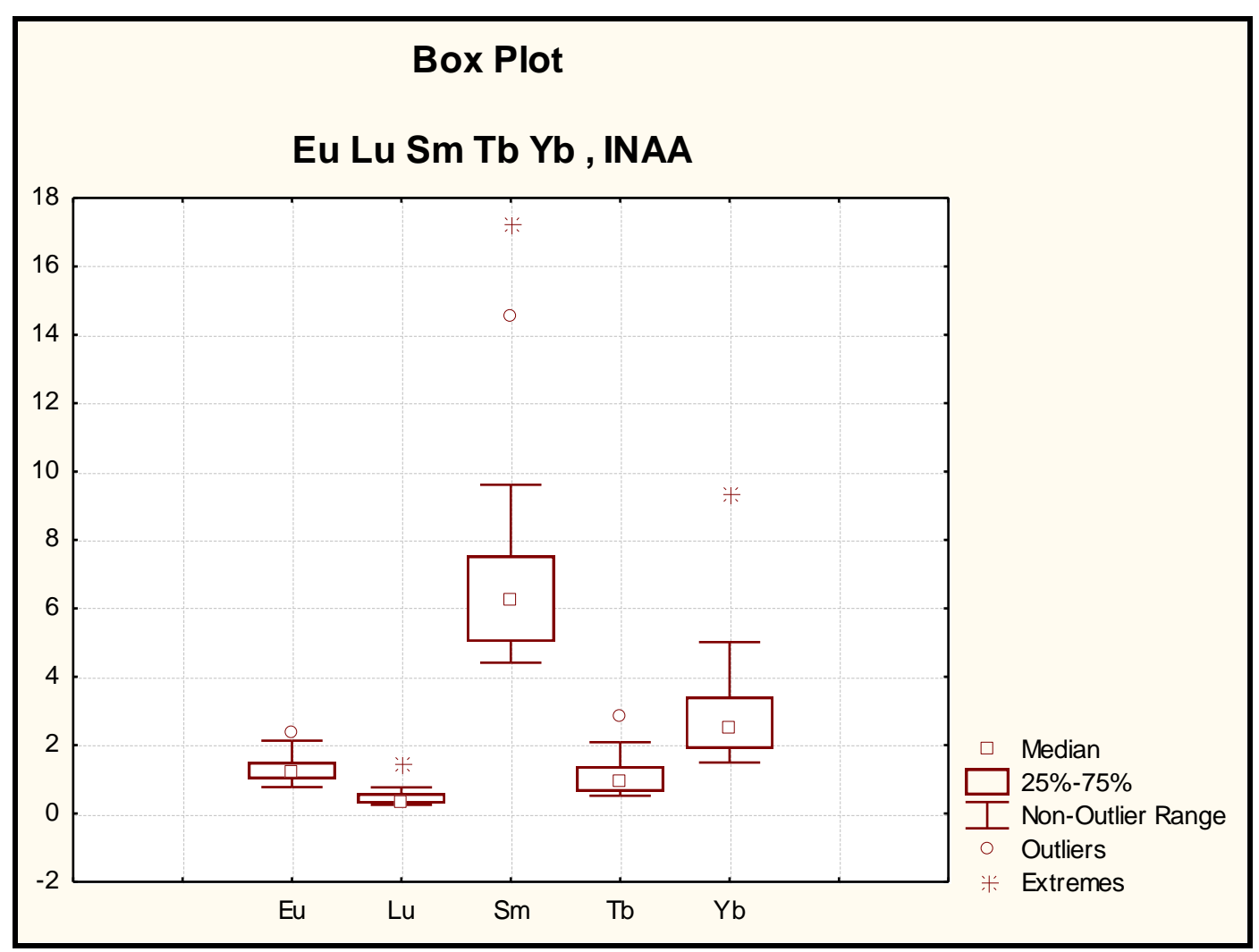

FIGURA 0.16 - Box plot dos elementos Eu, Lu, Sm, Tb e Yb 


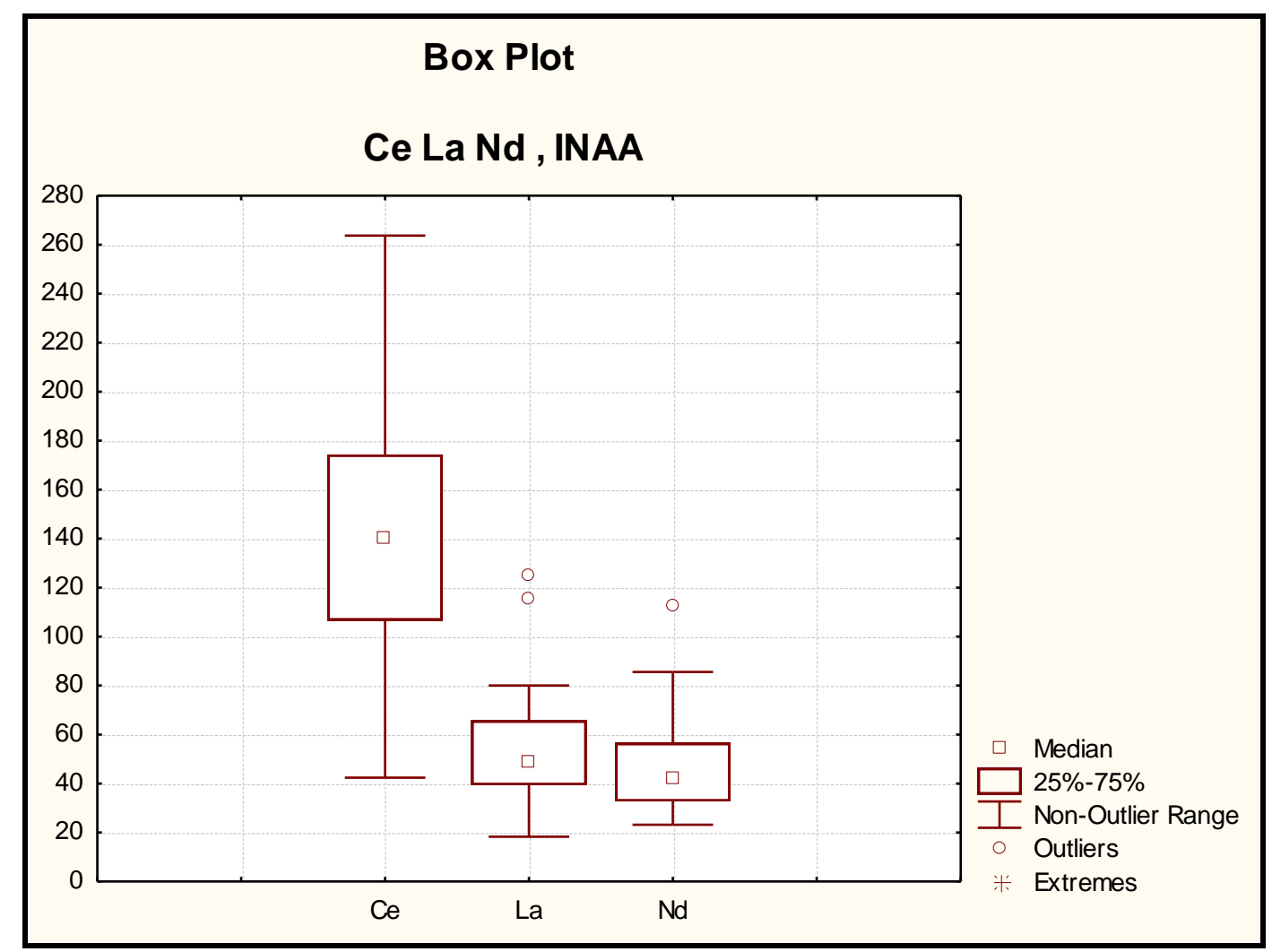

FIGURA 4.17 - Box plot dos elementos Ce, La e Nd

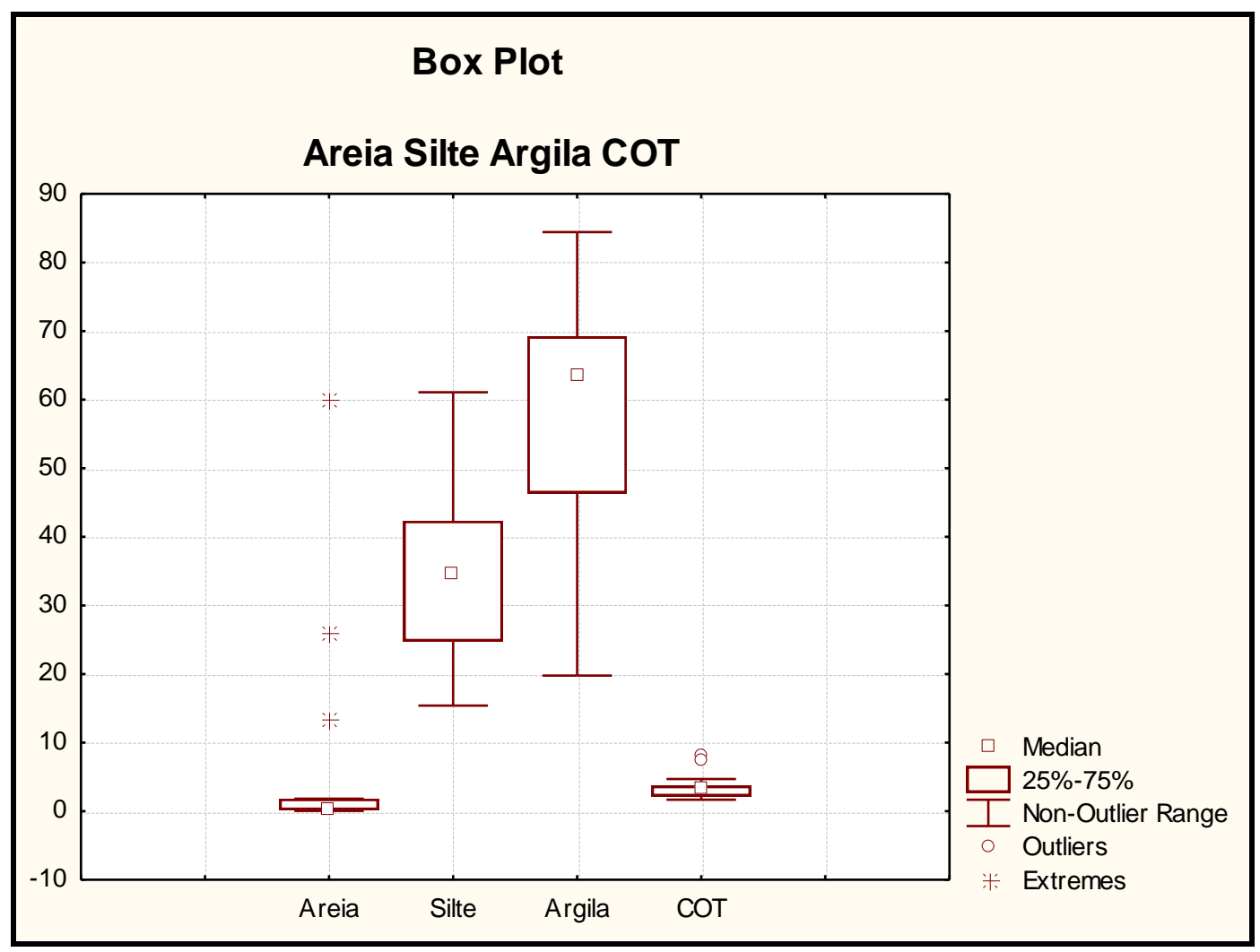

FIGURA 4.18 - Box plot para os dados de areia, silte, argila e COT 


\subsubsection{Fator de Enriquecimento (FE)}

O fator de enriquecimento foi calculado conforme descrito no item 3.9. Os resultados encontrados são apresentados nas TAB 4.24, 4.25 e 4.26, onde estão em destaque os valores que ficaram acima de $\mathrm{FE}>1,5$, indicativo de que a contribuição principal destes elementos é de origem antrópica.

$\mathrm{Na}$ TAB 4-24, apresentam-se os valores calculados para o FE utilizando-se como valores de referência os dados do UCC, a TAB 4-25 com os valores do NASC e, finalmente, a TAB 4-26 com os valores da base do perfil do ponto 03. Analisando-se essas tabelas, pode-se perceber uma nítida diferença entre os valores de FE encontrados em cada uma delas.

A partir dos valores da TAB 4.24, pudemos notar que:

Ponto 01: Ce, Hf, La, Lu, Nd, Sm, Tb, U e Yb, possuem FE>1,5, para as duas frações, com concentrações menores na fração superficial. Já para o elemento Th, o enriquecimento foi observado somente na base do perfil. Para os demais elementos determinados, foram encontrados valores de $\mathbf{0 , 5}<\mathbf{E F}<\mathbf{1 , 5}$, indicativo de que esses elementos são provenientes totalmente de contribuição crustal.

Ponto 02: não foi observado enriquecimento para nenhum dos elementos analisados.

Ponto 03: foram encontrados valores de $\mathbf{E F}>\mathbf{1 , 5}$ para As, em algumas amostras do ponto 3 (P3-10 e P3-30) e todas as frações do ponto 4.

Ponto 04: foram encontrados valores de $\mathbf{E F}>1,5$ para os elementos: As e $\mathrm{Sb}$ em todas as frações do ponto 4 e para Cs e Hf, na fração P4-60. 
TABELA 4.24 - Valores de FE, tendo Sc como elemento normalizador e valores de concentração do UCC como valores de referência

\begin{tabular}{|c|c|c|c|c|c|c|c|c|c|c|c|c|c|c|c|c|c|c|c|c|c|c|c|c|}
\hline \multicolumn{25}{|c|}{ Normalização com UCC } \\
\hline onto & Amostra & As & $\mathrm{Ba}$ & $\mathrm{Ca}$ & $\mathrm{Ce}$ & Co & $\mathrm{Cr}$ & Cs & Eu & $\mathrm{Fe}$ & Hf & $\mathrm{La}$ & $\mathbf{L u}$ & $\mathrm{Na}$ & Nd & $\mathbf{R b}$ & $\mathrm{Sb}$ & $\mathrm{Sm}$ & $\mathrm{Ta}$ & $\mathrm{Tb}$ & Th & $\mathrm{U}$ & $\mathbf{Y b}$ & $\mathbf{Z n}$ \\
\hline \multirow{2}{*}{ Pt 01} & & -- & 060 & & 1,83 & 0,52 & 1,00 & 05 & 1,14 & & 3,35 & & 1,44 & 0,02 & 1,67 & 0,38 & 0,35 & 1,56 & 0,94 & 1,58 & 1,44 & 2,09 & 1,69 & 0,70 \\
\hline & -20 & -- & 0,92 & 24 & 2,27 & 0,41 & 0,98 & 44 & 1,42 & 0,46 & 9,70 & & 3,08 & 0,03 & 2,45 & 0,48 & 0,24 & 2,07 & 1,18 & 2,36 &, 25 & 3,25 & 3,53 & 0,64 \\
\hline \multirow{5}{*}{ Pt 02} & P2-10 & 1,26 & 0,33 & 0,06 & 0,68 & 0,52 & 0,76 & 0,43 & 0,61 & 0,86 & 0,27 & 0,86 & 0,50 & 0,01 & 1,04 & 0,34 & 0,76 & 0,72 & 0,41 & 0,65 & 0,96 & 0,68 & 0,46 & 0,69 \\
\hline & $2-20$ & 1,06 & 0,37 & 0,15 & 0,64 & 0,60 & 0,80 & 0,52 & 0,49 & 0,83 & 0,34 & ,, 02 & 0,45 & 0,01 & 0,83 & 0,34 & 0,82 & 0,55 & 0,36 & 0,46 & 0,78 & 0,52 &, 45 & 0,66 \\
\hline & P2-30 & 1,28 & 0,35 & 0,11 & 0,47 & 0,48 & 0,78 & 0,46 & 0,51 & 0,61 & 0,37 & 0,59 & 0,64 & 0,01 & 0,72 & 0,39 & 1,08 & 0,54 & 0,29 & 0,73 & 0,72 & 0,60 & 0,61 & 1,08 \\
\hline & P2-40 & 1,12 & 0,27 & 0,06 & 0,90 & 0,43 & 0,78 & 0,49 & 0,57 & 0,59 & 0,35 & 0,60 & 0,49 & 0,01 & 0,64 & 0,39 & 1,21 & 0,53 & 0,44 & 0,79 & 0,71 & 0,63 & 0,67 & 0,50 \\
\hline & P2-50 & 75 & 0,20 & 0,01 &, 79 & 0,43 & 0,55 & 0,49 & 0,54 & 0,27 & 0,19 & 0,70 & 0,29 & 0,01 & 0,58 & 0,20 & 0,60 & 0,27 & 0,37 & 0,87 & 0,56 & 0,71 & 0,41 & 0,69 \\
\hline \multirow{6}{*}{ Pt 03} & & 76 & 0,21 & & 03 & 0,42 & 0,74 & 0,41 & 0,56 & 0,95 & 0,34 & 0,64 & 0,46 & 0,01 & 0,59 & 0,23 & 0,97 & 0,60 & 0,42 & 0,46 & 83 &, 84 & 52 & 0,40 \\
\hline & P3-20 & 1,29 & 0,26 & 0,12 & 1,12 & 0,45 & 0,94 & 0,41 & 0,65 & 0,84 & 0,27 & 0,72 & 0,45 & 0,01 & 0,58 & 0,22 & 0,76 & 0,66 & 0,35 & 0,53 & 0,88 & 0,89 & 0,51 & 0,55 \\
\hline & P3-30 & 1,72 & 0,19 & 0,14 & 1,05 & 0,56 & 0,78 & 0,35 & 0,54 & 0,99 & 0,34 & 0,79 & 0,53 & 0,01 & 0,77 & 0,17 & 1,50 & 0,67 & 0,41 & 0,46 & 0,82 & 0,56 & 0,61 & 0,72 \\
\hline & P3-40 & 1,36 & 0,21 & 0,11 & 0,91 & 0,63 & 0,74 & 0,41 & 0,47 & 0,77 & 0,41 & 0,57 & 0,45 & 0,01 & 0,76 & 0,41 & 0,95 & 0,54 & 0,43 & 0,46 & 0,70 & 0,75 & 0,71 & 0,68 \\
\hline & & & 0,26 & & 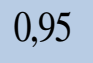 & 0,55 & 0,76 & & 0,51 & 0,59 & 0,4 & 0 , & 0,49 & 0,01 & 0,84 & 0,25 & 1,22 & 0,55 & 0,37 & 2,21 & 0,72 & 0,55 & 0,64 & 1,12 \\
\hline & P3-60 & 16 & 0,52 & 0,22 & 0,43 & 0,60 & 0,89 & 0,79 & 1,18 & 0,50 & 0,58 & 1,3 & 0,63 & 0,01 & 1,53 & 0,22 & 0,98 & 1,36 & 0,77 & 1,25 & 1,11 & 0,94 & 0,66 & 1,09 \\
\hline \multirow{6}{*}{ Pt 04} & P4-10 & 3,27 & 0,25 & 0,09 & 0,67 & 0,27 & 0,77 & 0,55 & 0,34 & 0,81 & 0,49 & 0,40 & 0,81 & 0,01 & 0,43 & 0,36 & 1,90 & 0,41 & 0,62 & 0,69 & 0,78 & 0,74 & 0,59 & 0,36 \\
\hline & P4-20 & & 0,29 & 0,07 & 0,78 & 0,29 & 0,19 & & 0,42 & 0,85 & 0,46 & 0, & 0,60 & 0,01 & 0,34 & 0,32 & 1,09 & 0,39 & 0,43 & 0,76 & 0,83 & 0,57 & 0,62 & 0,46 \\
\hline & P4-30 & 3,18 & 0,30 & 0,09 & 0,78 & 0,35 & 0,75 & 0,52 & 0,39 & 0,89 & 0,38 & 0, & 0,77 & 0,01 & 0,52 & 0,36 & 1,70 & 0,45 & 0,58 & 0,49 & 0,81 & 0,69 & 0,70 & 0,37 \\
\hline & P4-40 & 2,13 & 0,18 & 0,07 & 0,75 & 0,50 & 0,69 & 0,56 & 0,34 & 0,84 & 0,51 & 0,43 & 0,69 & 0,02 & 0,38 & 0,38 & 1,89 & 0,38 & 0,37 & 0,98 & 0,74 & 0,77 & 0,80 & 0,36 \\
\hline & P4-50 & 1,92 & 0,25 & 0,09 & 0,72 & 0,28 & 0,77 & 0,76 & 0,39 & 0,55 & 0,68 & 0,4 & 0,89 & 0,02 & 0,38 & 0,42 & 2,16 & 0,40 & 0,53 & 0,93 & 0,77 & 1,06 & 0,97 & 0,43 \\
\hline & P4-60 & 1,76 & 0,24 & 0,17 & 0,57 & 0,20 & 1,01 & 1,61 & 0,54 & 0,39 & 1,52 & 0,37 & 1,13 & 0,01 & 0,70 & 0,43 & 1,65 & 0,65 & 0,88 & 1,23 & 0,95 & 0,96 & 1,50 & 1,01 \\
\hline
\end{tabular}


A análise dos valores de $\mathbf{F E}$ da $\mathrm{TAB} 4.25$, mostra um número maior de elementos apresentaram valores de $\mathbf{F E}>\mathbf{1 , 5}$, a saber:

Ponto 01: Ba, Cs, Hf, Ta, Th, U e ETR (Ce, Eu, La, Lu, Nd, Sm, Tb, Th e Yb), apresentaram FE>1,5, para as duas frações, observando-se uma menor concentração na fração superficial para a maioria dos elementos, exceto para Cs.

Ponto 02: As, Cs, Sb, Th, U e ETR (Ce, La, Nd) apresentaram enriquecimento em todo o perfil.

Ponto 03: As, Cs, Sb, Th, U e ETR (Ce, Nd) apresentaram enriquecimento em todo o perfil. Os elementos $\mathrm{Hf}, \mathrm{Zn}$ e $\mathrm{Tb}$, somente apresentaram enriquecimento na base do perfil (P3-50 e P3-60).

Ponto 04: As, Cs, $\mathrm{Sb}, \mathrm{Ta}, \mathrm{Th}, \mathrm{U}$ e Ce, apresentaram enriquecimento em todo o perfil, enquanto que $\mathrm{Hf}, \mathrm{Lu}, \mathrm{Nd}, \mathrm{Tb}, \mathrm{Yb}$ e $\mathrm{Zn}$, somente na base do perfil. 
Tabela 4.25 - Valores de FE, tendo Sc como elemento normalizador e valores de concentração do NASC como valores de referência

\begin{tabular}{|c|c|c|c|c|c|c|c|c|c|c|c|c|c|c|c|c|c|c|c|c|c|c|c|c|}
\hline \multicolumn{25}{|c|}{ Normalização com NASC } \\
\hline Ponto & Amostra & As & $\mathrm{Ba}$ & $\mathrm{Ca}$ & $\mathrm{Ce}$ & Co & $\mathrm{Cr}$ & Cs & Eu & $\mathrm{Fe}$ & $\mathrm{Hf}$ & $\mathrm{La}$ & $\mathrm{Lu}$ & $\mathrm{Na}$ & $\mathrm{Nd}$ & $\mathbf{R b}$ & $\mathrm{Sb}$ & $\mathrm{Sm}$ & $\mathrm{Ta}$ & $\mathrm{Tb}$ & Th & $\mathrm{U}$ & $\mathrm{Yb}$ & Zn \\
\hline \multirow{2}{*}{ Pt 01} & P1-10 & & 1,62 & 0,33 & 4,57 & 0,57 & 0,63 & 2,12 & 1,90 & 0,80 & 9 & 4,45 & 2,53 & 0,06 & 3,67 & 1,23 & 0,84 & 3,17 & 2,93 & 2,78 & 4,00 & 7,03 & 2,90 & 1,27 \\
\hline & P1-20 & & 2,41 & 0,42 & 5,67 & 0,46 & 0,62 & 1,73 & 2,37 & 75 & 26,2 & 5,37 & 5,42 & 0,09 & 5,36 & 1,54 & 0,57 & 4,20 & 3,67 & 4,14 & 6,23 & 10,9 & 6,05 & 1,17 \\
\hline \multirow{5}{*}{ Pt 02} & P2-10 & 3,40 & 0,86 & 0,10 & 1,70 & 0,57 & 0,48 & 1,67 & 1,02 & 1,40 & 0,74 & 2,12 & 0,87 & 0,02 & 2,28 & 1,10 & 1,80 & 1,46 & 1,28 & 1,14 & 2,65 & 2,29 & 0,79 & 1,27 \\
\hline & P2-20 & 2,84 & 0,97 & 0,26 & 1,61 & 0,66 & 0,51 & 2,04 & 0,82 & 1,36 & 0,91 & 1,53 & 0,80 & 0,02 & 1,81 & 1,09 & 1,94 & 1,11 & 1,11 & 0,81 & 2,16 & 1,76 & 0,78 & 1,20 \\
\hline & P2-30 & 3,43 & 0,91 & 0,19 & 1,19 & 0,53 & 0,49 & 1,80 & 0,86 & 0,99 & 1,00 & 1,45 & 1,13 & 0,03 & 1,57 & 1,25 & 2,55 & 1,10 & 0,91 & 1,29 & 2,00 & 2,02 & 1,05 & 1,98 \\
\hline & P2-40 & 3,02 & 0,70 & 0,11 & 2,26 & 0,48 & 0,50 & 1,93 & 0,95 & 0,96 & 0,95 & 1,47 & 0,87 & 0,03 & 1,41 & 1,25 & 2,85 & 1,08 & 1,37 & 1,38 & 1,97 & 2,11 & 1,15 & 0,92 \\
\hline & P2-50 & 2,01 & 0,54 & 0,02 & 1,97 & 0,47 & 0,35 & 1,90 & 0,90 & 0,44 & 0,51 & 1,73 & 0,52 & 0,01 & 1,28 & 0,64 & 1,41 & 0,54 & 1,14 & 1,52 & 1,55 & 2,38 & 0,70 & 1,26 \\
\hline \multirow{6}{*}{ Pt 03} & P3-10 & 4,75 & 0,54 & 0,18 & 2,58 & 0,46 & 0,47 & 1,60 & 0,94 & 1,54 & 0,91 & 1,58 & 0,81 & 0,02 & 1,30 & 0,73 & 2,30 & 1,22 & 1,30 & 0,81 & 2,30 & 2,82 & 0,89 & 0,73 \\
\hline & P3-20 & 3,47 & 0,69 & 0,22 & 2,80 & 0,49 & 0,60 & 1,61 & 1,08 & 1,37 & 0,74 & 1,78 & 0,80 & 0,02 & 1,27 & 0,70 & 1,78 & 1,34 & 1,08 & 0,93 & 2,43 & 2,98 & 0,87 & 1,01 \\
\hline & P3-30 & 4,63 & 0,51 & 0,24 & 2,62 & 0,62 & 0,50 & 1,36 & 0,90 & 1,61 & 0,92 & 1,94 & 0,93 & 0,02 & 1,68 & 0,53 & 3,54 & 1,35 & 1,27 & 0,81 & 2,27 & 1,88 & 1,05 & 1,32 \\
\hline & $3-40$ & 3,65 & 0,54 & 0,19 & 2,27 & 0,69 & 0,47 & 1,61 & 0,79 & 1,26 & 1,12 & 1,39 & 0,79 & 0,02 & 1,66 & 1,32 & 2,25 & 1,10 & 1,34 & 0,81 & 1,94 & 2,52 & 1,21 & 1,24 \\
\hline & P3-50 & 2,82 & 0,69 & 0,17 & 2,38 & 0,60 & 0,48 & 1,69 & 0,85 & 0,97 & 1,11 & 1,46 & 0,86 & 0,02 & 1,85 & 0,79 & 2,87 & 1,12 & 1,16 & 3,88 & 1,98 & 1,85 & 1,10 & 2,06 \\
\hline & P3-60 & 3,13 & 1,36 & 0,39 & 1,08 & 0,66 & 0,57 & 3,09 & 1,97 & 0,82 & 1,57 & 3,34 & 1,10 & 0,02 & 3,36 & 0,71 & 2,32 & 2,76 & 2,40 & 2,20 & 3,08 & 3,15 & 1,13 & 2,00 \\
\hline \multirow{6}{*}{ Pt 04} & P4-10 & 8,79 & 0,64 & 0,16 & 1,69 & 0,30 & 0,49 & 2,13 & 0,57 & 1,33 & 1,33 & 0,98 & 1,43 & 0,03 & 0,95 & 1,17 & 4,49 & 0,82 & 1,93 & 1,21 & 2,17 & 2,47 & 1,01 & 0,66 \\
\hline & P4-20 & 7,68 & 0,76 & 0,13 & 1,94 & 0,32 & 0,12 & 1,86 & 0,70 & 1,38 & 1,24 & 1,13 & 1,05 & 0,02 & 0,75 & 1,02 & 2,58 & 0,80 & 1,35 & 1,33 & 2,30 & 1,91 & 1,07 & 0,84 \\
\hline & P4-30 & 8,56 & 0,78 & 0,15 & 1,96 & 0,39 & 0,48 & 2,01 & 0,65 & 1,45 & 1,02 & 1,12 & 1,35 & 0,03 & 1,15 & 1,17 & 4,03 & 0,91 & 1,80 & 0,87 & 2,25 & 2,31 & 1,19 & 0,68 \\
\hline & P4-40 & 5,72 & 0,48 & 0,12 & 1,88 & 0,56 & 0,44 & 2,18 & 0,57 & 1,36 & 1,38 & 1,06 & 1,22 & 0,04 & 0,82 & 1,23 & 4,47 & 0,77 & 1,16 & 1,71 & 2,05 & 2,60 & 1,38 & 0,65 \\
\hline & P4-50 & 5,16 & 0,66 & 0,15 & 1,79 & 0,31 & 0,49 & 2,96 & 0,66 & 0,89 & 1,85 & 1,09 & 1,57 & 0,04 & 0,83 & 1,34 & 5,11 & 0,81 & 1,64 & 1,64 & 2,14 & 3,55 & 1,66 & 0,78 \\
\hline & P4-60 & 4,73 & 0,63 & 0,29 & 1,43 & 0,22 & 0,64 & 6,26 & 0,89 & 0,63 & 4,12 & 0,92 & 1,99 & 0,02 & 1,54 & 1,39 & 3,91 & 1,31 & 2,75 & 2,16 & 2,63 & 3,23 & 2,57 & 1,84 \\
\hline
\end{tabular}


A partir dos valores de EF calculados a partir dos valores de concentração da base do perfil (TAB 4.26) pode-se observar que os elementos que apresentaram valores de FE > 1,5 foram:

Ponto 01: Hf, $\mathrm{Na}, \mathrm{Rb}, \mathrm{U}$ e ETR (Ce, Lu e Yb), apresentaram valores considerados enriquecidos em ambas as frações do perfil. Entretanto os elementos Ba, Ta, Th e ETR (La, Nd, Sm, Tb), apresentaram enriquecimento somente na base do perfil (P120).

Ponto 2: Ce e $\mathrm{Rb}$, apresentaram enriquecimento em todo o perfil e o $\mathrm{Fe}$, somente nas frações mais superficiais (P2-10 e P2-20).

Ponto 3: Ce e Fe apresentaram enriquecimento na maioria das frações.

Ponto 4: As, $\mathrm{Ce}, \mathrm{Fe}, \mathrm{Rb}$ e $\mathrm{Sb}$ apresentaram enriquecimento em quase todo o perfil, sendo que Cs, Hf, Lu e Yb, apresentaram enriquecimento somente na base do perfil (P4-60).

Pode-se observar que os elementos que anteriormente apresentaram valores de concentrações acima do esperado (FIG 4-11) apresentaram EF > 1,5, ou seja, indicação de um enriquecimento de origem antrópica, principalmente para $\mathrm{Ce}, \mathrm{Hf}, \mathrm{La}, \mathrm{Lu}, \mathrm{Nd}, \mathrm{Sm}, \mathrm{U}$ e Yb. Já o elemento Na somente apresentou enriquecimento para os valores da base do perfil usados como referencia e o Ba, em relação aos valores do NASC e da base do perfil. 
Tabela 4.26 - Valores de FE, tendo Sc como elemento normalizador e valores de concentração da base do perfil (Pt 03) como valores de referência

\begin{tabular}{|c|c|c|c|c|c|c|c|c|c|c|c|c|c|c|c|c|c|c|c|c|c|c|c|c|}
\hline \multicolumn{25}{|c|}{ Normalização com Base do Perfil } \\
\hline Ponto & Amostra & As & $\mathrm{Ba}$ & $\mathrm{Ca}$ & $\mathrm{Ce}$ & Co & $\mathrm{Cr}$ & Cs & Eu & $\mathrm{Fe}$ & Hf & $\mathbf{L a}$ & Lu & $\mathrm{Na}$ & Nd & $\mathbf{R b}$ & $\mathrm{Sb}$ & $\mathrm{Sm}$ & $\mathrm{Ta}$ & $\mathrm{Tb}$ & Th & $\mathrm{U}$ & $\mathbf{Y b}$ & $\mathrm{Zn}$ \\
\hline \multirow{2}{*}{ Pt 01} & P1-10 & & 1,19 & 0,85 & 4,25 & 0,87 & 1,11 & 0,69 & 0,96 & 0,98 & 5,77 & 1,33 & 2,29 & 2,30 & 1,09 & 1,72 & 0,36 & 1,15 & 1,22 & 1,26 & 1,30 & 2,23 & 2,56 & 0,64 \\
\hline & P1-20 & & 1,77 & 1,07 & 5,27 & 0,69 & 1,09 & 0,56 & 1,20 & 0,91 & 16,7 & 1,61 & 4,91 & 3,51 & 1,59 & 2,17 & 0,24 & 1,52 & 1,53 & 1,88 & 2,02 & 3,46 & 5,34 & 0,58 \\
\hline \multirow{5}{*}{$\operatorname{Pt} 02$} & P2-10 & 1,08 & 0,63 & 0,26 & 1,58 & 0,86 & 0,84 & 0,54 & 0,52 & 1,71 & 0,47 & 0,64 & 0,79 & 0,71 & 0,68 & 1,54 & 0,77 & 0,53 & 0,53 & 0,52 & 0,86 & 0,73 & 0,70 & 0,63 \\
\hline & P2-20 & 0,91 & 0,71 & 0,68 & 1,50 & 1,01 & 0,90 & 0,66 & 0,42 & 1,66 & 0,58 & 0,46 & 0,72 & 0,91 & 0,54 & 1,53 & 0,83 & 0,40 & 0,46 & 0,37 & 0,70 & 0,56 & 0,69 & 0,60 \\
\hline & P2-30 & 1,09 & 0,67 & 0,48 & 1,10 & 0,80 & 0,87 & 0,58 & 0,44 & 1,21 & 0,64 & 0,43 & 1,02 & 1,14 & 0,47 & 1,75 & 1,10 & 0,40 & 0,38 & 0,58 & 0,65 & 0,64 & 0,92 & 0,99 \\
\hline & P2-40 & 0,96 & 0,52 & 0,29 & 2,10 & 0,72 & 0,88 & 0,62 & 0,48 & 1,17 & 0,60 & 0,44 & 0,79 & 1,06 & 0,42 & 1,76 & 1,23 & 0,39 & 0,57 & 0,63 & 0,64 & 0,67 & 1,01 & 0,46 \\
\hline & P2-50 & 0,64 & 0,39 & 0,06 & 1,83 & 0,72 & 0,62 & 0,61 & 0,46 & 0,54 & 0,33 & 0,52 & 0,47 & 0,59 & 0,38 & 0,90 & 0,61 & 0,19 & 0,48 & 0,69 & 0,50 & 0,75 & 0,62 & 0,63 \\
\hline \multirow{6}{*}{ Pt 03} & P3-10 & 1,51 & 0,40 & 0,47 & 2,39 & 0,70 & 0,83 & 0,52 & 0,48 & 1,88 & 0,58 & 0,47 & 0,74 & 0,62 & 0,38 & 1,03 & 0,99 & 0,44 & 0,54 & 0,37 & 0,75 & 0,89 & 0,79 & 0,36 \\
\hline & P3-20 & 1,11 & 0,51 & 0,56 & 2,60 & 0,75 & 1,05 & 0,52 & 0,55 & 1,67 & 0,47 & 0,53 & 0,72 & 0,63 & 0,38 & 0,98 & 0,77 & 0,48 & 0,45 & 0,42 & 0,79 & 0,94 & 0,77 & 0,50 \\
\hline & P3-30 & 1,48 & 0,37 & 0,62 & 2,44 & 0,94 & 0,87 & 0,44 & 0,46 & 1,97 & 0,58 & 0,58 & 0,84 & 0,81 & 0,50 & 0,75 & 1,52 & 0,49 & 0,53 & 0,37 & 0,74 & 0,60 & 0,92 & 0,66 \\
\hline & P3-40 & 1,16 & 0,40 & 0,49 & 2,11 & 1,05 & 0,83 & 0,52 & 0,40 & 1,53 & 0,71 & 0,42 & 0,71 & 0,93 & 0,49 & 1,85 & 0,97 & 0,40 & 0,56 & 0,37 & 0,63 & 0,80 & 1,07 & 0,62 \\
\hline & P3-50 & 0,90 & 0,51 & 0,44 & 2,21 & 0,91 & 0,85 & 0,55 & 0,43 & 1,18 & 0,71 & 0,44 & 0,78 & 0,91 & 0,55 & 1,11 & 1,23 & 0,40 & 0,48 & 1,76 & 0,64 & 0,59 & 0,97 & 1,03 \\
\hline & P3-60 & 1,00 & 1,00 & 1,00 & 1,00 & 1,00 & 1,00 & 1,00 & 1,00 & 1,00 & 1,00 & 1,00 & 1,00 & 1,00 & 1,00 & 1,00 & 1,00 & 1,00 & 1,00 & 1,00 & 1,00 & 1,00 & 1,00 & 1,00 \\
\hline \multirow{6}{*}{$\mathrm{Pt} 04$} & P4-10 & 2,80 & 0,47 & 0,40 & 1,57 & 0,46 & 0,86 & 0,69 & 0,29 & 1,62 & 0,85 & 0,29 & 1,29 & 1,12 & 0,28 & 1,64 & 1,93 & 0,30 & 0,80 & 0,55 & 0,70 & 0,78 & 0,89 & 0,33 \\
\hline & P4-20 & 2,45 & 0,56 & 0,33 & 1,80 & 0,49 & 0,21 & 0,60 & 0,35 & 1,68 & 0,79 & 0,34 & 0,95 & 0,99 & 0,22 & 1,43 & 1,11 & 0,29 & 0,56 & 0,61 & 0,75 & 0,61 & 0,94 & 0,42 \\
\hline & P4-30 & 2,73 & 0,58 & 0,39 & 1,82 & 0,59 & 0,84 & 0,65 & 0,33 & 1,77 & 0,65 & 0,34 & 1,22 & 1,13 & 0,34 & 1,64 & 1,73 & 0,33 & 0,75 & 0,39 & 0,73 & 0,73 & 1,05 & 0,34 \\
\hline & P4-40 & 1,82 & 0,35 & 0,30 & 1,75 & 0,85 & 0,77 & 0,70 & 0,29 & 1,66 & 0,88 & 0,32 & 1,10 & 1,62 & 0,24 & 1,73 & 1,92 & 0,28 & 0,48 & 0,78 & 0,66 & 0,83 & 1,21 & 0,32 \\
\hline & P4-50 & 1,65 & 0,48 & 0,39 & 1,67 & 0,48 & 0,86 & 0,96 & 0,33 & 1,09 & 1,18 & 0,33 & 1,42 & 1,65 & 0,25 & 1,88 & 2,20 & 0,29 & 0,68 & 0,74 & 0,69 & 1,13 & 1,46 & 0,39 \\
\hline & P4-60 & 1,51 & 0,46 & 0,74 & 1,33 & 0,33 & 1,13 & 2,02 & 0,45 & 0,77 & 2,63 & 0,27 & 1,80 & 0,90 & 0,46 & 1,95 & 1,68 & 0,47 & 1,15 & 0,98 & 0,85 & 1,03 & 2,27 & 0,92 \\
\hline
\end{tabular}


Pode-se observar ao relacionar os resultados encontrados para os diferentes valores de referência que no ponto 1, pode-se ter amostrado solo, e não a calha do rio o que explicaria a pequena fração amostrada (apenas $20 \mathrm{~cm}$ ), e os maiores valores de concentração que foram encontrados.

Estes resultados indicam que os valores de FE calculados utilizando-se como referência os valores do UCC e NASC apresentaram resultados bastante similares, entretanto eles diferem quando comparados aos resultados calculados com as concentrações da base do perfil (TAB 4-26), o que pode indicar que os valores basais locais da região onde se situa o reservatório de Itupararanga, podem ser bem distintos dos valores utilizados como referencia UCC e NASC.

\subsection{6 Índice de Geoacumulação (Igeo)}

O índice de geoacumulação foi calculado conforme descrito nos itens $3.10 \mathrm{e}$ 4.2.9. As TAB 4-27, 4-28 e 4-29 apresentam os valores de Igeo obtidos para todos os elementos analisados, a partir dos valores de referência UCC, NASC e base do perfil, respectivamente.

A partir desses dados, pode-se observar que os seguintes elementos se destacaram por possuir um valor de Igeo > 1,0, valor considerado como moderadamente poluído para as amostras de sedimentos, conforme a classificação apresentada na TAB 3.6.

UCC: As (pontos 3 e 4), Hf, La, Lu, Nd, Sm, Tb, Th, U e Yb (ponto 1) e Sb (algumas amostras dos pontos 3 e 4 );

NASC: As (pontos 2, 3 e 4), Ce, Hf, La, Lu, Nd, Sm, Tb, Th, U e Yb (principalmente ponto 1) e $\mathrm{Sb}$, ponto 4;

Base do Perfil: As (ponto 4), Ce (ponto 1, amostras, P2-40, P2-50, P3-10 a P350 e P4-10 a P4-40), Fe ( P3-10, P4-10 a P4-40), Sb.

A partir desses resultados, pode-se observar que os valores de Igeo calculados utilizando-se como referência os valores do UCC e NASC apresentaram resultados bastante similares, entretanto bastante diferentes quando comparados aos resultados 
calculados com as concentrações da base do perfil, o que pode indicar que os valores basais locais da área onde se situa o reservatório de Itupararanga, podem ser bem distintos dos valores utilizados como referencia, UCC e NASC. 
TABELA 4.27 - Valores de Igeo obtidos a partir dos valores de concentração do UCC

\begin{tabular}{|c|c|c|c|c|c|c|c|c|c|c|c|c|c|c|c|c|c|c|c|c|c|c|c|c|}
\hline \multicolumn{25}{|c|}{ Normalização com UCC } \\
\hline Ponto & nostra & As & $\mathbf{B a}$ & $\mathrm{Ca}$ & $\mathrm{Ce}$ & Co & $\mathrm{Cr}$ & Cs & $\mathbf{E u}$ & $\mathrm{Fe}$ & Hf & $\mathbf{L a}$ & $\mathbf{L u}$ & $\mathrm{Na}$ & Nd & $\mathbf{R b}$ & $\mathrm{Sb}$ & $\mathrm{Sm}$ & $\mathrm{Ta}$ & $\mathbf{T b}$ & Th & $\mathbf{U}$ & $\mathbf{Y b}$ & $\mathbf{Z n}$ \\
\hline \multirow{2}{*}{ Pt 01} & & -- & $-0,3$ & & 1,3 & $-0,6$ & 0,4 & $-0,5$ & 0,6 & $-0,6$ & 2,1 & 1,2 & 0,9 & $-5,1$ & 1,1 & $-1,0$ & $-1,1$ & 1,0 & 0,3 & 1,1 & 0,9 & 1,5 & 1,2 & $-0,1$ \\
\hline & -20 & -- & $-0,8$ & 0,2 & $-0,7$ & 0,5 & 1,3 & $-1,4$ & $-0,1$ & $-0,1$ & $-0,8$ & $-0,7$ & $-0,2$ & $-0,7$ & $-0,5$ & $-1,1$ & $-0,6$ & $-0,4$ & $-1,0$ & $-0,2$ & $-0,9$ & $-1,1$ & $-0,2$ & $-0,3$ \\
\hline \multirow{5}{*}{ Pt 02} & & 1,0 & $-0,9$ & 3,4 & 0,1 & & 0,3 & $-0,6$ & 0,0 & 0,5 & & 0,5 & $-0,3$ & $-6,5$ & 0,7 & $-0,9$ & 3 & 0,2 & $-0,6$ & 0,0 & 6 & 1 &, 4 &, 1 \\
\hline & 20 & 0,8 & $-0,7$ & $-2,0$ & 0,1 & 0,0 & 0,4 & $-0,2$ & $-0,3$ & 0,4 & $-0,9$ & 0,0 & $-0,4$ & $-6,1$ & 0,4 & $-0,9$ & 0,4 & $-0,2$ & $-0,8$ & $-0,4$ &, 3 & $-0,2$ & $-0,4$ & 0,1 \\
\hline & & 0,8 & $-1,0$ & $-2,7$ & $-0,6$ & $-0,6$ & 0,1 & $-0,6$ & $-0,5$ & $-0,3$ & $-1,0$ & $-0,3$ & $-0,2$ & $-6,0$ & 0,0 & $-0,9$ & 0,6 & $-0,4$ & $-1,3$ & 0,0 & 0 & $-0,3$ &, 2 & 0,6 \\
\hline & P2-40 & 0,9 & $-1,1$ & $-3,2$ & 0,6 & $-0,5$ & 0,4 & $-0,3$ & $-0,1$ & 0,0 & $-0,8$ & 0,0 & $-0,3$ & $-5,8$ & 0,1 & $-0,6$ & 1,0 & $-0,2$ & $-0,4$ & 0,4 & 0,3 & 0,1 & 0,2 & $-0,2$ \\
\hline & & 0,8 & $-1,1$ & & 0,9 & 0,0 & 0,4 & 0,2 & 0,3 & & & & & & & & & $-0,7$ & & 1,0 & & & 0 &, 7 \\
\hline \multirow{6}{*}{ Pt 03} & & 1.6 & $-1,5$ & $-2,5$ & 0,8 & $-0,5$ & 0,3 & $-0,5$ & 0 & 0 & $-0,8$ & 0,1 & $-0,3$ & $-6,6$ & 0 , & $-1,4$ & 0,7 & 0,0 & $-0,5$ & $-0,3$ & 0,5 & 0,5 & $-0,2$ & $-0,5$ \\
\hline & & 1,1 & $-1,2$ & $-2,3$ & 0,9 & & 0,6 & $-0,6$ & 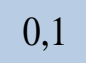 & & & 0,2 & & $-6,6$ & -0 & $-1,5$ & & 0,1 & $-0,8$ & $-0,2$ & & &, 3 & $-0,2$ \\
\hline & P3-30 & 1,4 & $-1,7$ & $-2,2$ & 0,7 & $-0,2$ & 0,3 & $-0,9$ & $-0,2$ & 0,6 & $-0,9$ & 0,3 & $-0,3$ & $-6,3$ & 0 & $-1,9$ & 1,2 & 0,1 & $-0,7$ & $-0,5$ & 0,4 & $-0,2$ & $-0,1$ & 0,2 \\
\hline & & 1,0 & $-1,7$ & $-2,6$ & 0,5 & $-0,1$ & 0,2 & $-0,7$ & $-0,5$ & 0,2 & $-0,7$ & $-0,2$ & $-0,6$ & $-6,2$ & 0 & $-0,7$ & 0,3 & $-0,3$ & $-0,6$ & $-0,5$ & & 0,2 & 1 & 0,0 \\
\hline & & 0,9 & $-1,1$ & $-2,6$ & 0,7 & $-0,1$ & 0,4 & $-0,4$ & $-0,2$ & 0,0 & $-0,5$ & 0,0 & $-0,3$ & $-6,0$ & 0 , & $-1,2$ & 1,1 & $-0,1$ & $-0,6$ & 1,9 & 3 & $-0,1$ & 0,1 & 1,0 \\
\hline & & 0,2 & $-0,9$ & $-2,2$ & $-1,2$ & $-0,7$ & $-0,2$ & $-0,3$ & 0,2 & $-1,0$ & & 0,4 & $-0,7$ & $-6,7$ & 0,6 & $-2,2$ & 0,0 & 0,4 & $-0,4$ & 0,3 & 0,2 & $-0,1$ & $-0,6$ & 0,1 \\
\hline \multirow{6}{*}{ Pt 04} & & 2,7 & $-1,1$ & $-2,5$ & 0,4 & $-0,9$ & 0,6 & 0,1 & $-0,6$ & 0,7 & $-0,1$ & -0, & 0,7 & $-5,5$ & $-0,2$ & $-0,5$ & 1,9 & $-0,3$ & 0,3 & 0,4 & & 0,5 & 0,2 & $-0,5$ \\
\hline & & 2,3 & $-1,0$ & $-2,9$ & 0,4 & $-1,0$ & $-1,6$ & $-0,3$ & $-0,4$ & 0,6 & $-0,3$ & -0 & 0,1 & $-5,9$ & $-0,7$ & $-0,9$ & 0,9 & $-0,5$ & $-0,4$ & 0,4 & 5 & 0,0 &, 1 & $-0,3$ \\
\hline & P4-30 & 2,6 & $-0,8$ & $-2,6$ & 0,6 & $-0,6$ & 0,5 & 0,0 & $-0,4$ & 0,8 & $-0,5$ & $-0,2$ & 0,5 & $-5,6$ & 0,0 & $-0,5$ & 1,7 & $-0,2$ & 0,1 & $-0,1$ & 0,6 & 0,4 & 0,4 & $-0,5$ \\
\hline & P4-40 & 2,0 & $-1,5$ & $-3,0$ & 0,5 & $-0,1$ & 0,4 & 0,1 & $-0,6$ & 0,7 & $-0,1$ & $-0,3$ & 0,4 & $-5,1$ & $-0,5$ & $-0,5$ & 1,8 & $-0,5$ & $-0,5$ & 0,9 & 0,5 & 0,5 & 0,6 & $-0,6$ \\
\hline & P4-50 & 1,6 & $-1,3$ & $-2,8$ & 0,2 & $-1,1$ & 0,3 & 0,3 & $-0,7$ & $-0,2$ & 0,1 & $-0,5$ & 0,5 & $-5,2$ & $-0,7$ & $-0,6$ & 1,8 & $-0,6$ & $-0,2$ & 0,6 & 0,3 & 0,8 & 0,6 & $-0,5$ \\
\hline & P4-60 & 0,8 & $-2,0$ & $-2,6$ & $-0,8$ & $-2,3$ & 0,0 & 0,7 & $-0,9$ & $-1,3$ & 0,6 & $-1,4$ & 0,2 & $-6,8$ & $-0,5$ & $-1,2$ & 0,7 & $-0,6$ & $-0,2$ & 0,3 & $-0,1$ & 0,0 & 0,6 & 0,0 \\
\hline
\end{tabular}


TABELA 4-28 Valores de Igeo obtidos a partir dos valores de concentração do NASC

\begin{tabular}{|c|c|c|c|c|c|c|c|c|c|c|c|c|c|c|c|c|c|c|c|c|c|c|c|c|}
\hline \multicolumn{25}{|c|}{ Normalização com NASC } \\
\hline Ponto & Amostra & As & $\mathbf{B a}$ & $\mathrm{Ca}$ & $\mathrm{Ce}$ & Co & $\mathrm{Cr}$ & Cs & $\mathbf{E u}$ & $\mathrm{Fe}$ & Hf & $\mathbf{L a}$ & $\mathbf{L u}$ & $\mathrm{Na}$ & Nd & $\mathbf{R b}$ & $\mathbf{S b}$ & $\mathrm{Sm}$ & Ta & $\mathbf{T b}$ & Th & $\mathbf{U}$ & $\mathbf{Y b}$ & $\mathbf{Z n}$ \\
\hline \multirow{2}{*}{ Pt 01} & $\mathrm{P} 1-10$ & -- & $-0,1$ & $-2,4$ & 1,4 & $-1,6$ & $-1,5$ & 0,3 & 0,1 & $-1,1$ & 2,4 & 1,4 & 0,5 & $-4,9$ & 1,1 & $-0,5$ & $-1,1$ & 0,9 & 0,8 & 0,7 & 1,2 & 2,0 & 0,7 & $-0,4$ \\
\hline & P1-20 & -- & 0,3 & $-2,2$ & 1,6 & $-2,1$ & $-1,6$ & $-0,2$ & 0,3 & $-1,4$ & 3,8 & 1,5 & 1,5 & $-4,5$ & 1,5 & $-0,3$ & $-1,8$ & 1,1 & 0,9 & 1,1 & 1,7 & 2,5 & 1,6 & $-0,7$ \\
\hline \multirow{5}{*}{ Pt 02} & P2-10 & 1,2 & $-0,7$ & $-3,8$ & 0,2 & $-1,3$ & $-1,6$ & 0,2 & $-0,5$ & 0,0 & $-1,0$ & 0,6 & $-0,7$ & $-6,4$ & 0,7 & $-0,4$ & 0,3 & 0,0 & $-0,2$ & $-0,3$ & 0,9 & 0,7 & $-0,9$ & $-0,2$ \\
\hline & P2-20 & 1,0 & $-0,5$ & $-2,4$ & 0,2 & $-1,1$ & $-1,5$ & 0,5 & $-0,8$ & $-0,1$ & $-0,6$ & 0,1 & $-0,8$ & $-6,0$ & 0,4 & $-0,4$ & 0,5 & $-0,4$ & $-0,3$ & $-0,8$ & 0,6 & 0,3 & $-0,9$ & $-0,2$ \\
\hline & P2-30 & 1,1 & $-0,9$ & $-3,1$ & $-0,5$ & $-1,6$ & $-1,7$ & 0,1 & $-0,9$ & $-0,7$ & $-0,7$ & $-0,2$ & $-0,5$ & $-5,9$ & $-0,1$ & $-0,4$ & 0,6 & $-0,6$ & $-0,9$ & $-0,4$ & 0,3 & 0,3 & $-0,7$ & 0,3 \\
\hline & P2-40 & 1,2 & $-1,0$ & $-3,6$ & 0,7 & $-1,5$ & $-1,4$ & 0,5 & $-0,5$ & $-0,5$ & $-0,5$ & 0,1 & $-0,6$ & $-5,7$ & 0,1 & $-0,1$ & 1,1 & $-0,3$ & 0,0 & 0,0 & 0,5 & 0,6 & $-0,2$ & $-0,6$ \\
\hline & P2-50 & 1,0 & $-0,9$ & $-5,5$ & 1,0 & $-1,0$ & $-1,5$ & 1,0 & $-0,1$ & $-1,1$ & $-0,9$ & 0,8 & $-0,9$ & $-6,1$ & 0,4 & $-0,6$ & 0,5 & $-0,9$ & 0,2 & 0,6 & 0,7 & 1,3 & $-0,5$ & 0,4 \\
\hline \multirow{6}{*}{ Pt 03} & P3-10 & 1,8 & $-1,3$ & $-2,9$ & 1,0 & $-1,5$ & $-1,5$ & 0,3 & $-0,5$ & 0,2 & $-0,5$ & 0,3 & $-0,7$ & $-6,5$ & 0,0 & $-0,9$ & 0,8 & $-0,1$ & 0,0 & $-0,7$ & 0,8 & 1,1 & $-0,6$ & $-0,9$ \\
\hline & & 1,3 & $-1,0$ & $-2,7$ & 1,0 & $-1,5$ & $-1,2$ & 0,2 & $-0,4$ & 0,0 & $-0,9$ & 0,3 & $-0,8$ & $-6,5$ & $-0,2$ & $-1,0$ & 0,3 & $-0,1$ & $-0,4$ & $-0,6$ & 0,8 & 1,1 & $-0,7$ & $-0,5$ \\
\hline & P3-30 & 1,7 & $-1,5$ & $-2,6$ & 0,8 & $-1,2$ & $-1,6$ & $-0,1$ & $-0,7$ & 0,1 & $-0,7$ & 0,4 & $-0,7$ & $-6,2$ & 0,2 & $-1,5$ & 1,3 & $-0,1$ & $-0,2$ & $-0,8$ & 0,6 & 0,4 & $-0,5$ & $-0,1$ \\
\hline & P3-40 & 1,3 & $-1,5$ & $-3,0$ & 0,6 & $-1,1$ & $-1,7$ & 0,1 & $-0,9$ & $-0,3$ & $-0,4$ & $-0,1$ & $-0,9$ & $-6,1$ & 0,1 & $-0,2$ & 0,6 & $-0,5$ & $-0,2$ & $-0,9$ & 0,4 & 0,7 & $-0,3$ & $-0,3$ \\
\hline & P3-50 & 1,1 & $-0,9$ & $-2,9$ & 0,8 & $-1,1$ & $-1,5$ & 0,4 & $-0,6$ & $-0,4$ & $-0,3$ & 0,1 & $-0,6$ & $-5,9$ & 0,5 & $-0,7$ & 1,1 & $-0,2$ & $-0,2$ & 1,6 & 0,6 & 0,5 & $-0,3$ & 0,6 \\
\hline & P3-60 & 0,5 & $-0,7$ & $-2,5$ & $-1,1$ & $-1,8$ & $-2,0$ & 0,4 & $-0,2$ & $-1,5$ & $-0,5$ & 0,5 & $-1,0$ & $-6,5$ & 0,6 & $-1,7$ & 0,0 & 0,3 & 0,1 & $-0,1$ & 0,4 & 0,5 & $-1,0$ & $-0,2$ \\
\hline \multirow{6}{*}{ Pt 04} & P4-10 & 2,9 & $-0,9$ & $-2,9$ & 0,5 & $-2,0$ & $-1,3$ & 0,9 & $-1,0$ & 0,2 & 0,2 & $-0,3$ & 0,3 & $-5,4$ & $-0,3$ & 0,0 & 1,9 & $-0,5$ & 0,7 & 0,0 & 0,9 & 1,1 & $-0,2$ & $-0,8$ \\
\hline & P4-20 & 2,6 & $-0,8$ & $-3,3$ & 0,6 & $-2,0$ & $-3,5$ & 0,5 & $-0,9$ & 0,1 & $-0,1$ & $-0,2$ & $-0,3$ & $-5,7$ & $-0,8$ & $-0,4$ & 1,0 & $-0,7$ & 0,0 & 0,0 & 0,8 & 0,6 & $-0,3$ & $-0,6$ \\
\hline & P4-30 & 2,8 & $-0,6$ & $-3,0$ & 0,7 & $-1,6$ & $-1,3$ & 0,7 & $-0,9$ & 0,3 & $-0,2$ & $-0,1$ & 0,2 & $-5,4$ & $-0,1$ & 0,0 & 1,7 & $-0,4$ & 0,6 & $-0,5$ & 0,9 & 0,9 & 0,0 & $-0,8$ \\
\hline & P4-40 & 2,2 & $-1,3$ & $-3,4$ & 0,6 & $-1,1$ & $-1,5$ & 0,8 & $-1,1$ & 0,2 & 0,2 & $-0,2$ & 0,0 & $-4,9$ & $-0,6$ & 0,0 & 1,9 & $-0,7$ & $-0,1$ & 0,5 & 0,8 & 1,1 & 0,2 & $-0,9$ \\
\hline & P4-50 & 1,9 & $-1,1$ & $-3,2$ & 0,3 & $-2,2$ & $-1,5$ & 1,1 & $-1,1$ & $-0,7$ & 0,4 & $-0,4$ & 0,2 & $-5,1$ & $-0,8$ & $-0,1$ & 1,9 & $-0,8$ & 0,2 & 0,2 & 0,6 & 1,3 & 0,2 & $-0,9$ \\
\hline & P4-60 & 1,1 & $-1,8$ & $-3,0$ & $-0,7$ & $-3,4$ & $-1,8$ & 1,5 & $-1,3$ & $-1,8$ & 0,9 & $-1,3$ & $-0,2$ & $-6,7$ & $-0,6$ & $-0,7$ & 0,8 & $-0,8$ & 0,3 & $-0,1$ & 0,2 & 0,5 & 0,2 & $-0,3$ \\
\hline
\end{tabular}


TABELA 4.29 - Valores de Igeo obtidos a partir dos valores de concentração da base do perfil

\begin{tabular}{|c|c|c|c|c|c|c|c|c|c|c|c|c|c|c|c|c|c|c|c|c|c|c|c|c|}
\hline \multicolumn{25}{|c|}{ Normalização com Base do Perfil } \\
\hline Ponto & Amostra & As & $\mathbf{B a}$ & $\mathrm{Ca}$ & $\mathrm{Ce}$ & Co & $\mathrm{Cr}$ & Cs & Eu & $\mathrm{Fe}$ & Hf & $\mathbf{L a}$ & $\mathbf{L u}$ & $\mathrm{Na}$ & Nd & $\mathbf{R b}$ & $\mathrm{Sb}$ & $\mathrm{Sm}$ & $\mathrm{Ta}$ & $\mathrm{Tb}$ & Th & $\mathbf{U}$ & $\mathbf{Y b}$ & $\mathbf{Z n}$ \\
\hline \multirow{2}{*}{ Pt 01} & & -- & 0,1 & $-0,4$ & 1,9 & $\overline{-0,4}$ & 0,0 & $-0,7$ & $-0,2$ & $-0,2$ & 2,3 & 0,2 & 1,0 & 1,0 & $-0,1$ & 0,6 & $-1,7$ & 0,0 & 0,1 & 0,1 & 0,2 & 1,0 & 1,2 & $-0,8$ \\
\hline & P1-20 & -- & 0,5 & $-0,2$ & 2,1 & $-0,9$ & $-0,2$ & $-1,2$ & $-0,1$ & $-0,5$ & 3,7 & 0,3 & 1,9 & 1,5 & 0,3 & 0,8 & $-2,4$ & 0,3 & 0,3 & 0,6 & 0,7 & 1,4 & 2,1 & $-1,1$ \\
\hline \multirow{5}{*}{ Pt 02} & P2-10 & 0,2 & $-0,6$ & $-1,8$ & 0,7 & $-0,1$ & $-0,2$ & $-0,8$ & $-0,9$ & 0,9 & $-1,0$ & $-0,6$ & $-0,3$ & $-0,4$ & $-0,5$ & 0,7 & $-0,3$ & $-0,8$ & $-0,8$ & $-0,9$ & $-0,1$ & $-0,4$ & $-0,4$ & $-0,6$ \\
\hline & $\mathrm{P} 2-20$ & 0,0 & $-0,4$ & $-0,5$ & 0,7 & 0,1 & 0,0 & $-0,5$ & $-1,2$ & 0,8 & $-0,7$ & $-1,0$ & $-0,4$ & 0,0 & $-0,8$ & 0,7 & $-0,2$ & $-1,2$ & $-1,0$ & $-1,3$ & $-0,4$ & $-0,7$ & $-0,4$ & $-0,6$ \\
\hline & $\mathrm{P} 2-30$ & 0,0 & $-0,7$ & $-1,2$ & 0,0 & $-0,4$ & $-0,3$ & $-0,9$ & $-1,3$ & 0,2 & $-0,8$ & $-1,3$ & $-0,1$ & 0,1 & $-1,2$ & 0,7 & 0,0 & $-1,4$ & $-1,5$ & $-0,9$ & $-0,7$ & $-0,8$ & $-0,2$ & $-0,1$ \\
\hline & P2-40 & 0,1 & $-0,8$ & $-1,6$ & 1,2 & $-0,3$ & 0,0 & $-0,5$ & $-0,9$ & 0,4 & $-0,6$ & $-1,0$ & $-0,2$ & 0,3 & $-1,1$ & 1,0 & 0,5 & $-1,2$ & $-0,6$ & $-0,5$ & $-0,5$ & $-0,4$ & 0,2 & $-1,0$ \\
\hline & P2-50 & 0,0 & $-0,7$ & $-3,5$ & 1,5 & 0,2 & 0,0 & $-0,1$ & $-0,5$ & $-0,3$ & $-1,0$ & $-0,3$ & $-0,5$ & $-0,1$ & $-0,7$ & 0,5 & $-0,1$ & $-1,7$ & $-0,4$ & 0,1 & $-0,3$ & 0,2 & 0,0 & 0,0 \\
\hline \multirow{6}{*}{ Pt 03} & P3-10 & 0,8 & $-1,1$ & $-0,9$ & 1,5 & $-0,3$ & $-0,1$ & $-0,8$ & $-0,9$ & 1,1 & $-0,6$ & $-0,9$ & $-0,2$ & $-0,5$ & $-1,2$ & 0,2 & 0,2 & $-1,0$ & $-0,7$ & $-1,3$ & $-0,2$ & 0,0 & $-0,2$ & $-1,3$ \\
\hline & & 0,3 & $-0,9$ & $-0,7$ & 1,5 & $-0,3$ & 0,2 & $-0,8$ & $-0,8$ & 0,8 & $-1,0$ & $-0,8$ & $-0,4$ & $-0,6$ & $-1,3$ & 0,1 & $-0,3$ & $-0,9$ & $-1,0$ & $-1,1$ & $-0,2$ & 0,0 & $-0,3$ & $-0,9$ \\
\hline & P3-30 & 0,6 & $-1,4$ & $-0,6$ & 1,3 & 0,0 & $-0,1$ & $-1,1$ & $-1,1$ & 1,0 & $-0,7$ & $-0,7$ & $-0,2$ & $-0,2$ & $-0,9$ & $-0,4$ & 0,7 & $-1,0$ & $-0,9$ & $-1,4$ & $-0,4$ & $-0,7$ & $-0,1$ & $-0,5$ \\
\hline & P3-40 & 0,2 & $-1,3$ & $-1,0$ & 1,1 & 0,1 & $-0,3$ & $-0,9$ & $-1,3$ & 0,6 & $-0,5$ & $-1,3$ & $-0,5$ & $-0,1$ & $-1,0$ & 0,9 & 0,0 & $-1,3$ & $-0,8$ & $-1,4$ & $-0,7$ & $-0,3$ & 0,1 & $-0,7$ \\
\hline & & 0,0 & $-0,8$ & $-1,0$ & 1,3 & 0,1 & 0,0 & $-0,7$ & $-1,0$ & 0,4 & $-0,3$ & $-1,0$ & $-0,2$ & 0,1 & $-0,7$ & 0,4 & 0,5 & $-1,1$ & $-0,8$ & 1,0 & $-0,4$ & $-0,6$ & 0,2 & 0,2 \\
\hline & & $-0,6$ & $-0,6$ & $-0,6$ & $-0,6$ & $-0,6$ & $-0,6$ & $-0,6$ & $-0,6$ & $-0,6$ & $-0,6$ & $-0,6$ & $-0,6$ & $-0,6$ & $-0,6$ & $-0,6$ & $-0,6$ & $-0,6$ & $-0,6$ & $-0,6$ & $-0,6$ & $-0,6$ & $-0,6$ & $-0,6$ \\
\hline \multirow{6}{*}{ Pt 04} & & 1,9 & $-0,7$ & $-0,9$ & 1,0 & $-0,7$ & 0,2 & $-0,2$ & $-1,4$ & 1,1 & 01 & $-1,4$ & 0,7 & 0,5 & $-1,5$ & 1,1 & 1,3 & $-1,4$ & 0,1 & $-0,5$ & $-0,1$ & 0,0 & 0,2 & $-1,2$ \\
\hline & P4-20 & 1,5 & $-0,6$ & $-1,4$ & 1,1 & $-0,8$ & $-2,0$ & $-0,5$ & $-1,3$ & 1,0 & $-0,1$ & $-1,3$ & 0,2 & 0,2 & $-1,9$ & 0,7 & 0,4 & $-1,6$ & $-0,6$ & $-0,5$ & $-0,2$ & $-0,5$ & 0,1 & $-1,0$ \\
\hline & P4-30 & 1,8 & $-0,5$ & $-1,0$ & 1,2 & $-0,4$ & 0,1 & $-0,3$ & $-1,3$ & 1,2 & $-0,3$ & $-1,2$ & 0,6 & 0,5 & $-1,2$ & 1,0 & 1,1 & $-1,3$ & $-0,1$ & $-1,0$ & $-0,1$ & $-0,1$ & 0,4 & $-1,2$ \\
\hline & P4-40 & 1,2 & $-1,2$ & $-1,4$ & 1,1 & 0,1 & 0,0 & $-0,2$ & $-1,5$ & 1,1 & 0,1 & $-1,3$ & 0,5 & 1,0 & $-1,7$ & 1,1 & 1,3 & $-1,5$ & $-0,7$ & 0,0 & $-0,3$ & 0,1 & 0,6 & $-1,3$ \\
\hline & & 0,8 & $-0,9$ & $-1,2$ & 0,8 & $-1,0$ & $-0,1$ & 0,0 & $-1,5$ & 0,2 & 0,3 & $-1,5$ & 0,6 & 0,8 & $-1,9$ & 1,0 & 1,2 & $-1,7$ & $-0,4$ & $-0,3$ & $-0,4$ & 0,3 & 0,7 & $-1,3$ \\
\hline & P4-60 & 0,0 & $-1,7$ & $-1,0$ & $-0,2$ & $-2,2$ & $-0,4$ & 0,5 & $-1,7$ & $-0,9$ & 0,8 & $-2,4$ & 0,3 & $-0,7$ & $-1,7$ & 0,4 & 0,2 & $-1,6$ & $-0,4$ & $-0,6$ & $-0,8$ & $-0,5$ & 0,6 & $-0,7$ \\
\hline
\end{tabular}




\subsubsection{Tratamento Estatístico dos Dados}

Os resultados obtidos pela técnica de INAA, granulometria, COT e NKT foram reunidos e submetidos a tratamento estatístico e os resultados estão apresentados a seguir.

\subsubsection{Análise Fatorial}

Foi efetuada a Análise de Fatores com extração de Componentes Principais e Rotação Varimax normalizada, utilizando-se os resultados das amostras de sedimento e os elementos determinados pela técnica de INAA e também os dados de granulometria, conteúdo de MO e NKT. Foi utilizado o programa Statistica 7.0 (STATSOFT). Os resultados estão apresentados na $\mathrm{TAB} 4.31$ e estão marcados os valores > /0,6/. A extração de Componentes Principais é apresentada na TAB 4.32.

Verificou-se a partir dos dados da TAB 4.32 que 5 fatores puderam ser extraídos, respondendo por $86,8 \%$ da variância observada. O Fator 1 explica 46,8\% da variância total; o Fator 2 é responsável por 17,0\%; o Fator 3 por 11,9\%. O Fator 4, por $7,1 \%$ e o Fator 5 , por $3,9 \%$ da variância observada.

O Fator 1 compreende os elementos $\mathrm{Ba}, \mathrm{Ce}, \mathrm{Eu}, \mathrm{Hf}, \mathrm{La}, \mathrm{Lu}, \mathrm{Na}, \mathrm{Nd}, \mathrm{Sm}$, Ta, Th, U, Yb e areia e apresenta uma correlação negativa com a fração silte+argila; o Fator 2, compreende os elementos $\mathrm{Eu}, \mathrm{Nd}$ e apresenta correlação negativa para os elementos As, $\mathrm{Cs}, \mathrm{Rb}$ e $\mathrm{Sb}$; o Fator 3, apresenta uma correlação positiva para Fe e negativa para COT, NKT e Cs; Fator 4, correlações positivas para Tb e Zn e o Fator 5, para o Cr. 
TABELA 4.30 - Resultado da Análise Fatorial utilizando Rotação Varimax com valores $/ 0,6 /$ selecionados

\begin{tabular}{cccccc}
\hline & Fator 1 & Fator 2 & Fator 3 & Fator 4 & Fator 5 \\
\hline As & $-0,05661$ & $-0,799397$ & 0,248942 & $-0,331812$ & 0,066780 \\
Ba & 0,83158 & 0,290877 & 0,233831 & 0,030298 & $-0,097697$ \\
Ca & 0,43586 & 0,446805 & $-0,117888$ & $-0,594840$ & 0,116918 \\
Ce & 0,65876 & 0,141482 & 0,480283 & 0,084047 & 0,357575 \\
Co & $-0,35605$ & 0,239322 & 0,591997 & 0,375026 & 0,381631 \\
Cr & 0,07199 & $-0,077312$ & 0,111800 & 0,025476 & 0,854437 \\
Cs & $-0,07232$ & $-0,625590$ & $-0,631506$ & 0,198562 & 0,008728 \\
Eu & 0,63833 & 0,627727 & 0,151926 & 0,165969 & 0,144907 \\
Fe & $-0,37421$ & $-0,381717$ & 0,610429 & $-0,431519$ & 0,244491 \\
Hf & 0,94999 & 0,213675 & 0,007340 & $-0,058114$ & $-0,102962$ \\
La & 0,70720 & 0,568108 & 0,258662 & 0,135790 & 0,128716 \\
Lu & 0,96994 & $-0,103872$ & 0,019039 & $-0,131676$ & $-0,045062$ \\
Na & 0,86308 & $-0,270616$ & 0,176542 & 0,020879 & 0,026051 \\
Nd & 0,69938 & 0,626536 & 0,131589 & 0,138738 & 0,076277 \\
Rb & 0,27211 & $-0,765851$ & 0,266510 & 0,093284 & $-0,103080$ \\
Sb & $-0,25152$ & $-0,860335$ & $-0,007609$ & $-0,102864$ & 0,270966 \\
Sc & $-0,23143$ & $-0,512616$ & 0,561307 & 0,381878 & 0,350824 \\
Sm & 0,77487 & 0,568863 & 0,066371 & $-0,179420$ & 0,069225 \\
Ta & 0,84338 & $-0,221716$ & $-0,122308$ & $-0,097189$ & 0,151042 \\
Tb & 0,52495 & 0,050365 & $-0,141355$ & 0,611627 & 0,204802 \\
Th & 0,89120 & 0,105684 & 0,330387 & $-0,136128$ & 0,082750 \\
U & 0,94845 & 0,106922 & 0,111001 & 0,005946 & 0,106159 \\
Yb & 0,96841 & 0,008380 & $-0,038734$ & $-0,022213$ & $-0,064777$ \\
Zn & $-0,30626$ & 0,409589 & $-0,054983$ & 0,731583 & 0,025428 \\
Areia & 0,93010 & 0,270260 & $-0,080392$ & $-0,062623$ & $-0,113063$ \\
Silte+Argila & $-0,93004$ & $-0,270373$ & 0,080351 & 0,062542 & 0,113190 \\
COT & $-0,25321$ & 0,239087 & $-0,858207$ & 0,203975 & $-0,097818$ \\
NKT & $-0,44860$ & 0,082258 & $-0,719907$ & $-0,131404$ & 0,120603 \\
\hline Expl.Var & 12,07977 & 5,147919 & 3,453688 & 2,127048 & 1,497130 \\
Prp.Totl & 0,43142 & 0,183854 & 0,123346 & 0,075966 & 0,053469 \\
\hline & & & & & \\
\hline
\end{tabular}


TABELA 4.31 - Resultado da Análise Fatorial com extração de Componentes Principais

\begin{tabular}{c|c|c|c|c}
\hline & AutoValor & $\begin{array}{c}\text { Variância } \\
\text { Total (\%) }\end{array}$ & $\begin{array}{c}\text { AutoValor } \\
\text { Cumulativo }\end{array}$ & $\begin{array}{c}\text { Cumulativo } \\
\%\end{array}$ \\
\hline 1 & 13,11 & 46,83 & 13,11 & 46,83 \\
\hline 2 & 4,76 & 17,02 & 17,88 & 63,85 \\
\hline 3 & 3,33 & 11,90 & 21,21 & 75,75 \\
\hline 4 & 2,00 & 7,14 & 23,21 & 82,89 \\
\hline 5 & 1,10 & 3,91 & 24,31 & 86,81 \\
\hline
\end{tabular}

\subsubsection{Análise de Agrupamentos}

Utilizando-se a mesma base de dados da Análise de Fatores foi realizada a Análise de Agrupamento (Cluster Analysis), utilizando-se o método de Ward e as distâncias Euclidianas. O objetivo dessa análise foi verificar possíveis semelhanças entre os pontos de amostragem (FIG 4.19) e entre os elementos analisados e os demais parâmetros (FIG 4.20)

Verificou-se a formação de 2 grupos, na FIG 4.19 sendo que o ponto 1 formou um grupo separado dos demais pontos (grupo 1). O grupo 2 foi formado por 2 sub-grupos:

- sub-grupo 1: formado pelo ponto 4, com exceção da fração P4-10

- sub-grupo 2: constituído pela amostra P4-10 e todas as amostras dos pontos 02 e 03

O grupo 1 apresentou as maiores concentrações principalmente para os elementos $\mathrm{Ba}, \mathrm{Ca}, \mathrm{Cr}$, elementos terras raras (ETR) (Ce, Eu, La, Lu, Nd, Sm, Tb, Yb), Hf, Th e U e uma composição granulométrica bastante diferente dos demais pontos, com predomínio da fração areia.

O sub-grupo 1 do grupo 2, foi constituído pelas amostras do ponto 04, com exceção da camada superficial (P4-10) que apresentou concentrações mais altas para a maioria dos elementos e se localizou em outro sub-grupo (2). 
O sub-grupo 2 se constituiu das amostras $\mathrm{P} 4-10$ e todas as amostras dos pontos 02 e 03. Essas amostras apresentaram concentrações semelhantes para alguns parâmetros como As, Ca, Ce, Cr, Na, Sc, Ta, Tb, Th, U, Zn e COT.

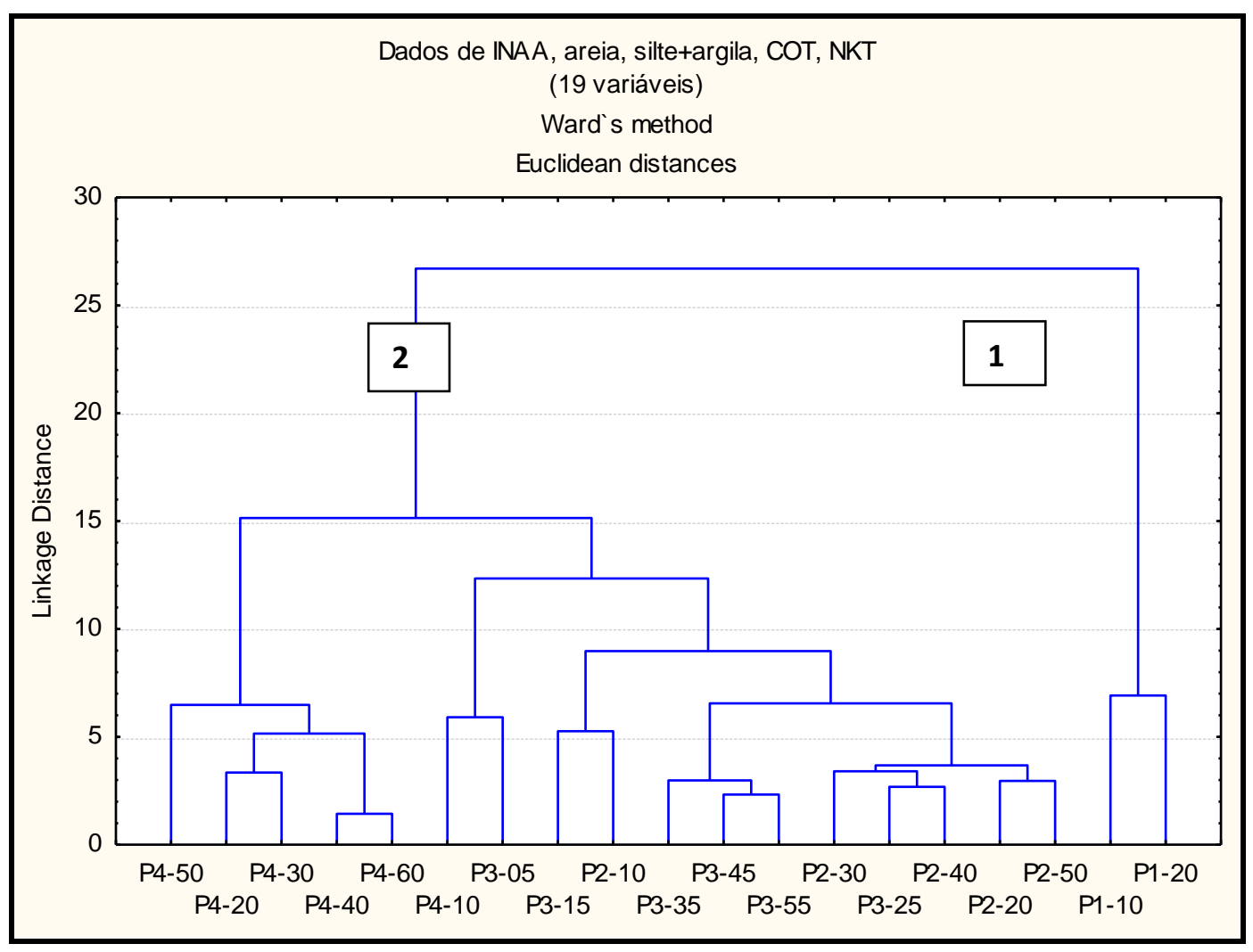

FIGURA 4.19 - Dendrograma resultante da Análise de Agrupamento, variáveis: pontos de amostragem 


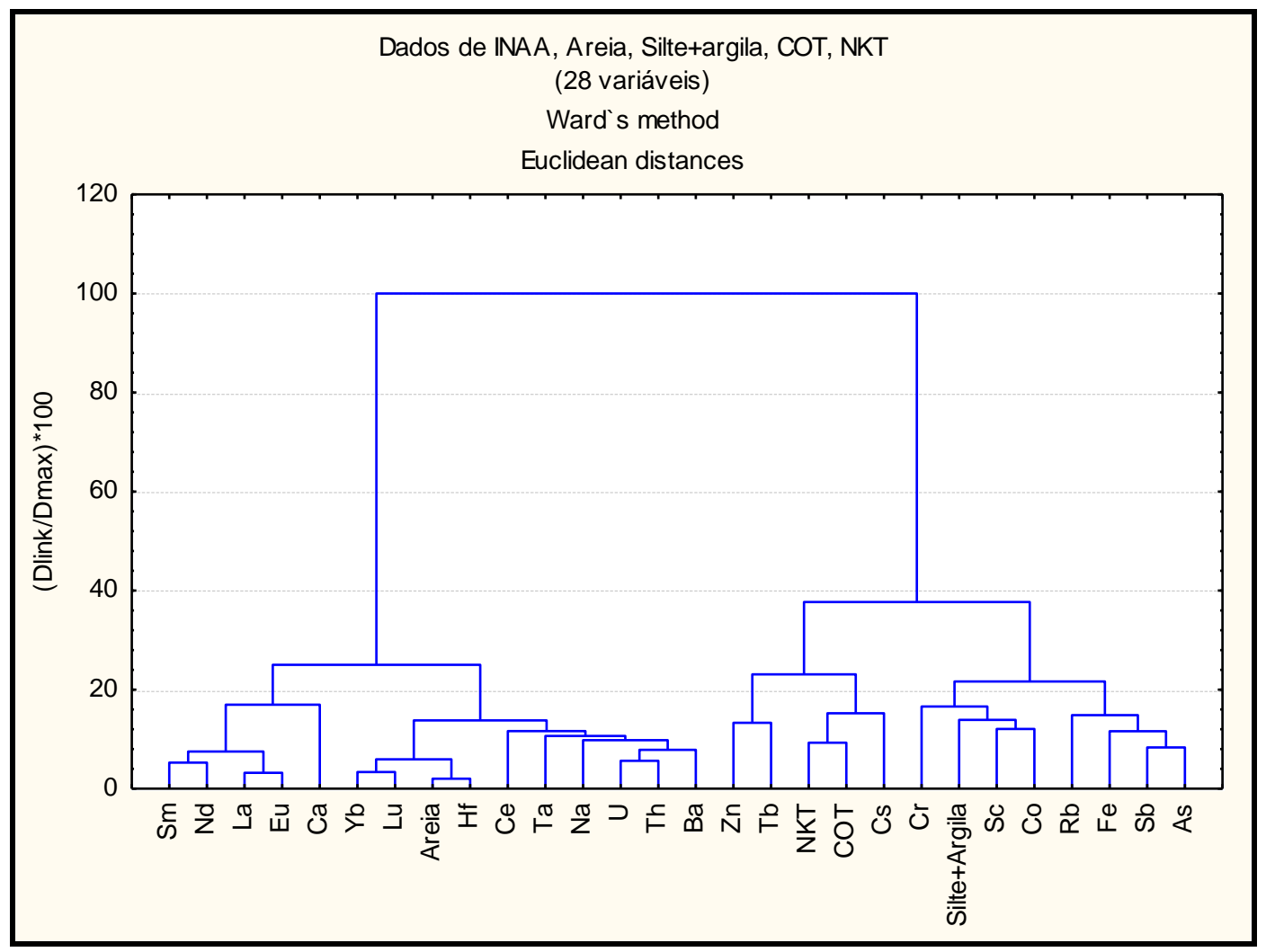

FIGURA 4.20 - Dendrograma resultante da Análise de Agrupamento, variáveis: elementos e parâmetros analisados

Quando a mesma base de dados foi rodada considerando-se os parâmetros analisados como variáveis, também houve a formação de 2 grupos. $\mathrm{O}$ grupo 1 formou 2 sub-grupos:

- sub-grupo 1 : formado pelos elementos ETR leves ( $\mathrm{Sm}, \mathrm{Nd}, \mathrm{La}, \mathrm{Eu})$ e $\mathrm{Ca}$

-sub-grupo 2: formado pelos ETR pesados ( $\mathrm{Yb}, \mathrm{Lu})$, Hf e teor de areia e Ce, Ta, Na, U, Th e Ba

O grupo 2 também se subdividiu em 2 sub-grupos:

-sub-grupo 1: formado por NKT, COT e Cs, Zn e Tb

- sub-grupo 2: Silte + Argila, Cr, Sc, Co, Rb, Fe e os semi-metais Sb e As

Os dois grandes grupos formados se constituíram de um grupo (2) composto por silte+argila, conteúdo de MO, conteúdo de $\mathrm{N}$ e dos principais metais $(\mathrm{Co}, \mathrm{Cr}, \mathrm{Cs}, \mathrm{Fe}$, $\mathrm{Rb}, \mathrm{Zn}$ ) e semi-metais As e $\mathrm{Sb}$. O grupo 1, ficou subdividido em 2 sub-grupos, um deles 
constituído das ETR leves ( $\mathrm{Sm}, \mathrm{Nd}, \mathrm{La}, \mathrm{Eu}$ ) e $\mathrm{Ca}$; o segundo sub-grupo formado pela fração areia, ETR pesados ( $\mathrm{Lu}$ e $\mathrm{Yb}$ ) e Hf e os elementos Ce, Ta, Na, U, Th e Ba. Esse resultado indica que a distribuição dos elementos é controlada, principalmente, pelas frações granulométricas e que o conteúdo de MO está estreitamente relacionado ao teor de silte e argila.

\subsection{Comparação dos resultados das Análises obtidos pelas técnicas ICP OES, FG AAS e INAA}

Como foram obtidos resultados para alguns metais por ambas as técnicas analíticas, estes são apresentados na forma de gráficos (concentração x ponto amostrado) e estão apresentados na FIG 4-21. A partir desses gráficos, pode-se perceber a relação entre as concentrações encontradas nas frações do sedimento, ponto a ponto. Essa comparação foi realizada mesmo tendo-se em vista a diferença primordial das técnicas, INAA fornece valores de concentração total dos elementos e ICP OES, com o processo de digestão utilizado no presente estudo, somente a fração disponível ao meio ambiente ou a fração extraível.

A partir dos dados da FIG 4-21, pode-se observar que para os elementos As, Co e Fe, os valores de concentração obtidos pelas duas técnicas foram bem semelhantes com pequenas diferenças em alguns pontos indicando que, no geral, a concentração total é também disponível ambientalmente para esses elementos. Entretanto para os elementos Ba, $\mathrm{Cr}$ e $\mathrm{Zn}$, pudemos observar que as concentrações encontradas por INAA foram sempre superiores em relação aquelas encontradas por ICP OES, o que nos indica que a concentração ambientalmente disponível é menor que a concentração total presente no ambiente.

Para o elemento As observam-se alguns pontos com discrepância de resultados, sendo que para alguns pontos os valores encontrados por FG AAS foram maiores que os encontrados por INAA. Não foi possível encontrar uma explicação para esta discrepância. 

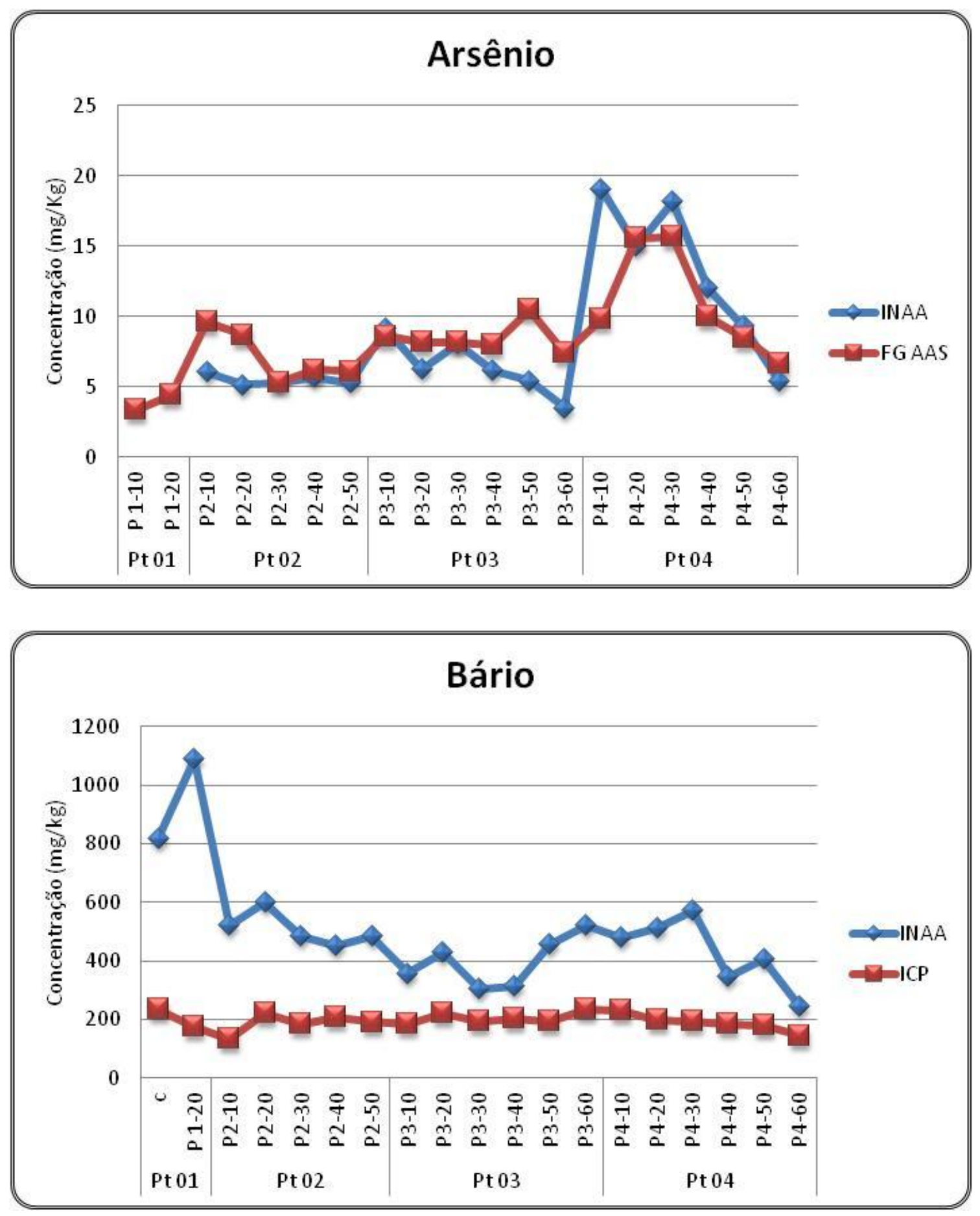

FIGURA 4.21 Comparação das concentrações obtidas pelas técnicas de INAA e ICP OES (Ba, Cr, Co, Fe e Zn) e GF AAS (As), nas amostras de sedimento 

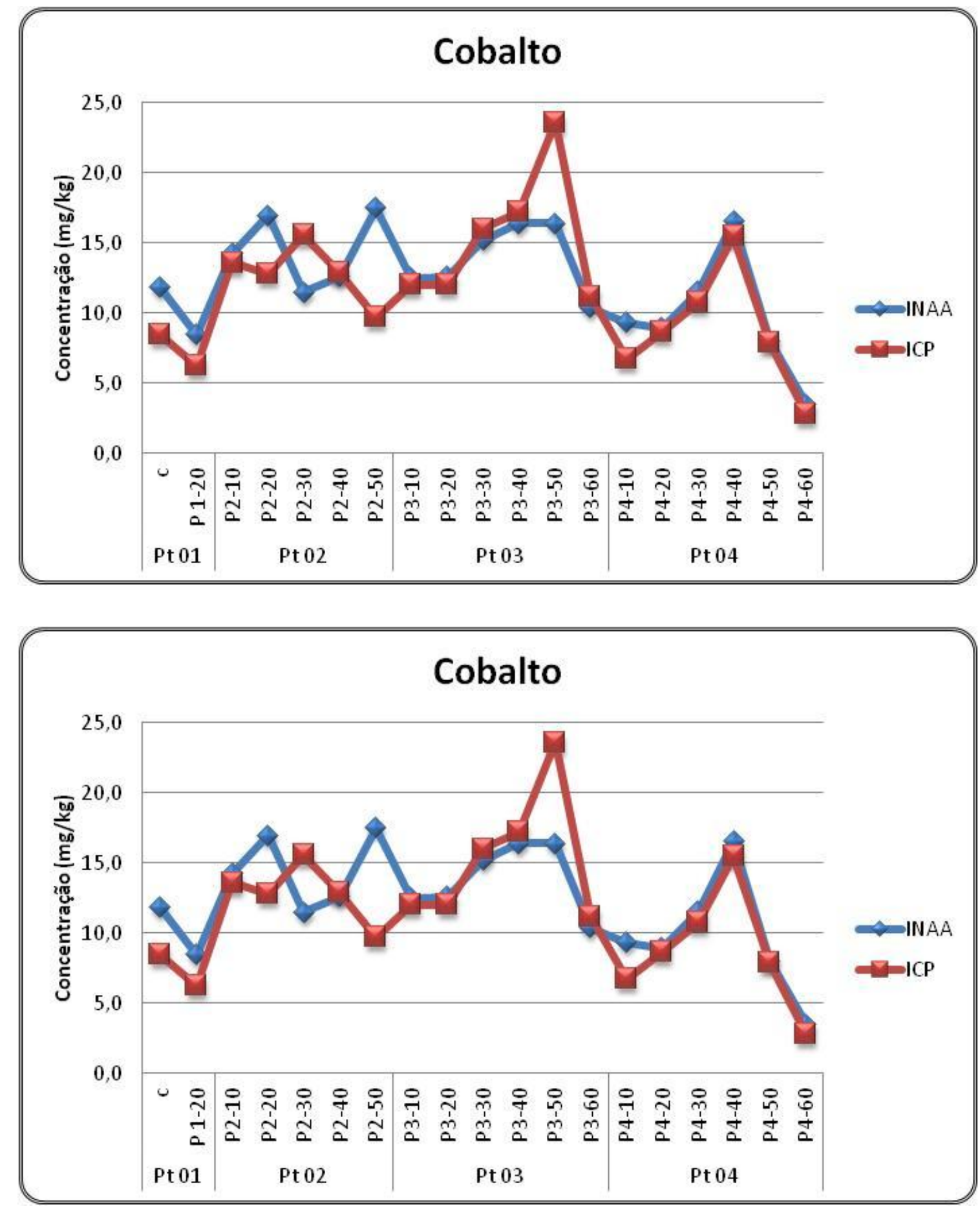

FIGURA 4.21 - Continuação 

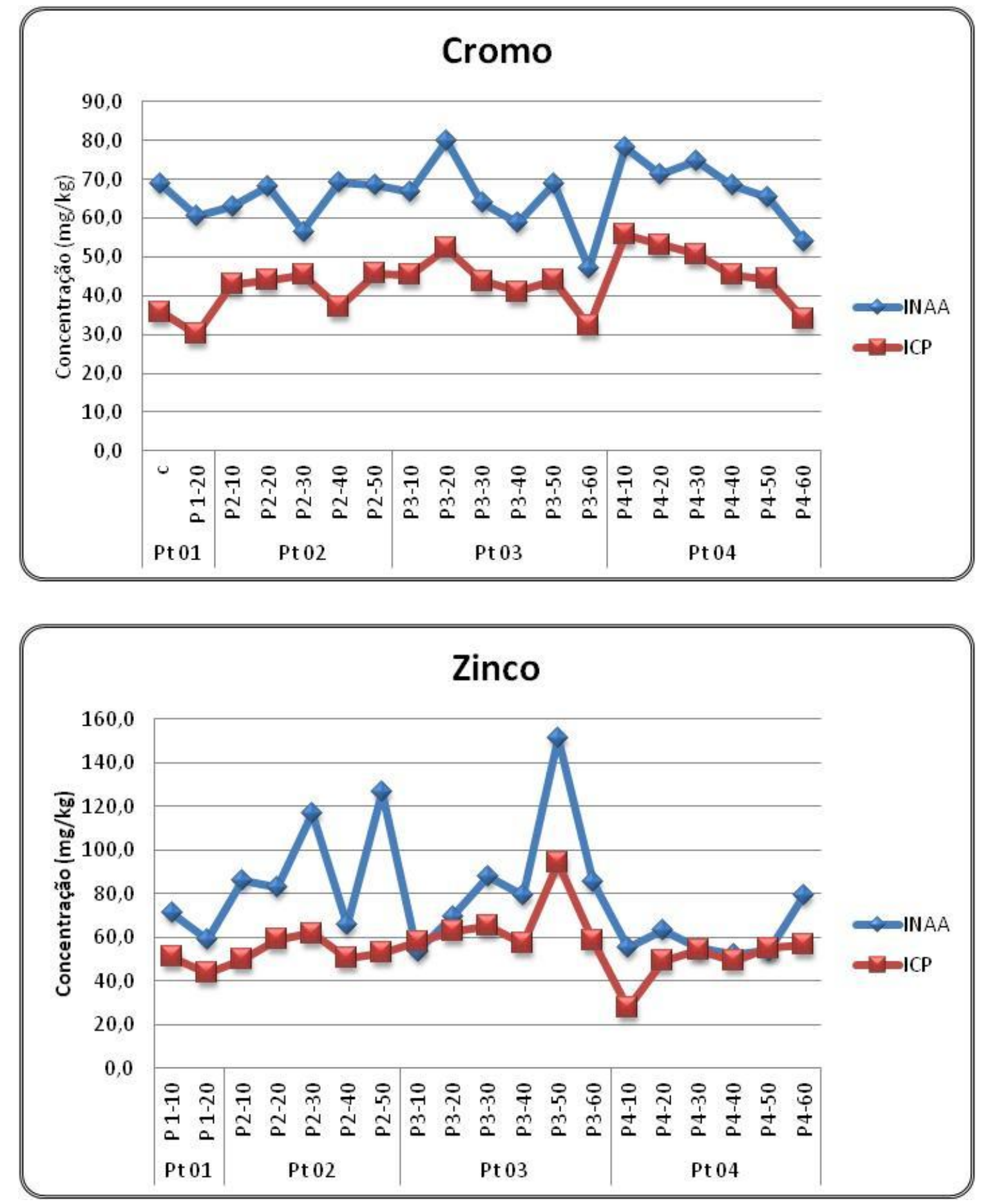

FIGURA 4.21- Comparação das concentrações obtidas pelas técnicas de INAA e ICP OES (Ba, Cr, Co, Fe e Zn) e GF AAS (As), nas amostras de sedimento 


\section{CAPÍTULO 5}

\section{CONCLUSÕES}

As técnicas analíticas utilizadas no presente estudo (INAA, ICP OES, FG AAS e Análise direta de $\mathrm{Hg}$ ) apresentaram sensibilidade, precisão e exatidão adequadas para a determinação de metais, elementos traço e terras raras em amostras de sedimento do reservatório de Itupararanga.

A partir dos dados da análise granulométrica, pode-se concluir que o sedimento do reservatório de Itupararanga, possui características de argila siltica na maioria dos pontos (exceto ponto 01), o que indica que possui potencial para reter a carga interna de nutrientes com possível redisposição ao corpo d'água.

Quanto aos teores de Nitrogênio e o Carbono Orgânico Total (COT) pode-se observar que no Pt 01, ocorreu um aumento de concentração de $\mathrm{N}$ da fração P1-10 para a fração P1-20 e uma diminuição no teor de COT. No Pt 02, os valores das concentrações foram muito semelhantes. Para os pontos Pt 03 e Pt 04, os valores de COT e Nitrogênio apresentaram uma queda acentuada do topo para a base dos perfis, sendo que para o Pt 03, observou-se uma elevação destas concentrações na última fração (P3-60). Os valores elevados de nitrogênio provavelmente estão ligados ao uso agrícola da bacia nesse ponto.

Com os resultados da relação carbono/nitrogênio, definiu-se a origem da matéria orgânica nos sedimentos desse reservatório, como sendo nos pontos 01 e 02 , de origem terrígena e para os pontos 3 e 4 , origem terrígena e aquática, respectivamente. 
A partir dos resultados obtidos por ICP OES observou-se, para o ponto 1, uma maior concentração para todos os elementos analisados na superfície do perfil em relação à base, o que nos sugere que ao longo dos anos vem aumentando a concentração destes metais nos sedimentos desse reservatório neste ponto. Os elementos $\mathrm{Al}, \mathrm{Ca}, \mathrm{Fe}$ e V apresentaram maior concentração na superfície do perfil nos pontos 1,3 e 4. Para os demais elementos, houve uma variação de comportamento ao longo do perfil, para os diferentes pontos.

Em relação aos teores de $\mathrm{P}$ total, em geral, os valores de concentração foram maiores na superfície do que na base, para todos os pontos, sendo a única exceção o ponto Pt 03, onde ocorreu uma inversão, com o maior valor de concentração encontrado na base do perfil. Um fato não esperado foi a concentração de $\mathrm{P}$ nos sedimentos do ponto 03 ser inferior ao do ponto 2 . O ponto 3 por estar localizado a jusante de um vilarejo, esperava-se valores de concentração de $\mathrm{P}$ maiores, o que acabou não acontecendo.

Os valores de $\mathrm{P}$ total encontrados no presente estudo variaram de 543 a $2011 \mathrm{mg} \mathrm{kg}^{-1}$. A partir dos resultados verificou-se que todos os pontos, com exceção do ponto 1 e fração P4-60, apresentaram concentrações de $\mathrm{P}$ que ultrapassaram os valores orientadores da província de Ontário $\left(600 \mathrm{mg} \mathrm{kg}^{-1}\right)$, o valor orientador CONAMA $344 / 2004$ (2000 $\mathrm{mg} \mathrm{kg}^{-1}$ - que se refere a dragagem de sedimentos) e o valor de alerta da CETESB que seria entre 750 a $1500 \mathrm{mg} \mathrm{kg}^{-1}$, o que justifica o alerta que vem sendo aplicado pela CETESB para esse reservatório quanto ao problema de eutrofização. Apesar de esse aumento ser pequeno, ele é constante, e leva a um valor médio, principalmente nos pontos $3 \mathrm{e} 4$, de $1000 \mathrm{mg} \mathrm{kg}^{-1}$, valor este que sugere um estado de alerta quanto ao futuro deste reservatório, principalmente levando-se em conta a expansão que ocorre nas áreas plantadas e empreendimentos imobiliários ao redor do reservatório, que são grandes fontes de fósforo. As concentrações encontradas ao longo do perfil principalmente no P04 está de acordo com os valores encontrados no monitoramento realizado pela CETESB nos anos de 2009 a 2011, onde a concentração de P ficou entre, 831 a 876.

A comparação dos resultados encontrados para os elementos: Al, As, Cd, Pb, $\mathrm{Cu}, \mathrm{Cr}, \mathrm{Fe}, \mathrm{Mn}, \mathrm{Hg}, \mathrm{Ni}, \mathrm{Zn}$ e $\mathrm{P}$, os quais são monitorados anualmente pela CETESB, nos sedimentos do reservatório de Itupararanga nota-se que para o ponto P 04, todos estes elementos são coerentes com os dados de monitoramento a partir de 2009. 
Ao comparar as concentrações encontradas com os valores orientadores TEL e PEL pode-se perceber que os maiores problemas em relação à biota são as concentrações dos elementos As e Cr, que excederam os valores de TEL, para todas as frações dos pontos 2, 3 e 4 . Outro fato que chama atenção é que para o elemento As, os valores da base dos perfis apresentaram valores acima de TEL, o que poderia ser indicativo de um valor basal local acima desse valor e não uma contaminação de origem antrópica. Para que isto fosse comprovado utilizou-se dos cálculos do FE e Igeo, utilizando-se como valores de referência os valores de UCC e NASC e em ambos os casos, verificou-se um enriquecimento para esse elemento. Entretanto, quando o FE foi calculado a partir dos dados de concentração da base do perfil, não foi observado enriquecimento para o elemento As em nenhuma das frações, em nenhum dos pontos, confirmando a hipótese de valor basal para o elemento As acima dos valores de UCC e NASC. Já para o elemento Cr, pode-se observar que para as frações superiores deste ponto apresenta valores acima de TEL, mas não apresenta enriquecimento quando se calcula FE e Igeo para UCC, NASC ou base do perfil. Os valores de Cr no UCC (35 mg kg-1) e para o NASC (125 mg kg-1) são valores acima do valor de TEL, que é $37,3 \mathrm{mg} \mathrm{kg}^{-1}$, o que justifica o não enriquecimento para este elemento.

O FE quando calculado com os dados da base do perfil, apresentou um enriquecimento para o elemento Fe para as superfícies dos pontos 2, 3 e 4, o que é confirmado pelo FE calculado com base nos valores do NASC que também apresentou enriquecimento para os pontos 3 e 4 .

Estes fatos podem ser confirmados através dos valores obtidos para o Igeo, que também apresentaram enriquecimento para o elemento Fe, quando calculado tomando-se como valores de referência os dados de concentração da base do perfil. Quando esses valores foram calculados utilizando-se os valores de UCC e NASC, o enriquecimento apareceu somente para o elemento As.

Os resultados para os metais e elementos traço analisados por INAA, indicam que os elementos: Ba, Ca, Hf, Na, Ta, Th, U e ETR (Ce, La, Lu, Nd, Yb e Sm), no ponto 1, possuem valores de concentração que decrescem da base para a superfície do perfil, o que sugere que talvez esses valores possam ser valores basais. 
Um fato que chamou a atenção foram as altas concentrações dos elementos $\mathrm{Ba}$, Ca, Hf, Na, Ta, Th, U e ETR (Ce, La, Lu, Nd, Yb e Sm no ponto 1 e o elemento U, em todos os pontos, com concentrações que oscilaram de 3,1 a $14,4 \mathrm{mg} \mathrm{kg}^{-1}$, o que deve ser melhor estudado no solo da região.

Nos cálculos do FE, verificou-se enriquecimento para o elemento As quando se calcula tomando-se como valores de referência os valores de UCC e NASC. Quando os dados da base do perfil foram usados, verificou-se enriquecimento somente para o ponto 4 .

Quando se compara os resultados encontrados para o elemento As, encontrados por FG AAS e INAA, pode-se perceber que há vários pontos que apresentam discrepâncias e estas geraram as diferenças entres alguns resultados do FE e Igeo. Entretanto, de modo geral, pode-se dizer que se considerarmos os valores de FE e Igeo obtidos utilizando-se a base do perfil como referência, que o elemento As somente apresenta enriquecimento nas frações superiores do ponto 4 .

$\mathrm{O}$ elemento $\mathrm{Fe}$ apresentou enriquecimento somente para o ponto 4 quando calculado com os dados da base do perfil. Na comparação dos resultados obtidos pelas duas técnicas analíticas, INAA e ICP OES, observou-se bastante similaridade entre os resultados, assim como para os resultados de FE e Igeo.

No ponto 01, foi possível notar enriquecimento para os elementos terras raras quando o FE foi calculado com base nos valores do UCC e NASC. Entretanto, quando os dados de concentração da base do perfil foram utilizados este enriquecimento não foi evidenciado, o que nos sugere que este local, pode possuir uma característica basal diferenciada. Essas informações sugerem a necessidade de maiores estudos do solo da região onde está localizado o reservatório de Itupararanga e seus arredores, com o intuito de se obter o real nível basal da região para estes elementos. Além disso, é interessante a análise de vários testemunhos de sedimento mais profundos, a datação dos mesmos e também o conhecimento da taxa de sedimentação dos respectivos pontos. A partir desses dados seria possível se obter uma informação mais verdadeira dos valores basais dessa região e principalmente para o ponto 1 , nitidamente diferente dos demais pontos analisados.

Levando-se em conta todos os resultados apresentados para o reservatório de Itupararanga, pode-se dizer que o ponto 1 , possui características muito distintas das 
apresentadas pelos demais pontos amostrados. Esse ponto apresentou concentrações mais baixas para os metais $\mathrm{Cu}, \mathrm{Fe}, \mathrm{Mn}, \mathrm{V}$ e $\mathrm{Zn}$ e maiores para os demais elementos analisados.

A partir dos resultados obtidos para as análises realizadas no reservatório Itupararanga pode-se concluir que apesar de ainda estar recebendo classificação como boa, vem recebendo alerta da CETESB desde 2003, merece mais atenção e estudos, pois vem sofrendo pressões antrópicas pela presença de metais tóxicos e alguns elementos traço em níveis acima do permitido para sedimentos, podendo sofrer um revés em sua classificação. 


\section{REFERÊNCIAS BIBLIOGRÁFICAS}

AL-JUNDI, J.; RANDLE, K. Instrumental neutron activation analysis (INAA) of estuarine sediments. Journal of Radioanalytical and Nuclear Chemistry, v.249, n.2, p. 361-367, 2001.

AL-JUNDI, J.; RANDLE, K.; EARWAKER, L.G.; Elemental analysis of the marine sediment reference materials MESS-1 and PACS-1 by instrumental neutron activation analysis. Journal of Radioanalytical and Nuclear Chemistry, v.174, n.1, p. 145-151, 1997.

AMORIM, E.P., FAVARO, D.I.T., BERBEL, G.B.B., BRAGA, E. S. Assessment of metal and trace element concentrations in the Cananéia estuary, Brazil, by neutron activation and atomic absorption techniques. Journal of Radioanalytical and Nuclear Chemistry, v.278, n.2, p. 485-489, 2008.

AMORIM, E.P., FAVARO, D.I.T., BERBEL, G.B.B., BRAGA, E.S. Metal and trace element assessment of estuary sediments from Santos, Brazil, by neutron activation and atomic absorption techniques. In: INTERNATIONAL NUCLEAR ATLANTIC CONFERENCE, September 30 to October 5, Santos, Proceeding, Santos, 2007.v.1, p. 01-09.

AMORIM, E. P., FAVARO, D. I. T., BERBEL, G. B. B., BRAGA, E. S. Santos estuarine sediments, Brazil - metal and trace element assessment by neutron activation analysis. INTERNATIONAL NUCLEAR ATLANTIC CONFERENCE, September 27 to October 2, Rio de Janeiro, Proceedin, v.1, p. 1-11, 2009a.

AMORIM, M. A., P.F.; TURCO, B.J.; CORDEIRO, R.C. Origem e dinâmica da deposição dos sedimentos superficiais na Várzea do Lago Grande de Curuai, Pará, Brasil. Acta Amaz. [online] v.39, n.1, p. 165-171, 2009b, ISSN 0044-5967. http://dx.doi.org/10.1590/S0044-59672009000100016. Acesso: 25 jan 2012

ARINE, D.R.. Análise de água de superfície e sedimentos de rios da região de Iperó, SP, por espectrometria de absorção atômica e por ativação neutrônica, 2000. Dissertação (Mestrado) - - Instituto de Pesquisas Energéticas Nucleares, Universidade de São Paulo, São Paulo, 2000

AUDRY, S., SCHAFER, J., BLANC, G., JOUANNEAU, J.M., Fifty-year record of heavy metal pollution $(\mathrm{Cd}, \mathrm{Zn}, \mathrm{Cu}, \mathrm{Pb})$ in the Lot River reservoir (France). Environmental Pollution, 132 (2004) 413-426.

AZEVEDO, F. A.; CHAIN, A. A.M. Metais: Gerenciamento da Toxicidade. São Paulo, Atheneu, 2003. 554 p. 
BACCAN, N. - Introdução Espectrometria de Absorção Atômica. UNICAMP, Campinas, 1994.

BAIRD, C.; CANN, M. Química Ambiental. 4 Porto Alegre: Bookman, 2011. 844 p.

BARRETO, M. S.; ALVES, J.P.H.; PASSOS, E.A.; GARCIA, A. B. Relação C:N e identificação da origem da matéria orgânica em Sedimentos. SBQ- SOCIEDADE BRASILEIRA DE QUÍMICA, 2002. Disponível em: HTTP://www.sec.sbq.org.br/cdrom/30ra/resumos/T1577-2.pdf, Acesso em: 15 nov 2011.

BAUDO, R.; GIESY, J.P.; MUNTAU, H. Sediments: Chemistry and toxicity of In-Place Pollutants. Chelsea: Lewis, 1990. 405 p.

BAUMGARTEN, M.G.; NIENCHESKI, L.F.; VEECK, L. Nutrientes na coluna da água e na água intersticial de sedimentos de uma enseada rasa estuarina com aportes de origem antrópica (RS-Brasil). Atlântica, [s.1], v. 23, p.101-116, 18 jul. 2001. Disponível em: <http://www.lei.furg.br/atlantica/vol23/K1400.pdf>. Acesso em: 27 mai 2009.

BEATY, R. D.; KERBER, J. D. Concepts, Instrumentations and Techniques in Atomic Absorption Spectrophotometry. Perkin Elmer, USA, 1993.

BODE, P., Instrumental and organizational aspects of a neutron activation analysis laboratory, Interfaculty Reactor Institute, Delft, Netherlands, p. 147, 1996.

BORGES, J.T. Avaliação do estado trófico e sanitário e a adsorção de fósforo no sedimento da Lagoa do Taquaral-campinas - SP. 1998. 120 f. Dissertação (Mestrado) Faculdade de Engenharia Civil, Universidade Estadual de Campinas, Campinas, 1998.

BOSTELMANN, E.; BEVILACQUA, J.E., FÁVARO, D.I.T. Avaliação da concentração de elementos maiores e trços em amostras de sedimentos do reservatório Billings, braço Rio Gande, por Ativação Neutrônica. Proceeding of International Nuclear Atlantic Conference, Santos, SP, Brazil, August 28 to Setember 2,v.1, p.1-10, 2005.

BOSTELMANN, E. Avaliação da concentração de metais em amostras de sedimento do Reservatório Billings, Braço Rio Grande, São Paulo, Brasil. 2006. 116 f. Dissertação (Mestrado) - Instituto de Pesquisas Energéticas Nucleares, Universidade de São Paulo, São Paulo, 2006.

BOtTINO, F. Diversidade, Biomassa e Decomposição de Macrófitas Aquáticas no Reservatório Itupararanga - SP. 2011. 128 f. Tese (Doutorado) - Departamento de Escola de Engenharia de São Carlos, Universidade de São Paulo, São Carlos, 2011.

BRYAN, G.W.; LANGSTON, W.J. Bioavailability, accumulation and effects of heavy metals in sediments to United Kingdom estuaries: a review. Environ. Pollut, v.76, p. 89-131, 1992. 
BURTON JUNIOR, G. A. Sediment Toxicity Assessment. Florida: Lewis, 1992. 457 p.

CARVALHO, T.M., TAVARES F.M. Avaliação de Exposição de Poluições Humanas a Metais Pesados no Ambiente: Exemplos do Recôncavo Baiano. Quimica Nova, v.15, n.2, p. 147-154, 1992. Disponível em: <http://www.quimicanova.sbq.org.br/qn/qno1/1992/vol15n2/v15_n2_\%20\%286\%29.pdf >. Acesso em: 30 jan. 2012.

CCME - CCME, 2001 - Canadian Environmental Quality Guidelines - Summary Tables- http://www.ccme.ca/publications/ceqg_rcqe.html. Acesso em out 2010

CETESB. Norma Técnica L6.160 - Sedimentos: determinação da distribuição granulométrica- método de ensaio. São Paulo, 15p., 1995.

CETESB. Relatório de qualidade das águas interiores do estado de São Paulo. São Paulo, 2003. 531 p. Disponível em: < http://www.cetesb.sp.gov.br/agua/aguassuperficiais/35-publicacoes-/-relatorios >. Acesso em: 01 jun. 2012.

CETESB. Relatório de qualidade das águas interiores do estado de São Paulo. São Paulo, 2004. 531 p. Disponível em: < http://www.cetesb.sp.gov.br/agua/aguassuperficiais/35-publicacoes-/-relatorios >. Acesso em: 01 jun. 2012.

CETESB. Relatório de qualidade das águas interiores do estado de São Paulo. São Paulo, 2005. 531 p. Disponível em: < http://www.cetesb.sp.gov.br/agua/aguassuperficiais/35-publicacoes-/-relatorios >. Acesso em: 01 jun. 2012.

CETESB. Relatório de qualidade das águas interiores do estado de São Paulo. São Paulo, 2006. 531 p. Disponível em: < http://www.cetesb.sp.gov.br/agua/aguassuperficiais/35-publicacoes-/-relatorios >. Acesso em: 01 jun. 2012.

CETESB. Relatório de qualidade das águas interiores do estado de São Paulo. São Paulo, 2007. 531 p. Disponível em: < http://www.cetesb.sp.gov.br/agua/aguassuperficiais/35-publicacoes-/-relatorios >. Acesso em: 01 jun. 2012.

CETESB. Relatório de qualidade das águas interiores do estado de São Paulo. São Paulo, 2008. 531 p. Disponível em: < http://www.cetesb.sp.gov.br/agua/aguassuperficiais/35-publicacoes-/-relatorios >. Acesso em: 01 jun. 2012.

CETESB. Relatório de qualidade das águas interiores do estado de São Paulo. São Paulo, 2009. 531 p. Disponível em: < http://www.cetesb.sp.gov.br/agua/aguassuperficiais/35-publicacoes-/-relatorios >. Acesso em: 01 jun. 2012.

CETESB. Relatório de qualidade das águas interiores do estado de São Paulo. São Paulo, 2010. 531 p. Disponível em: < http://www.cetesb.sp.gov.br/agua/aguassuperficiais/35-publicacoes-/-relatorios >. Acesso em: 01 jun. 2012. 
CETESB. Relatório de qualidade das águas interiores do estado de São Paulo. São Paulo, 2011. 531 p. Disponível em: < http://www.cetesb.sp.gov.br/agua/aguassuperficiais/35-publicacoes-/-relatorios >. Acesso em: 01 jun. 2012.

CETESB. Relatório de estabelecimento de valores orientadores para solos e águas subterrâneas no Estado de São Paulo. São Paulo, CETESB, 2001. 247p. (Relatório Técnico)

CONAMA - Conselho Nacional do Meio Ambiente, Ministério do Meio Ambiente. Resolução CONAMA n²74, de 29 de novembro de 2000.

CONAMA - Conselho Nacional do Meio Ambiente, Ministério do Meio Ambiente. Resolução CONAMA n³44, de 25 de março de 2004.

CONAMA - Conselho Nacional do Meio Ambiente, Ministério do Meio Ambiente. Resolução CONAMA n ${ }^{\circ} 357$, de 7 de março de 2005. Publicada no DOU n ${ }^{\circ} 53$, de 18 de março de 2005, Seção 1, páginas 58-63.

COSTA, G.G.O. Um Procedimento Inferencial para Análise Fatorial Utilizando as Técnicas Bootstrap e Jackknife: Construção de Intervalos de Confiança e Testes de Hipóteses. 2006. 190 f. Tese (Doutorado) - Departamento de Engenharia Elétrica, PUC - RIO, Rio de Janeiro, 2006.

COTTA, J.A.O; SALAMI, . H.; MARQUES, A. R.; REZENDE, M. O.O.; LANDGRAF, M. D.. Validação do método para determinação de nitrogênio kjeldahl total. Revista Analytica, São Paulo, n.26, p. 68-75, dez. 2006.

CRISTACHE, C., GMÉLING, K., CULICOV, O., FRONTASYEVA, M.V., TOMA, M., DULIU, O.G. An ENAA and PGAA comparative study of anoxic Black Sea sediments. Journal of Radioanalytical and Nuclear Chemistry., v.279, n.1, p. 7-12, 2009.

DIAS, J.C.; LIMA, W.N. Comparação de métodos para a determinação de matéria orgânica em amostras ambientais. Revista Cientifica da UFPA, v.4, 2004.

DINESCU, L.C.; DULIU, O.G.; BADEA, M.; MIÃILESCU, N.G.; VANGHELIE, I.M. Investigation of the vertical distribution of major and trace elements in Matita Lake (Danube Delta) sediment by activation analysis. Journal of Radioanalytical and Nuclear Chemistry, v.238, n.1-2, p. 75-81, 1998.

DURÃO JUNIOR, W.A. Especiação, Quantificação, Distribuição e Transporte de Mercúrio em solo contaminados do município de Descoberto, Minas Gerais. 2010. 117 f. Tese (Doutorado) - Departamento de Química, Universidade Federal de Minas Gerais, Belo Horizonte, 2010. 
EINAX, J.W.; SOLDT, U. Geostatistical and multivariate statistical methods for the assessment of polluted soils - merits and limitations. Chemometrics and Intelligent Laboratory Systems, 46, p.79-91, 1999.

ESTEVES, F.. Fundamentos de limnologia. Rio de Janeiro: Editora Interciencial Ltda, 1988.

FÁVARO, D.I.T., MOREIRA S.R.D, CAMPOS, V.A., MAZZILLI, B.P., CAMPAGNOLLI, F. Determinação Multielementar Por Ativação Neutrônica de Sedimentos do Reservatório Billings, Braço Rio Grande, São Paulo. In: V ENCONTRO NACIONAL DE APLICAÇÕES NUCLEARES, ENAN, 15 a 20 Outubro, Rio de Janeiro, RJ, Anais, CD-ROM, 2001.

FAVARO, D.I.T., MOREIRA, S R D, MOREIRA, E.G, MAZZILLI, B P, CAMPAGNOLLI, F. Chemical Characterization and Recent Sedimentation Rates in Sediment Cores from Rio Grande Reservoir, São Paulo, Brazil. Journal of Radio analytical and Nuclear Chemistry, v.273, p. 451 - 463, 2007.

FOnSECA, G.A.B. Contribuição Antrópica na Poluição de Reservatórios Hidrelétricos: o caso da Usina Hidrelétrica de São Simão - GO/MG - Rio de Janeiro/RJ. 2010. 129 f. Dissertação (Mestrado) - Universidade Federal do Rio de Janeiro, Rio de Janeiro, 2010 .

FIGUEIREDO FILHO, D.B.; SILVA JUNIOR, J.A.da.Visão além do alcance: uma introdução à análise fatorial. Opin. Pública, Campinas, v.16, n.1, Jun 2010 . Disponível em: http://www.scielo.br/scielo.php?script=sci_arttext\&pid=S010462762010000100007\&lng=en\&nrm=iso>. Acesso em: 18 Jul 2012.

FIGUEIREDO, A. M. G., ENZWEILER, J., CAMARGO, S.P., SÍGOLO, J. B., GUMIERO, F. C., PAVESE, A. C., MILIAN, F. M.. Metal contamination in urban park soils of São Paulo. Journal of Radioanalytical and Nuclear Chemistry, v.280, n.2, p. 423-429, 2009.

FRANKLIN, R.L., FERREIRA, F.J., BEVILACQUA, J.E., FAVARO, D.I.T. Assessment of Metals and Trace Elements in Sediments from Rio Grande Reservoir, Brazil, by Neutron Activation Analysis. Journal of Radioanalytical and Nuclear Chemistry. v.291, p. 147-153, 2012.

GAUDETTE, H. E., Flight, W.R., TOWER, L., FOLGER, D.W. An inexpensive titration method for determination of organic carbon in recent sediments. Journal of Sedimentary Petrology, v.44, n1, p.249-253, 1974

GLASCOCK, M. D. - An Overview of Neutron Activation Analysis - Disponível em: http://archaeometry.missouri.edu/naa_overview.html, Acesso em out 2010. 
GOMES, F.C., GODOY, J.M., GODOY, M.L.D.P., CARVALHO, Z.L., LOPES, R.T., SANCHEZ-CABEZA, J.A.S., LACERDA, L.D., WASSERMAN, J.L. Metal concentrations, fluxes, inventories and chronologies in sediments from Sepetiba and Ribeira Bays: A comparative study. Marine Pollution Bulletin, 59 (2009) 123-133.

GREENBERG, R.R; BODE, P.; FERNANDES, E. A. N.; Neutron Activation Analysis: A primary method of measurement. Spetrochimia Acta, Parte B, 66, p. 193-241,2011

GUIMARÃES, G.M., ZAHN, G.S., FRANKLIN, R.L., SILVA, P.C.S., FÁVARO, D.I.T. Neutron Activation Analysis applied in sediment samples from the Guarapiranga Reservoir for metals and trace elements assessment. Journal of Radioanalytical and Nuclear Chemistry, v.291, p. 155-161, 2012.

GUINÉ, M.F. Espectrometria de emissão atômica: plasma acoplado indutivamente ICP OES. Piracicaba: CPG/CENA, 1999.

HAIR JUNIOR, J.F. et al. Multivariate Data Analysis. 7. ed. Upper Saddle River: Prentice Hall, 2010.

IAEA - INTERNATIONAL ATOMIC ENERGY AGENCY. Collection and preparation of bottom sediment samples for analysis of radionuclides and trace elements. Jul 2003. (IAEA - TECDOC-1360).

INMETRO - Orientação sobre validação de métodos analíticos, Coordenação Geral de Acreditação, DOQ-CGCRE-008, revisão 3 (fev/2010).

INMETRO - VIM - Vocabulário Internacional de Metrologia - 1995 - Rio de Janeiro.

LAMPARELLI, M.C.L. Graus de trofia em corpos d'água: Avaliação dos métodos de monitoramento. 2004. 235 f. Tese (Doutorado) - Departamento de Ecologia, Instituto de Biociências, Universidade de São Paulo, São Paulo, 2004.

LARIZZATTI, F.E.; FAVARO, D. I. T.; MOREIRA, S. R. D.; MAZZILLI, B. P.; PIOVANO, E.L. Multielemental Determination by Instrumental Neutron Activation Analysis and Recent Sedimentation Rates Using 210 Pb Dating Method at Laguna del Plata, Cordoba, Argentina. Journal of Radioanalytical and Nuclear Chemistry, v.249, n.1, p. 263-8, 2001.

LBL - Lawrence Berkeley National Laboratory.Neutron activation analysis. Atulizado em agosto de 2000. Disponível em: http://www.ibl.govlabclwallchart\13〈5.html>. Acessado em: fev 2011.

LLOYD, A., PARRY, S.J., LYNN, N.M., GILES, I.S. Development of elemental tracer using neutron activation analysis for application in an estuarine environment. Journal of Radioanalytical and Nuclear Chemistry, v.264, n.1, p. 83-90, 2005. 
LOUREIRO, D.D. Evolução dos aportes de metais pesados na lagoa Rodrigo de Freitas, RJ. 2006. 126 f. Dissertação (Mestrado) - Universidade Federal Fluminense, Niterói, 2006.

PADIAL, P. R. Qualidade, heterogeneidade espacial e biodisponibilidade de metais no sedimento de um reservatório tropical urbano eutrofizado (Reservatório Guarapiranga, SP). 2008. 120 f. Dissertação (Mestrado) - Instituto de Biociências, Universidade de São Paulo, São Paulo, 2008.

PASCALICCHIO, A.E. Contaminação por Metais Pesados: Saúde Pública e medicina ortomolecular. São Paulo: Annablume, 2002.

MARIA, S. P.; FIGUEIREDO, A. M. G.; CECCANTINI, G. Determination of the contents and distribution characteristics of rare earth elements in Solanum lycocarpum from tropical ecosystems in Brazil by INAA. Journal of Radioanalytical and Nuclear Chemistry, v. 244, n.2, p. 303-306, 2000.

PORTARIA 518/2004. Padrão de Potabilidade da água para consumo humano. Ministério da Saúde Brasileira, 2005

PRESLEY, B.J.; TREFRY, J.H.; SHOKES, R.F. Heavy metal input to Mississippi delta sediments. Water Air Soil Pollut. Lett, v.13, p. 481-494, 1980.

PROTAZIO, L.; TANAKA, S.M.C.N.; CAVALCANTE, P.R.S. Avaliação de procedimentos de extração sequencial de fósforo em sedimento. Revista Analytica, n.08, p. 35-41, jan. 2004.

QUiNÁGliA, G. A. Caracterização dos Níveis Basais de Concentração de Metais nos Sedimentos do Sistema Estuarino da Baixada Santista. 2006. 239 f. - Tese (Doutorado), Departamento Química Analítica, Instituto de Química, Universidade de São Paulo, São Paulo. 2006.

REZAEE, K. H, ABDI, M.R., SAION, E.B., NAGHAVI, K., SHAFAEI, M.A. Distribution of trace elements in the marine sediments along the South China Sea, Malaysia.. Journal of Radioanalytical and Nuclear Chemistry, v.287, 2011 (online). (DOI 10.1007/s10967-010-0950-5)

SALLES, M.H.D.; CONCEIÇÃO, F.T.; ANGELUCCI, A. V.; SAI, R.; PEDRAZZI, F.J.M.; CARRA, T.A; MONTEIRO, G.; SARDINHA, D. S; NAVARRO, G. R. B. Avaliação Simplificada de impactos ambientais na Bacia do Alto Sorocaba (SP). REA Revista de Estudos Ambientais, [s.1], v. 10, n. 1, p.6-20, 2008. Disponível em: <http://proxy.furb.br/ojs/index.php/rea/article/view/897>. Acessado em: mai 2009.

SARDINHA, D.S; CONCEIÇÃO, F. T.; BONOTTO, D. M.; SALLES, M. H. D; ANGELUCCI, V. A.. Avaliação de balanço de cátions e ânions na bacia do Alto 
Sorocaba (SP). Revista Brasileira de Geociências, São Paulo, v. 4, n. 38, p.730-740, dez. 2008.

SENATORE, D.B. Uso de marcadores orgânicos moleculares na determinação da origem da matéria orgânica em sedimentos do sistema Estuarino- Lagunar de Cananéia-Iguape-SP- Brasil. 2010. 139 f. Dissertação (Mestrado) - Instituto Oceanográfico, Universidade de São Paulo, São Paulo, 2010.

SILVA, S.A., BEVILACQUA, J.E., FÁVARO, D.I.T. Major and Trace Elements Assessment in Sediment Cores From Itupararanga Reservoir by Activation Analysis and ICP OES. Proceeding of International Nuclear Atlantic Conference, Belo Horizonte, M.G., Brazil, October 24 to October 28,v.1, p.1-10, 2011.

SMITH, W.S. et al. Caracterização Limnológica do Rio Sorocaba e avaliação das suas condições após a entrada em operação da ETE S1. Revista Cientifica do Imapes., Sorocaba, v.5, n.5, p.65-74, 2007. Disponível em: <http://www.imapes.br/WEBFILES/revista_cientifica_2007.pdf $>$. Acessado em: jul 2009.

STM - STANDARD METHODS FOR THE EXAMINATION OF WATER AND WASTEWATER, 20 ${ }^{\text {th }}$ edition, Washington (DC), 1998.

TANIWAKI, R.H.; ROSA, A. H.; CALIJUI, M.C; CARLOS, V. M.; Variação espacial do grau de trofia e da biomassa fitoplanctonica no Reservatório de Itupararanga (São Paulo, Brasil). Holos Environment, v.11, n.2, p. 170, 2011.

TAYLOR, S.R. \& MC LENNAN, S.M. The Continental Crust: its composition and evolution. Oxford, London: Blackwell Scientific, ISBN 0632 011483, 1985

US EPA - Method 3051a - Microwave Assisted Acid Digestion of Sediments, Sludges, Soils and Oils. 2007

US EPA - Method 7473 - Mercury in Solids and Solutions by Thermal Decomposition, Amalgamation, and Atomic Absorption Spectrophotometry.2007

VIAU, C.M. Efeitos Tóxicos e Genotóxicos do Cloreto de estanho em Bactérias e Leveduras. 2005. 70 f. Dissertação (Mestrado) - Departamento de Biologia Molecular e Celular, Universidade Federal do Rio Grande do Sul, Porto Alegre, 2005.

V-MOSCHINI, C., PEDRAZZI, F.J.M., CONCEIÇÃO, F.T., POMPÊO, M.L.M. Qualidade de água do reservatório de Itupararanga (Bacia do Alto Sorocaba-SP) Gradiente espacial vertical. Congresso de Ecologia do Brasil, Caxambu-MG, 23 a 28 de setembro de 2007.

WEDPOHL, K.H. The composition of the continental crust. Geochim.Cosmochim. Acta, v.5, p. 1217-1232, 1995. 
YAQIN, J.L., FENG, Y., WU, J., ZHU, T., BAI, Z., DUAN, C. Using geoacumulation index to study source profiles of soil dust in China. Journal Environmental Sciences, 20(5), p. 571-578, 2008.

ZHANG, J. \& LIU, C. L., Riverine composition and Estuarine Geochemistry of Particulate Metals in China - Weathering Features, Anthropogenic Impact and Chemical Fluxes. Estuarine, Coastal and Shelf Science Lett., v.54, p. 1051-1070, 2002. 